\title{
A MORPHOLOGICAL AND HEMODYNAMIC ANALYSIS OF SKELETAL MUSCLE VASCULATURE
}

\author{
A Thesis \\ Presented to the Faculty of \\ California Polytechnic State University,
} San Luis Obispo

In Partial Fulfillment of the requirements for the Degree Master of Science in Engineering with a specialization in Biomedical Engineering

by

Stephanie Ann Wood

July 2008 


\section{APPROVAL PAGE}

TITLE: A Morphological and Hemodynamic Analysis of Skeletal Muscle Vasculature

AUTHOR: Stephanie Wood

DATE SUBMITTED:

Trevor Cardinal Adviser or Committee Chair

Scott Hazelwood Committee Member

JESSE MADDREN Committee Member
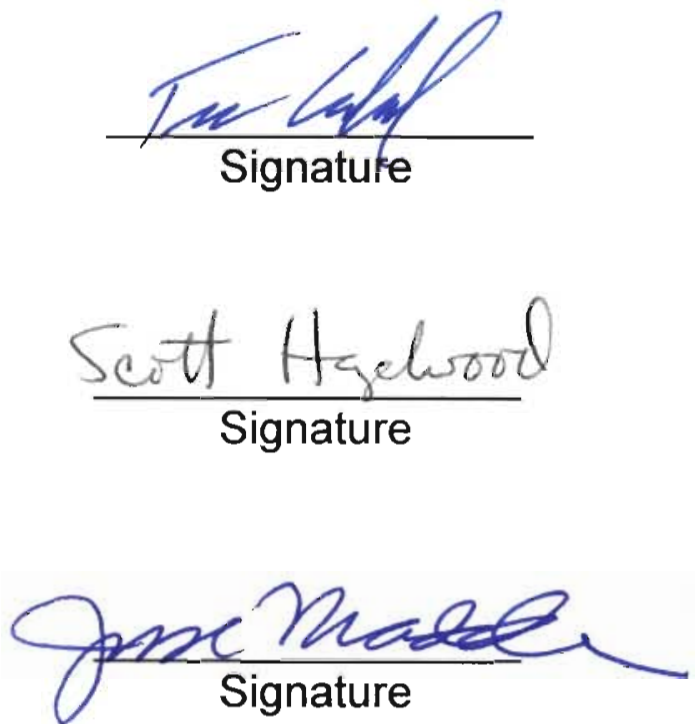


\section{AUTHORIZATION FOR REPRODUCTION OF MASTER'S THESIS (OR PROJECT REPORT)}

I grant permission for the reproduction of this thesis in its entirety or any of its parts, without further authorization from me.
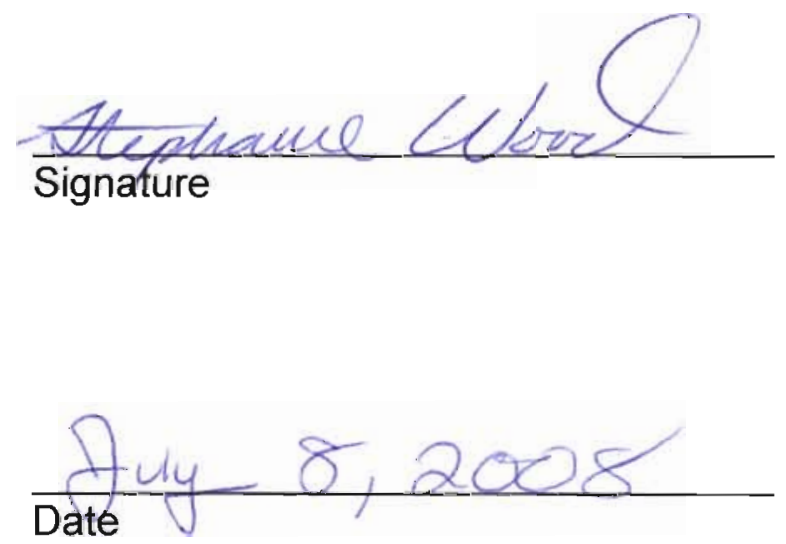


\begin{abstract}
A Morphological and Hemodynamic Analysis of Skeletal Muscle Vasculature
\end{abstract}

by

\title{
Stephanie Ann Wood
}

The goal of this study was to develop analysis tools to assess skeletal muscle vasculature on a network level. In conjunction with this goal, this project also assessed whether the gracillis anterior muscle of a mouse was sufficiently thin to perform a comprehensive morphological analysis, and whether the data generated from these methods would yield reasonable computation of hemodynamic parameters. Horton's Law of Stream Numbers and the diameter-defined Strahler method were applied to assess the vasculature as a whole, and the results were comparable to previous work. The dimensional and branching characteristics of the network were similar to previous experiments; however, the ability to reference microscope slides containing the muscle to cross-reference the degree of three-dimensional branching will improve results. On a whole, a comprehensive morphological assessment was performed on the gracillis anterior muscle using two-dimensional images; however, future work should supplement the images with cross-sectional measurements assessing capillary density for vessels of $8 \mu \mathrm{m}$ and smaller. The hemodynamic analysis yielded pressure profiles and individual vessel flow rates consistent with published literature values. The elemental network provides a more realistic representation of network morphology, whereas the segmental network should be used for hemodynamic calculations. Overall, the analysis methods presented in this paper provide a solid foundational tool that has the potential to illuminate patterns on a network (or systems) level that could not otherwise be seen. 


\section{Acknowledgements}

Special thanks to my advisor, Dr. Trevor Cardinal, for the patient advice and guidance over the course of this project. Thanks also to my committee members, Dr. Scott Hazelwood and Dr. Jesse Maddren, who provided valuable support as well. Also, appreciation goes to Dr. Gabriel Gruionu who generously provided the images used in this project. My fellow lab members, Allyse Alex, Tom Kessler, and Matt Yocum, supplied the moral support.

My boyfriend, Pete Danielski, who endured months of long distance, stressed out phone conversations with the patience of a saint. To my mom and dad who never once asked me when I would decide to stop going to school, and trusted that I was taking the right path. To my sisters, for their humor and support.

And last, to the many cats who have sat quietly by my side through the last few years: Molly traveled with me from house to house after I decided to go back to school, she provided a constant friend through a very dynamic time in my life. To Bump, a crazy cat that befriended Molly when I couldn't take her with me. To Mama, who laid by my side while I checked my MCAT scores, and always ran to the door to greet me. To Pismo, who has been a companion while I've been locked in my room working on this report. And, to my sister's cats, Ruby and Sweet Pea, for sending their love from a distance.

"No amount of safety and security is worth the suffering of a life lived chained to a routine that has killed your dreams. " $\sim$ Kent Nerburn 


\section{Table of Contents}

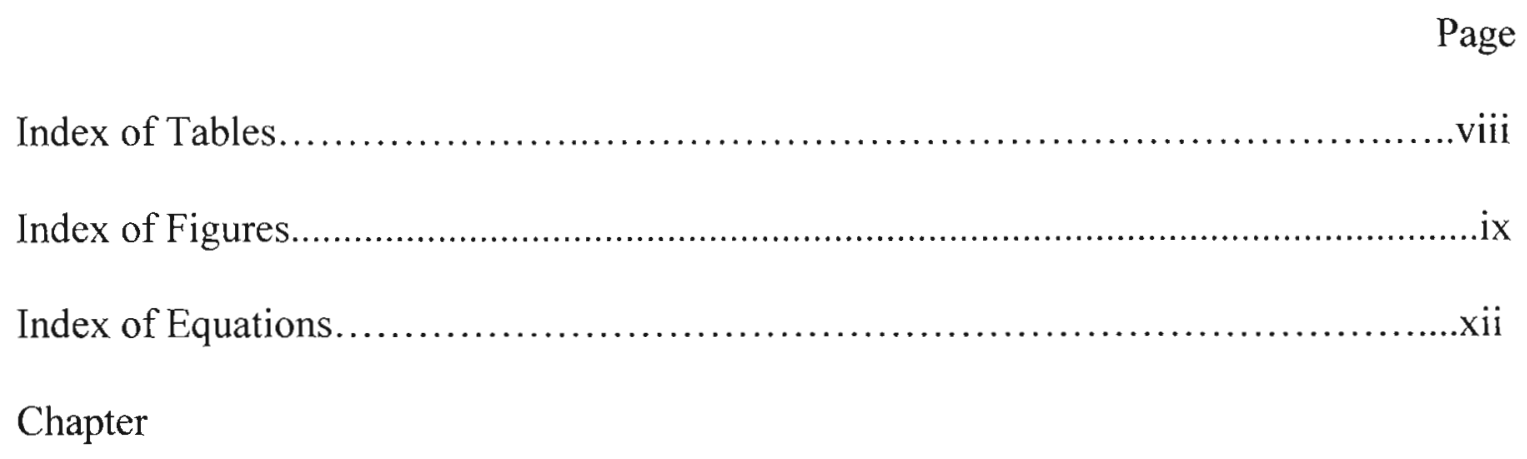

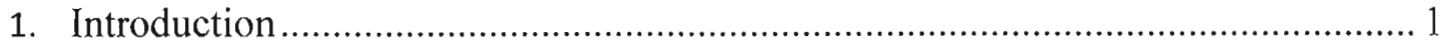

Normal Anatomy and Physiology of the Vascular Network .............................. 1

Effects of Dysfunction and Disease in the Vascular Network .............................. 3

Hemodynamic Properties ....................................................................... 9

Experimentation and Computational Approaches …..................................... 12

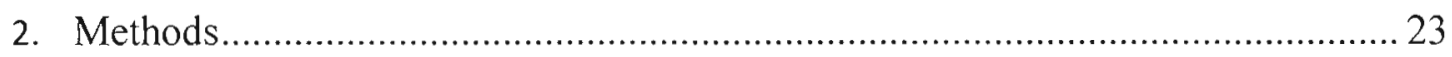

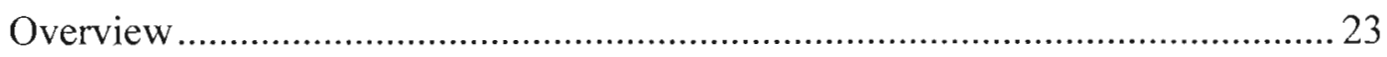

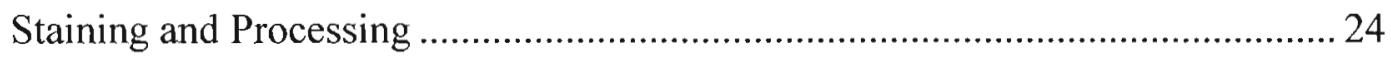

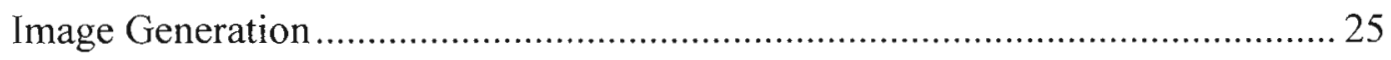

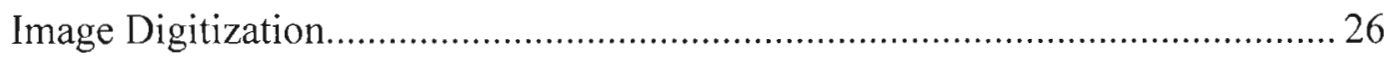

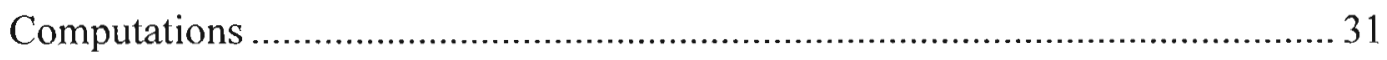

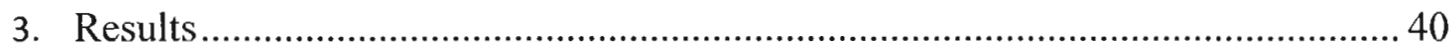

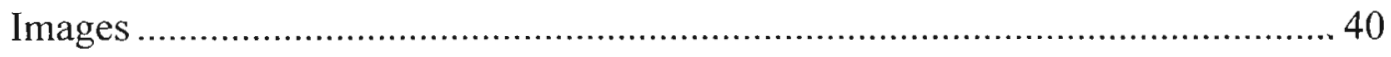

Morphometric Analysis..................................................................... 42

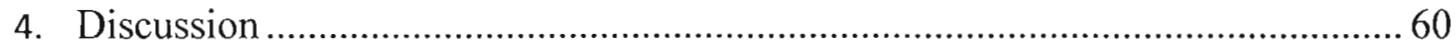

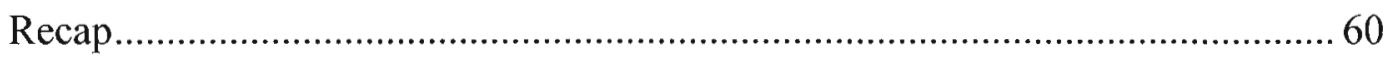

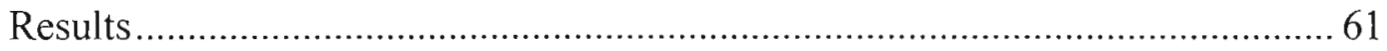




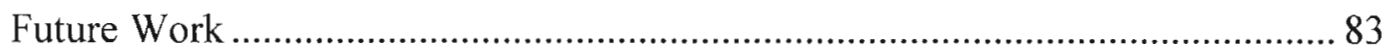

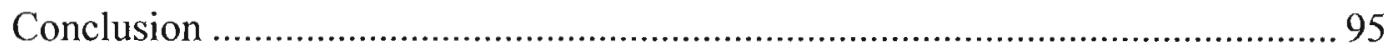

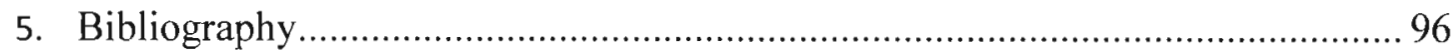

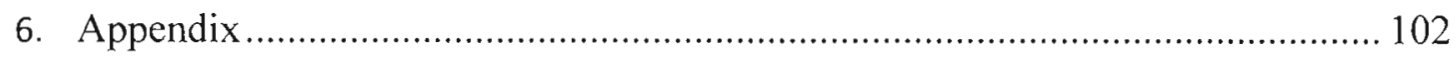

A: Digital Micrographs with labeled vessels ....................................... 102

B: Orginal morphological data from images......................................... 122

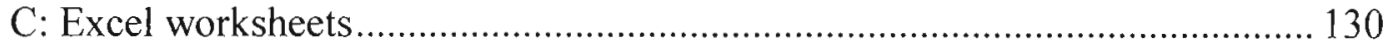

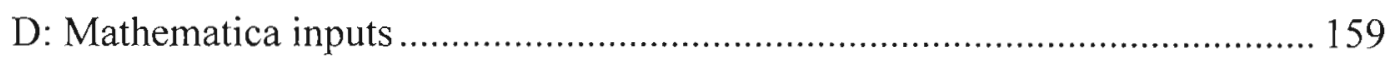

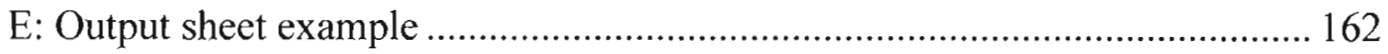




$$
\text { Index of Tables }
$$

Table 1. Definition of terms used in the morphometric analysis................................ 27

Table 2. Sample of data taken from digital micrographs....................................... 31

Table 3. Summary of segment and element characteristics for each vessel order........... 46

Table 4. Number, diameter, and length ratios computed according to Horton's Law...... 47

Table 5. Summary of total flow rates under varying conditions............................... 56

Table 6. Comparison of calculated versus measured literature values. .........................59

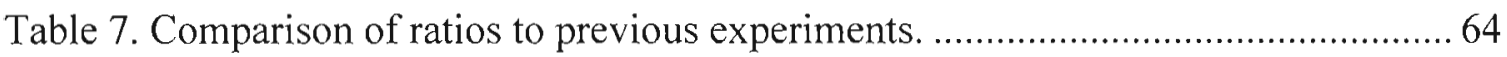




\section{Index of Figures}

Figure 1. Schematic of the human circulation system. ............................................ 1

Figure 2 . Schematic of the pressure throughout the circulatory system........................ 3

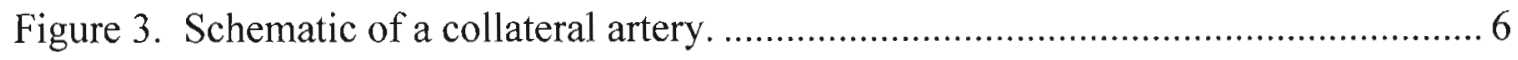

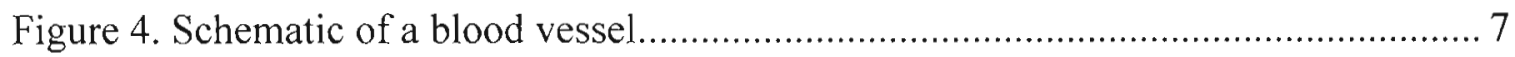

Figure 5. Simplified schematic of the formation of Rouleaux................................... 10

Figure 6. Schematic of the Fahraeus-Lindquist effect. ........................................ 11

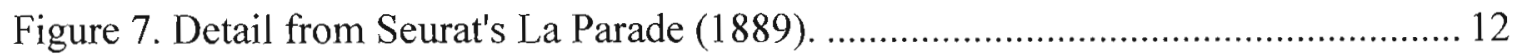

Figure 8. Schematic of interrelated hemodynamic and morphologic parameters............ 13

Figure 9. Schematic of an arbitrary connectivity matrix....................................... 20

Figure 10. Digital micrograph of a section of the vasculature ................................... 25

Figure 11. Comparison of two different view planes.......................................... 26

Figure 12. Schematic of a Strahler-ordered network ......................................... 27

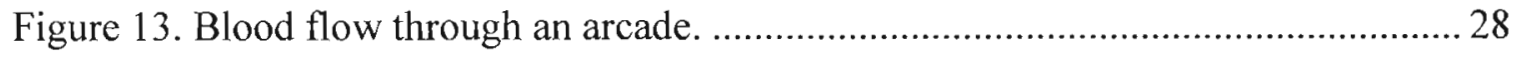

Figure 14. Digital micrograph of arcade and split point. ........................................ 29

Figure 15. Schematic of a the Strahler ordering process. .................................... 30

Figure 16. Segment and element reordering convention. .................................... 33

Figure 17. Comparison of segment and element vessel representations....................... 34

Figure 18. Schematic of Vessel 268 and its parent and offspring vessels. .................... 37

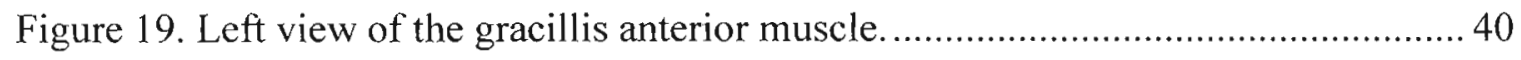

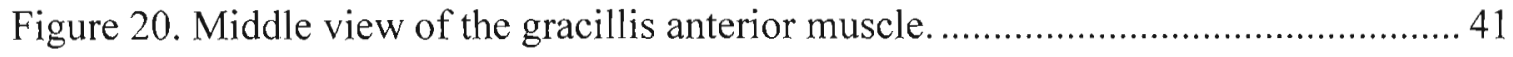

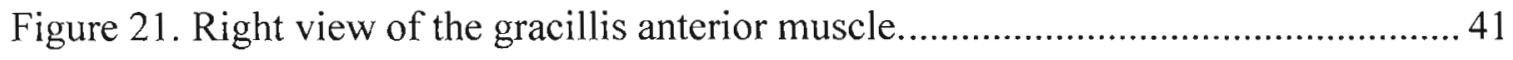

Figure 22. Number of segments of each order per iteration during reordering. ............. 42 
Figure 23. Number of elements of each order per iteration during reordering. 43

Figure 24. Segments before and after reordering......................................... 43

Figure 25. Total cross-sectional area of each order for segments and elements............. 44

Figure 26. Simplified schematic of a hypothetical branching network. ....................... 45

Figure 27. Order versus $\log _{10}$ of diameter for segments and elements....................... 48

Figure 28. Order versus $\log _{10}$ of quantity for segments and elements...................... 48

Figure 29. Order versus $\log _{10}$ of length for segments and elements........................... 49

Figure 30. Matrix of average branching ratios..................................................... 50

Figure 31. Matrix of percent distribution of parent vessels. ................................... 51

Figure 32. Branching matrices before and after re-ordering ................................. 52

Figure 33. Schematic of the simulated capillary bed.................................................. 53

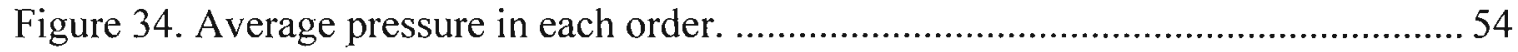

Figure 35. Average flow rate through individual vessels. ........................................ 55

Figure 36. Comparison of overall flow rate of segment and element data................... 57

Figure 37. Comparison of individual vessel flow rates. .......................................... 58

Figure 38. Comparison of calculated total flow compared with literature. ................... 59

Figure 39. Normal vasculature versus tumor vasculature ................................ 62

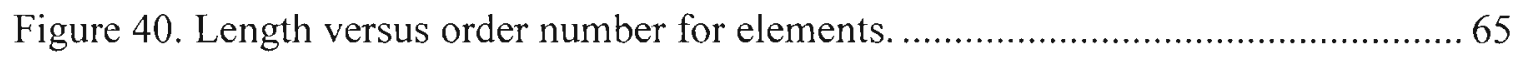

Figure 41. Schematic of 3D characteristics of the muscle .........................................66

Figure 42. Graphical representation of the segment connectivity matrix.....................68

Figure 43. Graphical representation of the element connectivity matrix......................6 68

Figure 44. Graphical representation of the connectivity matrix for segments............... 69

Figure 45. Graphical representation of the connectivity matrix for elements. ...............69 
Figure 46. Total cross-sectional area in each order. ………......................................... 71

Figure 47. Actual and predicted number of elements of each order............................... 73

Figure 48. Comparison between segments and element representations........................... 75

Figure 49. Comparison of total flow with literature values.......................................... 77

Figure 50. Comparison of individual segment flow rates........................................... 77

Figure 51. Baseline flow rate versus simulated capillary bed........................................ 79

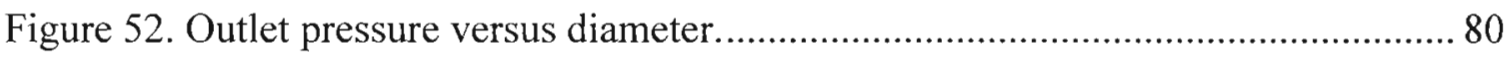

Figure 53. Comparison of average outlet pressure under different conditions.................81

Figure 54. Average branching ratio matrices for segments and elements. ....................... 84

Figure 55. Photomicrograph of vessel breakages ........................................................ 87

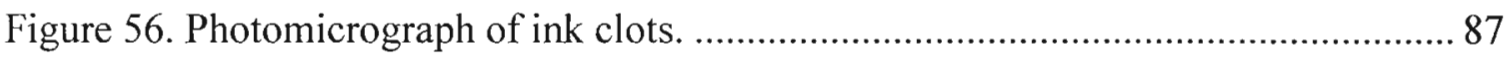

Figure 57. Hypothetical comparison of branching ratios...........................................92

Figure 58. Hypothetical comparison of percent of offspring......................................... 93

Figure 59. Flow rate comparison between baseline and hypothetical networks............... 94

Figure 60. Scatter plot of individual vessel flow rates in a hypothetical network........... 94 


\section{Index of Equations}

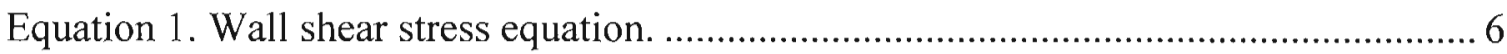

Equation 2. Hagen-Poiseuille equation............................................................ 7

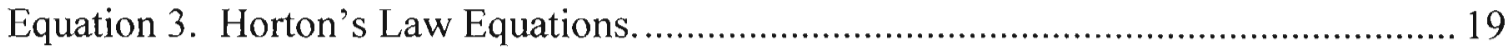

Equation 4. Hagen-Poiseuille Equation. ................................................................ 36

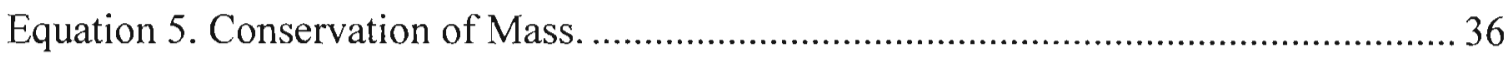

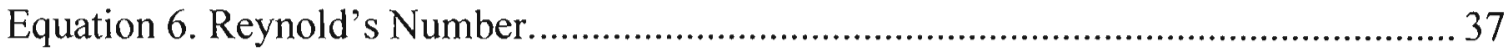

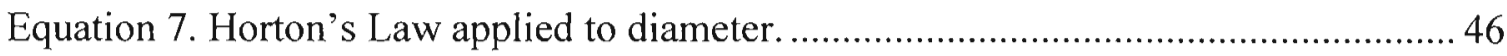

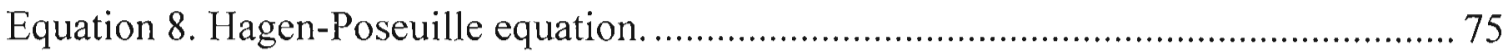

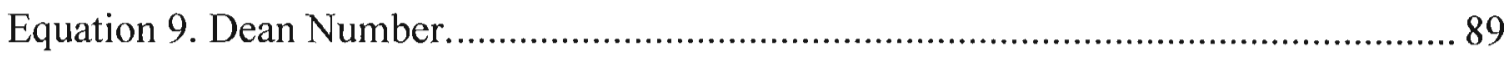


Introduction

\section{Normal Anatomy and Physiology of the Vascular Network}

The vascular system delivers nutrients to the body's tissues and removes waste products. To accomplish this the vascular system is organized into a branching network (Figure 1) (Guyton and Hall 2006).

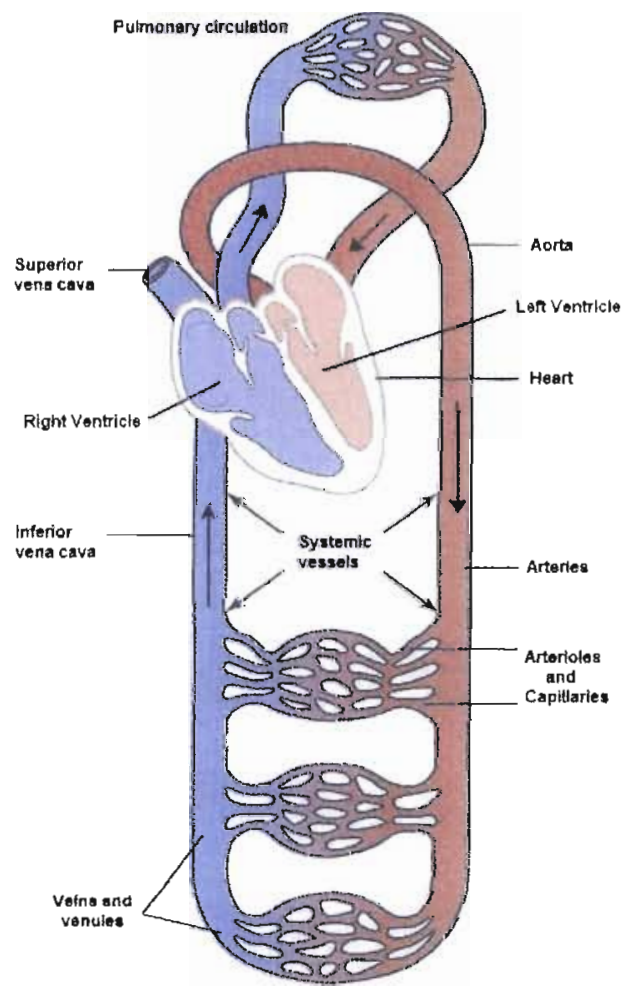

Figure 1. Schematic of the human circulation system.

Red denotes oxygenated blood, and blue denotes deoxygenated blood (Guyton and Hall 2006).

The circulatory system is comprised of an arterial side and a venous side. An artery is a vessel that carries blood away from the heart, while a vein is defined as a vessel that carries blood towards the heart. Oxygenated blood moves from the lungs, 
Introduction

through the left atrium and left ventricle, to the aorta, the primary artery in the body. As it moves away from the heart, the aorta and its daughter vessels branch extensively, eventually into capillaries. The capillaries evolve into venules, which then merge with other venules to form larger vessels called veins. Eventually the blood returns to the heart via the inferior and superior vena cava, entering the right atrium and ventricle of the heart, which pump it through the lungs where it is sent by the left ventricle back out to the body again (Figure 1) (Guyton and Hall 2006).

The nutrient and oxygen demands throughout the body can vary between the tissues and organs. For example, during exercise muscles require more blood flow to match the increase in energy expenditure. Therefore, it is important for the body to match blood flow to meet the individual tissue requirements. This flow control is accomplished by the arterioles, located immediately upstream of the capillaries, which alter the lumen diameter by contraction or relaxation of the surrounding smooth muscle (Guyton and Hall 2006).

The structure and location of each vessel type contributes to the cardiovascular system's purpose of meeting the tissue's nutrient and oxygen exchange requirements. For example, the capillaries are the primary site of nutrient and waste exchange; they are the smallest vessels, approximately $5-6 \mu \mathrm{m}$ in diameter, and contain extremely thin walls to maximize diffusion of oxygen, nutrients, and waste products.

In order for gases, such as oxygen, to diffuse into the tissues, the partial pressure of oxygen must be higher in the blood than in the tissues. The higher the pressure differential between the blood and the tissues, the larger the gas exchange, and vice versa. Therefore, it is advantageous to limit the diffusion of oxygen upstream of the capillaries 
and arterioles. Furthermore, it is also important to limit the hydrostatic pressure drop upstream of the arterioles to allow maximum blood flow control within the arterioles. This is accomplished by transporting the blood in the arteries: vessels which are larger in diameter with thicker walls, acting as low resistance conduits with minimal oxygen diffusion (Figure 2).

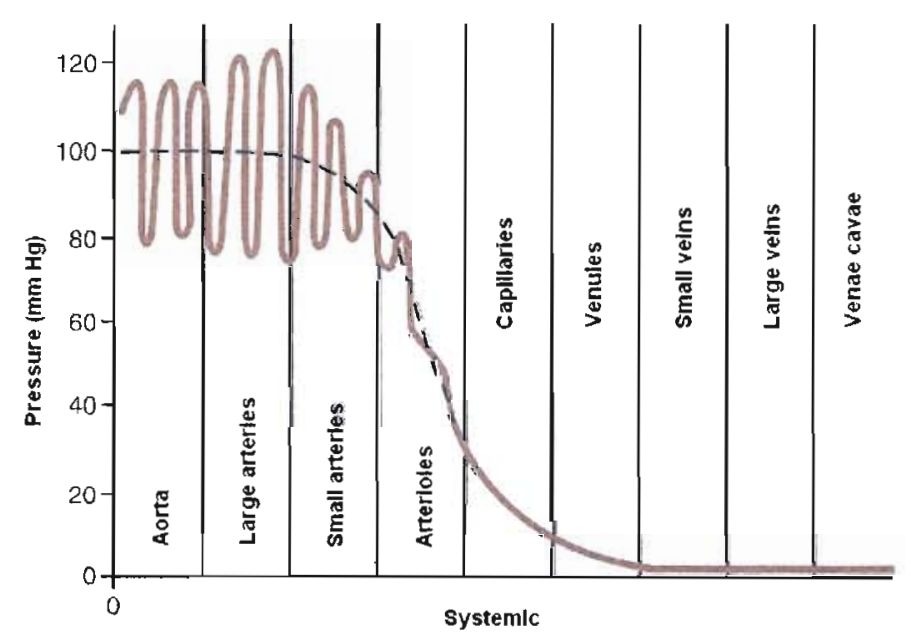

Figure 2. Schematic of the pressure throughout the circulatory system.

(Guyton and Hall 2006)

Under normal healthy conditions, blood flow is modulated to efficiently meet the nutrient demands of the body. However, certain disease states, such as peripheral arterial disease (PAD) can alter oxygen and nutrient delivery and lead to serious health risks.

\section{Effects of Dysfunction and Disease in the Vascular Network}

Overview

Peripheral arterial disease (PAD) involves blocked or reduced flow in peripheral vessels, most frequently due to atherosclerotic lesions that occlude the lumen. If present 
Introduction

for an extended period of time, arterial blockage results in chronic ischemia. Both acute and chronic arterial occlusions cause the tissues downstream to that vessel to be starved of oxygen (hypoxic) and nutrients (Peirce, Van Gieson et al. 2004). This can result in minor to major tissue damage, depending on the size of the vessel and or extent of the blockage.

This condition primarily affects older populations, and is responsible for approximately 200 lower limb amputations each year in non-diabetics, and 3900 each year in diabetics (Hershey, Baskin et al. 2001). Of note, diabetic patients have been found to have fewer collateral vessels (smaller arteries that run parallel to major arteries) and fewer capillaries, which results in a reduced ability to recover from artery occlusion (Wahlberg 2003). Gaining a deeper understanding of the processes underlying the body's response to blocked or reduced blood flow helps to target therapies, such as medications, to restore normal flow to ischemic limbs.

\section{Disease Models}

Oftentimes a patient with PAD will have additional health concerns, such as high blood pressure or diabetes. This can complicate attempts to study solely the body's response to arterial occlusion. Furthermore, in the patient, full and partial arterial occlusion occurs over a period of time; therefore, the reduction in blood flow is gradual (Garcia 2006). Modeling this in the laboratory is typically accomplished by surgically tying (ligating) an artery in the hindlimb of an animal and studying the subsequent vascular and tissue response to the occlusion. The approach discussed in this paper uses a mouse model; however, other common animal models include rats and rabbits. Although these models do not perfectly mimic PAD as it is seen in humans, it provides useful 


\section{Introduction}

information about physiologic response to vascular dysfunction (Hershey, Baskin et al. 2001; Scholz, Ziegelhoeffer et al. 2002; Prior, Lloyd et al. 2004; Gruionu, Hoying et al. 2005; Helisch, Wagner et al. 2006; Mees, Wagner et al. 2007; Penuelas, Aranguren et al. 2007).

\section{Responses to Arterial Occlusion}

There are two main responses that are observed upon ligation of the femoral artery of a mouse. The first is arteriogenesis - the outward remodeling of pre-existing smaller collateral arteries and arterioles. The second is angiogenesis - the formation of new capillaries from pre-existing vessels in the hypoxic tissues (Buschmann and Schaper 1999). Arteriogenesis is primarily localized to collateral vessels that circumvent the occlusion, and angiogenesis primarily occurs in the tissues downstream of the occlusion (Scholz, Ziegelhoeffer et al. 2002).

\section{Arteriogenesis}

At the onset of femoral artery occlusion in the mouse, downstream vessels experience a drop in blood flow, and consequently a drop in pressure (Heil and Schaper 2004). The pressure drop downstream creates a greater pressure differential across the collateral vessels that run parallel to the occluded artery. This leads to a relative increase in flow, and consequently wall shear stress, in those vessels (Figure 3). Wall shear stress is the force per unit area exerted on the vessel walls due to fluid flow (Fournier 2007). 


\section{Introduction}

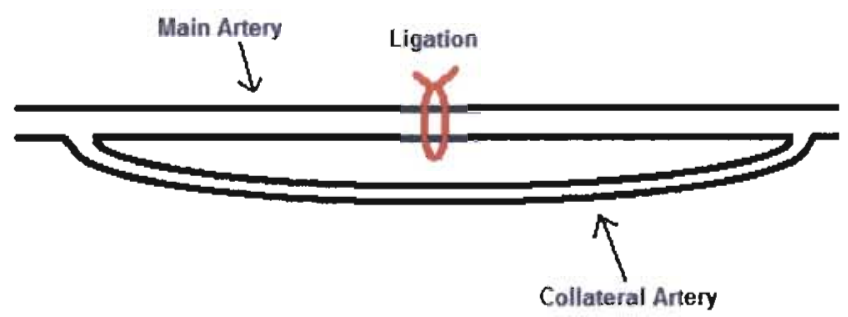

Figure 3. Schematic of a collateral artery.

Depicts the location of a collateral vessel with respect to the main ligated artery.

The increase in wall shear stress in the collateral arteries as a result of the increase in flow upregulates many genes and initiates arteriogenesis: a structural remodeling leading to an enlarged luminal diameter (Equation 1) (Heil and Schaper 2004).

$$
\tau=\frac{4 \cdot \eta \cdot Q}{\pi \cdot R^{3}}
$$

Equation 1. Wall shear stress equation.

Shows shear stress $(\tau)$ as it relates to flow rate $(Q)$, viscosity $(\eta)$, and radius $(R)$.

Although collateral vessels that circumvent the occlusion in the mouse grow in diameter, the overall conductance downstream of the occlusion remains at around $40 \%$ of normal (Peirce, Van Gieson et al. 2004). One reason for this is due to a premature halt to remodeling of collateral vessels. Shear stress is inversely related to the cube of the arterial radius (Equation 1), therefore an increase in radius during remodeling results in a marked reduction in shear stress, which leads to the cessation of the remodeling stimulus before optimal conductance is restored (Pipp, Boehm et al. 2004). 


\section{Introduction}

Additionally, as the flow is restored to the downstream tissues, the pressure differential across the collateral arteries decreases which leads to a decrease in flow (Pipp, Boehm et al. 2004), further lowering the shear stress felt by the endothelial cells and helping to halt collateral remodeling.

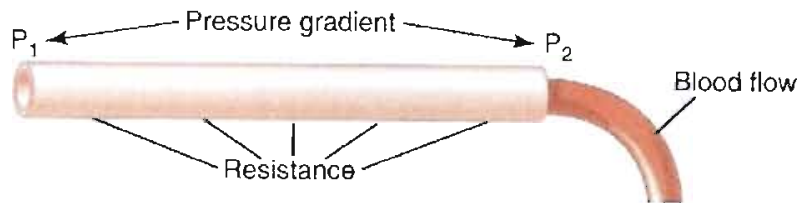

Figure 4. Schematic of a blood vessel.

Corresponding pressure drop, vascular resistance, and blood flow are shown.

Another reason why flow is not fully restored following remodeling is because flow resistance is higher. Several factors that account for this are smaller individual cross-sectional area and longer path length.

Vascular resistance is inversely proportional to the fourth power of vessel diameter according to the Hagen-Poiseuille equation (Equation 2) (Fournier 2007).

$$
\begin{aligned}
& Q=C \cdot \Delta P \\
& C=\frac{\pi \cdot D^{4}}{128 \cdot l \cdot \eta} \\
& R=\frac{1}{C}
\end{aligned}
$$

Equation 2. Hagen-Poiseuille equation.

Describes the relationship between flow rate $(\mathrm{Q})$, pressure drop $(\Delta \mathrm{P})$, vessel diameter $(\mathrm{D})$, vessel length (I), and viscosity ( $\eta)$. Resistance $(R)$ is the inverse of conductance (C). 
Introduction

Although the diameter of a normal artery is less than the sum of the diameters of the remodeled collaterals, the fourth power inverse relationship between resistance and diameter equates to an overall increase in vascular resistance due to flow being routed through the multiple smaller vessels (Scholz, Ziegelhoeffer et al. 2002). Again, this increase in overall resistance contributes to a reduction in blood flow.

Lastly, collateral arteries are typically at least twice the length of the original artery. Resistance increases with length, and therefore the relative increase in the blood path length from a point upstream of the occlusion to a point downstream increases the resistance, consequently decreasing conductance (Scholz, Ziegelhoeffer et al. 2002).

\section{Angiogenesis}

One primary stimulant of angiogenesis is hypoxia; inadequate oxygen supply in the tissues (Wahlberg 2003). This occurs under normal conditions, such as muscle endurance conditioning, and under pathological conditions, such as artery occlusion.

Upon artery occlusion, the tissues fed by that artery become hypoxic due to inadequate blood supply. The hypoxia increases production of several proteins, including vascular endothelial growth factor (VEGF) (Felmeden, Blann et al. 2003), an angiogenic growth factor. The presence of VEGF acts as a chemotactic signal that induces endothelial cell proliferation and migration to cause sprouting of neocapillaries in the direction of the stimulus (Peirce, Van Gieson et al. 2004). Increased capillary density provides more opportunity for oxygen exchange to the tissues, utilizing the low blood flow in a more efficient manner. Angiogenesis does not provide restoration of blood flow, but instead makes more use out of the blood that is present (Scholz, Ziegelhoeffer et al. 2002). 
Introduction

In summary, although angiogenesis and arteriogenesis can both occur following artery occlusion, they are stimulated through different mechanisms. Understanding these mechanisms can help to specifically target one or both for therapeutic benefits. Angiogenesis is induced due to hypoxic tissue; the hypoxic cells release VEGF in order to recruit new capillaries. Arteriogenesis, on the other hand, results from an increase in shear stress experienced by the endothelial cells of the collateral arteries (Mees, Wagner et al. 2007). In fact, the more hypoxic the tissue is following artery occlusion, the slower the arteriogenic response (Scholz, Ziegelhoeffer et al. 2002).

Arteriogenesis and angiogenesis combined involve a change in the structure, size, and quantity of pre-existing vessels. These changes lead to an alteration in network architecture, which can lead to changes in blood flow patterns throughout the network (VanBavel and Spaan 1992; Kalsho and Kassab 2004). In order to better understand the impact of this alteration a closer look at the hemodynamics (blood flow) is required.

\section{Hemodynamic Properties}

The end goal behind therapies aimed at treating PAD is restoration of blood flow to peripheral limbs. One challenge in assessing the blood flow rates, resistances, and pressures is that blood is a non-Newtonian fluid due to the fact that its viscosity changes depending on certain conditions. The main contributors to blood viscosity are blood velocity, hematocrit, and vessel diameter.

Blood is made up of cells suspended in plasma. The cellular composition of blood is comprised of erythrocytes (red blood cells), leukocytes (white blood cells), and platelets. The volume fraction of red blood cells in the blood is called the hematocrit. The plasma is made up of water, proteins, ions, hormones, and other components. One of 


\section{Introduction}

the major proteins found in plasma is fibrinogen, which plays a major role in hemostatis, or blood clotting (Fournier 2007).

Fibrinogen assists in the stacking of red blood cells into rouleaux, and those rouleaux can clump together to form aggregates (Figure 5). This mainly occurs at lower shear rates, and leads to the non-Newtonian aspects of blood. High shear rates tend to break apart the aggregated red blood cells making the blood behave closer to Newtonian. In general, the hematocrit affects how many aggregates can form, and in turn effects the physical properties of the blood, such as the viscosity. Increasing the hematocrit increases the apparent viscosity of blood leading to an increase in resistance (Fournier 2007).

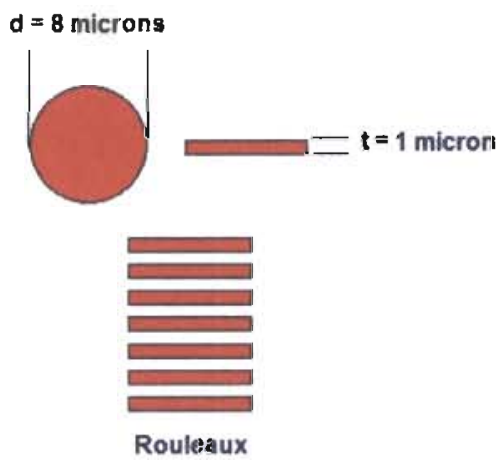

Figure 5. Simplified schematic of the formation of Rouleaux.

In addition to shear rate, the diameter of the vessel also affects viscosity of the blood. The Fahraeus-Lindquist effect describes how hematocrit varies as a function of diameter. In general this principle states that the hematocrit will be lower in the smaller vessels, such as capillaries, and larger in the feed and discharge vessels such as arteries and veins (Figure 6) (Fournier 2007). 


\section{Introduction}

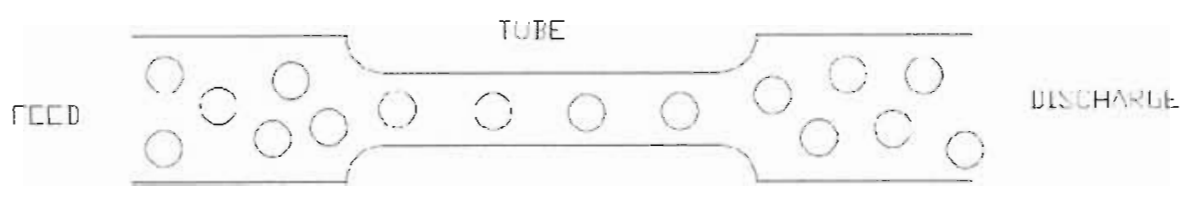

Figure 6. Schematic of the Fahraeus-Lindquist effect.

Blood flow goes from larger vessels (feed) to smaller capillaries (tube) and exiting (discharge).

This effect plays a role in the apparent viscosity of the blood as diameter changes. Because the hematocrit is lower in smaller vessels, the viscosity is lower as well. Lower viscosity, in turn, translates to a lower shear stress on the wall of the vessel (Equation 1). As mentioned previously, wall shear stress affects regulation of genes involved in arteriogenesis (Heil and Schaper 2004).

Another consideration when calculating viscosity is the phase separation effect. The hematocrit of the parent vessel is not necessarily equal to the hematocrit of the daughter vessels, but instead is a function of the diameters of the parent and daughter vessels (Pries, Secomb et al. 1990). As the vessels branch into networks of smaller vessels the hematocrit becomes increasingly more difficult to define precisely.

The relationship between network structure (which is altered during arteriogenesis and angiogenesis) and blood flow is complex. In order to develop effective therapies to treat PAD and ultimately restore flow, it is important to have a thorough understanding of how the structural and hemodynamic parameters interrelate. This can be accomplished by looking at the problem from a Systems Biology approach. 
Introduction

Experimentation and Computational Approaches

\section{Systems Biology}

Systems Biology incorporates medicine, biology, chemistry, math, and statistics, combined with experimental data, to describe the interconnectivity of individual components as well as emergent phenomena that arise when studying the system as a whole (van der Greef, Stroobant et al. 2004). Systems biology aims understand the mechanism and function of biological systems that can not be assessed through sets of individual experiments and intuitive connections (Kitano 2002). An analogy for Systems Biology can be seen in the artistic technique of pointillism, which incorporates using multiple, tiny, mono-colored dots to create an image (Figure 7). Experiments that focus on a few individual parameters would look at the picture and state that it contains 256 yellow dots, $56 \%$ of which are adjacent to a green dot. However, a systems approach will look at the entire image and see that it's of a man with a mustache.

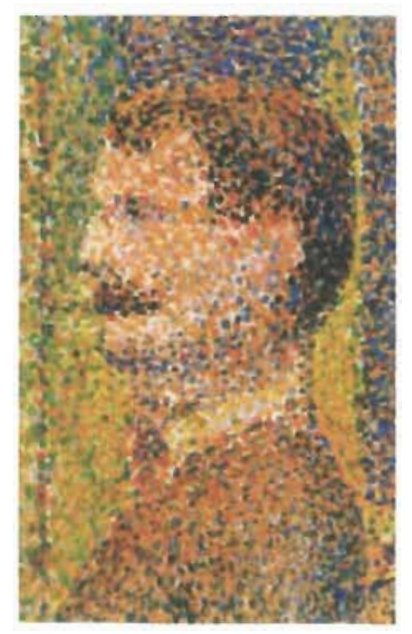

Figure 7. Detail from Seurat's La Parade (1889).

Meant as an analogy to the traditional versus systems approach in biology. 
There are two main branches to Systems biology. The first looks at extracting patterns from experimental data and formulating hypotheses from those patterns. The second branch utilizes predictive computational models that test a hypothesis and are verified by experimental data (Kitano 2002).

In general, Systems Biology approaches have been applied to several different areas of vascular research, such as relating morphometry and flow patterns in a pig heart, and using molecular signaling to predict vascular network patterning (Fenton and Zweifach 1981; Tsitlik, Halperin et al. 1992; Jiang, Kassab et al. 1994; Kassab, Berkley et al. 1997; Pries and Secomb 2000; Peirce, Van Gieson et al. 2004; Bailey, Thorne et al. 2007; Mac Gabhann, Ji et al. 2007). The usefulness of this approach is exemplified when considering the many interrelated hemodynamic and morphologic parameters involved in blood flow through a vascular network (Figure 8).

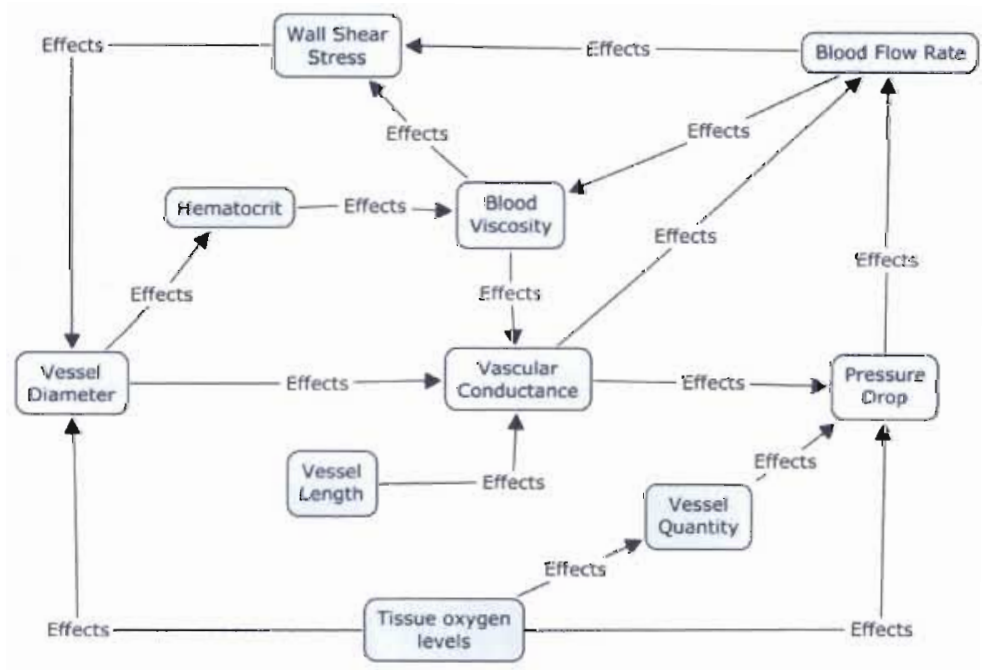

Figure 8. Schematic of interrelated hemodynamic and morphologic parameters. 
For example, low tissue oxygen levels lead to the release of chemicals that cause dilation of the blood vessels feeding that tissue and an increase in capillary number (angiogenesis) (Buschmann and Schaper 1999). That, in turn causes changes in vascular conductance, hematocrit, and pressure drop, which then lead to changes in blood viscosity, blood flow rate, and so on.

Following arterial occlusion, vascular dysfunctions arise that affect morphologic and hemodynamic parameters. The interrelatedness of these parameters means that changes in any one parameter can have a large impact on overall blood flow. Therefore, studying these dysfunctions is important for understanding the how to restore normal blood flow again.

\section{Change in Vasomotor Capacity}

There are two primary dysfunctions that arise following arterial occlusion. The first involves the ability of blood vessels to vasodilate (increase luminal diameter) and vasoconstrict (decrease luminal diameter), affecting one of the primary mechanisms used to modulate blood flow to match tissue demands (Guyton and Hall 2006). Vasoactive molecules, such as nitric oxide and endothelin, are released by the endothelium (lining of the blood vessels), eventually causing a relaxation or constriction of the surrounding smooth muscle, changing the diameter of the vessel (Guyton and Hall 2006). However, following blocked or reduced blood flow the vascular responsiveness to these molecules, and therefore the vasomotor capacity, is reduced (Takeshita, Isshiki et al. 1998).

The cause of the decreased responsiveness is not fully understood and is currently being researched (Hudlicka, Brown et al. 1994; Kelsall, Brown et al. 2001; Kelsall, 
Brown et al. 2004; Mac Gabhann, Ji et al. 2007); however, the focus of this paper is on the second main area of research: changes in architecture.

\section{Change in Architecture}

Vessel architecture encompasses any semi-permanent morphological characteristics related to individual blood vessels or the network as a whole. Following artery occlusion, the surrounding vasculature undergoes remodeling due to an increase in shear stress, leading to several morphological changes. First, there is an increase in resting diameter of collateral vessels in order to lower the shear stress experienced by the vessel wall. Second, there is an increase in blood path length due to re-routing of blood through the collaterals circumventing the occlusion. Furthermore, vascular network connectivity patterns are different due to shifts in flow direction (discussed later). As mentioned previously, remodeling halts before full flow is recovered (Heil and Schaper 2004) due to a number of factors. However, not only are these mechanisms not completely understood, but they also could be potential targets for therapy to help restore flow. Assessing normal vessel architecture and resulting changes in morphology and blood flow on an individual and systems level may shed some light on the role the morphological changes have in overall blood flow in order to better target efforts to return blood flow to normal levels. Computational tools offer an attractive option to accomplish this task as the level of detail utilized and output type can be adjusted based on the needs of the project. 


\section{Introduction}

\section{Previous Experimental Models}

Computational approaches to model blood flow relating to vascular architecture incorporate a full range of complexity. The simpler methods make assumptions around the properties of blood, such as constant viscosity, and averaging techniques regarding the network architecture (Lipowsky and Zweifach 1974; Fenton and Zweifach 1981; Kassab, Rider et al. 1993; Jiang, Kassab et al. 1994; Kassab, Berkley et al. 1997; Kassab, Pallencaoe et al. 1997; Kassab 2000; Gruionu, Hoying et al. 2005). Some attempt to calculate viscosity based on diameter and the phase separation effect and incorporate that into the blood flow assessment (Pries, Secomb et al. 1994; Pries and Secomb 2000; Penuelas, Aranguren et al. 2007). Other researchers attempt to use complex differential equations to account for variations in geometry and hematocrit to calculate blood flow, which requires more complex detail regarding the structural characteristics of the vessels, for example exact cross-sectional profiles (Quarteroni, Tuveri et al. 2000).

Each of these approaches yields useful information, it is therefore important to consider the goal of the experimental model when selecting the approach. If a predictive model is desired, then a more complex approach (Pries and Secomb 2000; Quarteroni, Tuveri et al. 2000; Peirce, Van Gieson et al. 2004; Bailey, Thorne et al. 2007) should be used since the output is not bounded. In other words, the final system can vary greatly from what is actually seen in vivo and therefore greater efforts towards computational accuracy should be made to minimize this. If a more descriptive or relational model is desired, or if there is not sufficient detail on the initial network to warrant a complex analysis, than a simpler model is appropriate (Fenton and Zweifach 1981; Jiang, Kassab et al. 1994; Gruionu, Hoying et al. 2005). The descriptive approach utilizes data from 
both the initial and final systems and is therefore somewhat constrained and bounded. Therefore, general assumptions and simplifications do not have as large of an impact on the output.

Comparing predictive to descriptive, a predictive model of vascular architecture would take the initial network dimensions and flow conditions, apply a stimulus (such as blockage of a vessel) and attempt to predict how the dimensions and flow will change. The model will then be validated and compared to experimental results. The descriptive model will assess observed experimental architectures in both normal networks and after the stimulus is applied, and look at the changes in architecture and flow rate and attempt to comment on the relation between structure and flow parameters. Both predictive and descriptive approaches have shown reasonable agreement with in vivo measurements (Lipowsky and Zweifach 1974; Fenton and Zweifach 1981; Kassab, Rider et al. 1993; Jiang, Kassab et al. 1994; Kassab, Berkley et al. 1997; Kassab, Pallencaoe et al. 1997; Kassab 2000; Pries and Secomb 2000; Quarteroni, Tuveri et al. 2000; Peirce, Van Gieson et al. 2004; Gruionu, Hoying et al. 2005; Bailey, Thorne et al. 2007).

This paper explores one of the descriptive since the goal of the model is to assess and compare network architecture between specimens and relate that to alterations in flow. The specific model used incorporates a type of systems level approach to assess vascular architecture, originally derived from Horton's Law of Stream Numbers (Fenton and Zweifach 1981).

\section{Models Explored in this Report}

Horton's Law was originally developed to describe the branching networks observed in streams in nature (Fenton and Zweifach 1981). This approach has since been 
modified and applied to vascular networks to describe the branching patterns in the cardiovascular system (Fenton and Zweifach 1981; Kassab, Rider et al. 1993; Jiang, Kassab et al. 1994; Kassab, Berkley et al. 1997; Kassab, Pallencaoe et al. 1997; Dimitropoulou, Maragoudakis et al. 2000; Kassab 2000).

Horton's Law states that certain characteristics of a given order (type of branching level) will form an inverse geometric sequence with order number (Fenton and Zweifach 1981). In other words, a value can be multiplied by a constant to reach the next value in the sequence. In the case of blood vessels, capillaries are considered order 1. Moving upstream, when two order 1 capillaries merge to form the feeding (parent) vessel, that vessel is considered order 2 . When two order 2 vessels merge together, the resulting vessel is order 3, and so on. A more detailed explanation of ordering methods will be addressed in the methods section.

According to Horton's Law, quantity (or bifurcation ratio), diameter, and length will each form inverse geometric sequences with order number that when assessed throughout the whole network will approach a single value (Fenton and Zweifach 1981). This concept has been applied to the vasculature in order better understand and compare the branching characteristics between and within muscle groups, organs, and species (Kassab 2000). 
If a network obeys Horton's Law, it can be described by the following equations (Kassab 2000):

$$
\begin{aligned}
& \log _{10} D_{n}=a+b n \\
& \log _{10} N_{n}=a+b n \\
& \log _{10} L_{n}=a+b n
\end{aligned}
$$

\section{Equation 3. Horton's Law Equations.}

Where $D_{n}, N_{n}$, and $L_{n}$ represent the average diameter, quantity, and average length of vessels of order $\mathrm{n}$, respectively. The values for $a$ and $b$ vary between these groups; however these values should be similar within the groups.

The diameter ratio $\left(R_{D}\right)$, number ratio $\left(R_{N}\right)$, and length ratio $\left(R_{L}\right)$, are defined as $10^{\mathrm{b}}$. The diameter ratio describes the increase in diameter that is seen when transitioning from one order to the next. Likewise the length ratio is seen as the average increase in vessel length from vessels of order $n$ to order $n+1$. The number ratio is sometimes referred to as the bifurcation ratio and describes the increase in total number of vessels of order $n$ compared with order $n+1$. The utility of such a method will be discussed in greater detail later in the report.

Although applying Horton's Law provides useful information on the overall network characteristics, it falls short in a few areas, namely that it only describes patterns between adjacent orders (Jiang, Kassab et al. 1994). Consequently, various adjustments have been made to the Horton's Law approach, resulting in what is called the diameterdefined Strahler system (Jiang, Kassab et al. 1994).

The first adjustment incorporated by this system involves accounting for diameter when assigning order numbers to vessels. In the original approach, ordering was solely 
based on the connections made originating from the capillaries and did not take into account diameter. Consequently, there was significant overlap in diameter between orders. As a result, it was possible to have an order 3 vessel with a larger diameter than an order 4 vessel, which as will be illustrated later equates to a smaller diameter vessel feeding a larger diameter vessel, something that is not typical of vascular trees. The new method uses statistical analysis to reorder the vessels based on their average diameters and standard deviations (Jiang, Kassab et al. 1994), as discussed in more detail in subsequent chapters.

The second alteration involved combining identical segments connected in series into one element. This is done to more accurately represent the vascular network, particularly the lengths of the different orders (Jiang, Kassab et al. 1994).

The third adjustment was incorporated to provide a more detailed description of the branching patterns. The bifurcation ratio describes the difference between the quantities of vessels from order $\mathrm{n}$ to order $n+1$; however, sometimes vessels of order $\mathrm{n}$ can branch from vessels of order $n, n+2, n+3$, and so on. The construction of a connectivity matrix allowed another dimension to be added to the branching ratios determined through Horton's Law (Figure 9).

\begin{tabular}{|c|c|c|c|c|c|c|c|}
\hline & \multicolumn{6}{|c|}{ Parent } \\
\hline & & $A$ & $B$ & $\mathrm{C}$ & $\mathrm{D}$ & $E$ & $F$ \\
\hline & $A$ & 0 & 0 & 0 & 0 & 0 & 0 \\
\hline & B & 0 & 0 & 1 & 0 & 0 & 0 \\
\hline & C & 1 & 0 & 0 & 0 & 0 & 0 \\
\hline & D & 0 & 0 & 0 & 0 & 0 & 1 \\
\hline & $E$ & 1 & 0 & 0 & 0 & 0 & 0 \\
\hline & $F$ & 0 & 0 & 1 & 0 & 1 & 0 \\
\hline
\end{tabular}

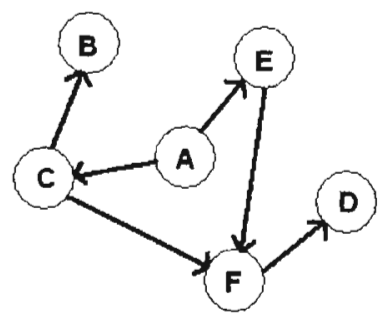

Figure 9. Schematic of an arbitrary connectivity matrix. 


\section{Introduction}

Horton's Law and the diameter-defined Strahler method have been applied to several different species and organs, such as coronary vessels of the pig, pulmonary vasculature of rats, cats, dogs, and humans, spinotrapezious muscle in the rat, omentum of the rabbit, and so on (Fenton and Zweifach 1981; Kassab, Rider et al. 1993; Jiang, Kassab et al. 1994; Kassab, Berkley et al. 1997; Kassab, Pallencaoe et al. 1997; Kassab 2000). None have applied this method to a mouse or to the gracillis muscle. The advantage to using the mouse gracillis muscle is that it undergoes significant remodeling upon occlusion of the femoral artery, allowing characterization of both healthy and remodeled vascular networks.

\section{Network Architecture Data}

Assessing network architecture requires experimentally obtained dimensional data, which includes vessel length, diameter, upstream vessel, and order number. Without processing or staining, dissected tissue is opaque and the vasculature is not easily seen. Therefore, there are two common approaches to processing the tissue in order to elucidate the detailed geometrical information. The first uses a contrast agent or dye to stain the blood vessels followed by chemical processing to make the surrounding tissue clear. This is well suited to thin samples, providing clear contrast to view the vessels under a microscope (Gruionu, Hoying et al. 2005). The second approach is geared towards thicker tissues and involves creating a three dimensional cast of the vasculature (Kassab, Rider et al. 1993; Kassab, Berkley et al. 1997; Kassab, Pallencaoe et al. 1997; Kassab 2000).

More complex imaging techniques such as computed tomography (CT) and magnetic resonance imaging (MRI) have lower resolution than techniques that allow 
Introduction

viewing under a microscope (McDonald and Choyke 2003). Although CT and MRI have the advantage of being non-invasive, the difference between resolution (100nm versus $100-500 \mu \mathrm{m})$ becomes significant when measuring vessels with diameters as small as

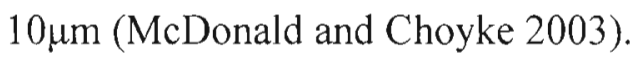

The mouse gracillis anterior is very thin and therefore dimensional data will be obtained by staining the vasculature with India Ink and viewing under a microscope.

\section{Goals and Hypothesis}

This project has three objectives. The first is to successfully obtain morphological data from a two dimensional image of the mouse gracillis muscle. The hypothesis is that the gracillis anterior muscle is sufficiently thin for a morphological analysis to be performed on a two dimensional image.

The second goal is to apply Horton's Law and the diameter-defined Strahler method to assess the network architecture in the gracillis anterior muscle of the mouse and relate that to computed hemodynamic parameters such as pressure and flow rate. The hypothesis is that using Horton's Law and the diameter-defined Strahler method will yield comparable ratios to previous studies with other animal models, and will provide information about the network from a systems level.

The third goal of this project is to compute blood flow using the segmental and elemental representations of the network (the second alteration of the Strahler method). The hypothesis is that both methods will yield comparable flow rate and pressure profiles compared with published literature values. 
Methods

Overview

This chapter details the methods used for vascular staining, image acquisition, morphometric analysis, and blood flow calculations. As mentioned in the introduction, vascular staining is an important step in creating contrast between the vessels and the surrounding tissue in order to see the vasculature network in an otherwise opaque tissue. The morphometric analysis and blood flow calculations are done in accordance with the diameter defined Strahler method first mentioned in the Introduction. Although this chapter presents some basic assessment of the utility of these methods, a more thorough analysis will be presented in the Discussion.

Note that the specimen used to generate the photomicrographs used in this report was obtained from an experiment performed previously (Gruionu, Hoying et al. 2005). Therefore the actual methodology used for the ink fills, and image generation can be found in that report. The methods presented here are aimed at future experiments in this lab. That is to say, vascular staining was performed and the methods will be described; however, the data generated from that procedure was not usable and necessary modifications to that procedure will therefore be discussed later.

There are several steps required in order to obtain pressure and flow calculations for the gracillis anterior muscle:

1. Stain the vasculature and process the tissue

2. Generate detailed digital images

3. Perform morphological Analysis

4. Perform the computations 
Methods

\section{Staining and Processing}

Staining of the vasculature was accomplished with India ink. The mouse was anesthetized with $25 \%$ Avertin $(0.10 \mathrm{ml} / 10 \mathrm{~g})$ and placed on a heating pad. The skin was separated from the muscle between the abdomen and thoracic cavity. A thoracotomy was performed and a small incision was made at the left ventricular apex. A PE 50 catheter was inserted into the left ventricle and $20 \mathrm{ml}$ of heparinized vasodilator cocktail (Sodium Nitroprusside, Adenosine, in $\mathrm{PBS}, 37^{\circ} \mathrm{C}$ at $8 \mathrm{ml} / \mathrm{min}$ ) was injected and drained from an incision in the right atrium. Next, $4 \mathrm{ml}$ of warm India ink was injected at $2 \mathrm{ml} / \mathrm{min}$, and it was observed that the entire mouse turned black, indicating that the stain had been adequately dispersed in the entire vasculature.

Following the India ink staining, the gracillis anterior muscles of each hindlimb were dissected and placed into microfuge tubes making sure to maintain in situ length and orientation. The muscles were then dehydrated in increasing concentrations of ethanol $(25 \%, 50 \%, 75 \%, 95 \%, 99 \%)$ for a minimum twelve hours per solution.

Following dehydration, the muscles were transferred to glass vials and clarified in methyl salicylate overnight to improve image resolution of the vasculature. During the dehydration and clearing steps, the muscles were kept pressed up against the side of the tube and the tubes stored on their sides to prevent the tissue from curling or folding.

Following the methyl salicylate clarification, the muscle was placed flat between two microscope slides. The entire circumference was sealed to secure the slides and to prevent the methyl salicylate vapors from escaping. 


\section{Image Generation}

The slide was viewed under a normal light microscope and the images were taken by a portable digital camera aiming through the ocular lens. In the future, use of a normal light microscope with incorporated image acquisition system is preferred. To capture the entire muscle, overlapping images were taken. A magnification of $100 \mathrm{x}$ provided sufficient detail for the morphological analysis (Figure 10).

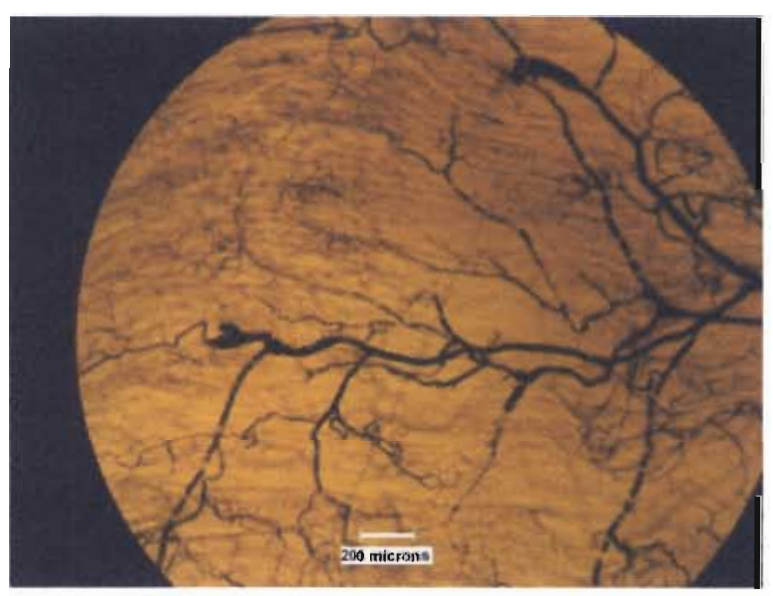

Figure 10. Digital micrograph of a section of the vasculature.

Taken of a non-ischemic gracillis anterior muscle of a mouse at a magnification of $100 x$.

Figure 11 shows the same field of view with two different focal planes. These two views illustrate the three dimensionality of the gracillis anterior, even though it is a comparatively thin muscle. The larger vessels can be seen in both views; however, the visibility of the smaller vessels changes between views. Therefore, the smaller the vessel, the greater the possibility that it is not resolved on a single 2-D image. 


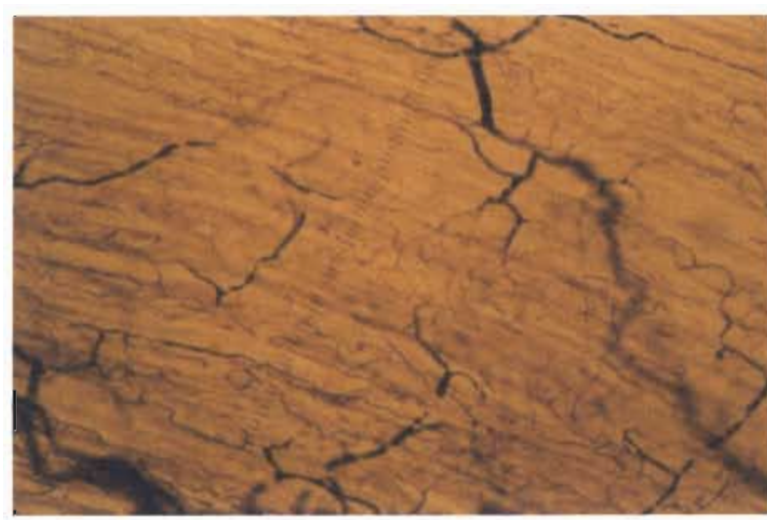

View 1

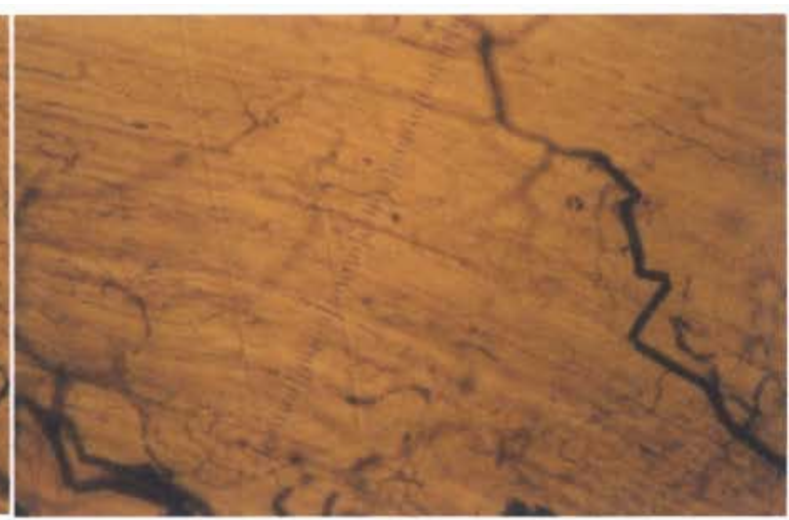

View 2

Figure 11. Comparison of two different view planes.

Digital micrographs were taken in the same field of view, but with slightly different focusing. Magnification is $100 x$.

In order for the images to be usable, the majority of the arteries and veins must be discernable and measurable. Additionally, there must be a minimum amount of breakage and discontinuity seen in the vessel diameters and lengths in order to accurately assess the network architecture and flow parameters.

\section{Image Digitization}

Morphological analysis describes the process of measuring the anatomic features of an image. The morphometric data was then used for computational model development. This section describes the procedure for completing the morphometric analysis of the gracillis anterior arterial networks, which involved: zoning, vessel identification, vessel ordering number, feeding (parent) vessel identification, as well as measuring vessel length diameter, and feeding (parent) vessel label (Table 1, Figure 12). 


\section{Methods}

Table 1. Definition of terms used in the morphometric analysis.

\begin{aligned} \hline Term & Definition \\ \hline Zone: & $\begin{array}{l}\text { A user defined area of the image. The purpose of zoning the images is to } \\ \text { easily transition and reference between the morphological and } \\ \text { photom icrograph data. }\end{array} \\$ Vessel & A user defined unique identification number assigned to each individual \\ identification: & vessel segment. \\ Split Point: & Point where an arcade is split in half. \\ Segment: & Vessel between two nodes. \\ Node: & Point of intersection between two vessels. \\ Order: & Vessel classification, with the tem inal vessels assigned order 1, and \\ Paccessive larger vessels arbitrarily assigned higher orders. & Feeding vessel upstream of the segment or element \\ Element: & Multiple segments of ident ical orders that are connected in series \end{aligned}

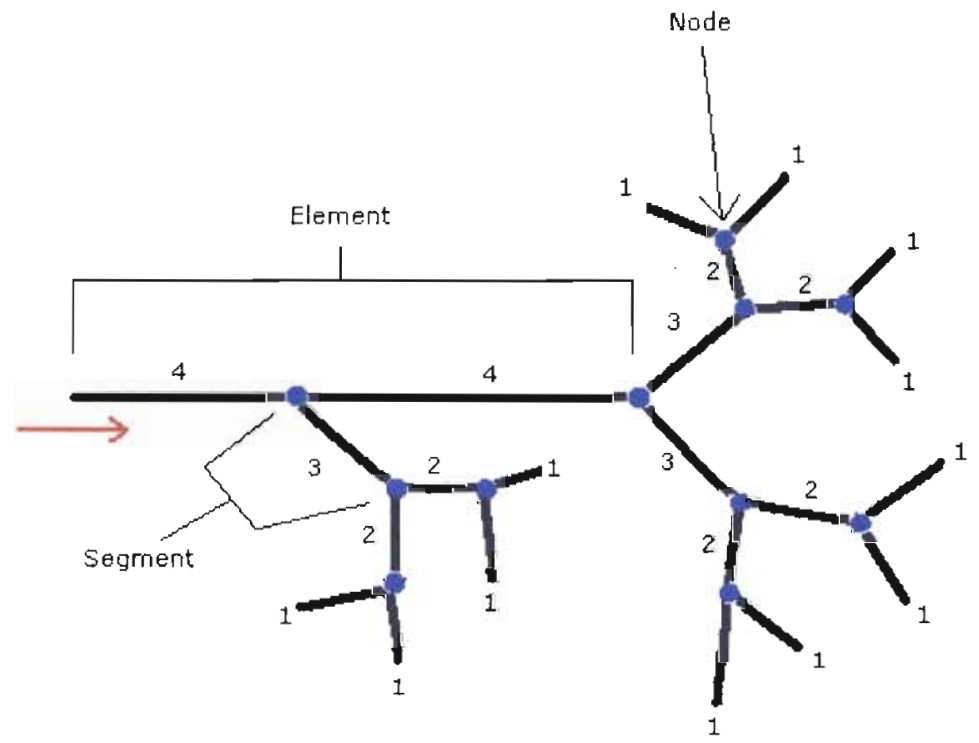

Figure 12. Schematic of a Strahler-ordered network.

Location of nodes, segments, and elements are labeled as well as ordering scheme. The red arrow indicates flow path.

The gracillis anterior muscle is fed by two different arteries: the muscular branch and the saphenous branch (Figure 13). Blood flow enters the muscle at these two 
locations, each supplying blood to approximately half of the muscle. The first step in the morphometric analysis was to identify the arteries and veins between the muscular branch and saphenous branch, and describe the basic flow path through the arteries and arterioles, to the capillaries. Some arterioles traverse the entire length of the muscle, and have two separate inlets (muscular and saphenous); these vessels are called arcades and contain opposing flow directions and feed different arterioles and capillary beds.

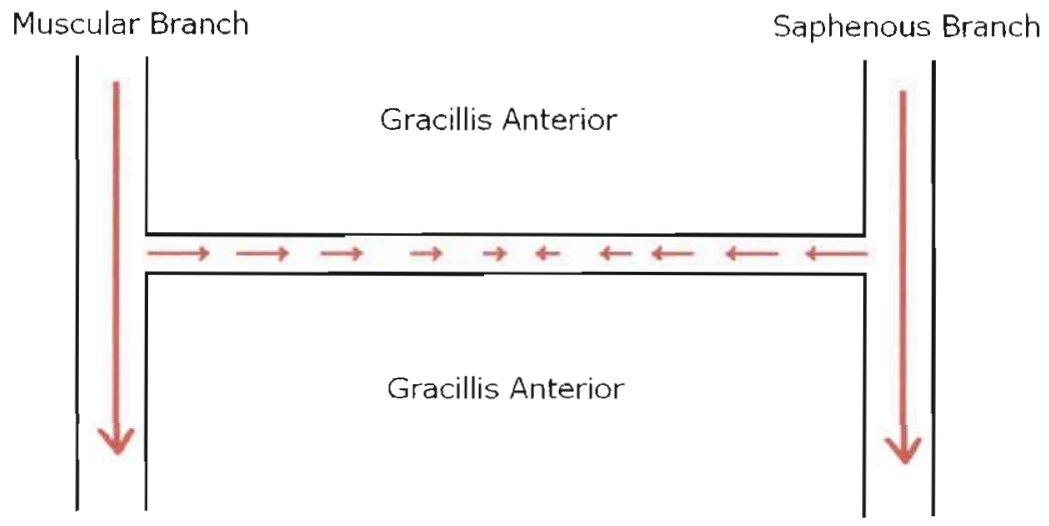

Figure 13. Blood flow through an arcade.

Schematic shows the flow through the gracillis anterior from the saphenous and muscular branches.

The center arcade (horizontal) has many branches that break off along the length to feed the surrounding tissue.

Therefore, it was assumed that these arcades could be split in half and treated as separate networks. The split point was chosen based on two criteria. First, the angle with which branches separate from the arcade was used to determine primary flow in that area. For example, Figure 14 shows an arcade where one branch is angled towards the right (indicating flow is to the right) and one branch is angled towards the left (indicating flow is to the left). Therefore, the split point should be between these two points. Next, within 


\section{Methods}

that short segment the point with the smallest diameter was chosen to be the split point. If there was no discernable variation in diameter, the center point of that short segment between the two branches was chosen. Everything to the left of the split point was assumed to be fed from the muscular branch, and everything to the right was assumed to be fed from the saphenous artery.

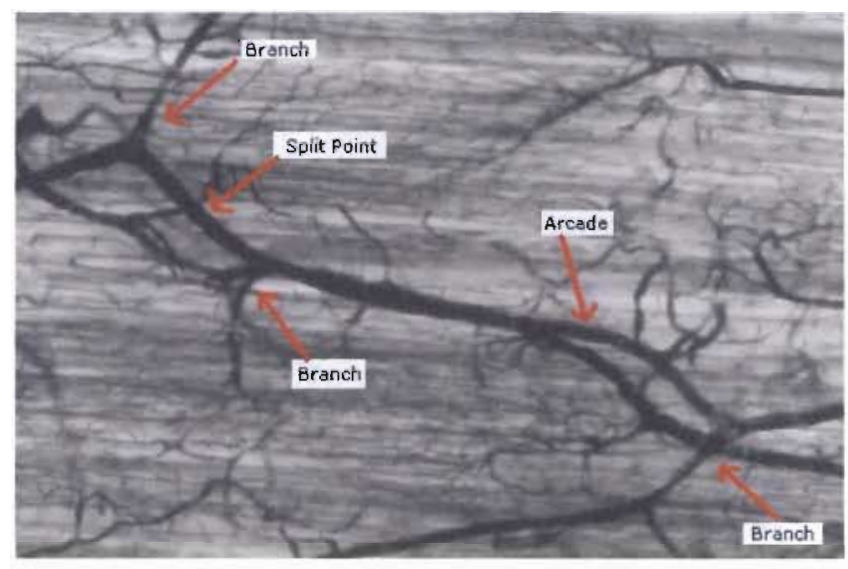

Figure 14. Digital micrograph of arcade and split point.

One of the arcades in the gracillis anterior muscle is shown. The branch angles help to discern flow direction and the location of the split point.

After identifying arteries, veins, and the split points of the vascular arcade, the images were zoned into overlapping squares. The number of zones is arbitrary and should be optimized for the user. Labeling was done by hand on a printed zone image and then digitized on a flat-bed scanner; however, labeling can also be performed on the computer.

Labeling was performed with the modified Strahler method for each zone (Jiang, Kassab et al. 1994). In summary, the smallest consistently discernable vessels were assigned as order 1, and ordering continued upstream for each vessel segment. Where 
two order 1 vessels come together, the resulting vessel is assigned order 2 . When two order 2 vessels come together, the resulting vessel is assigned order 3 , and so on. When two vessels of unequal order come together, the higher order is retained. For example, if an order 2 and order 3 vessel come together, the resulting vessel is assigned order 3 .

Figure 15 shows a sample tree that is ordered in this method.

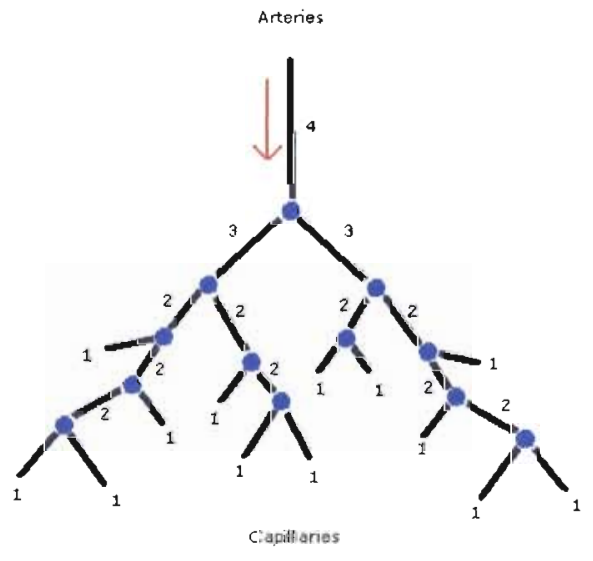

Figure 15. Schematic of a the Strahler ordering process.

A hypothetical branching vascular tree is shown with corresponding orders, the arrow indicates flow direction.

In addition to assigning the order, each vessel segment was also assigned a unique ID number, and the parent's ID number was recorded for referencing later. ImageJ was used to measure the lengths and diameters of each segment. The resolution was approximately $0.5 \mu \mathrm{m}$ per pixel, resulting in a resolution of $\pm 1 \mu \mathrm{m}$. Additionally, the transition between "vessel" and "not vessel" was gradual, often several gray pixels formed the transition, especially for the smaller vessels. This potentially introduced additional measurement error. Lastly, since the image was $2 \mathrm{D}$, any vessels that branch towards or away from the plane of view will appear shorter than they actually are, if they 
appear at all. Again, smaller vessels are affected to a larger degree. Table $\mathbf{2}$ contains an example of the data obtained during digitization.

Table 2. Sample of data taken from digital micrographs.

(P1=parent, $\mathbf{L}=$ length, $\mathrm{D}=$ diameter).

\begin{tabular}{cccccc}
\hline Zone & Label & PI & Order & L (micron) & D (micron) \\
\cline { 1 - 2 } 2.1 & 34 & 33 & 1 & 53.5 & 7.9 \\
2.1 & 35 & 33 & 1 & 92.8 & 7.9 \\
2.1 & 36 & 32 & 1 & 167.1 & 7.2 \\
2.1 & 37 & 42 & 4 & 248.5 & 15.7 \\
2.1 & 38 & 42 & 1 & 76.8 & 8.7 \\
2.1 & 39 & 41 & 1 & 71.5 & 5.6 \\
2.1 & 40 & 41 & 1 & 88.5 & 5.6 \\
2.1 & 41 & 42 & 2 & 80.5 & 5.7 \\
\hline
\end{tabular}

The gracillis anterior has two main feeding arteries, the muscular branch and the saphenous branch; however, these vessels were not included in the morphological analysis. Extrapolation beyond the tissue being characterized (in this case the gracillis anterior) is not possible since the downstream branching of these feed arteries is unknown, therefore, the order is unknown (Fenton and Zweifach 1981).

\section{Computations}

Overview

Once the morphological analysis was complete and the data were input into Excel, the next step was to calculate the flows and pressures, which involved several steps (parenthesis indicate the software used to accomplish this step):

1. Selection of boundary conditions and assumptions 
Methods

2. Re-ordering of segments based on diameter-defined Strahler method (Excel)

3. Combining segments into elements (Excel)

4. Generation of linear flow equations (Excel)

5. Solving system of linear equations (Mathematica)

The appendix contains more detailed information on the computations.

\section{Boundary Conditions and Assumptions}

The pressures at the inlet and outlet of the muscle were assumed constant and set at $77 \mathrm{mmHg}$ and $30 \mathrm{mmHg}$ respectively (Pries, Secomb et al. 1995). Blood was assumed to behave as Newtonian, and viscosity was assumed constant at 3cP (Gruionu, Hoying et al. 2005). A type of variable viscosity was also simulated by setting different values for viscosity for different vessel diameters. This method assumed a linear decrease in viscosity as diameter decreased. The data presented in this report were calculated with an entrance viscosity of 4.2cP and capillary viscosity of 3cP (Pries, Secomb et al. 1994; Gruionu, Hoying et al. 2005). It was assumed that the vessel walls were non-distensible. The effect of these assumptions will be addressed further in the discussion.

\section{Segment Reordering}

The initial ordering was performed based on physical connectivity, diameter was not considered. Therefore, without reordering it is possible to have an order 4 vessel that is smaller than an order 2. The overall intent behind assigning orders is to categorize vessels into groups to facilitate assessing the branching vascular network as a whole. Instead of analyzing each individual vessel, the characteristics within and between each 
group are analyzed. Reordering of the segments is important so that there is no overlap in diameter from one order to the next (Jiang, Kassab et al. 1994), leading to a more meaningful categorization (i.e. vessels with the same diameter would not be categorized differently).

First, the average diameters and standard deviations were calculated for each order. Then, the midpoints between the standard deviations of adjacent orders were calculated and these became the upper and lower bounds for that order. Any vessels whose diameter fell outside of these bounds were reordered accordingly. For example, if the diameter of an order 3 segment was larger than the upper bound calculated for order 3 , that vessel became order 4 . Figure 16 shows a schematic of the upper and lower bounds for different orders based on their standard deviations.

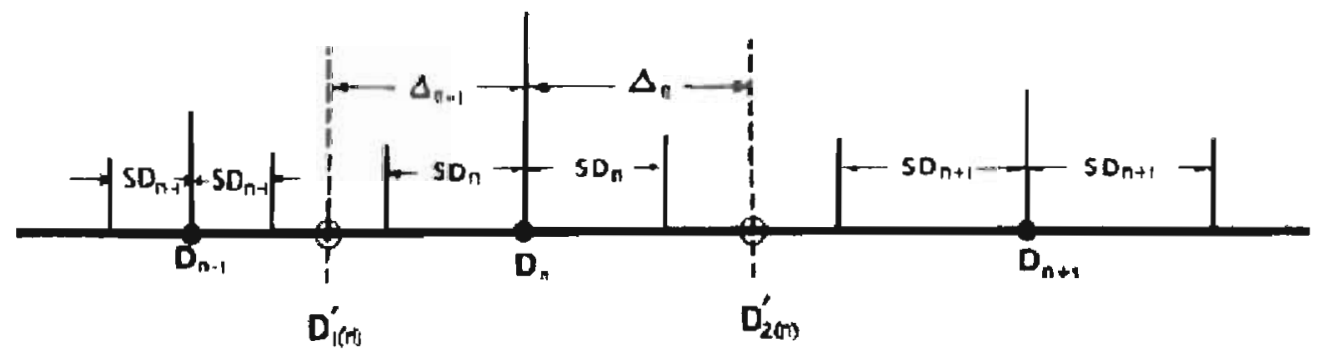

Figure 16. Segment and element reordering convention.

Average diameters and standard deviations are used to reorder the vessels (Jiang, Kassab et al. 1994).

After the first round of reordering, the average diameter and standard deviations were recalculated for each order. New upper and lower bounds were determined and the 
vessels were once again reordered according to these new values. A total of four such iterations were sufficient to obtain convergence.

\section{Combining Segments into Elements}

The goal of combining segments into elements is to provide a more accurate depiction of the actual vascular network. For example, a large vessel that has one small capillary at its midpoint would be treated as two separate segments of half the actual length. This effects the description of network topology including average vessel connectivity, vessel quantity, and the lengths of each vessel order.
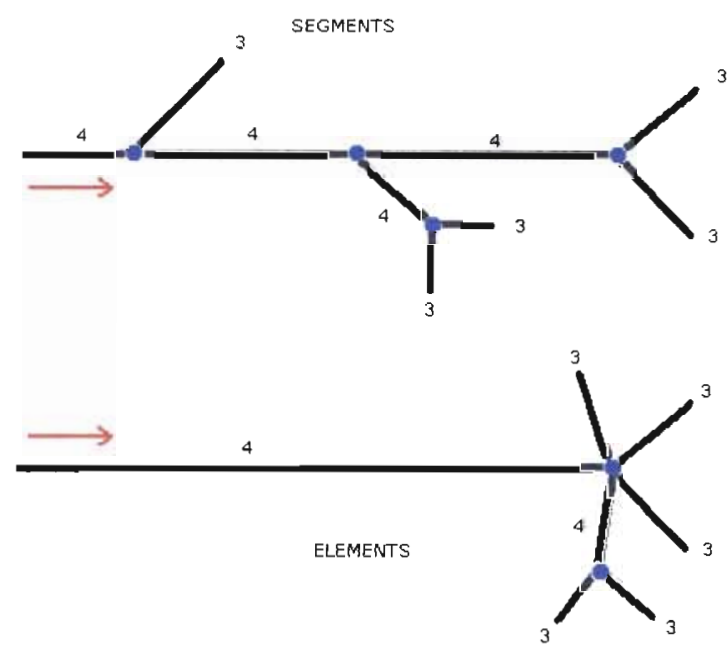

Figure 17. Comparison of segment and element vessel representations.

Note that one of the order 4 segments was kept as a separate vessel in order to retain the correct parallel/series connections. The red arrow indicates flow direction.

At first glance the segmental representation appears more accurate than the elemental (Figure 17). This is true for hemodynamic analysis, but not for architectural analysis. The elemental representation is more accurate for describing the total quantity 


\section{Methods}

and average length of order 4 segments compared with the segmental. This concept will be validated later when applying Horton's Law to both the segmental and elemental representations later.

All segments of the same order that were connected in series were joined together by reassigning the ID numbers to be that of the segment at the start of the element. The diameters of each segment were averaged to give the diameter of that element, and the length of each segment was added together to yield the total length of the element.

After re-ordering, sometimes the outlet vessels at a node were both of the same order as the parent vessel. In this case, the outlet with the larger diameter was joined into the element and the other remained as a branch off the newly formed element (Figure 17). The vessel of the larger diameter was chosen to be combined into the element, whereas the vessel with the smaller diameter was not combined into the element.

The aim behind calculating nodal pressures and flows using the modified element network and average conductance values was to assess whether it would provide a smoothing of the data such that small variations in the anatomy of each specimen are averaged out (Fenton and Zweifach 1981). There are some drawbacks to using this approach, such as the fact that branching points along the length of the element are not taken into account. The benefits and drawbacks will be addressed in more detail in the discussion section.

The elements were reordered using the same method described above for the segments. Two iterations were adequate to ensure convergence. 


\section{Methods}

Generation of Linear Equations

In order to solve for pressures and flows, there needs to be the same number of equations as there are unknowns. The unknowns are the pressure at a node and the flow through a segment. These required equations are generated based on the HagenPoiseuille flow relationship (Equation 4) and Conservation of Mass at each node (Equation 5) where flow into a node must equal flow out of a node (Kassab, Berkley et al. 1997).

$$
Q=\left(\frac{\pi \cdot D^{4}}{128 \cdot l \cdot \eta}\right) \cdot \Delta P
$$

Equation 4. Hagen-Poiseuille Equation.

$\mathrm{I}=$ length of tube, $\mathbf{D}=$ diameter of tube, $\eta=$ viscosity of blood, $\Delta \mathbf{P}=$ pressure gradient $($ Kaul and Jayaweera 2006).

$$
\sum Q_{i}=0
$$

Equation 5. Conservation of Mass. $\mathrm{Q}_{\mathrm{i}}=$ flow into node $i$ (Kassab, Berkley et al. 1997).

Where diameter, length, and viscosity are assumed to be known, leaving flow rate and pressure to be calculated.

The Hagen-Poiseuille Equation (Equation 4) assumes laminar flow, therefore the Reynold's number (dimensionless number used to predict laminar or turbulent flow) was calculated for segment that had the highest blood velocity to verify flow did not become turbulent (Equation 6) (Kassab, Berkley et al. 1997). 


$$
\operatorname{Re}=\frac{U \cdot D \cdot \rho}{\eta}
$$

Equation 6. Reynold's Number.

$U=$ average velocity of blood, $D=$ diameter,$\rho=$ density of blood, and $\eta=$ viscosity of blood.

One goal of this project is to compare the calculated flow values between two different network representations: one that uses the actual network data (segments) and one that uses a more averaged, categorized network (elements). When using the segment data, conductances for each individual vessel were calculated. When using the element data, the conductance values were based on average diameters and lengths for vessels of that order since, as mentioned previously, the aim was to assess the ability of the element network to smooth small variations between specimens.

The actual format of the equations that Excel generated at each node is shown below for node 268 (Figure 18). More detail on the methods used within Excel to generate these equations can be found in the Appendix.

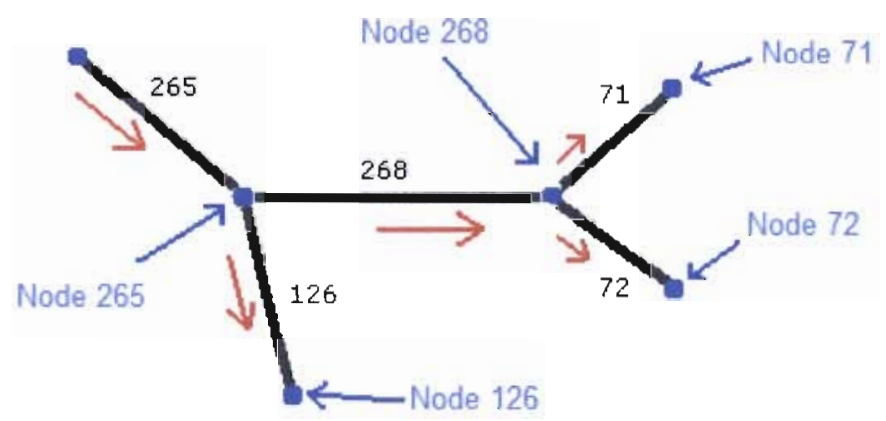

Figure 18. Schematic of Vessel 268 and its parent and offspring vessels. 
Equations for Node 268:

Equation 1: (P265-P268)*C268-((P268-P71)*C71+(P268-P72)*C72) $=0$

Equation 2: q268-(P265-P268)* $\mathrm{C} 268=0$

Where P625 indicates the pressure at node 265, C268 indicates the conductance of vessel 268 , q268 indicates the volumetric flow rate through vessel 268 , and so on.

Equation 1 employs conservation of mass: Flow in - Flow out $=0$. Equation 2 employs the Hagen-Poseuille relationship to calculate the flow through vessel 265. Vessel 265 is the parent vessel to 268, and the 'offspring' are vessels 71 and 72.

Solving

There were a total of 385 segments in the network described in this report. This equates to a system of 470 linear equations that must be solved for simultaneously in order to characterize flow and pressure throughout the network. To accomplish this, a sparse array was generated in Mathematica that contained the coefficients of the equations. This array could then be solved using normal matrix operations.

A sparse array is a matrix that has few non-zero elements. In the current example, the standard matrix required to represent all the equations would be $470 \times 470$. Using a sparse array, only the locations of the non-zero elements are stored and utilized in the calculations, simplifying the process. The actual code and equations used to generate the solutions can be found in the appendix.

\section{Testing of Hypotheses}

The first objective is to explore whether or not the gracillis anterior muscle is thin enough to allow morphological analysis using a two dimensional image. The hypothesis 
is that it is sufficiently thin. This will be assessed by comparing the results of the morphological analysis to trends seen in literature, for example the logarithmic relation of quantity, diameter, and length to order number. Furthermore, the hemodynamic analysis will indicate whether the data obtained from the image is sufficient to compute blood flow by comparing computed values with those measured previously.

The second objective is to develop a set of tools that can assess the vascular network as a whole. The hypothesis is that the diameter-defined Strahler system and Horton's Law, neither of which have been applied to a mouse or to the gracillis anterior muscle, can be used to accomplish this. The applicability of these methods will be assessed by first comparing the results with those obtained previously with other species and organs. Following that, a comparison between the segments and elements will show whether or not these methods will depict the differences between two different networks.

The third objective looks at computation of hemodynamic parameters using both the segment and element networks. The hypothesis is that both networks will yield pressure and flow rate profiles comparable to previous experiments. This will be tested by first computing the pressure and flow rate through the segment and element networks, then comparing that to published literature values.

\section{Statistical Analysis}

Data are presented in mean \pm one standard deviation. Statistical significance was determined by $\mathrm{p}<0.05$. Differences between means were determined by Student's $t$-test. Regression analysis and analysis of variance (ANOVA) were performed to determine logarithmic correlations. 


\section{Results}

\section{Images}

Photomicrographs were taken of the gracillis anterior muscle of a mouse, split into three consecutive views (Figure 19, Figure 20, Figure 21). These images were used for all calculations. Details showing how the images were zoned and the individual vessel labels can be found in the Appendix.

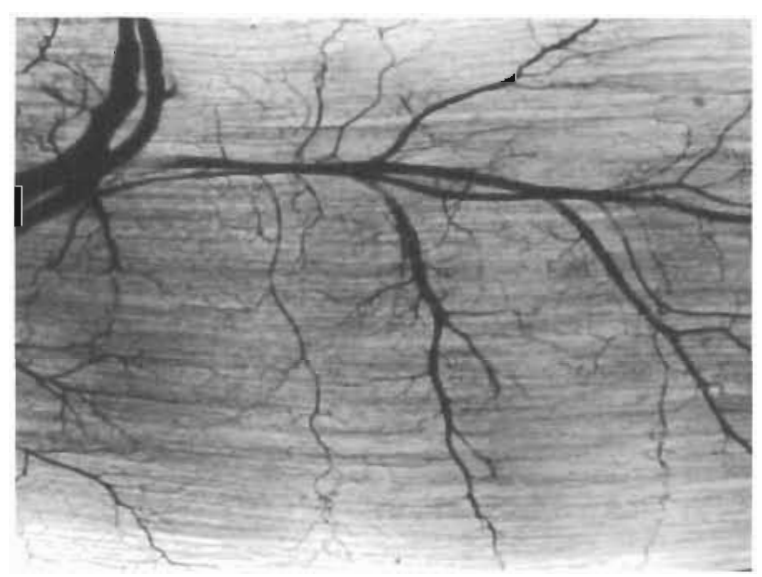

Figure 19. Left view of the gracillis anterior muscle.

Shows the digital micrograph modeled in this report. Note the large vessels in the top left corner are the muscular branch vein and artery feeding one half of the muscle. 


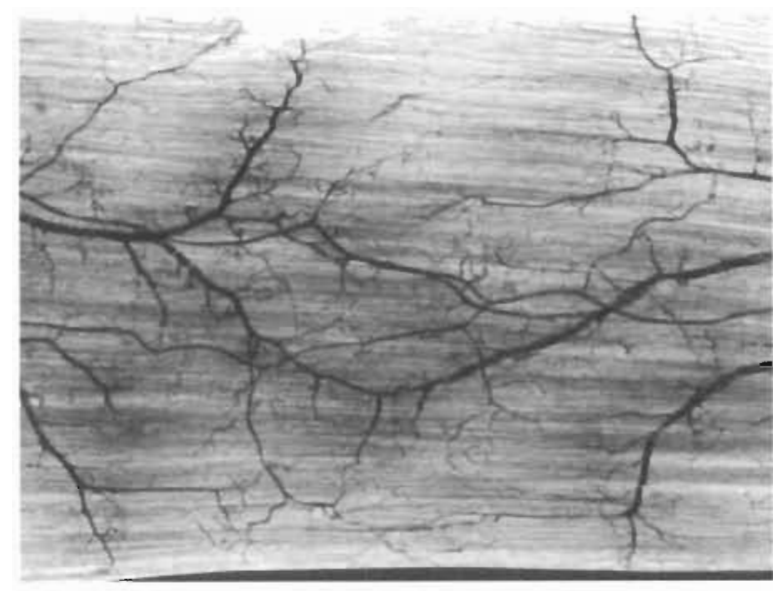

Figure 20. Middle view of the gracillis anterior muscle.

Shows the digital micrograph modeled in this report. This image depicts the middle portion of the muscle fed by both the muscular branch and saphenous artery.

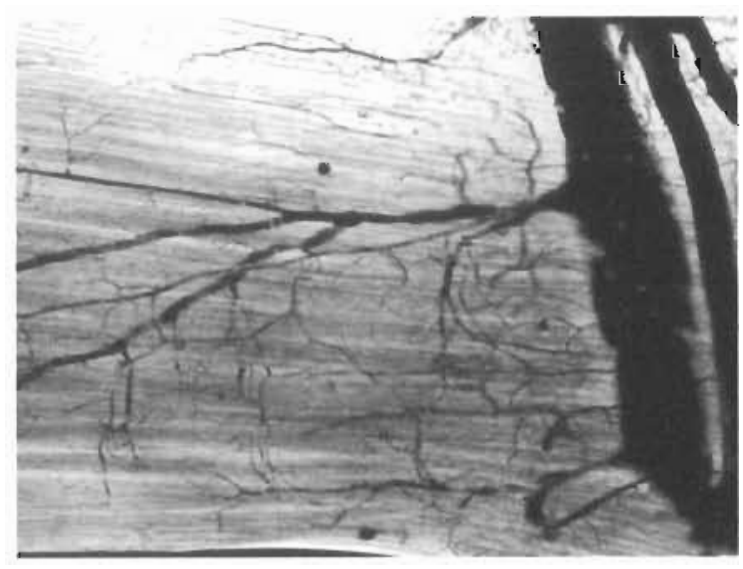

Figure 21. Right view of the gracillis anterior muscle.

Shows the digital micrograph modeled in this report. Note the large vessels on the right are the saphenous artery and vein feeding one half of the muscle. 
Results

Morphometric Analysis

Quantity and Dimensions

The morphological analysis encompassed initial ordering followed by re-ordering of the segments, in addition to combining segments into elements and re-ordering those as well. Re-ordering of segments and elements was an iterative process due to the fact that the upper and lower bounds of each order is based on the average diameter and standard deviation within that order; both values that change as vessels are moved from one order to the next. Convergence was obtained after three iterations for the segments (Figure 22), and after five iterations for the elements (Figure 23).

\begin{tabular}{cccccc}
\hline \multirow{2}{*}{ I teration } & \multicolumn{5}{c}{ ORDER } \\
& 1 & 2 & 3 & 4 & 5 \\
\hline 0 & 191 & 99 & 54 & 24 & 15 \\
1 & 155 & 123 & 48 & 39 & 18 \\
2 & 147 & 128 & 50 & 40 & 18 \\
3 & 147 & 128 & 49 & 41 & 18 \\
4 & 147 & 128 & 49 & 41 & 18 \\
\hline
\end{tabular}

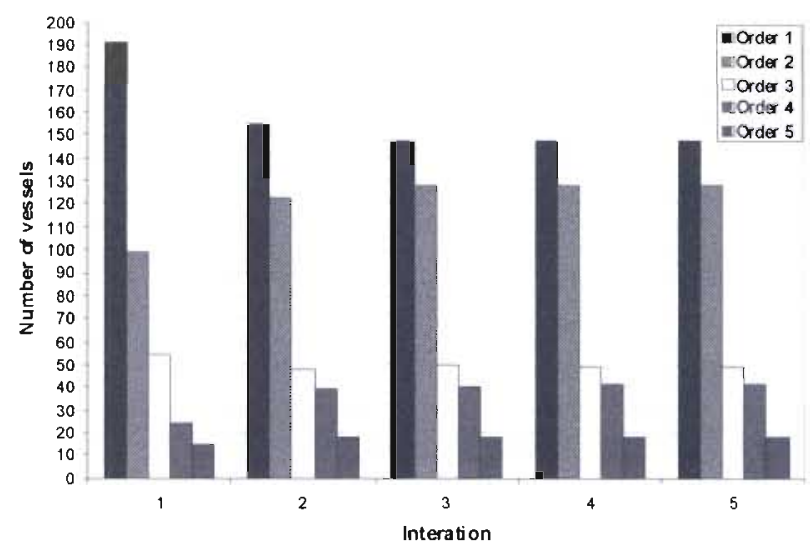

Figure 22. Number of segments of each order per iteration during reordering. 
Results

\begin{tabular}{cccccc}
\hline \multirow{2}{*}{ Iteration } & 1 & 2 & 3 & 4 & 5 \\
\hline 0 & 140 & 95 & 30 & 12 & 4 \\
1 & 140 & 93 & 32 & 12 & 4 \\
2 & 140 & 91 & 34 & 12 & 4 \\
3 & 140 & 87 & 38 & 12 & 4 \\
4 & 140 & 85 & 40 & 12 & 4 \\
5 & 140 & 84 & 41 & 12 & 4 \\
6 & 140 & 84 & 41 & 12 & 4 \\
\hline
\end{tabular}

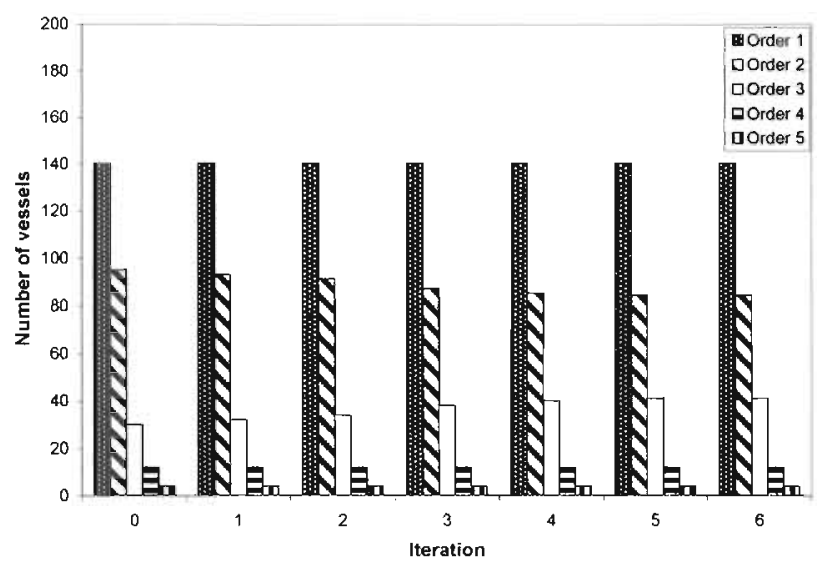

Figure 23. Number of elements of each order per iteration during reordering.

The utility of re-ordering is that it facilitates a tighter range of diameters found within each order and zero overlap of vessel diameter between orders (Figure 24). This yields a more meaningful and accurate categorization since it prevents vessels of the same order from having two different order numbers.

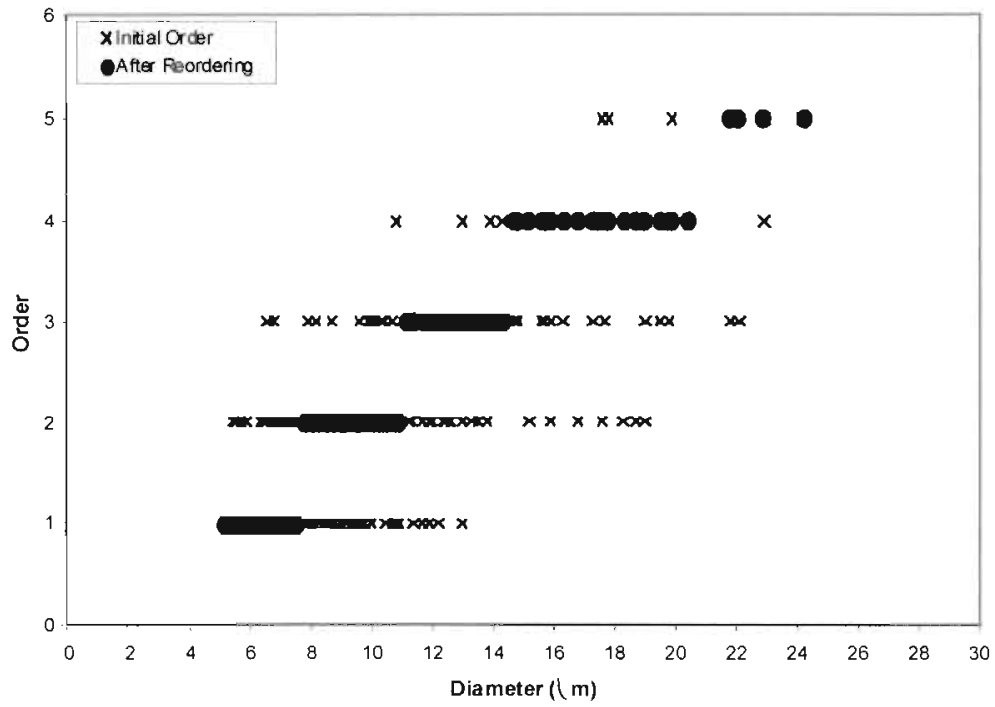

Figure 24. Segments before and after reordering. 


\section{Results}

When comparing total cross-sectional area (TCA) of all vessels within each order, the segmental data showed a general increase of TCA with increasing order, whereas the elements exhibited a general decrease in TCA with increasing order (Figure 25).

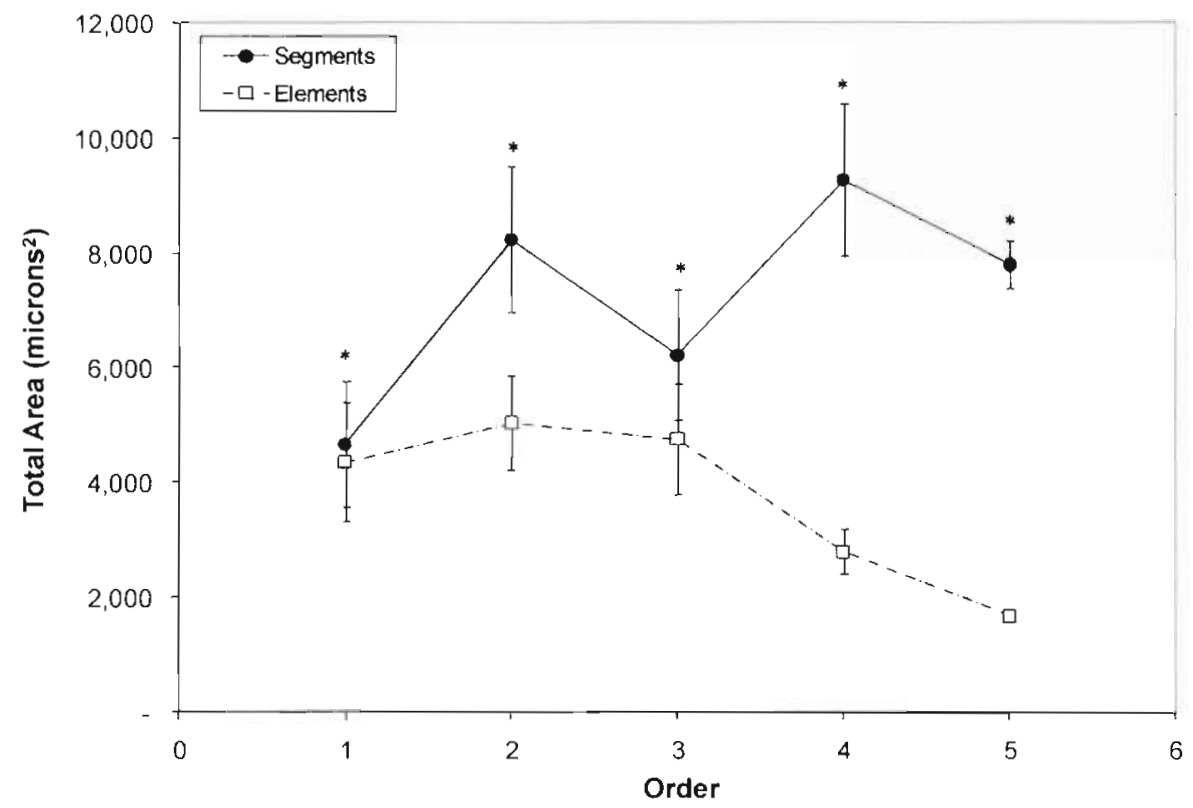

Figure 25. Total cross-sectional area of each order for segments and elements.

Bars represent standard deviation. $\left(^{*}\right)$ indicates statistical difference between segments and elements of that order $(p<0.05)$.

Recall that the circulatory system consists of larger vessels that branch into multiple smaller vessels. Conservation of mass dictates that the same volume flow rate of blood must pass through the larger vessels at it does through the smaller vessels (Figure 26). 


\section{Results}

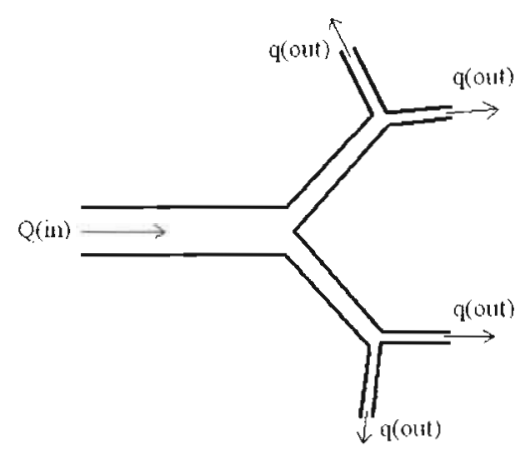

Figure 26. Simplified schematic of a hypothetical branching network.

In this case, $Q$ (in) must be equal to $4 \times \mathrm{q}(\mathrm{out})$, where $Q$ (in) and $q($ out) represent flow rates at the inlet and outlets, respectively (not to scale).

Flow rate in smaller vessels is much lower than in larger vessels due to the 4th power dependence of flow on diameter discussed in the introduction, combined with a relatively smaller pressure drop. Therefore, the summation of the cross-sectional areas of the smaller vessels must be greater than that of the larger vessels in order to accommodate an equal volumetric flow rate (Guyton and Hall 2006). Since ordering is based upon vessel diameter, the TCA of the smaller orders should be highest.

The reason for the discrepancy between the TCA of segments and elements can be seen when looking at the relative percentages of segments that were joined into an element (Table 3). TCA was computed by summing the individual vessel crosssectional areas in each order. When segments were joined into elements, the total number of vessels of each order decreased, thereby reducing the number of crosssectional areas included in the computation. This further supports the assessment that elements provide a more realistic representation of the actual network architecture.

Compared with segments, the diameter of order 2 elements is slightly smaller and the diameter of order 3 elements is slightly larger. The segments were greater in number 
than their elemental counterparts by virtue of the fact that the elements are comprised of multiple segments (Table 3).

Table 3. Summary of segment and element characteristics for each vessel order.

$\left(^{*}\right)$ indicates statistical difference between the means of segments and elements $(p<0.05)$.

\begin{tabular}{|c|c|c|c|c|c|c|c|c|c|c|c|c|}
\hline \multirow[b]{2}{*}{ Order } & \multicolumn{3}{|c|}{ Quantity } & \multicolumn{5}{|c|}{ Diameter $(. m)$} & \multicolumn{4}{|c|}{ Length $(, \mathrm{m})$} \\
\hline & Segments & Elements & $\%$ Combined & Segments & $S D$ & Elements & $S D$ & & Segments & $S D$ & Elements & $S D$ \\
\hline 1 & 147 & 140 & $5 \%$ & 6.37 & 0.71 & 6.30 & 0.72 & & 111.41 & 102.25 & 82.49 & 69.14 \\
\hline 2 & 128 & 84 & $34 \%$ & 9.06 & 0.99 & 8.74 & 0.69 & * & 119.55 & 99.58 & 174.16 & 121.86 \\
\hline 3 & 49 & 41 & $16 \%$ & 12.73 & 0.89 & 12.16 & 1.17 & * & 142.97 & 170.77 & 230.78 & 193.37 \\
\hline 4 & 41 & 12 & $71 \%$ & 16.98 & 1.53 & 17.20 & 1.16 & & 267.56 & 153.00 & 738.62 & 573.25 \\
\hline 5 & 18 & 4 & $78 \%$ & 23.52 & 0.81 & 23.15 & 0.62 & & 297.55 & 171.45 & 1728.43 & $1,527.02$ \\
\hline
\end{tabular}

\section{Network Connectivity}

Once the data were ordered, the trends between each order in the network were analyzed in order to examine the vascular network from a Systems Biology approach. As discussed in the introduction, Horton's Law states that the branching ratio from one order to the next will tend to approach a constant through the series (Fenton and Zweifach 1981). Additionally, if the network obeys Horton's Law the diameter, length, and quantity will grow as a geometric sequence (meaning each value can be multiplied by a constant to reach the next) as order number increases (Kassab, Rider et al. 1993) according to the equations (using diameter as an example):

$$
\frac{D_{n}}{D_{n-1}}=R_{D}
$$

Equation 7. Horton's Law applied to diameter. 
$\mathrm{D}_{n}$ is the average diameter of vessels of order $n . \mathrm{N}_{n}$ and $\mathrm{L}_{n}$ can be substituted for $D_{n}$ to calculate the ratio for quantity and length, respectively. The number, diameter, and length ratios are defined as $R_{N}, R_{D}$, and $R_{L}$, respectively.

The diameter ratios $\left(R_{D}\right)$ of the segments and elements were almost identical, which was expected since there were no changes made to diameter when combining segments into elements. On average, the elemental length ratio $\left(\mathrm{R}_{\mathrm{L}}\right)$ is higher than the segmental length ratio, also expected since as segments are joined into elements their lengths are added together. Overall, the number ratio $\left(\mathrm{R}_{N}\right)$ for the segments was higher than for the elements, which was also in line with expectations since one element is comprised of multiple segments (Table 4). Although the number, diameter, and quantity ratios between segments and elements appear different, the values were statistically $\operatorname{similar}(\mathrm{p}>0.05)$.

Table 4. Number, diameter, and length ratios computed according to Horton's Law. No statistical significance between ratios of segments to elements $(p>0.05)$.

\begin{tabular}{ccccccc}
\hline & & \multicolumn{2}{c}{ Segments } & & \multicolumn{2}{c}{ Elements } \\
\cline { 1 - 3 } Ratio & & Average & $\mathrm{SD}$ & & Average & $\mathrm{SD}$ \\
\cline { 1 - 1 } \cline { 5 - 6 } \cline { 5 - 6 } $\mathrm{R}_{\mathrm{N}}$ & & 0.59 & 0.26 & & 0.40 & 0.14 \\
$\mathrm{R}_{\mathrm{D}}$ & & 1.38 & 0.04 & & 1.39 & 0.03 \\
$\mathrm{R}_{\mathrm{L}}$ & & 1.32 & 0.38 & & 2.12 & 0.77 \\
\hline
\end{tabular}

According to Table 4, each segment of order $n$ will have a diameter that is on average 1.39 times larger than a vessel of order $n-1$. Likewise, each segment of order $n$ will be on average 1.31 times as long as a vessel of order $n-1$. Lastly, each segment of order $n$ will have 0.63 times as many vessels as order $n-l$. 


\section{Results}

The diameter, quantity, and length vary logarithmically with order, consistent with what is expected from a network that follows Horton's Law (Figure 27, Figure 28, Figure 29).

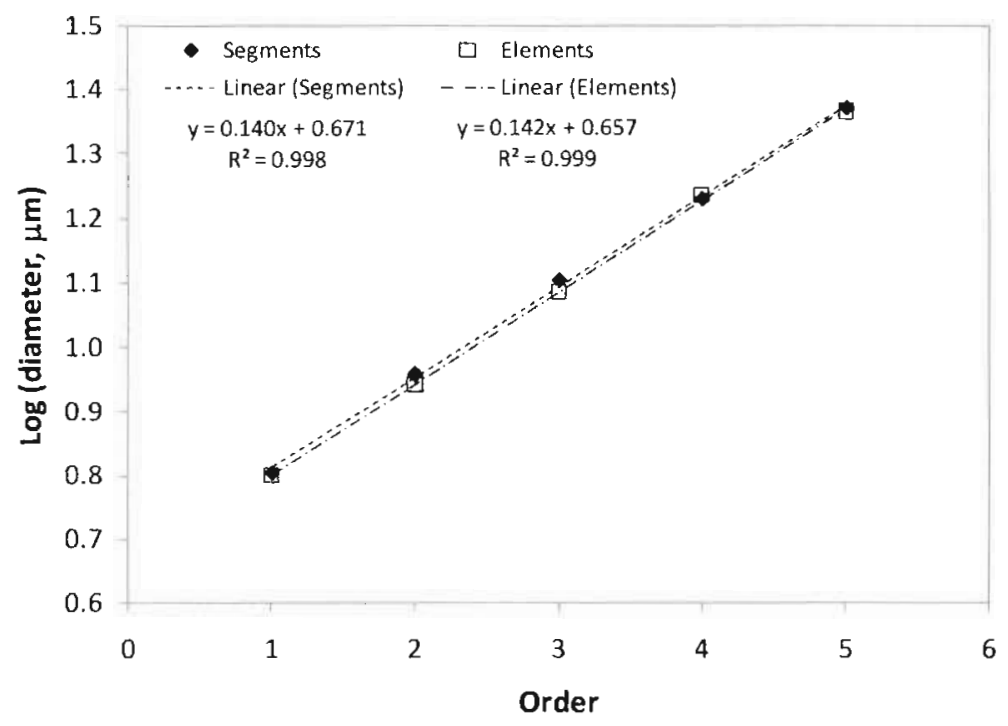

Figure 27. Order versus $\log _{10}$ of diameter for segments and elements.

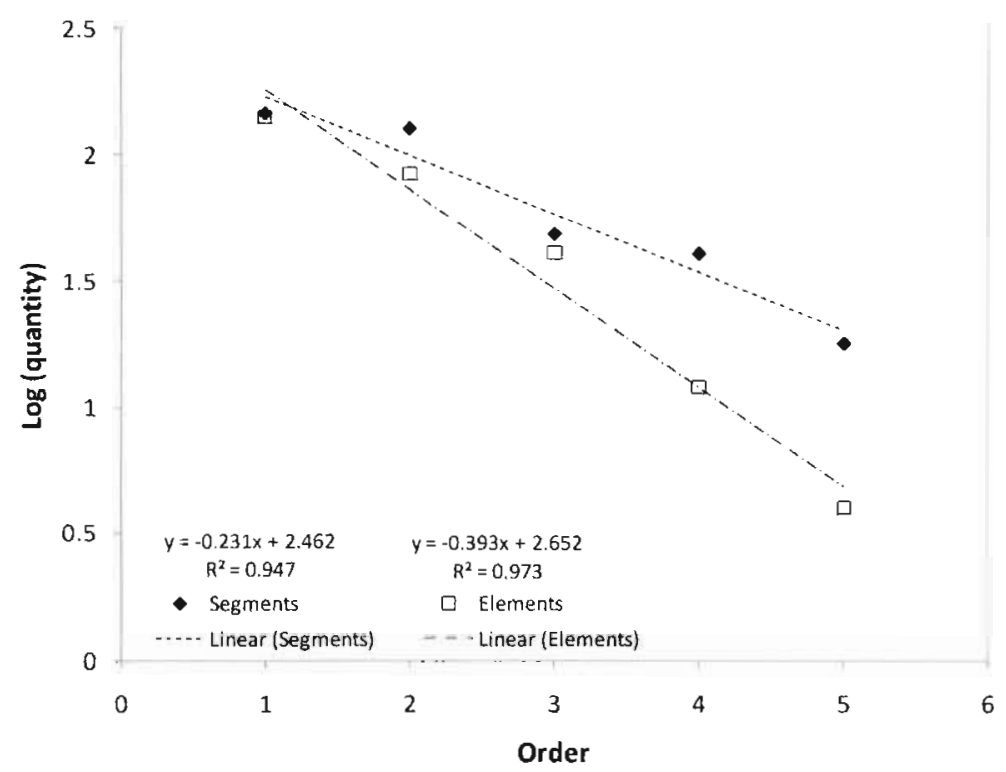

Figure 28. Order versus $\log _{10}$ of quantity for segments and elements. 


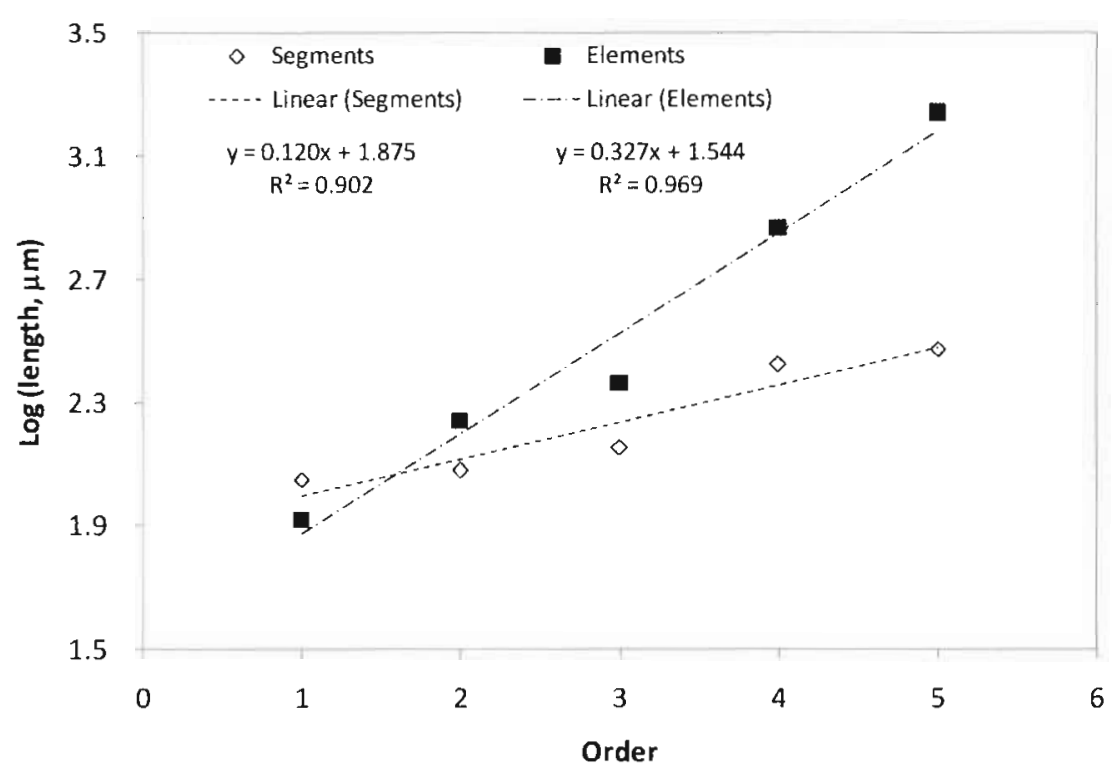

Figure 29. Order versus $\log _{10}$ of length for segments and elements.

The next step to analyzing the vascular network as a whole was to construct matrices that represent the unique connections within the network. Not all vessels of order $n$ branch from a vessel of $n+1$, sometimes they branch from order $n, n+2, n+3$, and so forth. The ratios determined by applying Horton's Law show the trends between orders; however, matrices aim to show trends between specific types of connections across all orders. The first matrix is consistent with previous literature (Jiang, Kassab et al. 1994; Kassab, Berkley et al. 1997) where each cell represents the average number of vessels of order $\mathrm{m}$ that branch from a single vessel of order $n$ (Figure 30). The second matrix calculates the percent of all vessels of order $m$ that branch from a vessel of order $n$ (Figure 31). 


\begin{tabular}{|c|c|c|c|c|c|}
\hline & \multicolumn{5}{|c|}{ Parent (n) } \\
\hline & 1 & 2 & 3 & 4 & 5 \\
\hline 1 & 0.40 & 0.53 & 0.29 & 0.15 & - \\
\hline 2 & - & 0.46 & 0.92 & 0.54 & 0.11 \\
\hline 3 & - & - & 0.45 & 0.49 & 0.39 \\
\hline 4 & - & - & - & 0.73 & 0.61 \\
\hline 5 & - & - & - & - & 0.89 \\
\hline Sum & 0.40 & 0.99 & 1.65 & 1.90 & 2.00 \\
\hline
\end{tabular}

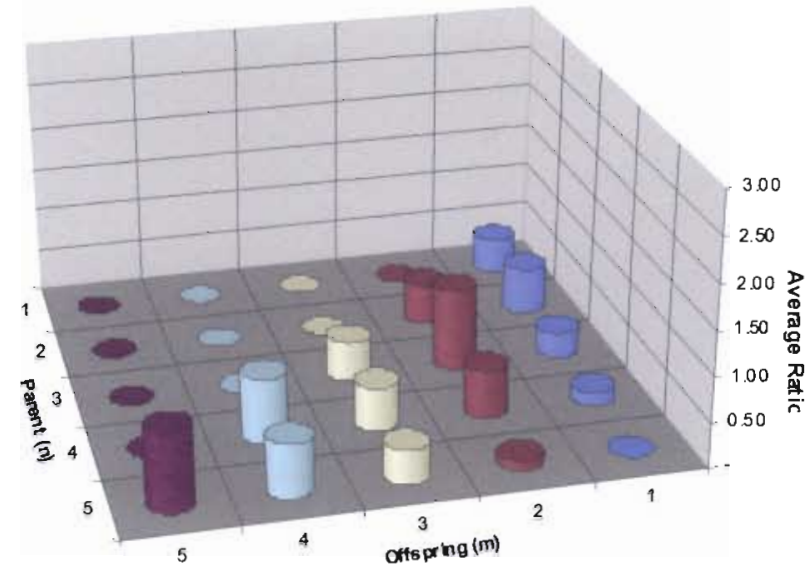

Segments

\begin{tabular}{|c|c|c|c|c|c|}
\hline & \multicolumn{5}{|c|}{ Parent (n) } \\
\hline & 1 & 2 & 3 & 4 & 5 \\
\hline 1 & 0.38 & 0.81 & 0.32 & 0.50 & - \\
\hline 2 & - & 0.31 & 0.88 & 1.67 & 0.50 \\
\hline 3 & - & - & 0.29 & 1.83 & 1.75 \\
\hline 4 & - & - & - & 0.08 & 2.75 \\
\hline 5 & - & - & - & - & 0.50 \\
\hline Sum & 0.38 & 1.12 & 1.49 & 4.08 & 5.50 \\
\hline
\end{tabular}

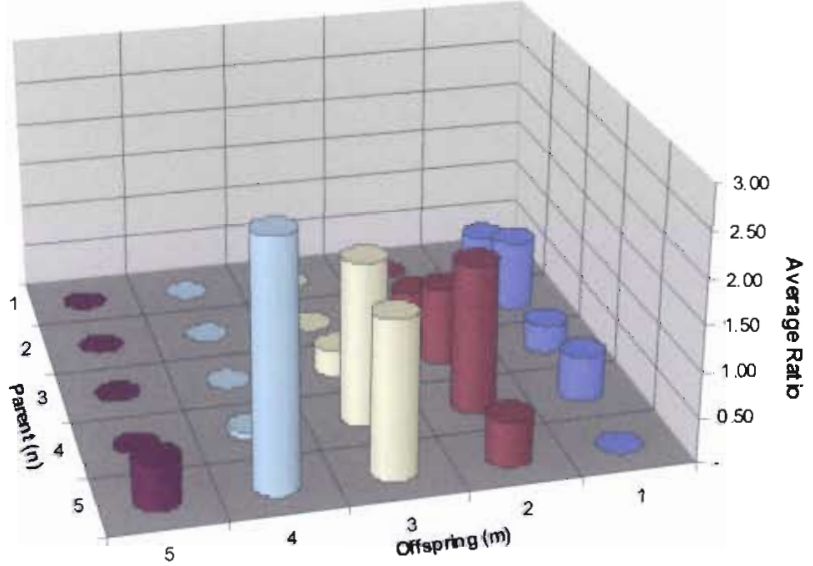

Elements

Figure 30. Matrix of average branching ratios.

Tabular and graphical representations of matrices showing the average branching ratios for segments (top) and elements (bottom). Values describe the average number of vessels of order $m$ that branch from a single vessel of order $n$. 


\begin{tabular}{|c|c|c|c|c|c|}
\hline & \multicolumn{5}{|c|}{ Parent (n) } \\
\hline & 1 & 2 & 3 & 4 & 5 \\
\hline 1 & $40 \%$ & $46 \%$ & $10 \%$ & $4 \%$ & $0 \%$ \\
\hline 2 & - & $46 \%$ & $35 \%$ & $17 \%$ & $2 \%$ \\
\hline 3 & - & - & $45 \%$ & $41 \%$ & $14 \%$ \\
\hline 4 & - & - & - & $73 \%$ & $27 \%$ \\
\hline 5 & - & - & - & - & $89 \%$ \\
\hline
\end{tabular}

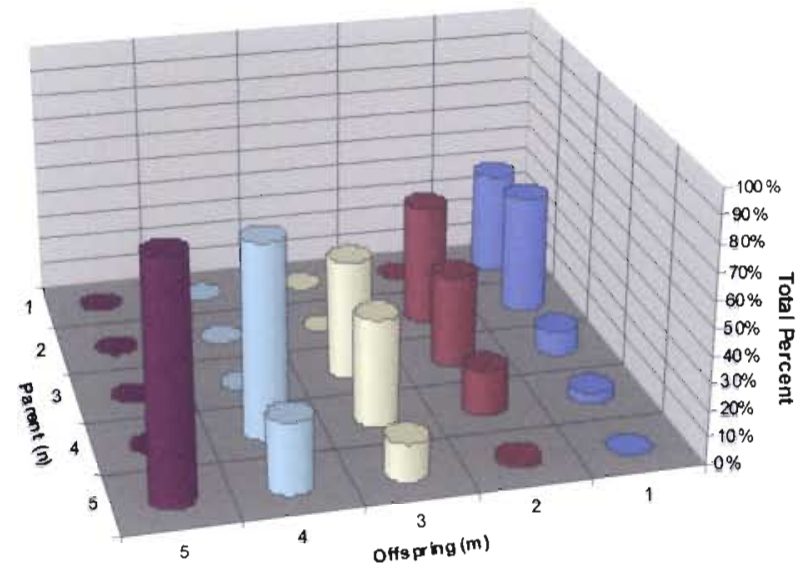

Segments

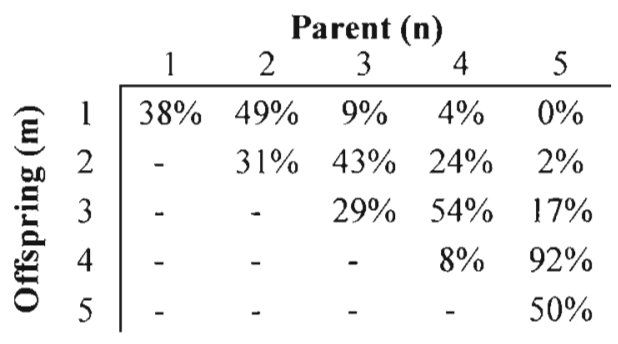

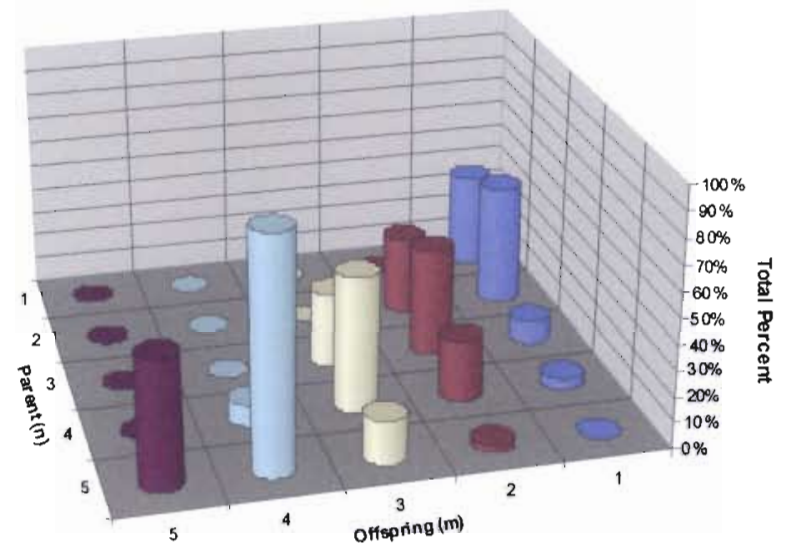

Elements

Figure 31. Matrix of percent distribution of parent vessels.

Tabular and graphical representations of matrices showing the percent distribution of parent vessels within a particular order, for segments (top) and elements (bottom). Values describe the percent of all vessels of order $\boldsymbol{m}$ that branch from a vessel of order $n$.

The average branching ratio for each order (summation in the last line of the matrices in Figure 30) appears low. Referring back to the re-ordering performed at the very beginning (Figure 24), there were many vessel segments that were originally set at order 1, and therefore had zero branching by convention of the Strahler method. 
Furthermore, the smaller vessels were not entirely captured in the morphological analysis (discussed in more depth later). Re-ordering diluted the branching ratios of orders 1 through 3 for these reasons, which was verified by constructing a branching matrix before re-ordering (Figure 32). The average ratios before re-ordering are approximately 2 for order 2 through 5 , and zero for order 1 .

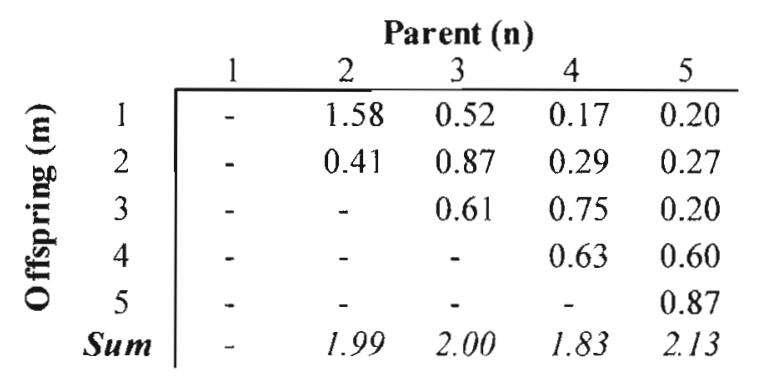

Before re-ordering

\begin{tabular}{|c|c|c|c|c|c|}
\hline & \multicolumn{5}{|c|}{ Parent (n) } \\
\hline & l & 2 & 3 & 4 & 5 \\
\hline 1 & 0.40 & 0.53 & 0.29 & 0.15 & - \\
\hline 2 & - & 0.46 & 0.92 & 0.54 & 0.11 \\
\hline 3 & - & - & 0.45 & 0.49 & 0.39 \\
\hline 4 & - & - & - & 0.73 & 0.61 \\
\hline 5 & - & - & - & - & 0.89 \\
\hline Sum & 0.40 & 0.99 & 1.65 & 1.90 & 2.00 \\
\hline
\end{tabular}

After re-ordering

Figure 32. Branching matrices before and after re-ordering

Flow and Pressure

After analyzing the morphology of the network, the flow rates and pressure drops were calculated. The end goal of studying occluded arteries is to eventually develop successful therapies for restoring full flow; however, asymmetric branching affects flow heterogeneity (VanBavel and Spaan 1992; Kalsho and Kassab 2004). Therefore comparing the branching patterns observed in the morphological analysis to the hemodynamic calculations can help assess the structure/function relationship of the vascular network as a whole.

Several different conditions were explored. First, three different viscosity conditions were applied; constant $3 \mathrm{cP}$, constant $4.2 \mathrm{cP}$, and linear variation with diameter 


\section{Results}

from 3 to $4.2 \mathrm{cP}$. As was mentioned in the introduction, the viscosity of blood is not constant. Past computational models have assumed constant viscosity between values of 3 and $4.2 \mathrm{cP}$ (Lipowsky and Zweifach 1974; Fenton and Zweifach 1981; Jiang, Kassab et al. 1994; Gruionu, Hoying et al. 2005), as is done here. By computing flow and pressure with different values for viscosity, the impact of these assumptions on the model can be quantified.

The next condition looked at changing the inlet pressure of $77 \mathrm{mmHg}$ to $90 \mathrm{mmHg}$ to assess the impact a change in pressure would have, giving a sense of how sensitive computed flow rate is to inlet pressure.

Last, small vessels were added along the lengths of the vessels in the existing network to simulate the capillary bed in order to assess the impact on flow rate. As discussed earlier in this chapter, due to the challenge of assessing the quantity and branch points of capillaries, it was suspected that the number counted was low. Therefore, "capillaries" were added to the network based on a capillary/linear distance value (LD) that was based on calculated average values for order 1 and order 2 vessels (Figure 33).

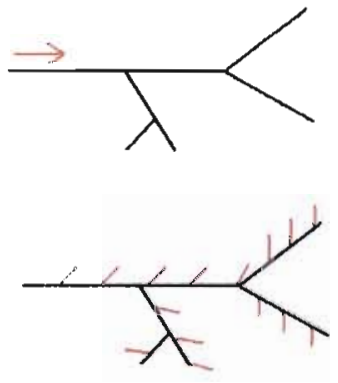

Figure 33. Schematic of the simulated capillary bed.

Schematic of before (top) and after (bottom) the addition of vessels along the length of the original network. Note that the drawing is not to scale. The arrow indicates flow direction. 


\section{Results}

Overall, the segment nodal pressures were higher than the element nodal pressures (Figure 34). Both segments and elements showed a drop in pressure across the entire network when the simulated capillary network was added.

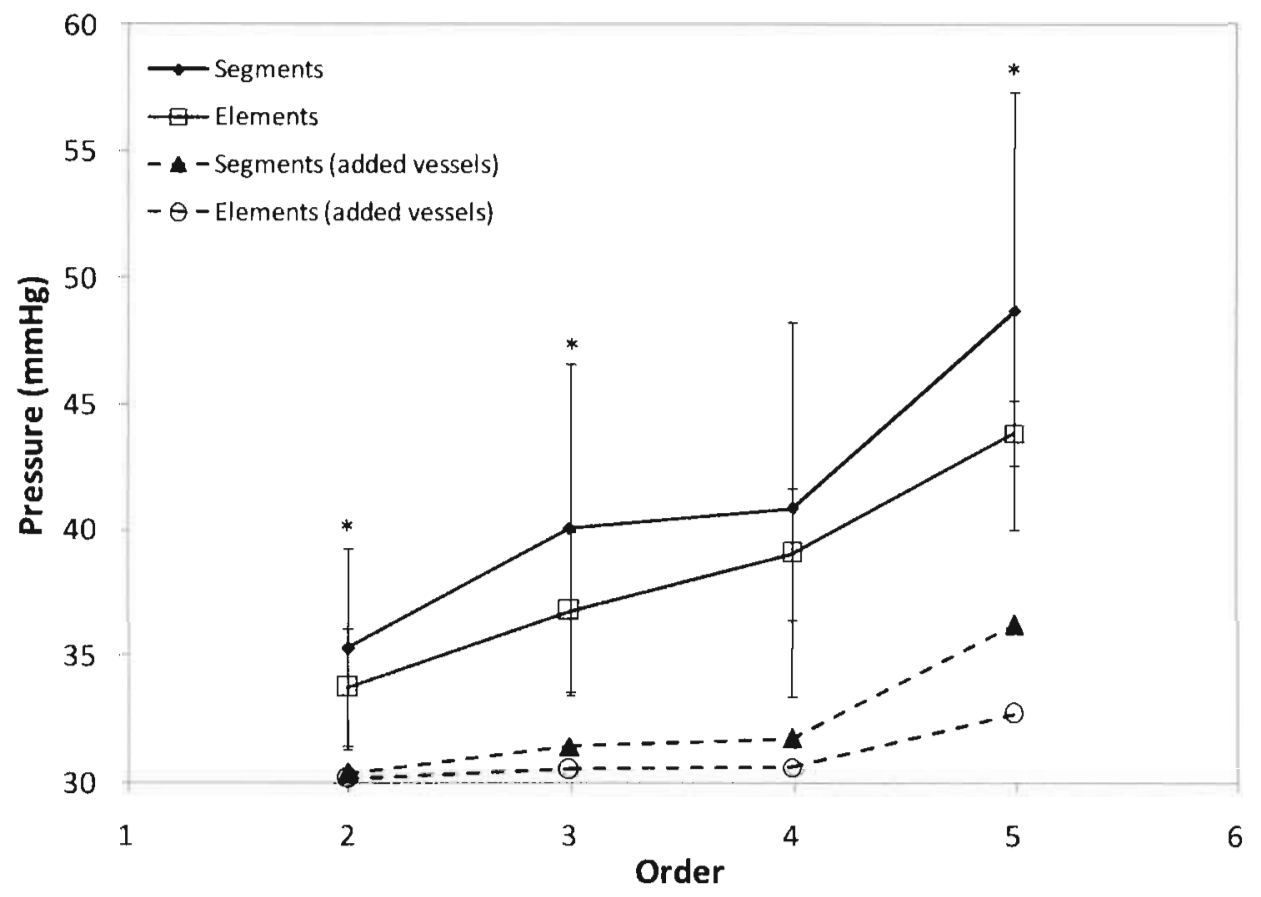

Figure 34. Average pressure in each order.

Bars are standard deviations of segments and elements, respectively. $\left(^{*}\right)$ indicates statistical difference between segments and elements $(p<0.05)$. Viscosity was set at $3 \mathrm{cP}$. The dashed lines represent vessels that have had vessels added along its length to simulate capillaries.

The Hagen-Poseuille equation assumes laminar flow, which is supported by a Reynold's number that is less than one (Kassab, Berkley et al. 1997). The Reynold's number in the segment with the highest flow rate was calculated to be much less than one, indicating blood flow was laminar. 
The average individual vessel flow rate in the smaller vessels was lower in the elemental network compared with the segmental. Additionally, a high variability of flow rate is seen in order 5 vessels (Figure 35). This is likely due, in part, to the wide range of flow in the arcading vessels that are fed by both the muscular and saphenous branches.

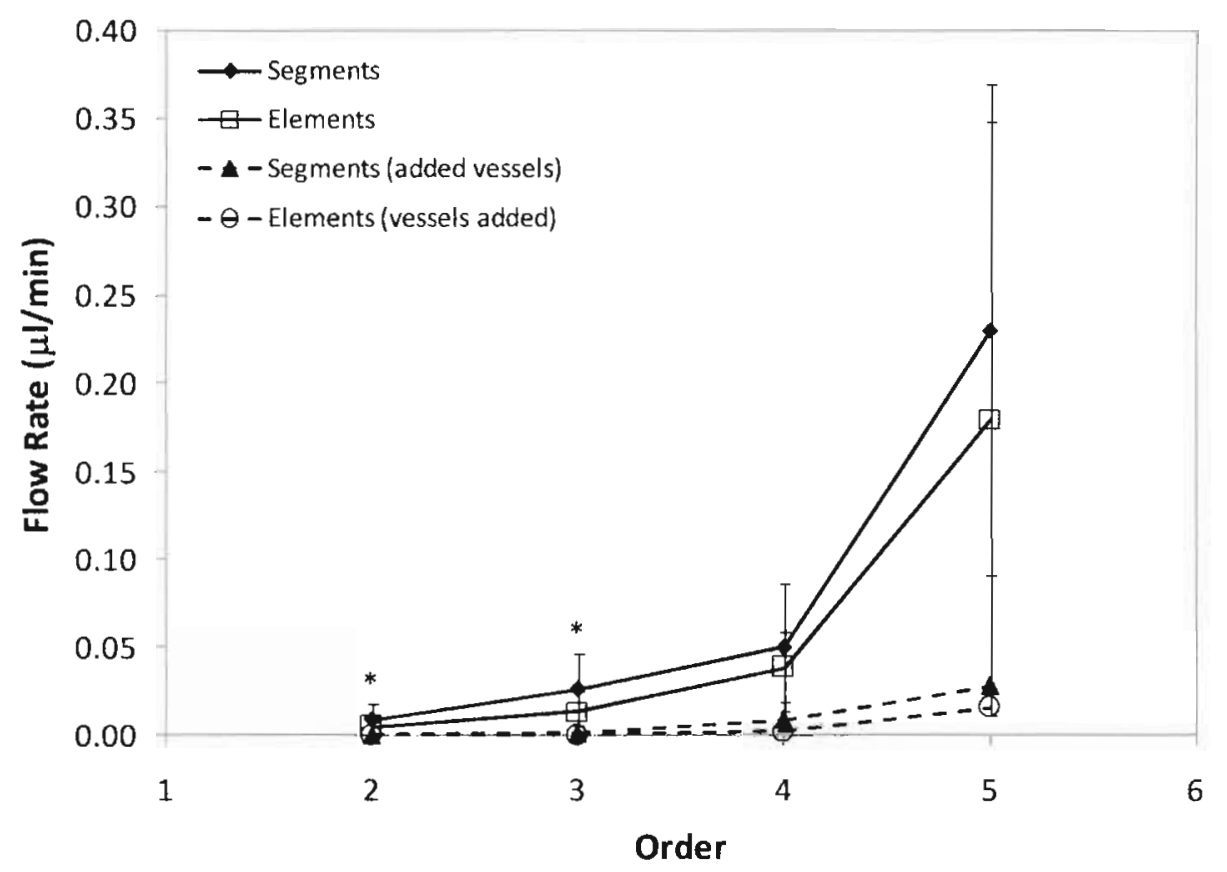

Figure 35. Average flow rate through individual vessels.

Bars represent standard deviation. $\left({ }^{*}\right)$ indicates statistical difference between segments and elements $(p<0.05)$. The dashed lines represent vessels that have had vessels added along its length to simulate capillaries.

The total muscle flow rates under varying conditions for segments and elements were compared (Table 5 ,Figure 36). Data are represented as $\mathrm{ml} / \mathrm{min}$ per gram of tissue in order to compare with literature values (Table 6, Figure 38). Based on the dimensions of the muscle in the images used for morphological analysis and with the dimensions obtained in preliminary ink castings, I assumed the total weight of the muscle modeled in 
this paper was $50 \%$ of the total muscle mass. The actual weight of the muscle used for this paper was not known, therefore, average values from past experiments were used (11.1mg) (Cardinal and Hoying 2007).

Overall, the total muscle flow rate in the segment model is higher than the element model (Table 5, Figure 36). Note that this is purely observational since only one gracillis anterior muscle was analyzed. Multiple samples need to be assessed prior to determining the statistical difference between the test conditions.

Table 5. Summary of total flow rates under varying conditions.

The top four lines represent the baseline with no vessels added. LD means linear distance per vessel added, and D is diameter of vessel added. "Small" indicates $6.4 \mu \mathrm{m}$ for segments and $6.3 \mu \mathrm{m}$ for elements. "Medium" indicates $9.1 \mu \mathrm{m}$ for segments and $8.7 \mu \mathrm{m}$ for elements.

\begin{tabular}{|c|c|c|c|c|c|c|}
\hline \multirow[b]{2}{*}{ CONDITIONS } & \multicolumn{3}{|c|}{ SEGMENTS } & \multicolumn{3}{|c|}{ ELEMENTS } \\
\hline & $\begin{array}{l}\text { Flow rate } \\
(\mathrm{ml} / \mathrm{min} / \mathrm{g})\end{array}$ & SD & SEM & $\begin{array}{l}\text { Flow rate } \\
(\mathrm{ml} / \mathrm{min} / \mathrm{g})\end{array}$ & SD & SEM \\
\hline$v=3 \mathrm{cP}$ & 0.185 & 0.025 & 0.006 & 0.128 & 0.031 & 0.016 \\
\hline$v=4.2 \mathrm{cP}$ & 0.132 & 0.018 & 0.004 & 0.092 & 0.022 & 0.011 \\
\hline$v=3 \mathrm{cP}, \mathrm{Pi}=90 \mathrm{mmHG}$ & 0.237 & 0.032 & 0.008 & 0.164 & 0.040 & 0.020 \\
\hline$v=3 \cdot 0-4.2 \mathrm{cP}$ & 0.151 & 0.021 & 0.005 & 0.094 & 0.023 & 0.011 \\
\hline $\mathrm{LD}=15$ micron, $\mathrm{D}=$ small & 0.380 & 0.060 & 0.014 & 0.174 & 0.043 & 0.022 \\
\hline $\mathrm{LD}=15$ micron, $\mathrm{D}=$ small - medium & 0.420 & 0.067 & 0.016 & 0.176 & 0.044 & 0.022 \\
\hline $\mathrm{LD}=15-40 \mathrm{micron}, \mathrm{D}=$ small & 0.308 & 0.047 & 0.011 & 0.165 & 0.041 & 0.020 \\
\hline $\mathrm{LD}=15-40$ micron, $\mathrm{D}=$ small-medium & 0.339 & 0.052 & 0.012 & 0.167 & 0.041 & 0.113 \\
\hline
\end{tabular}


Results

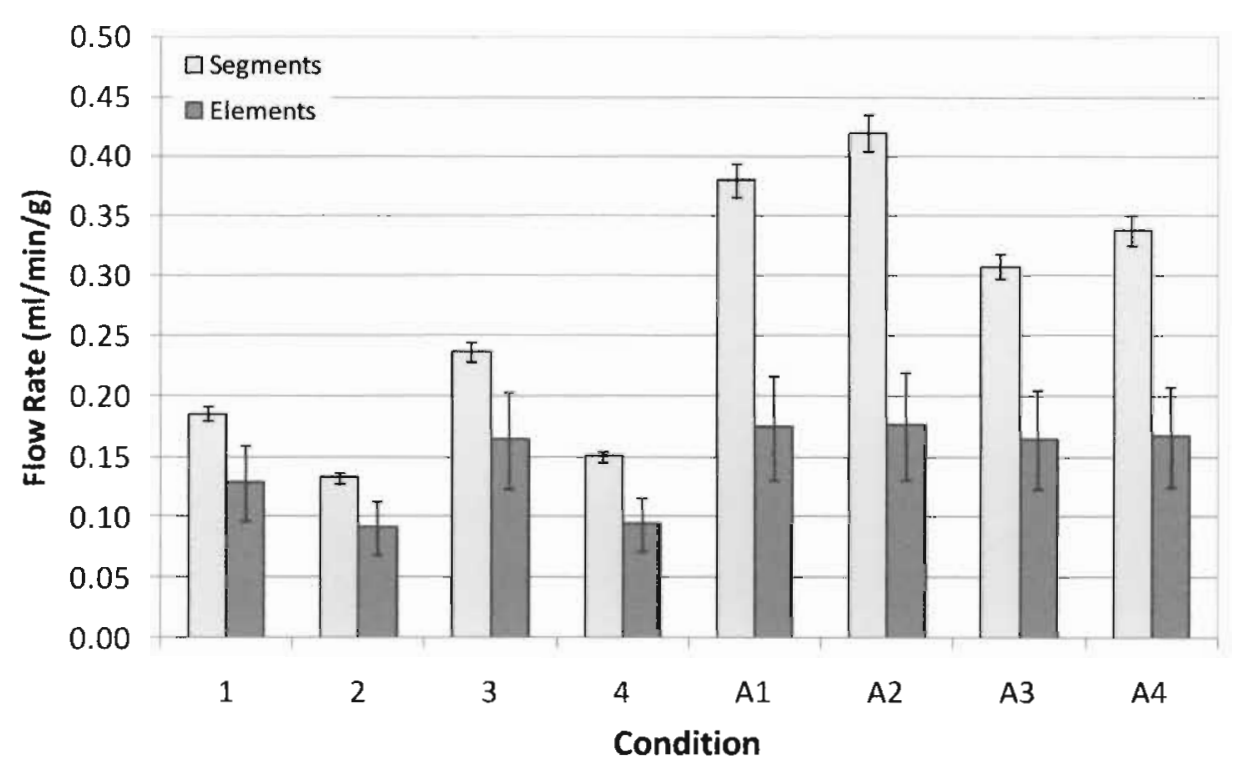

Figure 36. Comparison of overall flow rate of segment and element data.

Bars represent the standard deviation of order 5 vessels. 1) Baseline, $v=3 \mathrm{cP} ; 2$ ) Baseline, $v=4.2 \mathrm{cP} ; 3$ ) Baseline, $P_{\text {inlet }}=90 \mathrm{mmHg}, v=3 \mathrm{cP}$; 4) Baseline, $v=3-4.2 \mathrm{cP}$; A1) Added vessels, $L D=15 \mu \mathrm{m}, \mathrm{D}=\mathrm{small}$; A2) Added vessels, $L D=15 \mu \mathrm{m}, \mathrm{D}=$ small-medium; A3) Added vessels, $\mathrm{LD}=15-40 \mu \mathrm{m}, \mathrm{D}=$ small; $\mathrm{A4}$ ) Added vessels, $L D=40 \mu \mathrm{m}, \mathrm{D}=$ small-medium.

The average flow rates within individual vessels of each order were compared to literature values (Zweifach, Kovalcheck et al. 1981). Overall, the larger vessels had good agreement with blood flow measurements; however, the computed flow rate in small vessels was low (Figure 37). 
Results

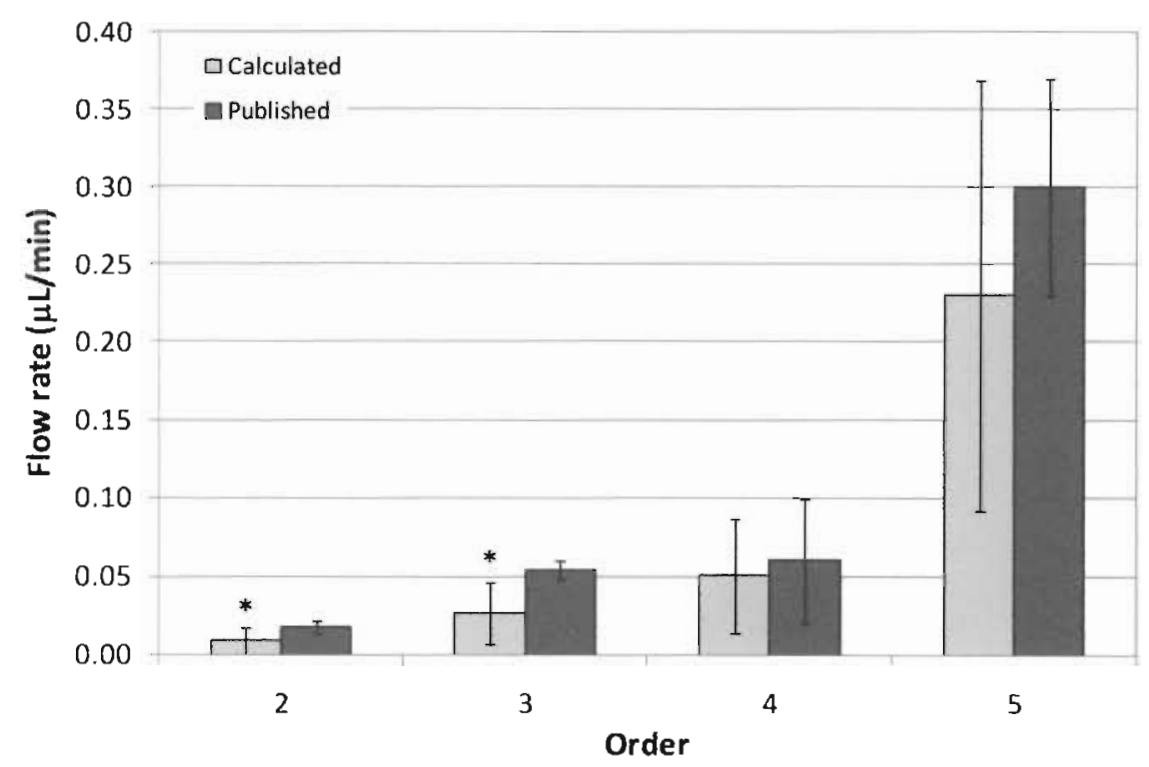

Figure 37. Comparison of individual vessel flow rates.

Calculated values are for the segmental baseline network. Literature values are taken from skeletal muscle of a rat (Zweifach, Kovalcheck et al. 1981). ( $\left.{ }^{*}\right)$ indicates statistical difference between calculated and published values $\left(p^{<0.05}\right)$. Bars represent standard deviation.

In order explore the statistical difference between calculated and published values, it was assumed the sample size was 3 even though only one gracillis anterior muscle was analyzed. With this assumption, the computed blood flow rates were below published literature values (Cardinal and Hoying 2007). The simulated capillary bed on the segment model appeared to bring the calculated flow rates closer to published values, indicating that more effort should be placed upon accurately modeling the smallest vessels. 


\section{Results}

Table 6. Comparison of calculated versus measured literature values.

\begin{tabular}{ccc}
\hline & $\begin{array}{c}\text { Flow rate } \\
\text { Source }\end{array}$ & \\
\hline Segment & 0.19 & 0.03 \\
Segment (added vessels) & 0.38 & 0.06 \\
Element & 0.13 & 0.03 \\
Element (added vessels) & 0.17 & 0.04 \\
Cardinal, et al. & 1.04 & 0.21 \\
\hline
\end{tabular}

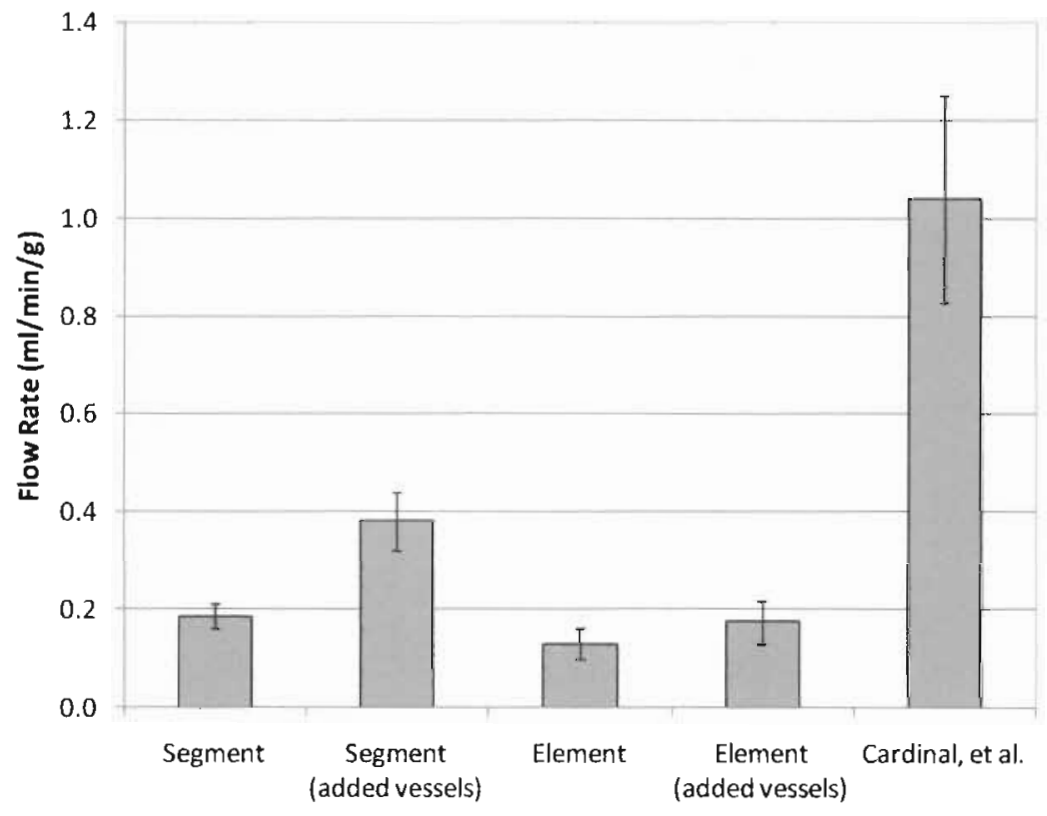

Figure 38. Comparison of calculated total flow compared with literature.

Bars represent the standard deviation. 
Discussion

\section{Recap}

Peripheral arterial disease (PAD) affects a significant portion of the population and poses series health risks (Hershey, Baskin et al. 2001). Prolonged reduction in blood flow results in two forms of vascular dysfunction. The first is a decrease in vessel vasomotor capacity (ability to increase or decrease luminal diameter). This paper focuses on the second dysfunction; a premature halt in vascular remodeling (permanent architectural changes in response to a stimulus).

The governing objective was to develop analysis methods in order to elucidate the structure/function relationships within vascular networks. Understanding these relationships may help to more effectively target therapies to treat vascular dysfunction. Three hypotheses were explored in this paper when developing these analysis methods:

1. The mouse gracillis anterior muscle is sufficiently thin to allow for morphological analysis using a two-dimensional image.

2. The application of the diameter-defined Strahler method and of Horton's Law to the morphological data yields useful information of the network as a whole, comparable to literature values.

3. Computation of blood flow and pressure profiles within the vascular network can be accomplished using both segmental and elemental representations of the network. 


\section{Discussion}

\section{Results}

\section{Morphological Analysis}

Morphological analysis describes the process of measuring the anatomic features of the vascular network. When applying Horton's Law and the Strahler method, two main approaches have been used for obtaining this information: three dimensional vascular casts (for thicker tissues) and two dimensional images (for thinner tissues). The objective was to assess whether the gracillis anterior muscle of a mouse was sufficiently thin to perform analysis of the network using a two dimensional image following ink casting.

Overall, the results indicate that morphological analysis can be performed on vessels greater than approximately $8 \mu \mathrm{m}$ in diameter using a two-dimensional image. The difficulties of assessing vessels smaller than $8 \mu \mathrm{m}$ will be discussed later; however, previous experiments have also reported challenges directly applying the Strahler ordering method to small vessels (Kassab, Berkley et al. 1997).

Assessment of the approach was based on how well the morphological data matched trends in previous assessments of vascular networks. The diameter, length, and vessel quantity varied logarithmically with order number (Figure 27, Figure 28), and the number of segments that were connected into elements increased with order number (Table 3), both in line with previous experiments (Kassab, Rider et al. 1993; Jiang, Kassab et al. 1994). Furthermore, when applying Horton's Law, the results (discussed later) were comparable to expected trends and literature values, also supporting the validity of the morphological analysis performed on the images. 


\section{Discussion}

\section{Strahler System and Horton's Law}

The complexity of the vascular network architecture (i.e. numerous vessels, asymmetric branching, varying lengths and diameters) makes assessing it on a systems level challenging. Take, for example, the normal versus tumor vasculature. Differences in the architecture can be visually seen in the images; however, quantitatively stating those differences is difficult.
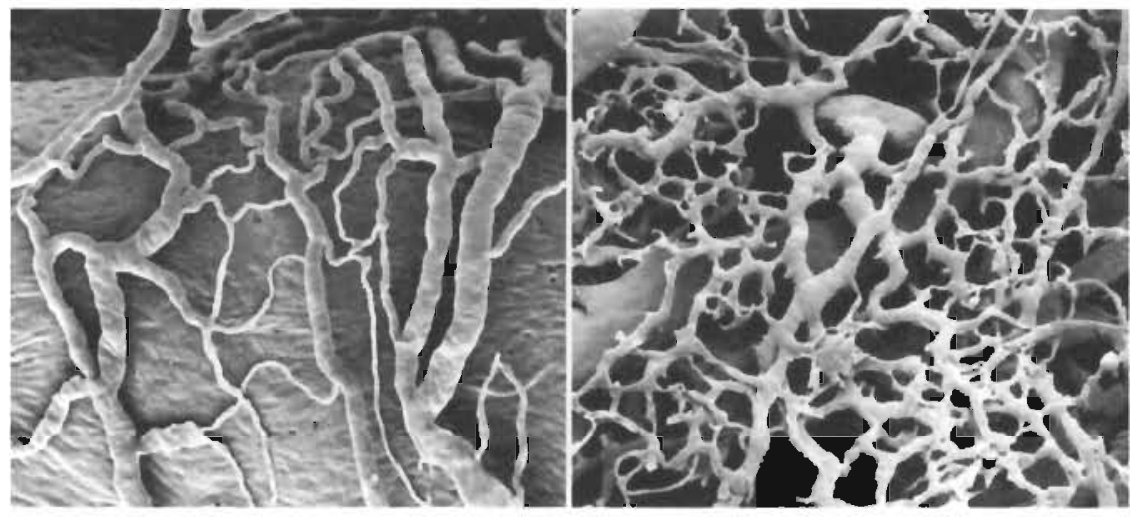

Figure 39. Normal vasculature versus tumor vasculature.

Normal architecture is depicted on the left, and tumor is depicted on the right (McDonald and Choyke 2003).

The purpose behind applying the Strahler System and Horton's Law was to quantitatively capture the network as a whole. In addition to describing the physical characteristics of isolated vessels or groups of vessels, these methods also assess the connectivity patterns and morphological patterns between orders within the network. This allows quantitative comparison of network properties between specimens, such as healthy versus ischemic mouse hindlimbs, and across different species, organs, and tissues are possible. Both are useful when assessing structure/function relationships in 


\section{Discussion}

vascular networks. For example, comparison within the same species and organ can be applied to experiments exploring one or two variables. Comparisons across species and organs can show similarities in vascular networks and perhaps shed light on the governing design principles as a whole.

The application of Horton's Law examines the length, diameter, and number relationships between orders in the form of ratios $\left(R_{L}, R_{N}, R_{D}\right)$. If a network obeys Horton's Law then length, diameter, and vessel quantity will vary logarithmically with order, described by a geometric series. The diameter-defined Strahler Method (Strahler method for short) is aims to categorize network components through a diameter dependent re-ordering system. This method also combines similar segments connected in series into elements to mimic the actual network, and the unique, asymmetrical branching patterns is described in the form of a matrix.

\section{Horton's law}

In general the calculated ratios $\left(R_{L}, R_{N}, R_{D}\right)$ fit well within those typically observed in vascular networks (Table 7$)$. Note that the number ratio $\left(\mathrm{R}_{N}\right)$ listed in Table 7 is simply the inverse of that listed in this report. Instead of representing the change in number from order $n$ to order $n+1$, it represents the change from order $n+l$ to order $n$. 


\section{Discussion}

Table 7. Comparison of ratios to previous experiments.

Length $\left(R_{L}\right)$, Diameter $\left(R_{N}\right)$, and Number $\left(R_{N}\right)$ ratios from previous experiments in different animals, muscles, and organs (Kassab 2000). Note the number ratio listed here is the inverse of that

represented in this report.

\begin{tabular}{llcccc}
\hline Species & Vasculature & $\mathrm{R}_{\mathrm{L}}$ & $\mathrm{R}_{\mathrm{D}}$ & $\mathrm{R}_{\mathrm{N}}$ & Orders \\
\hline Human & Pulmonary & 1.46 & 1.6 & 3.09 & $1-17$ \\
Human & Pulmonary & 1.49 & 1.56 & 3.36 & $1-15$ \\
Dog & Pulmonary & 1.52 & 1.67 & 3.69 & $1-12$ \\
Cat & Pulmonary & 1.81 & 1.72 & 3.58 & $1-11$ \\
Rat & Pulmonary & 1.6 & 1.58 & 2.76 & $1-11$ \\
Human & Conjunctiva & 1.36 & 1.26 & 2.77 & $1-5$ \\
Cat & Sartorius Muscle & 1.86 & 1.31 & 3.17 & $1-4$ \\
Hamster & Retractor Muscle & 2.59 & 1.63 & 3.43 & $1-4$ \\
Hamster & Skin Muscle & 2.03 & 1.55 & 2.75 & $1-4$ \\
Rat & Spinotrapezious Muscle & 1.62 & 1.43 & 2.99 & $2-4$ \\
Rabbit & Omentum & 1.61 & 1.3 & 3.12 & $1-4$ \\
Rat & Messenteric & 1.81 & 1.33 & 3.34 & $1-4$ \\
Rat & Pial & & 1.43 & 4.14 & $1-5$ \\
Pig & Coronary & 1.63 & 1.51 & 3.3 & $2-8$ \\
Pig & Coronary RCA & 1.91 & 1.81 & 3.5 & $1-11$ \\
Pig & Coronary LAD & 1.88 & 1.84 & 3.51 & $1-11$ \\
Pig & Coronary LCx & 2.03 & 1.89 & 3.57 & $1-10$ \\
Mouse & Gracillis Anterior & $\mathbf{2 . 1 2}$ & $\mathbf{1 . 3 9}$ & $\mathbf{2 . 5 0}$ & $\mathbf{1 - 5}$ \\
\hline
\end{tabular}

Once multiple muscles have been analyzed using these methods, statistical analysis can be performed to determine if the ratios remain consistent between muscles. 
Discussion

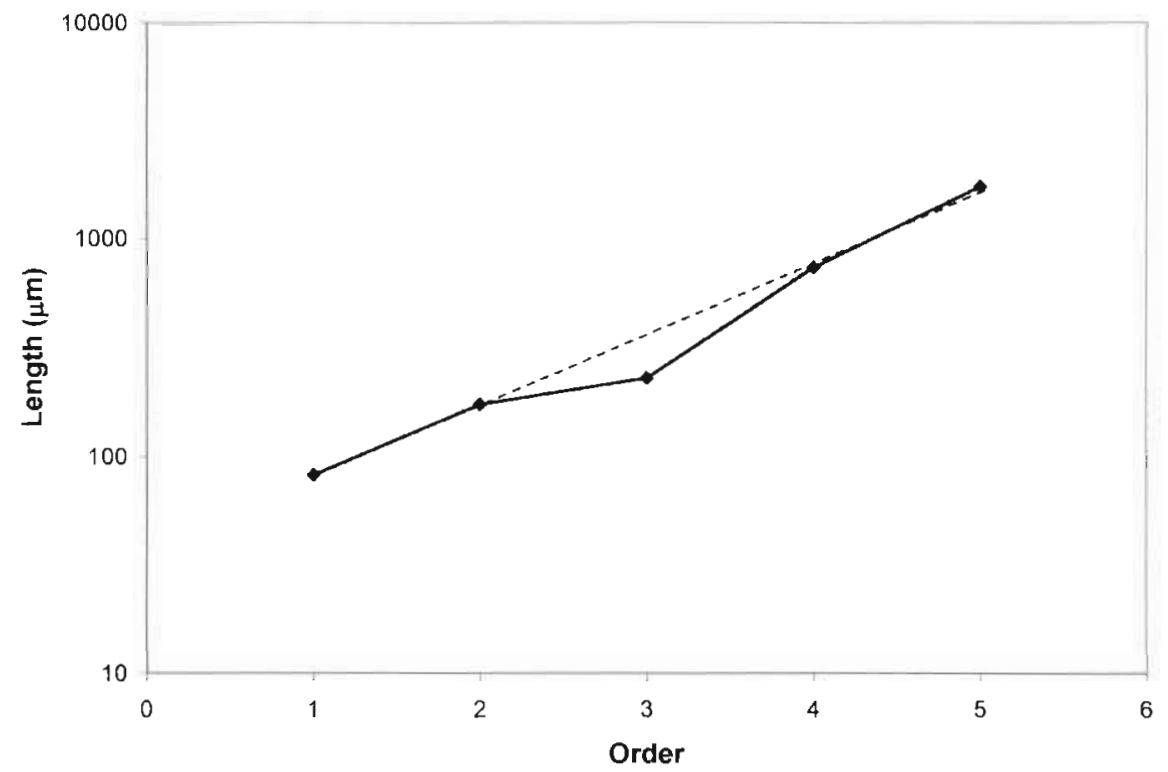

Figure 40. Length versus order number for elements.

Note the logarithmic scale. The dashed line shows an extension through the order $1,2,4$, and 5 data points to illustrate the difference in predicted length for order 3.

One possible reason that order 3 elements lengths are shorter than predicted may be related to the two-dimensional nature of the images. The gracillis anterior muscle is extremely thin; however, it is not perfectly two dimensional. The larger vessels, such as order 4 and 5, are sufficiently large such that they are essentially parallel to the two dimensional viewing plane with negligible movement into or out of the plane ( $z$ direction, Figure 41). As mentioned before, order 1 and 2 vessels were difficult to capture in the analysis, due in part to their short length and small diameter making them less visible when running in the z-direction (Figure 41). Therefore, it is likely that some order 1 and 2 vessels that had significant movement in the z-direction were not captured in the assessment, and therefore those measurements did not weigh down the average length calculated. Order 3 segments were sufficiently small in diameter to run in the z- 


\section{Discussion}

direction but they were sufficiently long enough to be visible in the two dimensional image. Consequently, segments moving the z-direction would appear shorter than their actual length.

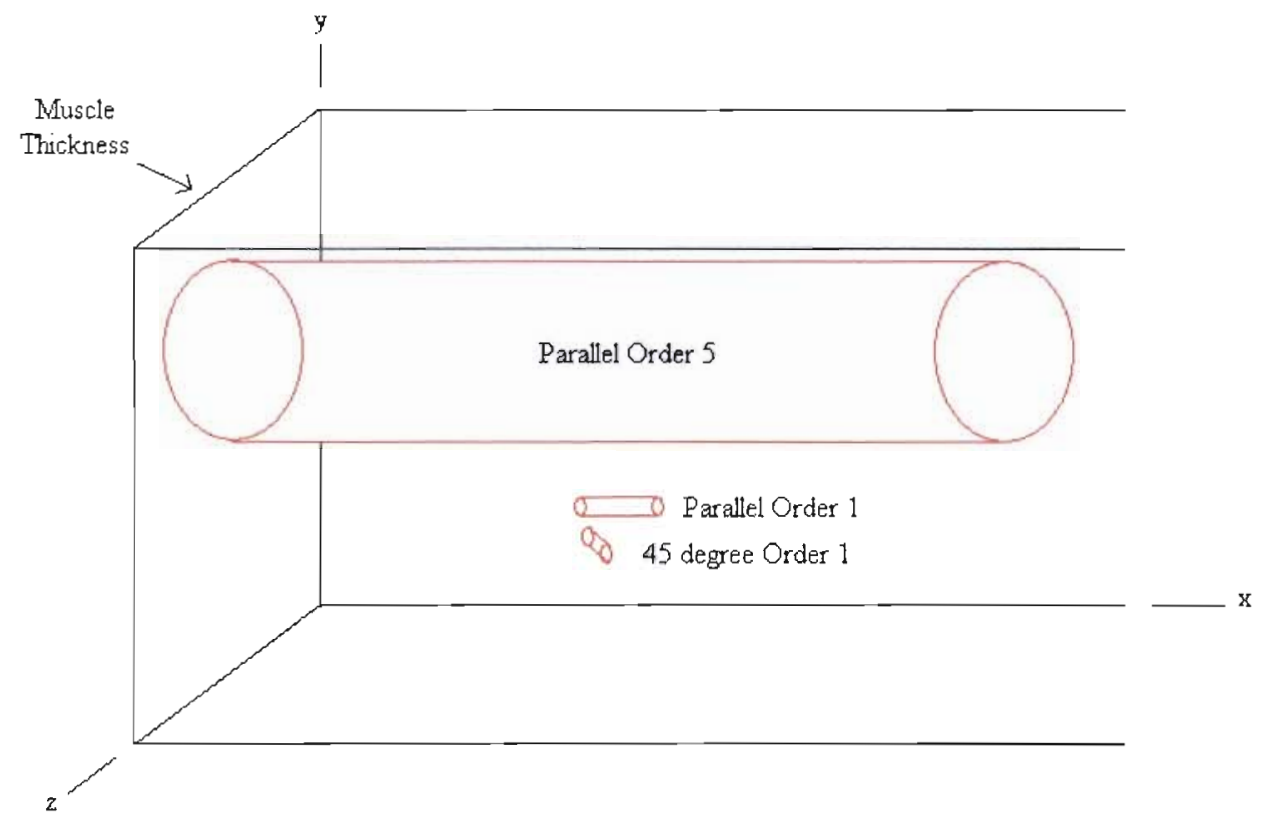

Figure 41. Schematic of 3D characteristics of the muscle.

Order 1 and order 5 blood vessels are shown running through the gracillis anterior. The order 5 vessel is not able to move significantly in the z-direction due to its larger size, whereas the order 1 vessel almost appears as a dot when oriented $45^{\circ}$ in the $\mathrm{z}$-direction. Note that drawing is not to scale.

In the future, the microscope slide containing the muscle can be referenced to check whether there is extensive movement in the z-direction and use estimates to account for the lost length information. On a whole, the vascular network assessed in this paper followed the trends predicted by Horton's Law. 


\section{Discussion}

\section{Connectivity Matrix}

In addition to looking at trends between orders, the branching characteristics across the entire network can provide another tool to assess the system. Asymmetric branching contributes to the heterogeneity of flow through vascular networks (VanBavel and Spaan 1992; Kalsho and Kassab 2004). Asymmetry refers in part to the fact that not all vessels of order $n$ branch from a vessel of order $n+1$. Therefore, branching patterns are an important piece to understanding the flow characteristics of a vascular network.

The branching ratio describes the average number of branches originating from a single vessel of order $n$; however, it does not give any detail on asymmetry or the patterns between specific orders. The two types of connectivity matrices presented in this report provided a multi-dimensional version of the branching ratio (Figure 30, Figure 31), including patterns in the asymmetric branching within the network. The benefit to constructing the matrices is geared towards comparing branching patterns between samples, such as with healthy versus ischemic hindlimbs (Jiang, Kassab et al. 1994; Kassab, Berkley et al. 1997).

The first matrix represents the branching ratios between orders (Figure 42, Figure 43). At first glance, the segment version shows that the average branching ratios exhibit a relatively flat dispersion and overall low branching within the network. However, the values in the element version represent the branching patterns when series segments are considered the same vessel. Overall, the branching of the order 4 and 5 vessels increased by virtue of the face the segment branches were added together. Orders 4 and 5 had a greater than $70 \%$ rate of combination of segments into elements, and therefore exhibit a more noticeable change in branching ratio. 


\section{Discussion}

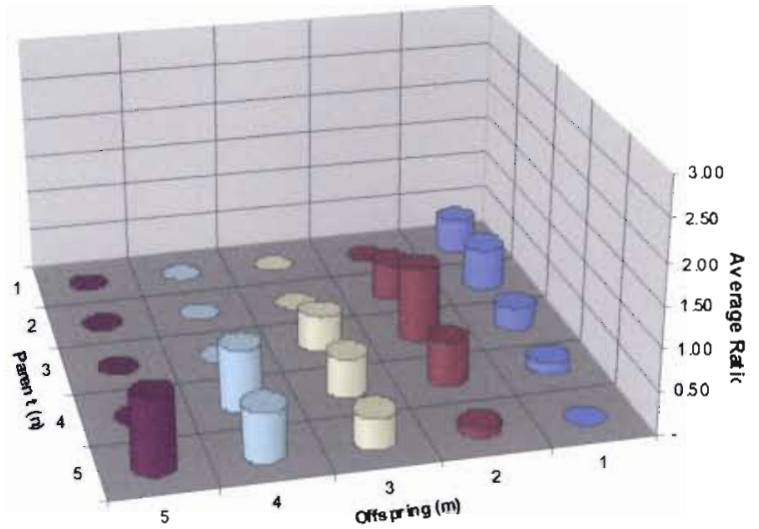

Figure 42. Graphical representation of the segment connectivity matrix.

The values represent the average number of vessels of order $m$ that branch from a single vessel of $\operatorname{order} \boldsymbol{n}$ (duplicated from Figure 30)

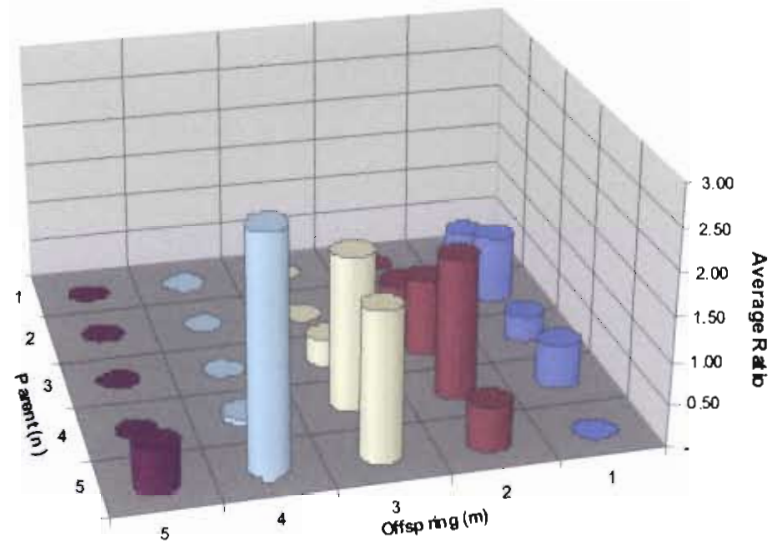

Figure 43. Graphical representation of the element connectivity matrix.

The values represent the average number of vessels of order $\boldsymbol{m}$ that branch from a single vessel of order $\boldsymbol{n}$ (duplicated from Figure 30).

The number of order 1 and 2 vessels captured in the morphological analysis was low which explains the low branching ratios of order 1 and 2 vessels.

The second type of matrix describes the percent distribution of parent vessels within a particular order (Figure 44, Figure 45). In other words, this matrix helps to 


\section{Discussion}

show where most vessels of order $m$ (offspring) originate from, whereas the first matrix describes the average branching ratio per individual parent vessel of order $n$, giving no information from an offspring perspective.

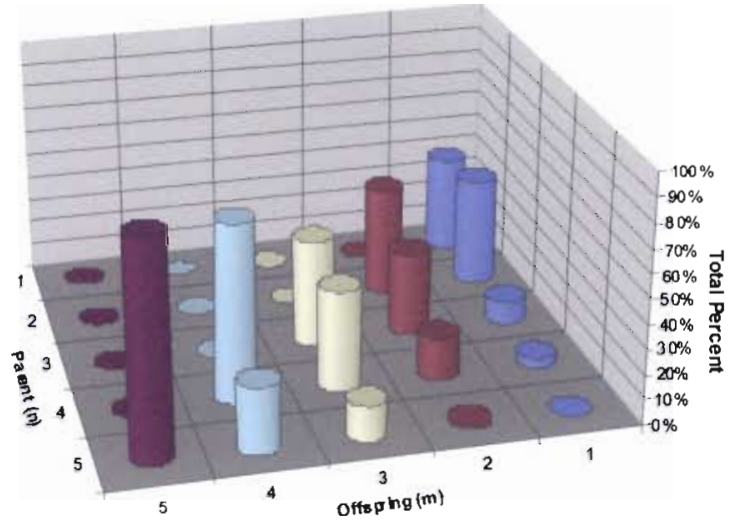

Figure 44. Graphical representation of the connectivity matrix for segments.

Values represent the percent of all vessels of order $\boldsymbol{m}$ that branch from a vessel of order $\boldsymbol{n}$ (duplicated from Figure 31).

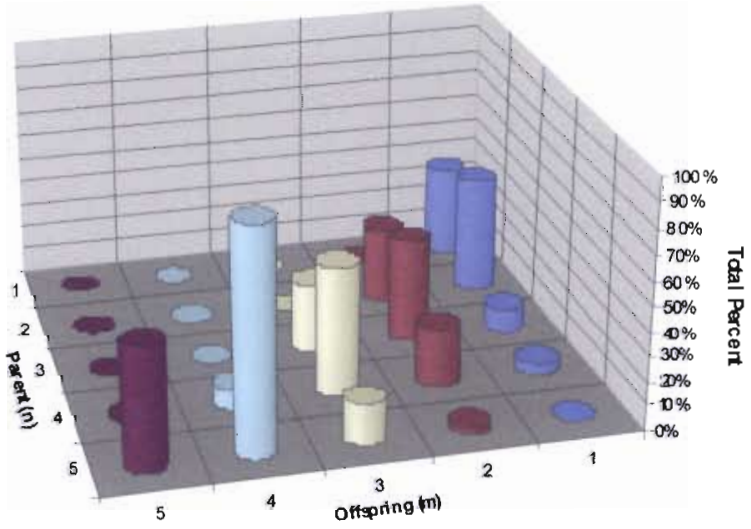

Figure 45. Graphical representation of the connectivity matrix for elements.

Values represent the percent of all vessels of order $m$ that branch from a vessel of order $n$ (duplicated from Figure 31). 


\section{Discussion}

The advantage to the second type of matrix is that it shows where most branches of a particular order originate from. For example, most order 4 segments are connected in series since the bar in the 4 from 4 cell is the highest, a fact that could not have been determined from the first matrix. Likewise, the element version shows that the majority of the order 4 segments were joined into elements. The relatively small changes in orders 1 and 2 between segments and elements indicates that the majority of those vessels are in parallel.

The element matrices from the first and second types can be used together to assess the overall branching heterogeneity of the network. Furthermore, these matrices can provide a tool to compare the branching characteristics of the network with other samples. For example, the gracillis anterior from a healthy and ischemic hindlimb can be compared on a quantitative level to assess the effect that vascular remodeling has on normal branching patterns. Some of the singular network details described here, such as number of order 4 vessels that were combined into elements, could also be found in separate tables or graphs; however, the usefulness of the matrix is that the information is in one place such that systems level patterns can start to emerge.

\section{Segment versus element representation}

In addition to looking at the ratios between orders and the connectivity matrices, there were two different representations of the system that could be used: segments or elements. Overall, the elements provided a more realistic representation of the actual physical network than the segments. This was apparent in the graph of total area versus order number (Figure 46). As mentioned briefly in the results section, the total crosssectional area of the smaller vessels should be higher than larger vessels. However, each 


\section{Discussion}

segment's cross-section was counted in the computation of total area for that order, even if it was connected in series with other identical segments. Also, a higher percentage of the larger vessels were connected into elements (Table 3), which explains why the total cross-sectional areas of order 4 and 5 vessels showed significant differences between segments and elements (Figure 46).

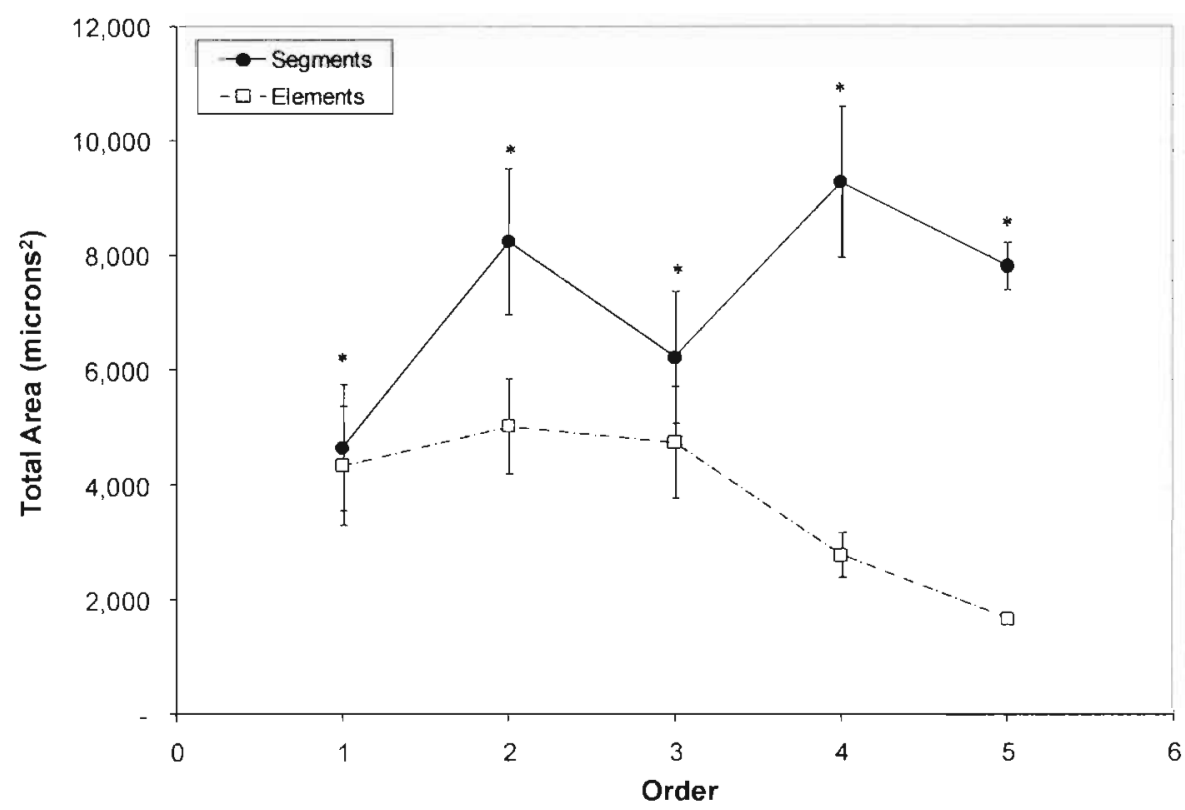

Figure 46. Total cross-sectional area in each order.

$\left.{ }^{*}\right)$ represents statistical difference between segments and elements $(\mathrm{p}<0.05)$ (duplicate of Figure 25$)$.

Another reason why the elements may be more useful in assessing the actual network architecture can be seen when looking at the branching matrices (Figure 30, Figure 31). The segment network by definition has two branches per vessel. Even though the segments shift during re-ordering, the branching characteristics remain constrained; however, the element network is not constrained by the ordering convention (i.e. a segment is defined as the point between bifurcations). 


\section{Discussion}

The r-squared values obtained through regression analysis show a slightly better correlation for the elements when looking at order number versus $\log _{10}$ of length and quantity. Analysis of variance (ANOVA) indicated that length, diameter, and quantity in both segments and elements were logarithmically related to order number. Furthermore, there was no statistical difference between the slopes of the lines (Figure 27, Figure 28, Figure 29).

Overall, both segment and element systems provide useful information; however, the elemental network is less constrained with branching patterns, and follows physiologic trends better in regards to total cross-sectional area at each order.

\section{Overall utility}

The value of applying the Strahler system and Horton's Law was exemplified by the observation that the results quantitatively supported the suspicion that vessels smaller than $8 \mu \mathrm{m}$ had not been adequately captured. First, there is a kink in the line associated with orders 1 and 2 when examining the logarithmic relationship between order and quantity (Figure 47), possibly due to the smaller vessels being under-assessed. 


\section{Discussion}

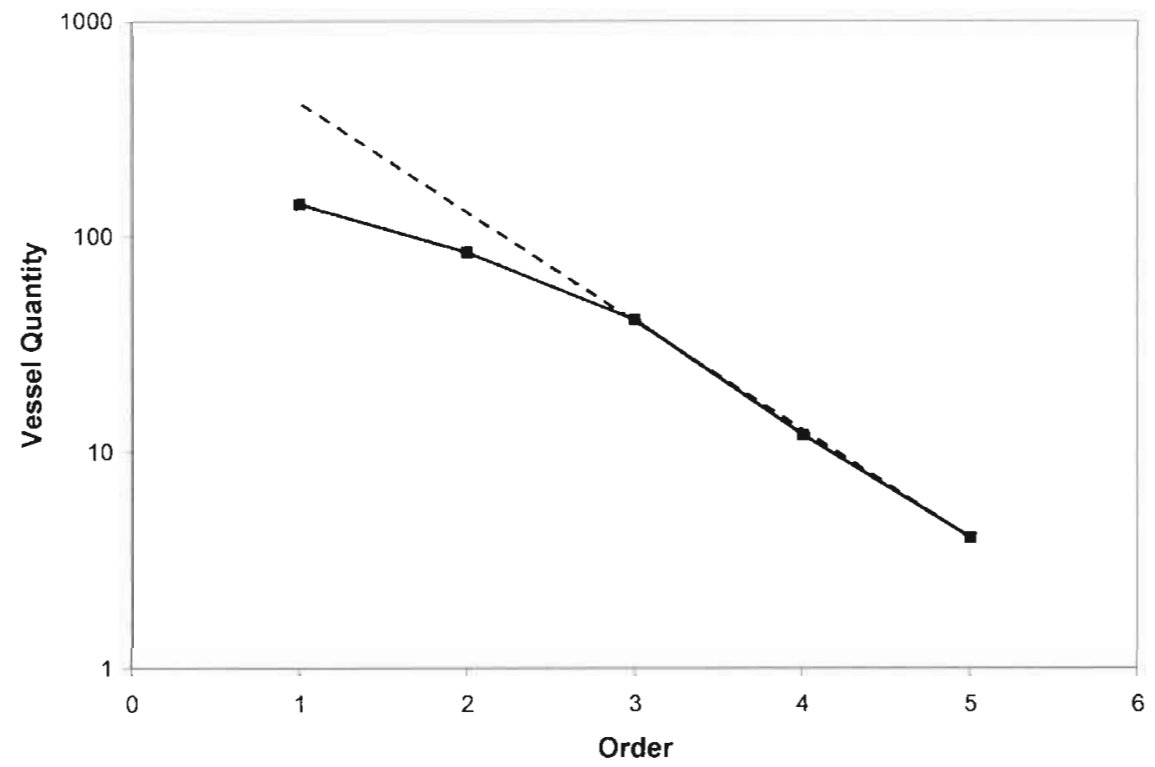

Figure 47. Actual and predicted number of elements of each order.

Note the dimensions are on a logarithmic scale. The dashed line passes through the data points for order 3, 4, and 5, and illustrates the expected quantity of vessels for order 1 and 2.

The computation of total cross-sectional area of elements of each order (Figure 46) also provides further indication that the total quantity of order 1 and 2 vessels is low. As mentioned, total cross-sectional area should increase with decreasing order, and does so for orders 3-5. However, orders 1 and 2 show obvious deviation from this pattern.

Lastly, the segment and element connectivity matrices (Figure 42, Figure 43) also showed low branching ratios for orders 1,2, and 3 (i.e. less than one). Overall, the data generated by applying these methods points towards a lower than predicted vessel quantity in the smaller orders. Granted, this was a result that was already suspected as will be discussed later; however, it illustrates how the data can illuminate characteristics about the network on a whole (i.e. too few small vessels compared with expected). 


\section{Discussion}

Although it is reasonable to expect that not every order will perfectly obey predicted trends, these approaches can still help bring attention to possible sources of error in data gathering, in addition to network level deviations between experiments in the future.

\section{Hemodynamics}

Computing the pressure and flow rate profiles within and through the muscle is an important component in relating structure to function. The function of the vascular network is to provide nutrient and waste exchange in the tissues, which are transported by the blood. Therefore, blood flow profiles provide insight to the functionality of a vascular network, and how that functionality is altered by network structure.

\section{Segments versus elements}

Hemodynamic parameters were calculated using both the segment and element representations of the vascular network. Overall, the segment network yielded a higher flow rate through the muscle compared with the elements. As mentioned in the results section, this is observation only as there was only one sample analyzed. Furthermore, the data suggest that the segmental data yield a more realistic assessment of flow, contrary to the original hypothesis. The reason for this, briefly discussed in the methods section, can be seen in the physical depiction of segments versus elements (Figure 48). By convention of the Strahler method, all segment branches were connected to the terminal end of the newly formed element. 


\section{Discussion}

Revisiting the Hagen-Poseuille equation:

$$
Q=\frac{\pi \cdot D^{4}}{128 \cdot L \cdot \eta} \cdot \Delta P
$$

Equation 8. Hagen-Poseuille equation.

$I=$ length of tube, $D=$ diameter of tube, $\eta=$ viscosity of blood, $\Delta P=$ pressure gradient (Kaul and Jayaweera 2006).
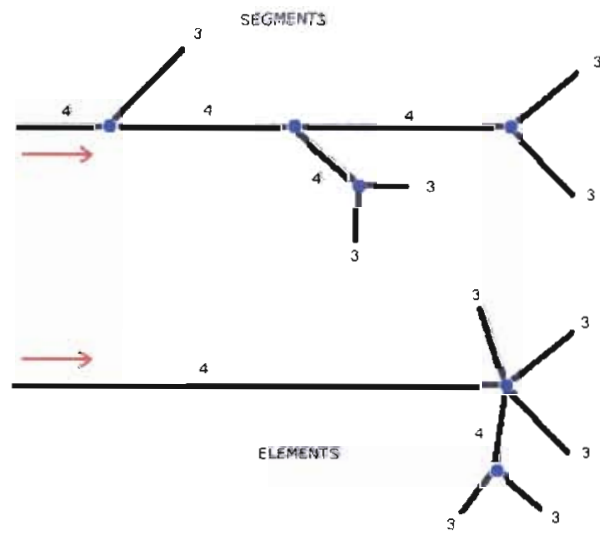

Figure 48. Comparison between segments and element representations.

(Duplicated from Figure 17). The arrow indicates flow direction.

Flow rate, pressure drop, and length are interrelated. Branches located farther upstream along an element would experience a drop in inlet pressure when converting from segments to elements due to the vessel being relocated to the end of the element. For example, an order 2 vessel branching near the inlet of an order 3 element showed a $4 \mathrm{mmHg}$ decrease in inlet pressure going from the segment to element networks. This value is larger than the average pressure drop in order 2 vessels, possibly explaining why 
Discussion

the pressure profile throughout the network is roughly $4 \mathrm{mmHg}$ lower in the elemental network compared with the segmental (Figure 34).

The goal behind using the elemental network and average conductance values for each order to assess blood flow and pressure was based on reports that it would average out extreme variations in network topology due to chance (Fenton and Zweifach 1981). However, this was not verified to be true, and in light of the alterations in the pressure profile in the elemental network, the segment network should be used for the hemodynamic analysis since it required the same amount of time and effort as the elemental network.

Previous work has explored looking at a longitudinal position matrix (LPM) that describes the branch point of a vessel along the length of an element for hemodynamic calculations (Kassab, Pallencaoe et al. 1997). However, this is simply back-calculating to the segment network for the purpose of computing flow, a task already accomplished by using the segment network in the first place.

\section{Flow rate}

Total flow rate through the muscle was below literature values $(\mathrm{p}<0.05)$ (Cardinal and Hoying 2007) (Figure 49). As mentioned in the results section, the sample size was assumed to be 3 in order to explore the statistical relationship; however, additional samples should be analyzed in order to compare to published values. The individual segment flow rates in the larger vessels were similar to published literature values (Zweifach, Kovalcheck et al. 1981) (Figure 50). This suggests that flow rate was calculated properly but not all vessels were captured in the analysis. 


\section{Discussion}

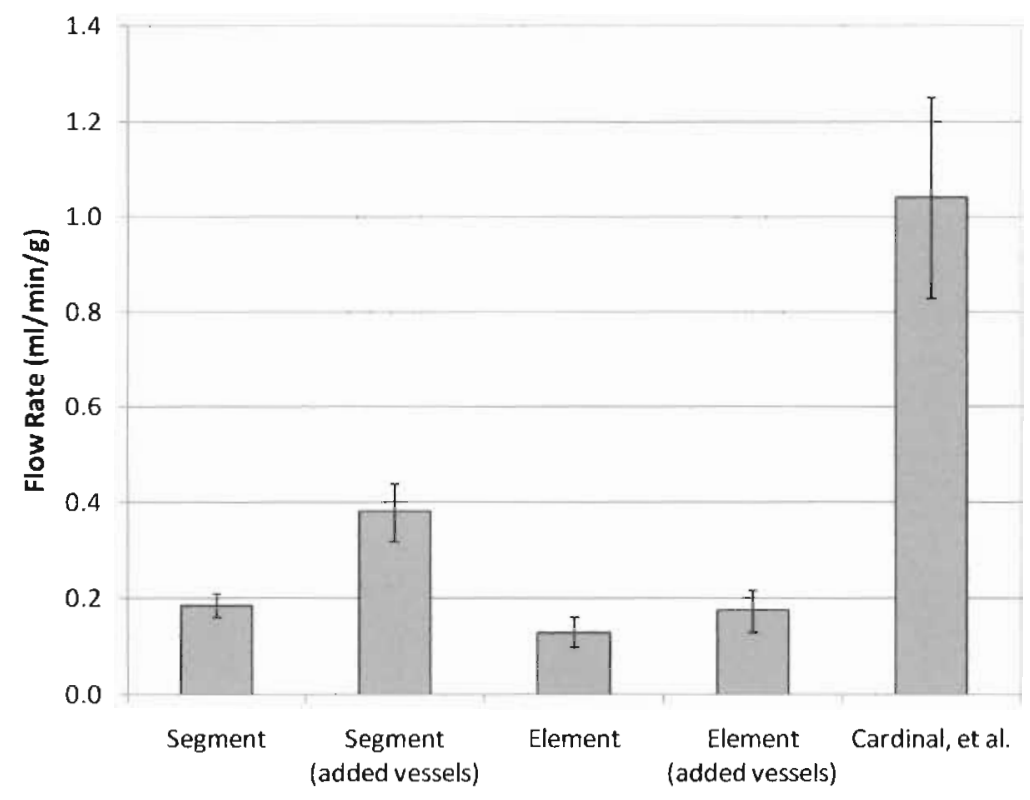

Figure 49. Comparison of total flow with literature values.

(Duplicated from Figure 38). Bars represent the standard deviation.

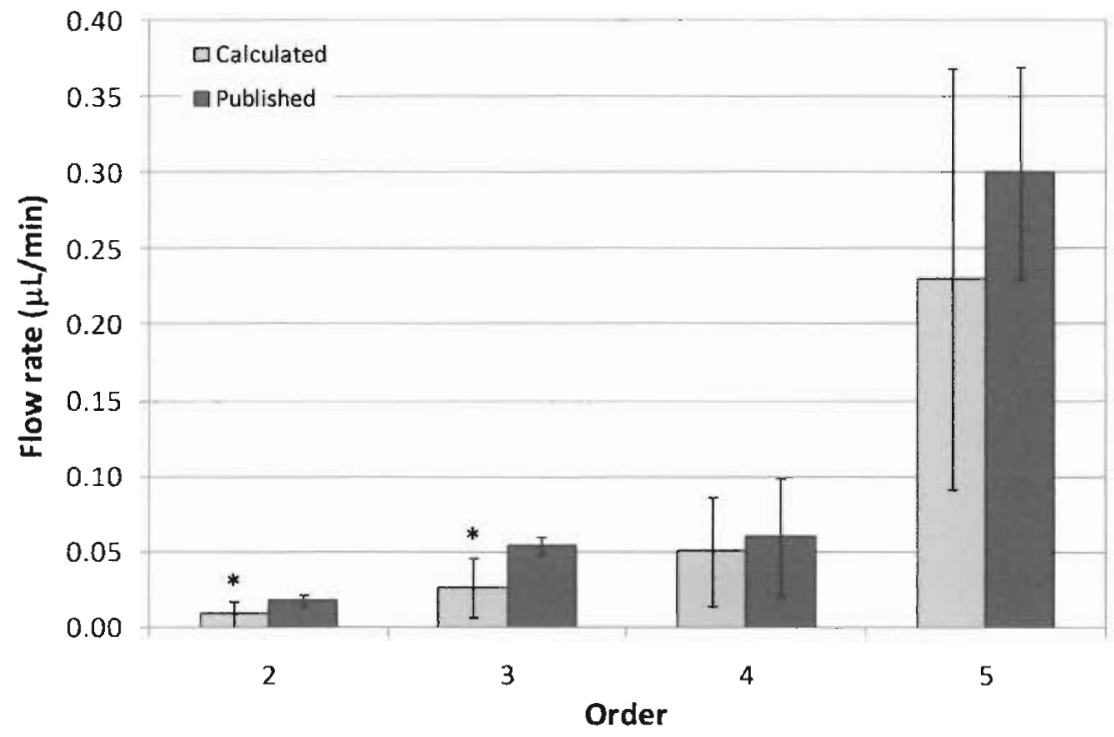

Figure 50. Comparison of individual segment flow rates.

$\left.{ }^{*}\right)$ indicates statistical difference between calculated and published values $(p<0.05)$. Bars represent the standard deviation. Note that the published data represent flow rates through the skeletal muscle of a rat, comparing flow based on average diameter. 


\section{Discussion}

The reason why computed flow was low is due in part to inadequate capture of the order 1 and 2 vessels. A simulated capillary network was added to the baseline network in order to assess the impact it has on flow rate (Figure 51). The vascular images were analyzed to obtain an estimated distance between capillaries. The network was then simulated by adding a capillary at a set distance along the length of the vessels in the baseline network, utilizing the same governing flow equations, boundary conditions, and assumptions used for the original hemodynamic analysis. The estimated linear distances per capillary were $15-40 \mu \mathrm{m}$, and the length and diameters of the capillaries were based on calculated averages for order 1 and order 2 vessels in the segments and elements.

Overall, the addition of the simulated capillary network resulted in a total flow rate almost double that of the original network (Figure 51), bringing computed flow values nearer to those published (Figure 49). 


\section{Discussion}

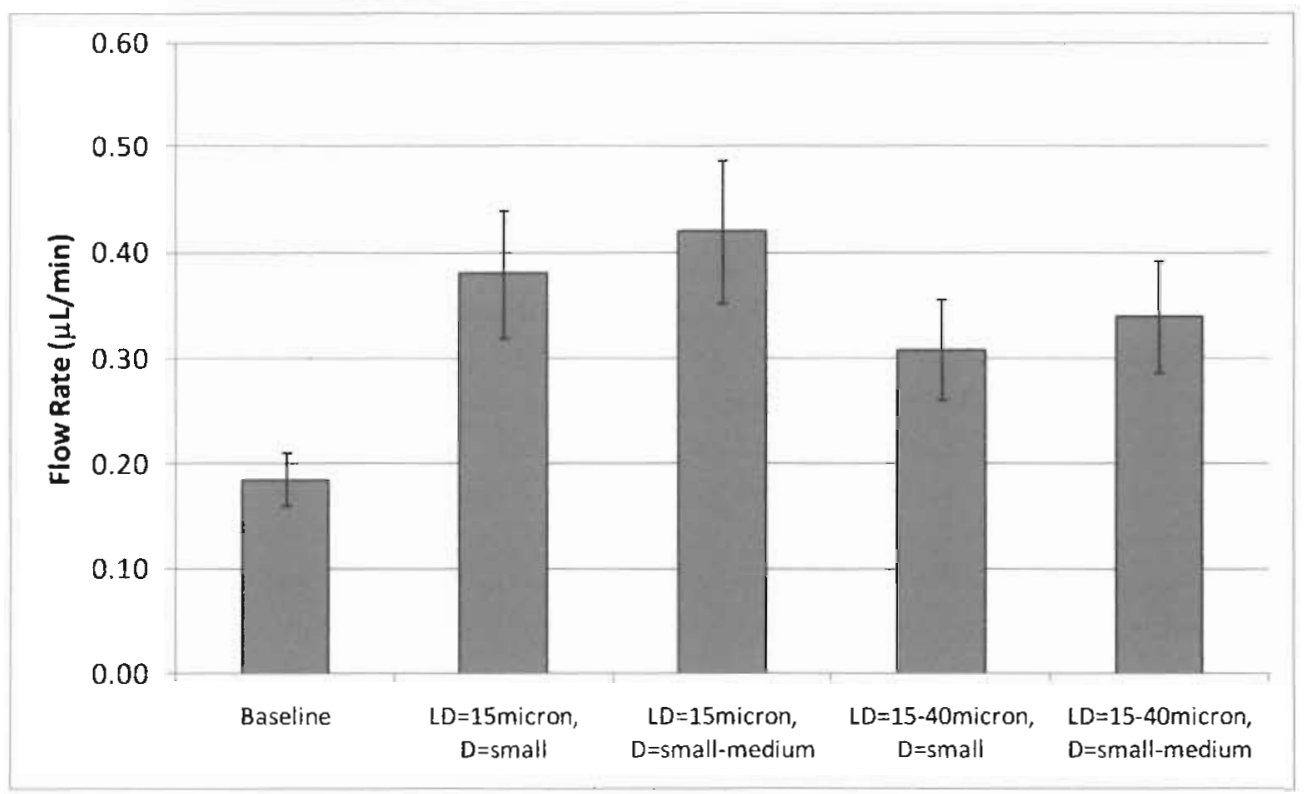

Figure 51. Baseline flow rate versus simulated capillary bed.

Comparison of total baseline flow rate with simulated capillary beds added to the base segment network. "Small" indicates a $6.4 \mu \mathrm{m}$ diameter and "Medium" indicates a $9.1 \mu \mathrm{m}$ diameter, based upon computed average diameters for order 1 and 2 vessels.

The higher density capillary bed yielded higher overall flow rates, and smaller diameters yielded lower flow rates. Although this simulated network cannot be considered an accurate representation of the capillary branching of the entire network, it does illustrate the importance of fully capturing the smaller vessels and incorporating them into the analysis.

\section{Pressure}

Pressure is the driving force behind blood flow. When the femoral artery of a mouse is ligated (tied off), the pressure drop downstream of the ligation increases the overall pressure differential across the arcading vessels that circumvent the occlusion, increasing flow through those arcades and initiating the process of arteriogenesis (Heil 
and Schaper 2004). Furthermore, blood flow through the muscle cannot be determined without determining pressure at every node.

Overall, the pressure as a function of diameter within the segment network exhibited the same high degree of variability seen in previous work (Zweifach, Kovalcheck et al. 1981; Pries, Secomb et al. 1999) (Figure 52).

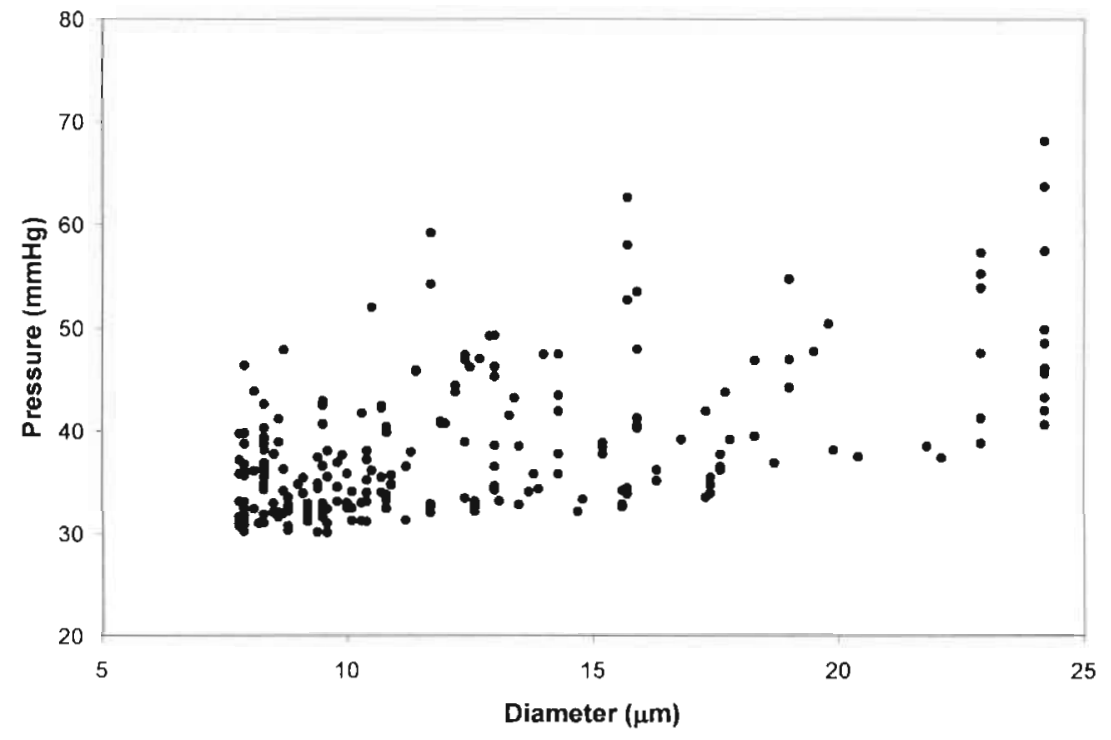

Figure 52. Outlet pressure versus diameter.

Scatter plot for the segmental network showing the high degree of variability.

The average outlet pressures of each order fit within the range established previously (Zweifach, Kovalcheck et al. 1981; Pries, Secomb et al. 1999; Levy, Ambrosio et al. 2001). Increasing the inlet pressure to $90 \mathrm{mmHg}$ yielded an increase in outlet pressure across the network, likewise the addition of the capillary network lead to a decrease in pressure (Figure 53). 


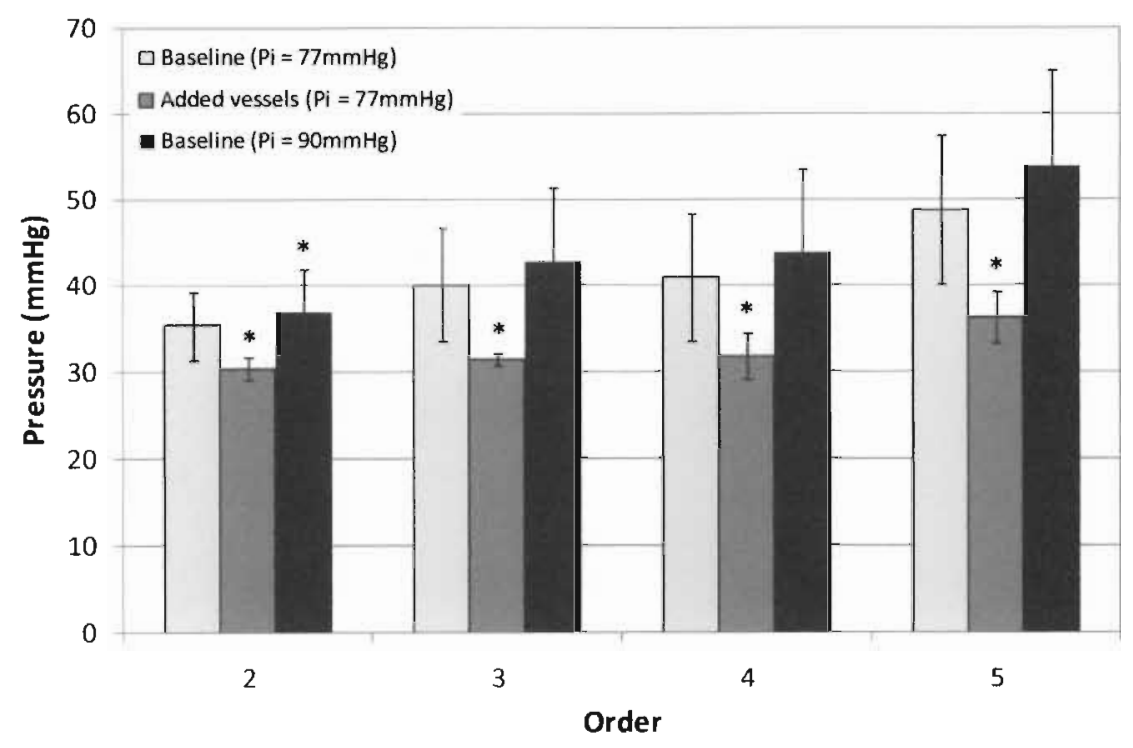

Figure 53. Comparison of average outlet pressure under different conditions.

All networks use a constant viscosity of $3 \mathrm{cP}$. The segmental network is the baseline. $\left(^{*}\right)$ indicates statistical difference from Baseline $(\mathrm{Pi}=77 \mathrm{mmHg})$. Pi stands for inlet pressure.

When comparing healthy to remodeled vascular systems, the profiles in Figure 53 are expected to undergo a large shift due to changes in flow direction. Blood flow into and out of the muscle will switch from two inlets (muscular branch and saphenous branch) and one outlet through the capillary bed to the venous system, to a situation where there is one inlet (muscular branch) and two outlets: the capillary bed and the ligated branch (saphenous). Overall, the calculated pressure profiles within the vascular network match well with the published ranges (Zweifach, Kovalcheck et al. 1981; Pries, Secomb et al. 1999; Levy, Ambrosio et al. 2001).

\section{Boundary conditions and assumptions}

Calculating blood flow rate and pressure profiles throughout a tissue requires knowledge of either the pressure or flow rates at the inlet and exit, called boundary 


\section{Discussion}

conditions. By choosing to set the inlet and outlet pressures as the boundary conditions, the pressure profiles were forced to fit within those boundaries. Likewise, the blood flow rate at the inlet and outlet could have been fixed which would have placed similar bounds on the flow rates within each vessel. Pressure was chosen as the boundary condition based on previous measurements (Pries, Secomb et al. 1995), and flow rate was calculated and compared to literature values (Cardinal and Hoying 2007) since there was more available data on pressure conditions, especially at the capillary level.

The inlet blood pressure to the muscle in both the saphenous and muscular branches were set at $77 \mathrm{mmHg}$, and the outlet blood pressure at the capillary level was set at $30 \mathrm{mmHg}$ (Pries, Secomb et al. 1995). Likewise, viscosity was set as constant, $3 \mathrm{cP}$ (Gruionu, Hoying et al. 2005). As mentioned in the introduction, since the objective of this project was to assess experimental data, and not to predict physiologic responses to match experimental data, more simplifying assumptions could be made for the computations.

In addition to viscosity and pressure conditions, assumptions were made concerning the distensibility. Blood vessels are distensible, which means that changes is pressure will result in a change in vessel diameter. The assumption that the blood vessels were non-distensible was made to simplify computations and was based on two factors. First, systolic and diastolic pressure cycles are not as large in the arteriole and capillary levels (Figure 2). Second, during ink casting the blood vessels were vasodilated, which was followed by dehydration of the tissue; both of which can have an impact on apparent diameter of the vessels. Therefore, attempting to account for distensibility would be pointless unless the vasculature is analyzed in such a way that the diameter was not 


\section{Discussion}

affected. Consequently, for the aims of this project, distensibility was assumed negligible.

In summary, the hemodynamic calculations performed on the segments adequately assessed flow rate and pressure profiles within the vascular network since the individual flows and pressure profiles fit within the range published values. An incomplete capture of small blood vessels lead to a low value for total muscle blood flow. Overall, the objectives of this project were met; however some modifications to future work would enhance the analysis.

\section{Future Work}

Overview

This paper has presented a solid foundation for future morphological and hemodynamic analysis of the gracillis anterior using two dimensional photomicrographs. However, much was learned through the process, and several alterations can improve future application of these methods.

\section{Connectivity Matrices}

The connectivity matrix was shown earlier to be a useful tool for examining the 'bigger picture' of vascular branching within a network. However, the matrices give misleading information if any of the orders represented within the matrix are at the downstream boundary of the system and therefore, by convention of the Strahler method, have no offspring included in the analysis.

The computed branching ratios were especially low for orders 1 and 2, and lower than expected in order 3 (Figure 54). 


\section{Discussion}

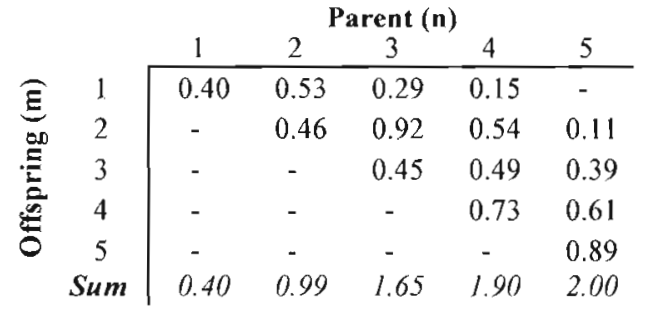

Segments

\begin{tabular}{|c|c|c|c|c|c|}
\hline & \multicolumn{5}{|c|}{ Parent (n) } \\
\hline & 1 & 2 & 3 & 4 & 5 \\
\hline 1 & 0.38 & 0.81 & 0.32 & 0.50 & - \\
\hline 2 & - & 0.31 & 0.88 & 1.67 & 0.50 \\
\hline 3 & - & - & 0.29 & 1.83 & 1.75 \\
\hline 4 & - & - & - & 0.08 & 2.75 \\
\hline 5 & - & - & - & - & 0.50 \\
\hline Sum & 0.38 & 1.12 & 1.49 & 4.08 & 5.50 \\
\hline
\end{tabular}

Elements

Figure 54. Average branching ratio matrices for segments and elements.

Values represent the average number of vessels of order $\boldsymbol{m}$ branching from a single vessel of order $\boldsymbol{n}$.

As mentioned briefly, the total quantity of order 1 and 2 vessels is low, therefore the actual network would likely exhibit higher branching ratios for orders 1, 2, and 3. But this does not fully account for the low branching ratio.

By convention, the order 1 vessels contained zero branches, which weighed down the branching ratios of order 1,2 , and 3 . Through re-ordering of 2 to 1 , some branching in order 1 was shown in the matrix, which can give a misleading representation of the branching ratio. Therefore, the connectivity matrix cannot contain the vessels at the terminal boundary conditions. The upstream boundary (inlet to the muscle) does not present the same issue since ordering originates and is based upon downstream vessels, not upstream.

A more accurate re-ordering and construction of the connectivity matrices would involve assessment of one to several orders downstream (into the capillary bed) of "order 1" since re-ordering can lead to as much as a two level change in some vessels (Figure 24). 


\section{Discussion}

Assessment of Small Vessels

A constant theme throughout this paper has been the low capillary number, both in structure and flow analysis. A rough estimate of branching ratios points to a diameter lower limit $8 \mu \mathrm{m}$, anything below that cannot be assessed with the methods presented here.

Previous experiments have used histological staining to assess capillary density, overlapping the analysis with the Strahler ordering system $[29,30,36]$. Therefore, the cross-sectional staining should assess vessels slightly larger than $8 \mu \mathrm{m}$ to ensure that the data match with the measurements derived from the two-dimensional images.

The capillary density assessment should be comprehensive, meaning capillary branching at each order needs to be analyzed through the microscope to determine if different orders have varying numbers of capillaries. The computational tool developed in this project allows for different densities to be applied at each order.

Overall, a more comprehensive assessment of the smaller vessels is expected to bring calculated total flow rate closer to published literature values, in addition to yielding more realistic values for network branching ratios.

\section{Ink Castings and Images}

The vessel ink castings followed by generation of digital micrographs provides the foundation for the morphological and hemodynamic analysis. Staining the vessels followed by clearing of the surrounding tissue provides the necessary contrast for viewing the vasculature in an otherwise opaque muscle. Care needs to be taken during this process due to the delicate nature of the muscle and vascular bed. 


\section{Discussion}

The images used for this report were generated in a previous study; however, ink castings are performed in our lab as well. Currently there are several challenges that need to be overcome before usable images are generated for future experiments.

The first challenge is the presence of multiple breakages in the vessels (Figure 55). The probable reason for this is that during tissue processing, the muscle curled and folded. Mounting the muscle flat on the slide following the processing required forcefully pressing it flat, which is likely how much of the breakage occurred.

In an attempt to compensate for this, a fixative (Histachoice) was poured over the muscle after the ink perfused the vasculature. The muscle was also gently laid flat against a tube during processing. The resulting images had significantly less breakage; however, there was decreased contrast between the vessels and the surrounding tissue leading to difficult in elucidating the network. The cause of the decreased contrast could be due to a stain that is too dilute; however, the veins appeared to contain equal amounts of ink as the arteries, and the liver of the mouse turned black during the procedure, both indicators that the stain had good penetration throughout the vasculature. Therefore future staining should explore methods of keeping the muscle flat during processing without the use of Histachoice to examine if that improves contrast. 


\section{Discussion}

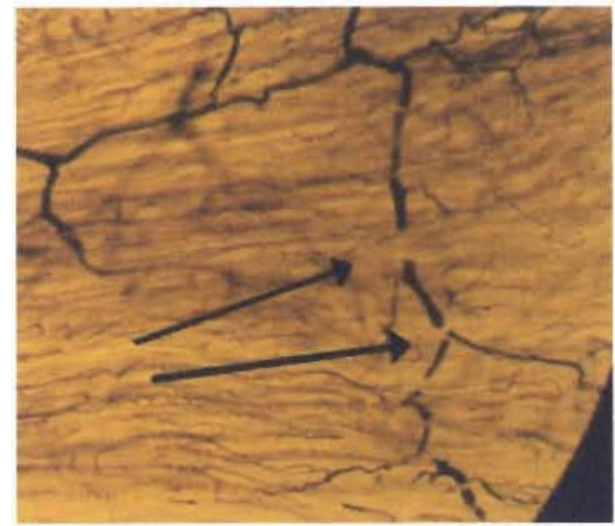

Figure 55. Photomicrograph of vessel breakages

Arrows point to the breakage locations.

The second issue involved several locations in the images where the diameter of the vessels changed abruptly, likely due to a particulate lodged in the vessel (Figure 56). Diameter has the largest impact on flow rate, therefore discontinuities in diameter result in significant error. Future ink castings should use finer filtration of the ink to remove particulates. Additionally, the use of heparin, an anticoagulant that prevents blood clotting, and a vasodilator mixed with the ink may alleviate this problem.

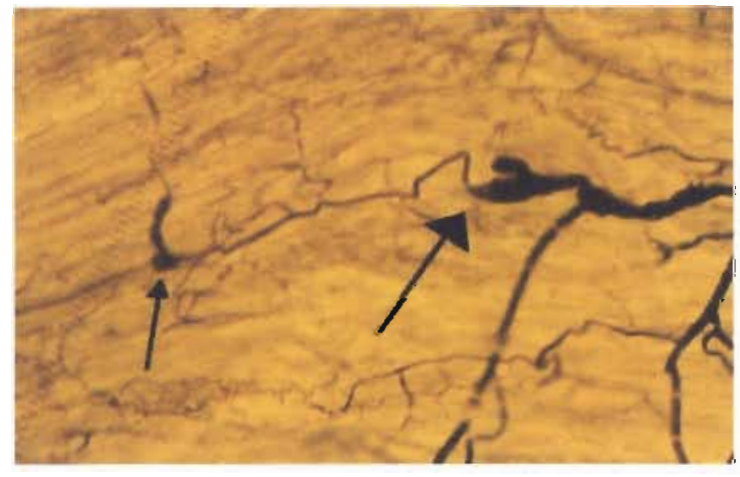

Figure 56. Photomicrograph of ink clots.

The arrows point to two locations where there is possible an ink particulate causing the apparent diameter to change abruptly. 


\section{Discussion}

It is important to note that the microscope slide containing the muscle should be kept for the duration of the analysis. As mentioned in the methods section, the muscle is not perfectly two dimensional and information is lost, especially on the smaller vessels, without the ability to adjust the viewing plane in the z-direction. Once successful ink casting and tissue processing procedures have been established, the digital micrographs can be captured and morphological analysis may begin.

\section{Enhancement of Analysis}

In addition to fine tuning procedures, such as improving the ink casting methods and developing ways to comprehensively capture small vessels, there are several areas that leave room for further development.

The first involves accounting for the increase in tortuosity and corkscrew appearance that sometimes occurs with remodeled vessels (Heil and Schaper 2004). Upon occlusion, collateral arteries begin in physically remodel to increase their diameter in response to the increase in shear stress. This physical remodeling also results in longitudinal growth. The increase in length occurs in a constrained tissue, resulting in a corkscrew like appearance of the remodeled arcades.

The increase in tortuosity leads to an increase in resistance due to the increase in centrifugal forces on the vessel wall. The Dean number, developed from the Reynolds number, is a dimensionaless parameter that describes the ratio between centrifugal forces

to viscous forces (Manno, Moulin et al. 1998) (Equation 9). This number can then be multiplied by the resistance term in the Hagen-Poseuille equation (Equation 8) to account for excess tortuosity. 
Discussion

$$
D e=\operatorname{Re} \sqrt{\frac{d_{i}}{d_{c}}}
$$

Equation 9. Dean Number.

$d_{i}$ is the vessel diameter, and $d_{c}$ is the pitch of the corkscrew.

The second area to explore in more depth involves the bifurcation angles at each node. Referring back to the image comparing normal and tumor vasculatures (Figure 39), it is apparent that there are differences between the two architectures, including with many of the angles that the vessel branch at. However, the effect that these branch angles have on flow resistance has not been incorporated into the present analysis The prediction is that increasing branching angle will increase flow resistance, and that the flow and resistance profiles will vary based on the diameters of the parent and offspring vessels.

In order to accurately assess the effect of branching angle, it is recommended that the morphological analysis be automated such that more complex geometry can be incorporated into the computations. Variations in diameter between parent and offspring and their respective branching angles would be time consuming and tedious to perform by hand.

Overall, taking into account tortuosity and branching angle would enhance the hemodynamic analysis as it relates to vessel morphology. 


\section{Discussion}

Future Application to Vascular Remodeling

\section{Overview}

The long-term purpose behind this project was to develop tools to be used to determine the structure/functionional relationships within vascular networks. In particular, the aim is to assess a normal, healthy muscle and compare that with one that has undergone remodeling (arteriogenesis) due to arterial occlusion.

\section{Simulating remodeling}

To illustrate the utility of these methods, the network data was altered in several ways to mimic remodeling. First, certain vessel labels were changed such that instead of having two inlets (the saphenous and muscular branch), there was only one inlet (the muscular branch) and all vessels branched from there. This was done because when blood flow through the saphenous branch is reduced or blocked, flow will no longer enter the muscle at that location.

In addition to changing the flow direction through part of the muscle, the outlet pressure to the saphenous branch was set at a constant value, ranging from $27 \mathrm{mmHg}$ ( 50 $\mathrm{mmHg}$ drop in pressure) to $67 \mathrm{mmHg}(10 \mathrm{mmHg}$ drop in pressure). This was done because upon artery occlusion, the pressure in the saphenous branch will drop, increasing the pressure differential across the arcade that runs horizontal through the muscle. The different outlet pressure conditions were tested to see how it would affect flow rate through the muscle. Experimentally reported changes in pressure (relative to nonoccluded) are approximately $70 \mathrm{mmHg}$ immediately following occlusion, to $40 \mathrm{mmHg}$ after several weeks of remodeling (Hudlicka, Brown et al. 1994). 


\section{Discussion}

Last, the diameters of the arcading vessels were increased by $25 \%$ to mimic vascular remodeling. The $25 \%$ increase was based upon estimates made of remodeled arcades from a previous experiment (Gruionu, Hoying et al. 2005).

The morphological analysis presented below is based upon the elemental network, and the hemodynamic is based upon the segmental. Viscosity was assumed to be constant at $3 \mathrm{cP}$ in all cases.

\section{Preliminary results}

Preliminary morphological and hemodynamic assessments were performed by comparing the connectivity matrices and flow rates between the networks. The first matrix, representing the branching ratios, shows an overall increase in branching ratio for order 5 and an overall decrease in order 4 (Figure 57). This makes sense because when the diameters in the arcade were increased by $25 \%$, any order 4 vessels that were a part of the arcades fell within order 5 bounds.

It is important to note that the upper and lower diameter bounds for each order were fixed in the remodeled muscle; re-ordering was prevented so that each order had the same meaning in both muscles. 
Discussion

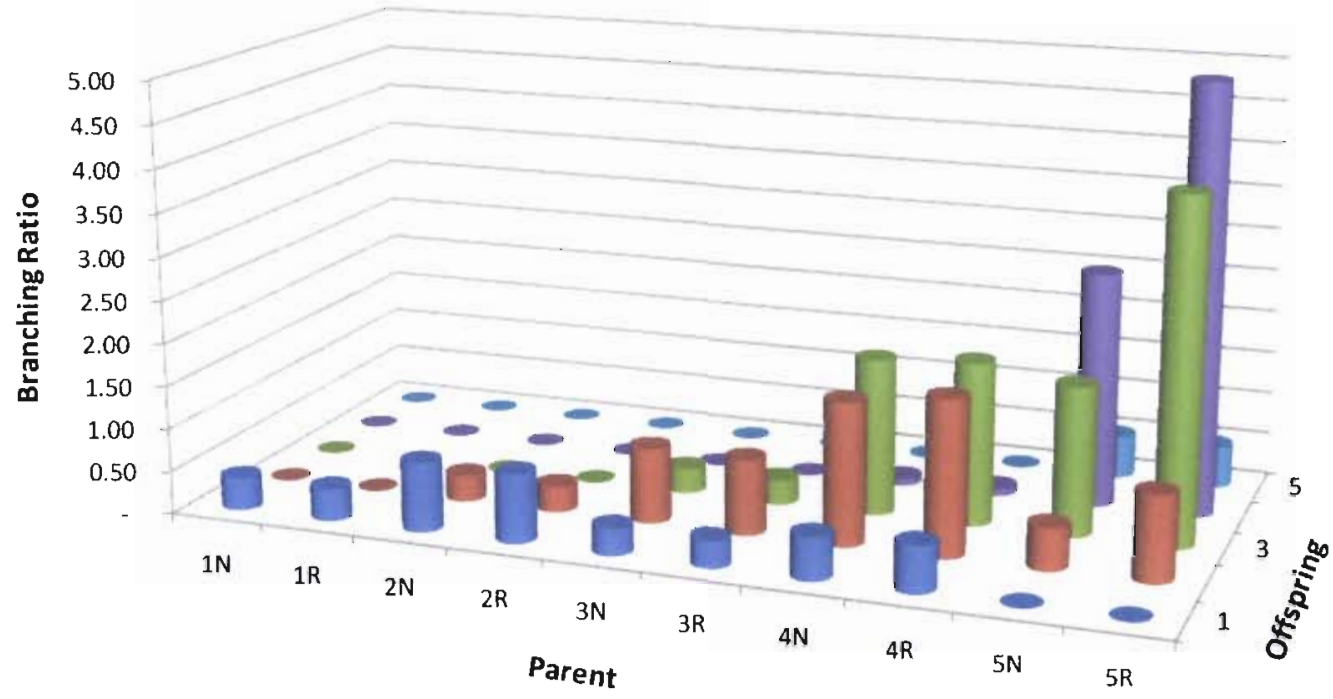

Figure 57. Hypothetical comparison of branching ratios.

The values represent the average number of vessels of order $m$ that branch from a single vessel of order n. "N" stands for normal and "R" stands for remodeled.

The second type of matrix did not show a significant change between healthy and remodeled networks (Figure 58) indicating that relatively the same percentage of vessels of order $m$ branch from vessels of order $n$. This was surprising since it was expected that the increase in diameter of the arcade vessels would cause a greater shift in the distribution of where vessels of order $\mathrm{m}$ branch from. 


\section{Discussion}

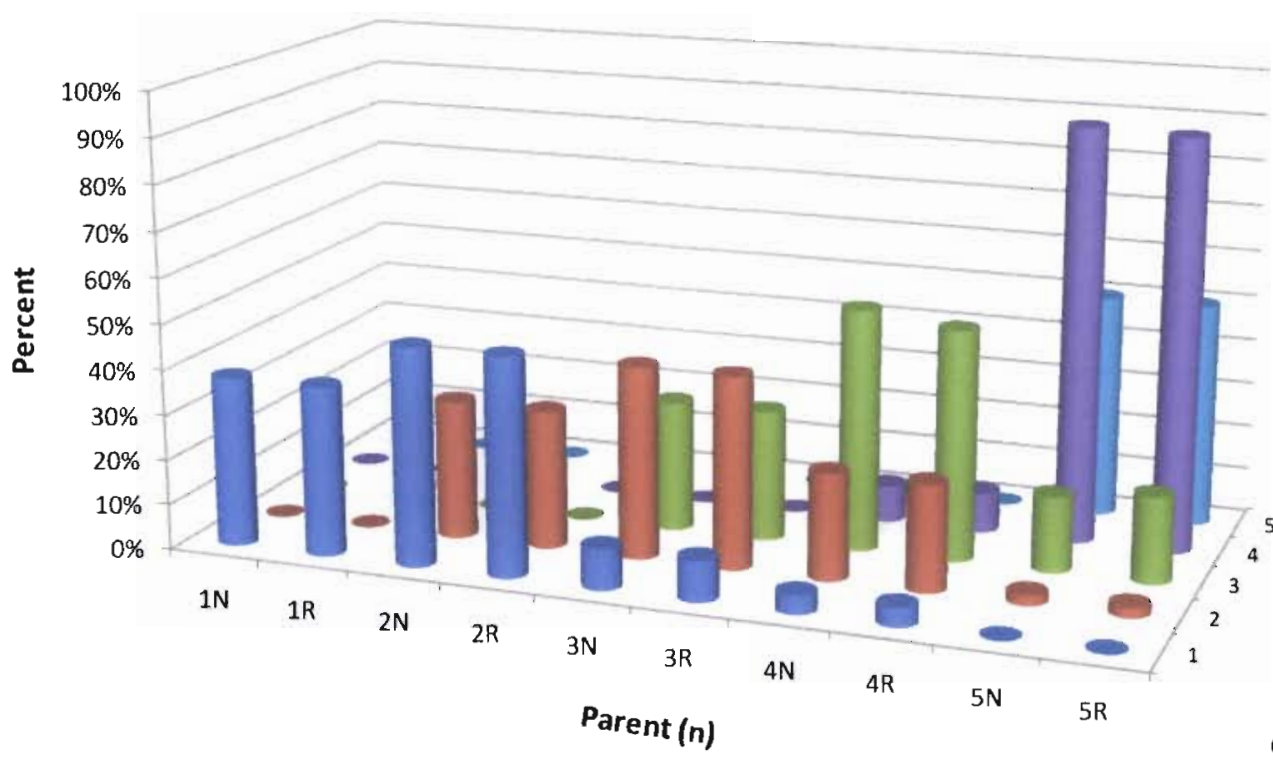

Figure 58. Hypothetical comparison of percent of offspring.

The values represent the percent of all vessels of order $m$ that branch from a vessel of order $n$. "N" stands for normal and "R" stands for remodeled.

Next, the average flow rate through the remodeled network was analyzed and compared to the healthy muscle (Figure 59, Figure 60). The blood flow through the smaller vessels is not significantly affected by the change in downstream pressure of the saphenous branch. The large differences in average flow rate in order 5 vessels can be better understood by looking at the scatter plot (Figure 60). Each scenario has some vessels with high flow rates of around $0.5 \mu \mathrm{l} / \mathrm{min}$, higher than published values (Figure 50). This means that blood is entering the muscle at a higher rate than in the healthy limb. As the saphenous outlet pressure is increased, flow rates started to slow and some reversed direction back into the muscle from the saphenous branch. 


\section{Discussion}

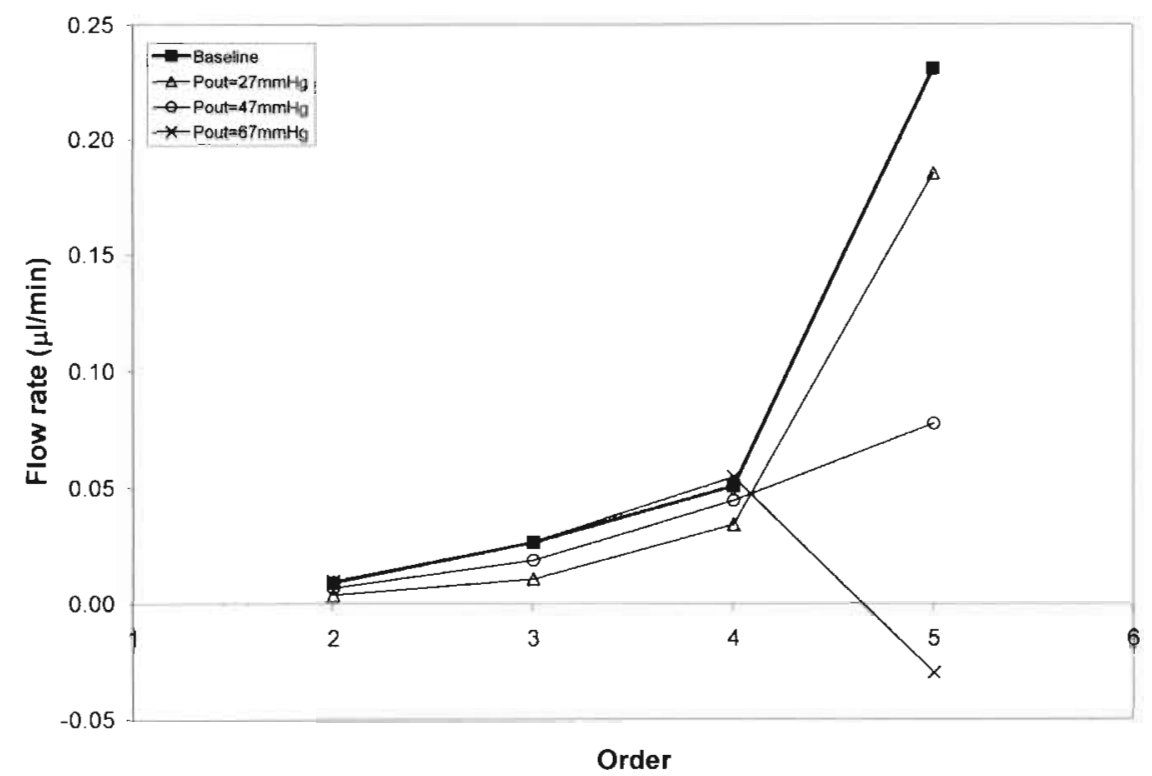

Figure 59. Flow rate comparison between baseline and hypothetical networks.

Shows average blood flow rate through individual vessels of each order in the baseline and hypothetical

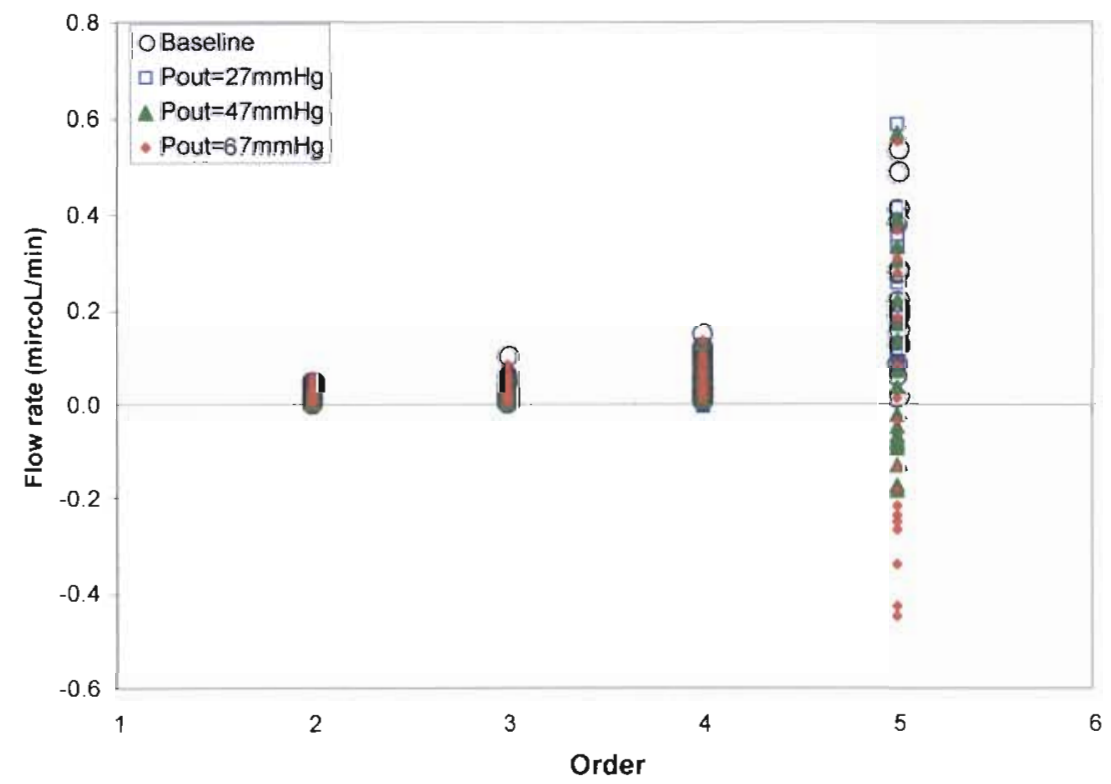

Figure 60. Scatter plot of individual vessel flow rates in a hypothetical network. 


\section{Discussion}

The outlet pressure at the saphenous branch was arbitrary, and set over a range of values to help show the impact of various pressure conditions. In future studies, realistic values for pressure at this location should be used since its effect on the flow profiles is significant (Figure 59, Figure 60). The results presented in this hypothetical case of vascular remodeling are purely speculative and are meant to illustrate the potential of these methods when applied to the study of vascular remodeling.

\section{Conclusion}

In summary, the use of two-dimensional images is sufficient, but should be supplemented with capillary density measurements for vessels of $8 \mu \mathrm{m}$ and smaller. The ink casting methods should be perfected as they provide the basis for later assessments. The dimensional and branching characteristics of the network are similar to previous experiments; however, the ability to reference microscope slides containing the muscle to cross-reference the degree of three-dimensional branching will improve results. The hemodynamic analysis yielded pressure profiles and individual vessel flow rates consistent with published literature values. The elemental network provides a more realistic representation of network morphology, whereas the segmental network should be used for hemodynamic calculations. Overall, the analysis methods presented in this paper provide a solid foundational tool that has the potential to illuminate patterns on a network (or systems) level that could not otherwise be seen. These patterns can then help to target therapies to restore full blood flow to patients with PAD. 


\section{Bibliography}

1. Bailey, A., B. Thorne, et al. (2007). "Multi-cell Agent-based Simulation of the Microvasculature to Study the Dynamics of Circulating Inflammatory Cell Trafficking." Annals of Biomedical Engineering 35(6): 916-936.

2. Buschmann, I. and W. Schaper (1999). "Arteriogenesis Versus Angiogenesis: Two Mechanisms of Vessel Growth." News Physiol Sci 14: 121-125.

3. Cardinal, T. R. and J. B. Hoying (2007). "A modified fluorescent microspherebased approach for determining resting and hyperemic blood flows in individual murine skeletal muscles." Vascul Pharmacol 47(1): 48-56.

4. Dimitropoulou, C., M. E. Maragoudakis, et al. (2000). "Effects of thrombin and of the phospholipase C inhibitor, D609, on the vascularity of the chick chorioallantoic membrane." Gen Pharmacol 35(5): 241-7.

5. Felmeden, D. C., A. D. Blann, et al. (2003). "Angiogenesis: basic pathophysiology and implications for disease." Eur Heart J 24(7): 586-603.

6. Fenton, B. and B. Zweifach (1981). "Microcirculatory model relating geometrical variation to changes in pressure and flow rate." Annals of Biomedical Engineering 9(4): 303-321.

7. Fournier, R. L. (2007). Basic Transport Phenomena in Biomedical Engineering. New York, Taylor and Francis Group, LLC.

8. Garcia, L. A. (2006). "Epidemiology and pathophysiology of lower extremity peripheral arterial disease." J Endovasc Ther 13 Suppl 2: II3-9. 
9. Gruionu, G., J. B. Hoying, et al. (2005). "Structural remodeling of mouse gracilis artery after chronic alteration in blood supply." Am J Physiol Heart Circ Physiol 288(5): H2047-54.

10. Guyton, A. C. and J. E. Hall (2006). Textbook of Medical Physiology. Philadelphia, Elsevier Saunders.

11. Heil, M. and W. Schaper (2004). "Influence of mechanical, cellular, and molecular factors on collateral artery growth (arteriogenesis)." Circ Res 95(5): 449-58.

12. Helisch, A., S. Wagner, et al. (2006). "Impact of mouse strain differences in innate hindlimb collateral vasculature." Arterioscler Thromb Vasc Biol 26(3): $520-6$.

13. Hershey, J. C., E. P. Baskin, et al. (2001). "Revascularization in the rabbit hindlimb: dissociation between capillary sprouting and arteriogenesis." Cardiovasc Res 49(3): 618-25.

14. Hudlicka, O., M. D. Brown, et al. (1994). "Effect of long-term electrical stimulation on vascular supply and fatigue in chronically ischemic muscles." $\mathrm{J}$ Appl Physiol 77(3): 1317-24.

15. Jiang, Z. L., G. S. Kassab, et al. (1994). "Diameter-defined Strahler system and connectivity matrix of the pulmonary arterial tree." J Appl Physiol 76(2): 882-92.

16. Kalsho, G. and G. S. Kassab (2004). "Bifurcation asymmetry of the porcine coronary vasculature and its implications on coronary flow heterogeneity." Am I Physiol Heart Circ Physiol 287(6): H2493-500. 
17. Kassab, G. S. (2000). "The coronary vasculature and its reconstruction." Ann Biomed Eng 28(8): 903-15.

18. Kassab, G. S., J. Berkley, et al. (1997). "Analysis of pig's coronary arterial blood flow with detailed anatomical data." Ann Biomed Eng 25(1): 204-17.

19. Kassab, G. S., E. Pallencaoe, et al. (1997). "Longitudinal position matrix of the pig coronary vasculature and its hemodynamic implications." Am J Physiol 273(6 Pt 2): H2832-42.

20. Kassab, G. S., C. A. Rider, et al. (1993). "Morphometry of pig coronary arterial trees." Am J Physiol 265(1 Pt 2): H350-65.

21. Kaul, S. and A. R. Jayaweera (2006). "Determinants of microvascular flow." Eur Heart J 27(19): 2272-4.

22. Kelsall, C. J., M. D. Brown, et al. (2001). "Alterations in reactivity of small arterioles in rat skeletal muscle as a result of chronic ischaemia." $\underline{\mathrm{J} \text { Vasc Res }}$ 38(3): 212-8.

23. Kelsall, C. J., M. D. Brown, et al. (2004). "Arteriolar endothelial dysfunction is restored in ischaemic muscles by chronic electrical stimulation." J Vasc Res 41(3): 241-51.

24. Kitano, H. (2002). "Computational systems biology." Nature 420(6912): 206-10.

25. Levy, B. I., G. Ambrosio, et al. (2001). "Microcirculation in hypertension: a new target for treatment?" Circulation 104(6): 735-40.

26. Lipowsky, H. H. and B. W. Zweifach (1974). "Network analysis of microcirculation of cat mesentery." Microvasc Res 7(1): 73-83. 
27. Mac Gabhann, F., J. W. Ji, et al. (2007). "Multi-scale computational models of pro-angiogenic treatments in peripheral arterial disease." Ann Biomed Eng 35(6): 982-94.

28. Manno, P., P. Moulin, et al. (1998). "Mass transfer improvement in helically wound hollow fibre ultrafiltration modules: Yeast suspensions." Separation and Purification Technology 14(1-3): 175-182.

29. McDonald, D. M. and P. L. Choyke (2003). "Imaging of angiogenesis: from microscope to clinic." Nat Med 9(6): 713-25.

30. Mees, B., S. Wagner, et al. (2007). "Endothelial nitric oxide synthase activity is essential for vasodilation during blood flow recovery but not for arteriogenesis." Arterioscler Thromb Vasc Biol 27(9): 1926-33.

31. Peirce, S. M., E. J. Van Gieson, et al. (2004). "Multicellular simulation predicts microvascular patterning and in silico tissue assembly." FASEB J 18(6): 731-3.

32. Penuelas, I., X. L. Aranguren, et al. (2007). "(13)N-ammonia PET as a measurement of hindlimb perfusion in a mouse model of peripheral artery occlusive disease." J Nucl Med 48(7): 1216-23.

33. Pipp, F., S. Boehm, et al. (2004). "Elevated fluid shear stress enhances postocclusive collateral artery growth and gene expression in the pig hind limb." Arterioscler Thromb Vasc Biol 24(9): 1664-8.

34. Pries, A. R. and T. W. Secomb (2000). "Microcirculatory network structures and models." Ann Biomed Eng 28(8): 916-21.

35. Pries, A. R., T. W. Secomb, et al. (1995). "Design principles of vascular beds." Circ Res 77(5): 1017-23. 
36. Pries, A. R., T. W. Secomb, et al. (1999). "Structural autoregulation of terminal vascular beds: vascular adaptation and development of hypertension." Hypertension 33(1): 153-61.

37. Pries, A. R., T. W. Secomb, et al. (1990). "Blood flow in microvascular networks. Experiments and simulation." Circ Res 67(4): 826-34.

38. Pries, A. R., T. W. Secomb, et al. (1994). "Resistance to blood flow in microvessels in vivo." Circ Res 75(5): 904-15.

39. Prior, B. M., P. G. Lloyd, et al. (2004). "Time course of changes in collateral blood flow and isolated vessel size and gene expression after femoral artery occlusion in rats." Am J Physiol Heart Circ Physiol 287(6): H2434-47.

40. Quarteroni, A., M. Tuveri, et al. (2000). "Computational vascular fluid dynamics: problems, models and methods." Computing and Visualization in Science 2(4): 163-197.

41. Scholz, D., T. Ziegelhoeffer, et al. (2002). "Contribution of arteriogenesis and angiogenesis to postocclusive hindlimb perfusion in mice." $\underline{\mathrm{J} \text { Mol Cell Cardiol }}$ 34(7): 775-87.

42. Takeshita, S., T. Isshiki, et al. (1998). "Endothelium-dependent relaxation of collateral microvessels after intramuscular gene transfer of vascular endothelial growth factor in a rat model of hindlimb ischemia." Circulation 98(13): 1261-3.

43. Tsitlik, J. E., H. R. Halperin, et al. (1992). "Modeling the circulation with threeterminal electrical networks containing special nonlinear capacitors." $\underline{\text { Ann }}$ Biomed Eng 20(6): 595-616. 
44. van der Greef, J., P. Stroobant, et al. (2004). "The role of analytical sciences in medical systems biology." Curr Opin Chem Biol 8(5): 559-65.

45. VanBavel, E. and J. A. Spaan (1992). "Branching patterns in the porcine coronary arterial tree. Estimation of flow heterogeneity." Circ Res 71(5): 1200-12.

46. Wahlberg, E. (2003). "Angiogenesis and arteriogenesis in limb ischemia." J Vasc Surg 38(1): 198-203.

47. Zweifach, B. W., S. Kovalcheck, et al. (1981). "Micropressure-flow relationships in a skeletal muscle of spontaneously hypertensive rats." Hypertension 3(5): 60114. 
Appendix

A: Digital Micrographs with labeled vessels 


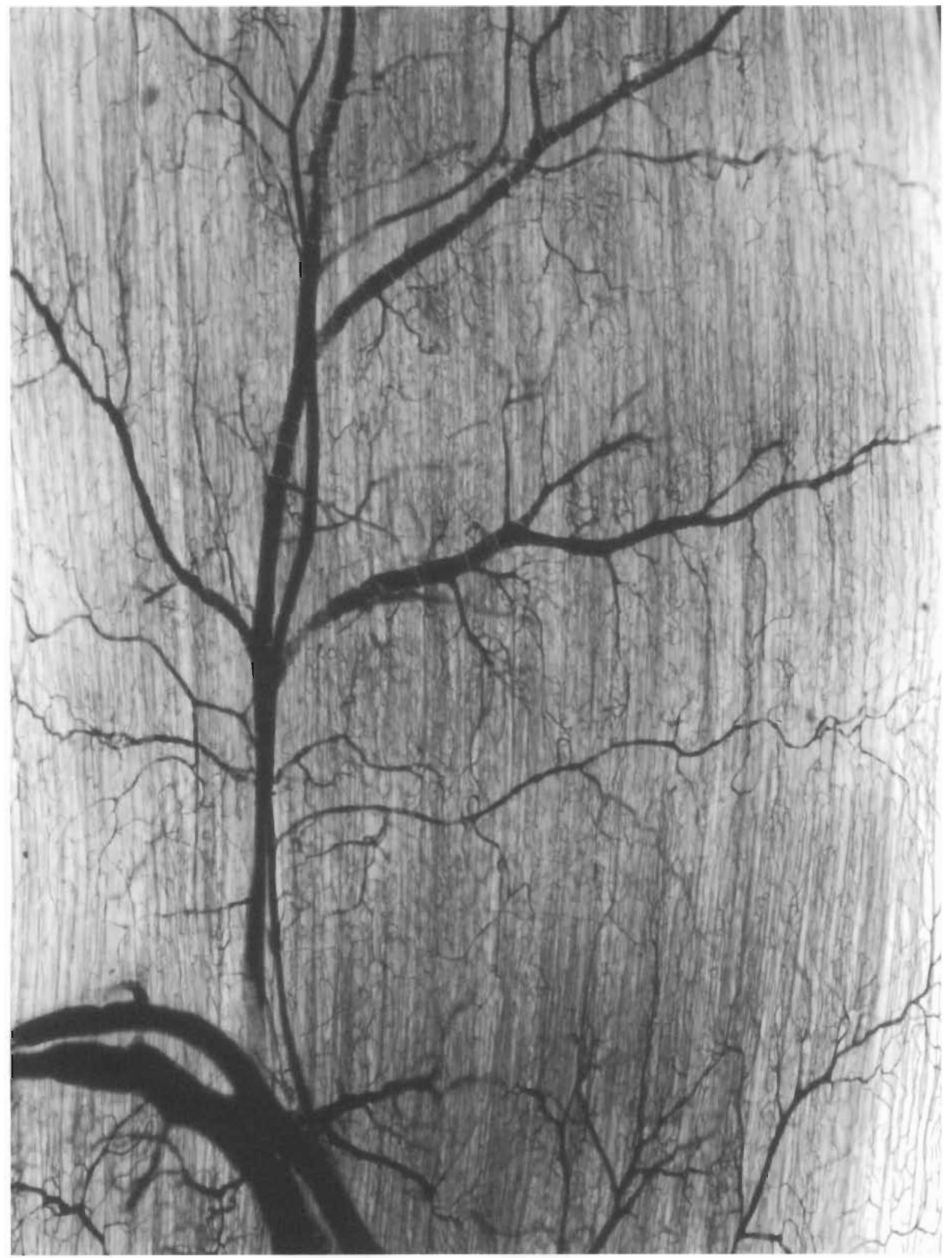




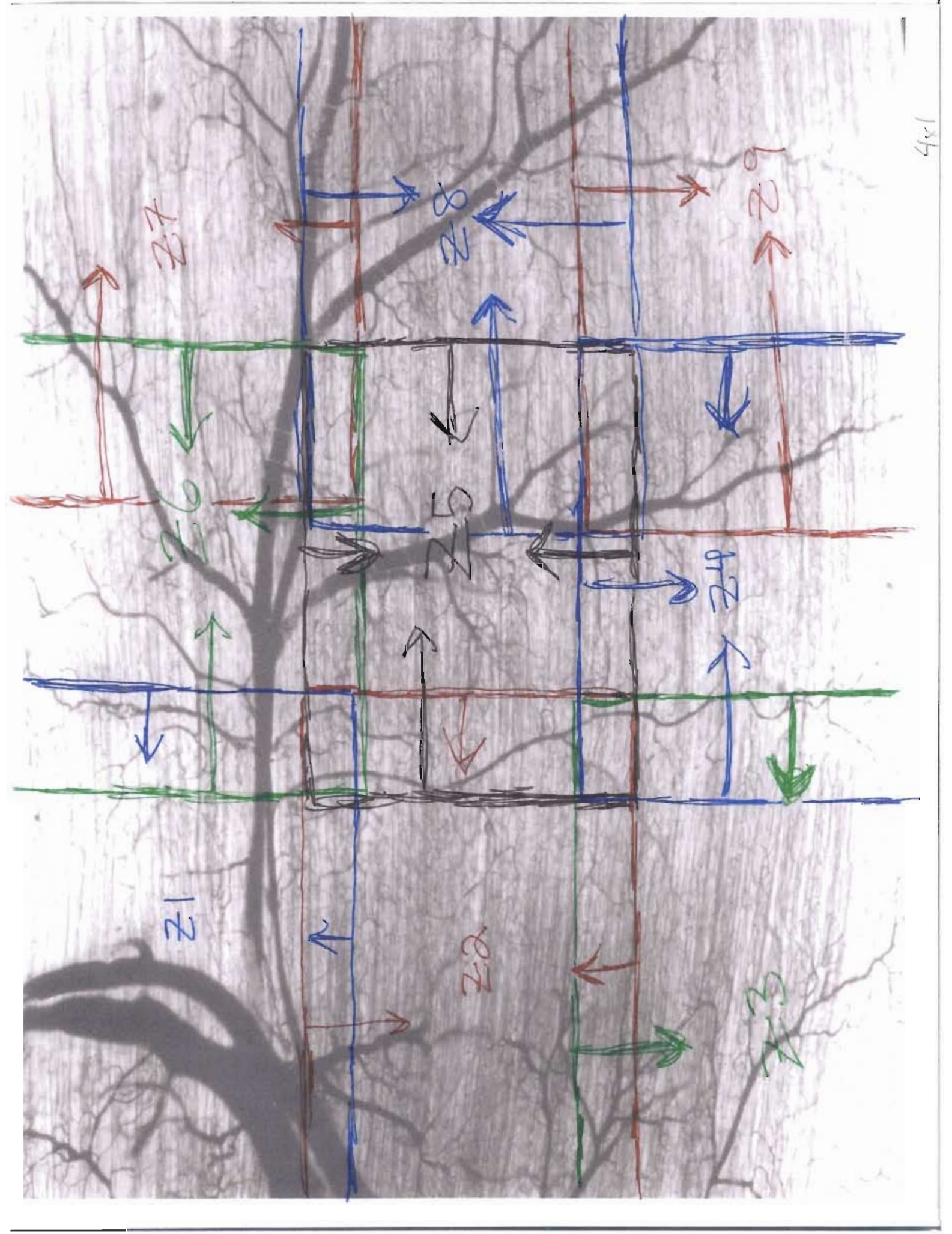



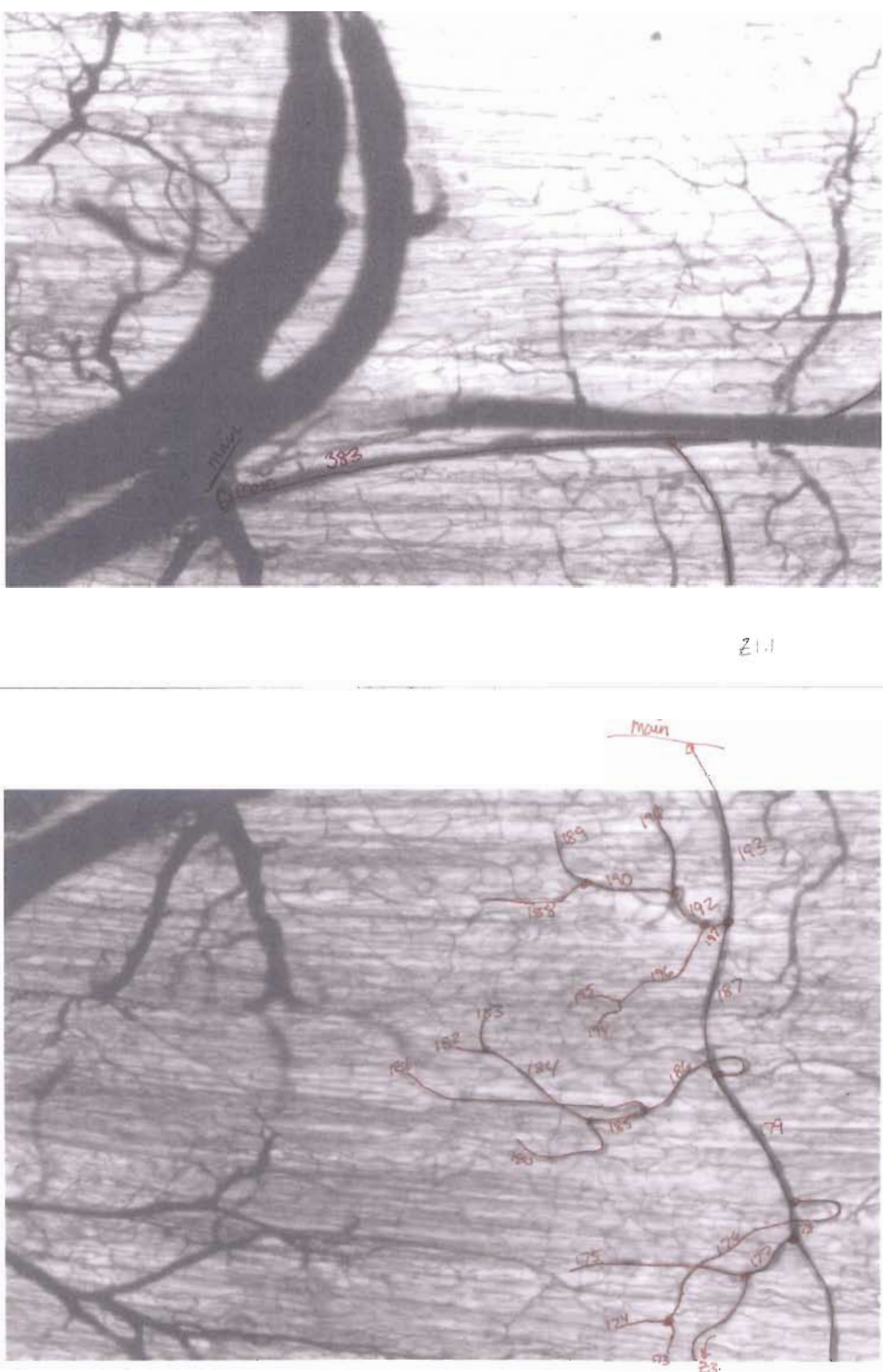

212 

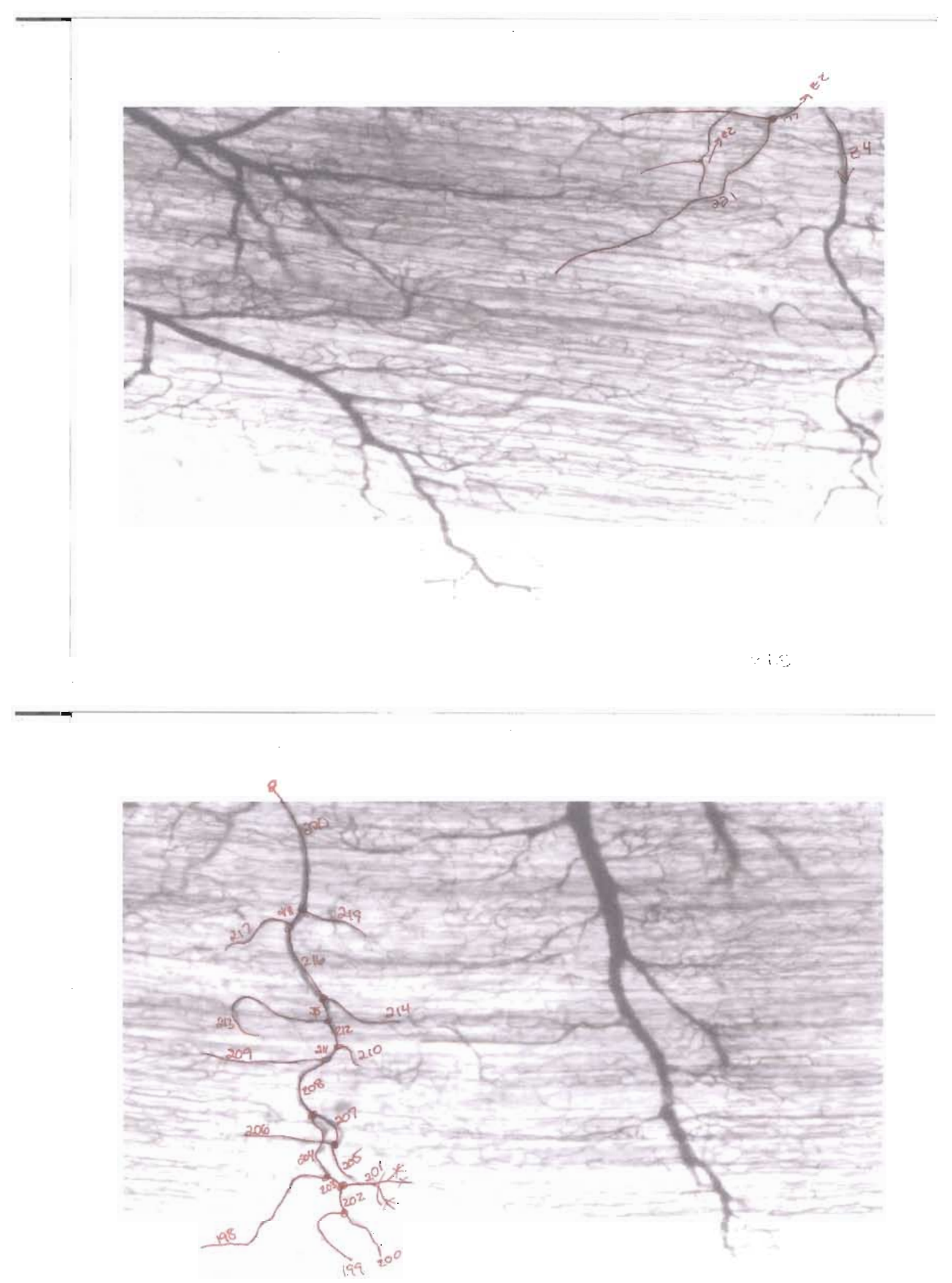


\section{$1452^{6}$}

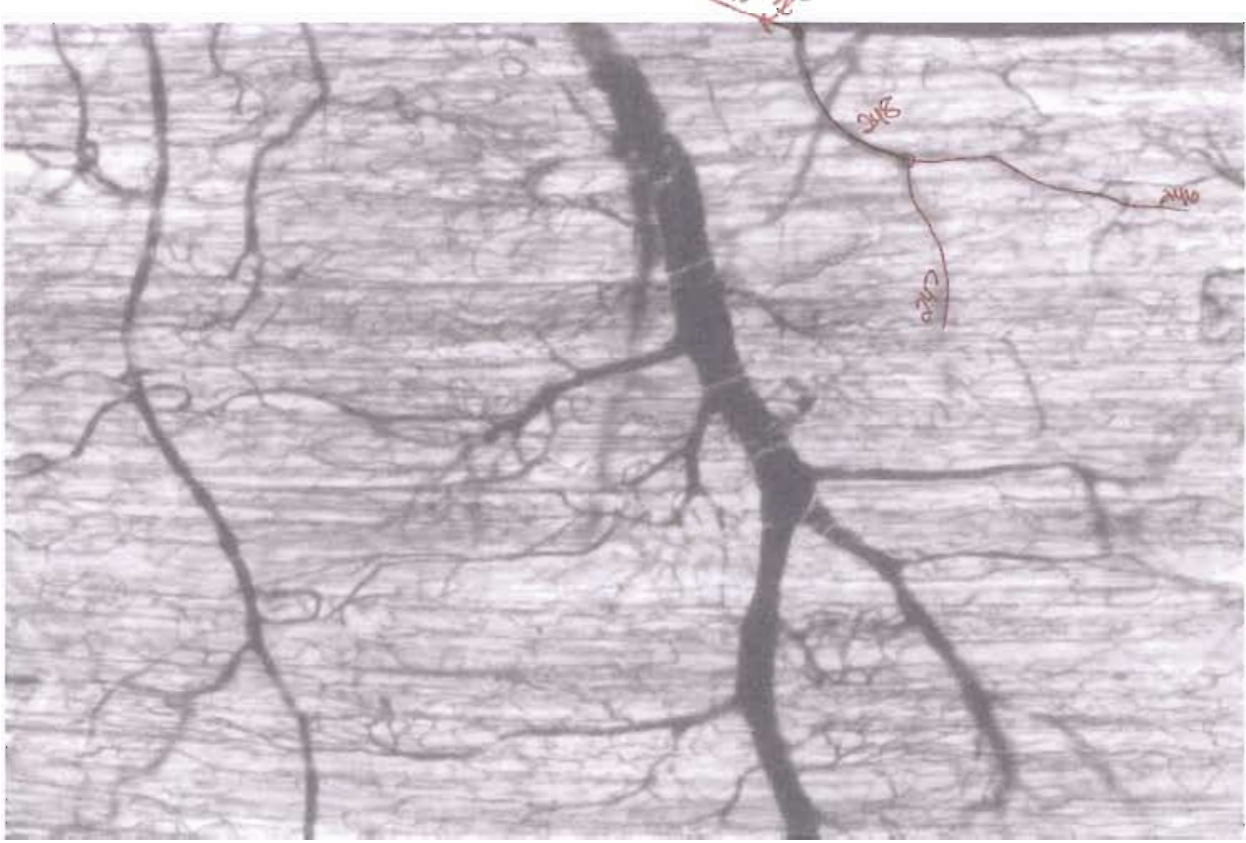

$z 1.5$

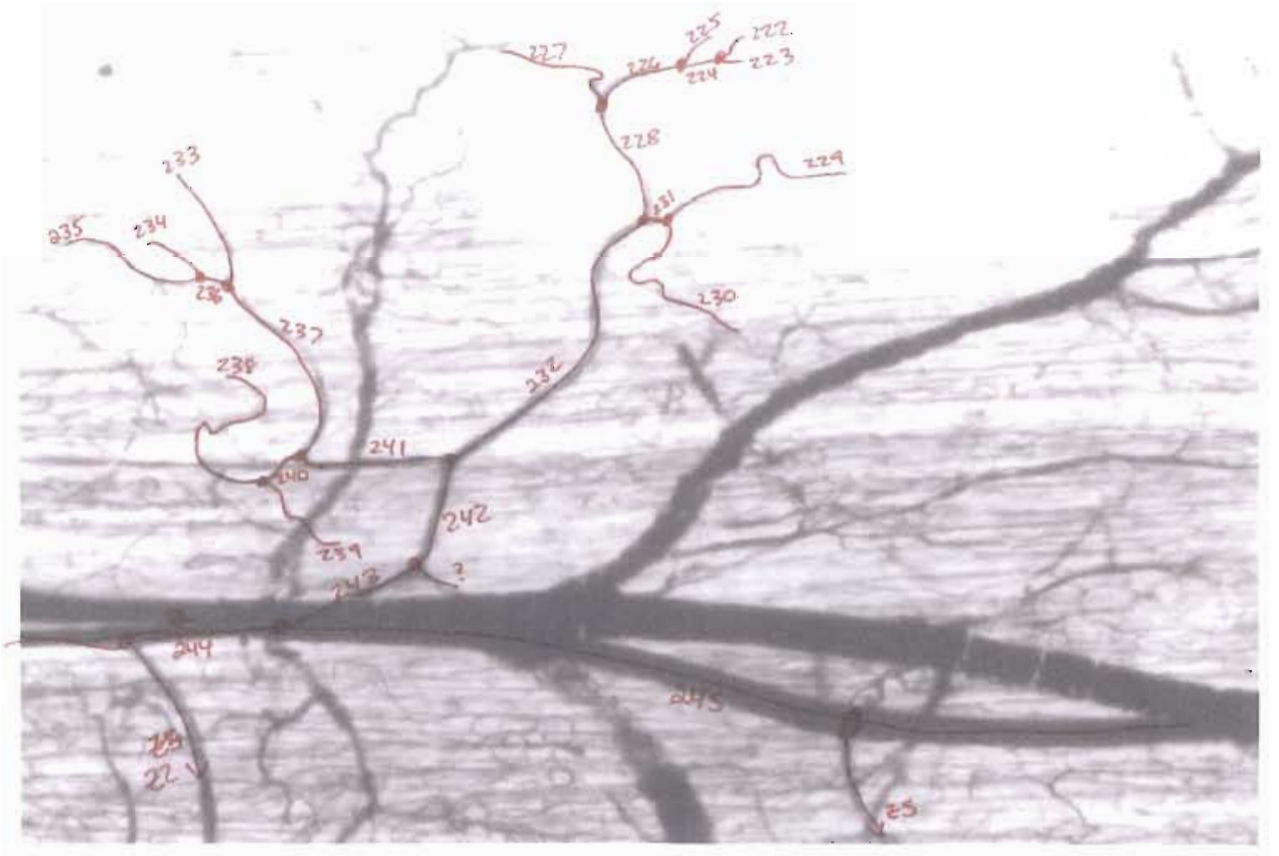




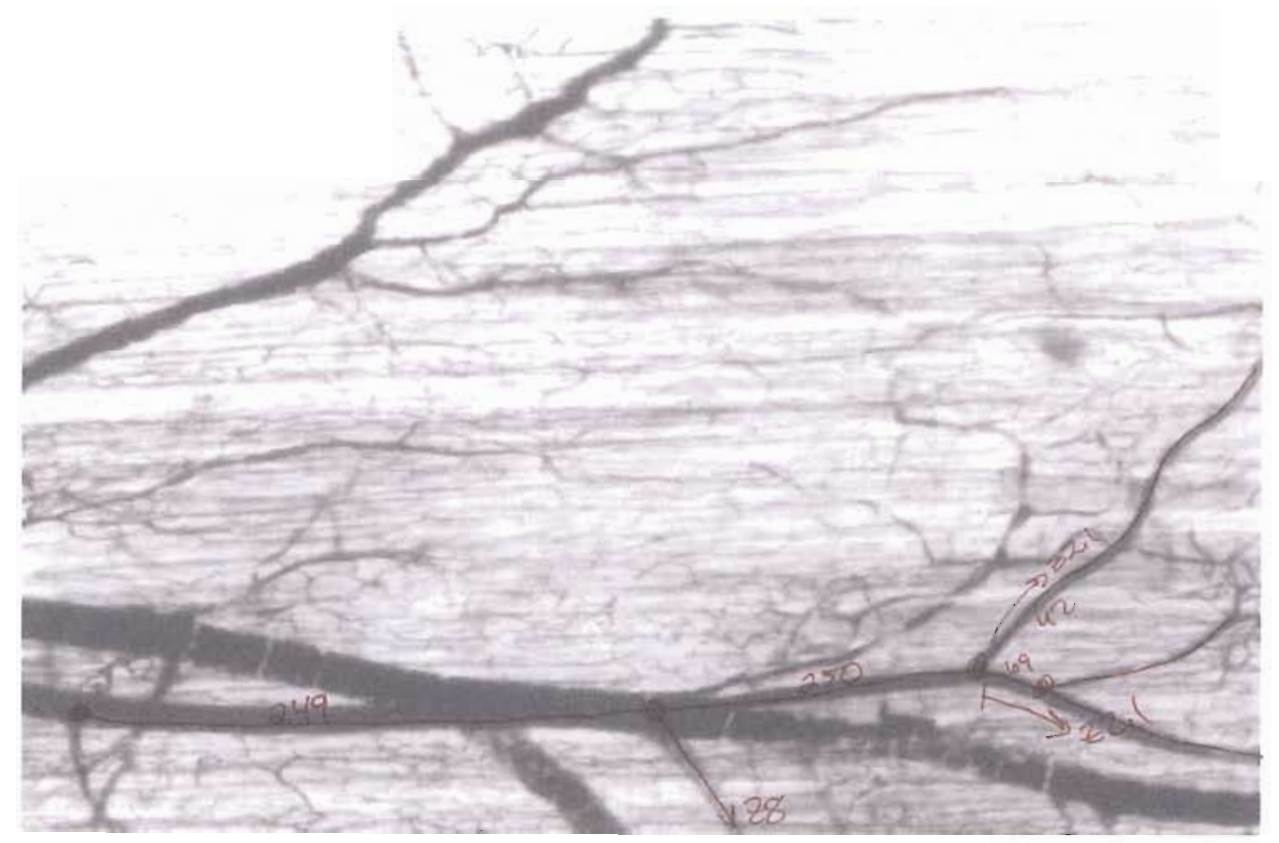

21.7

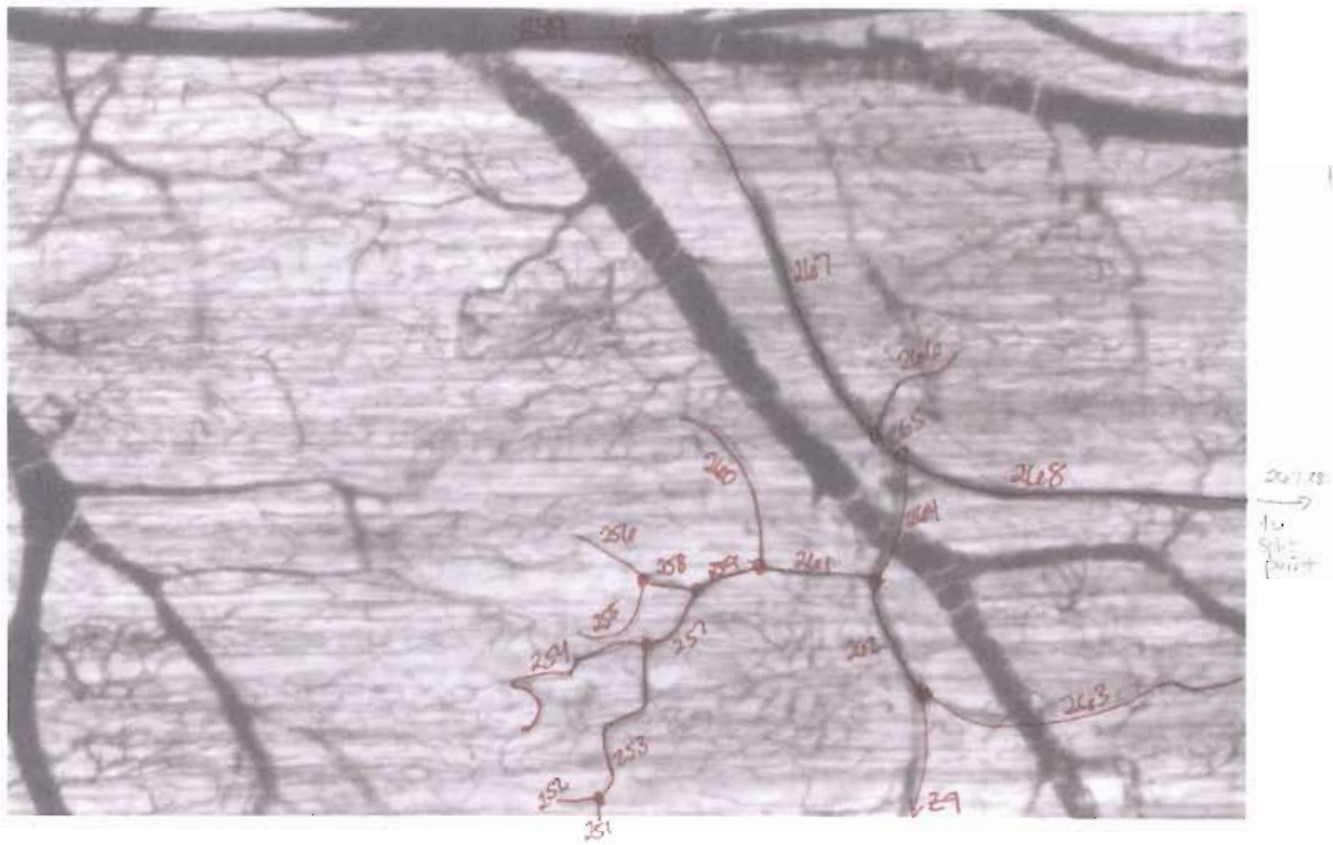

21.8 


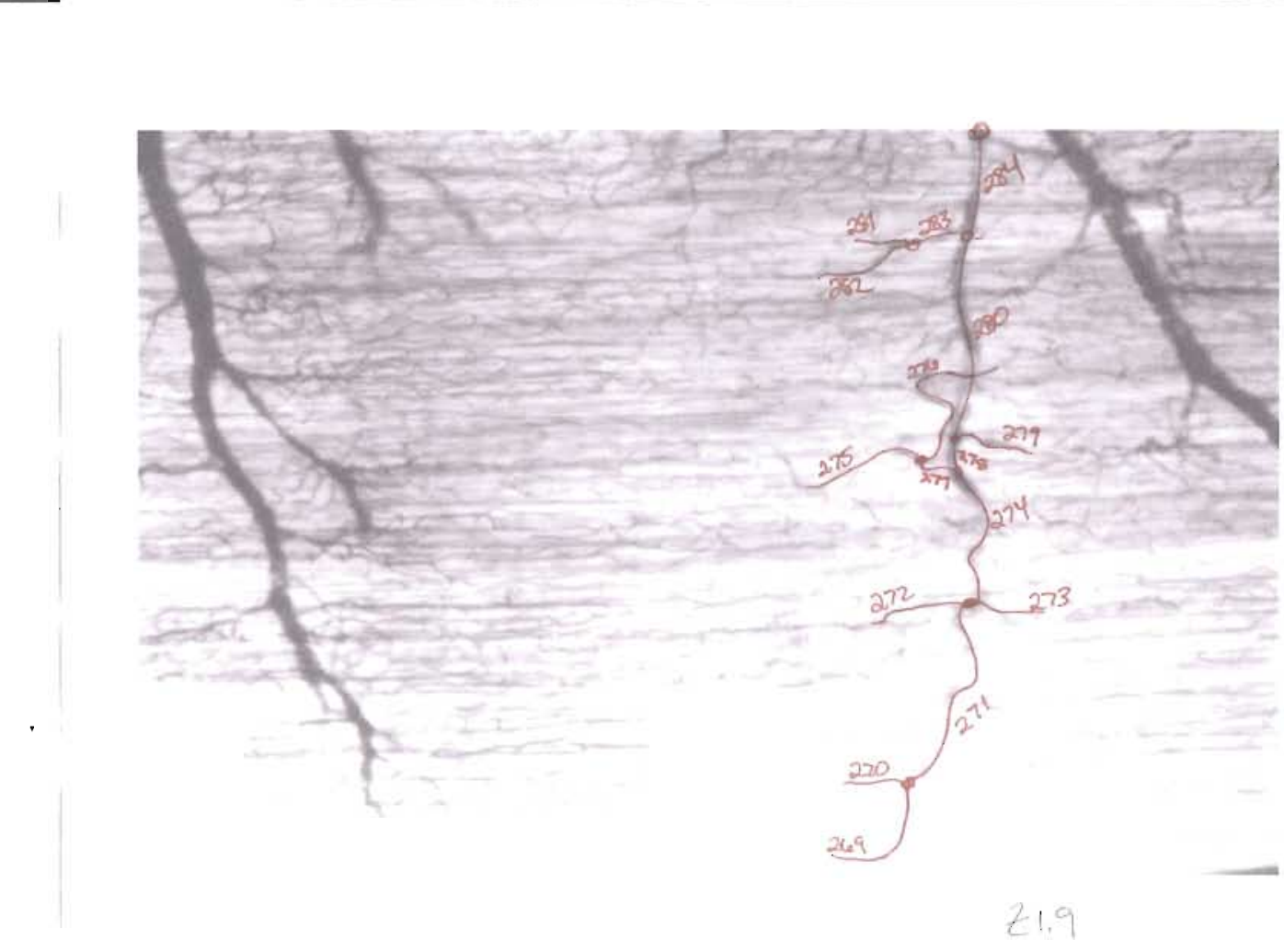




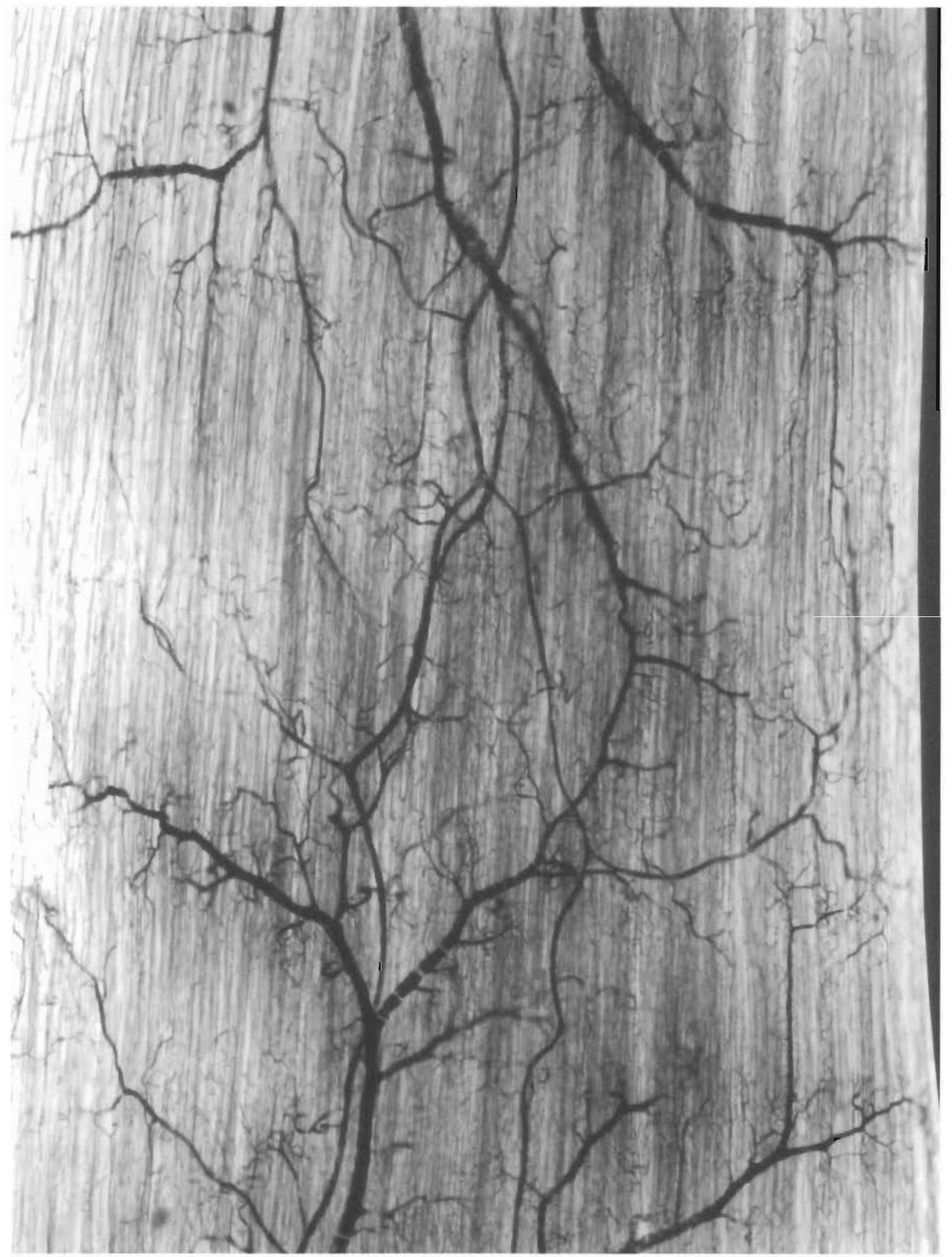




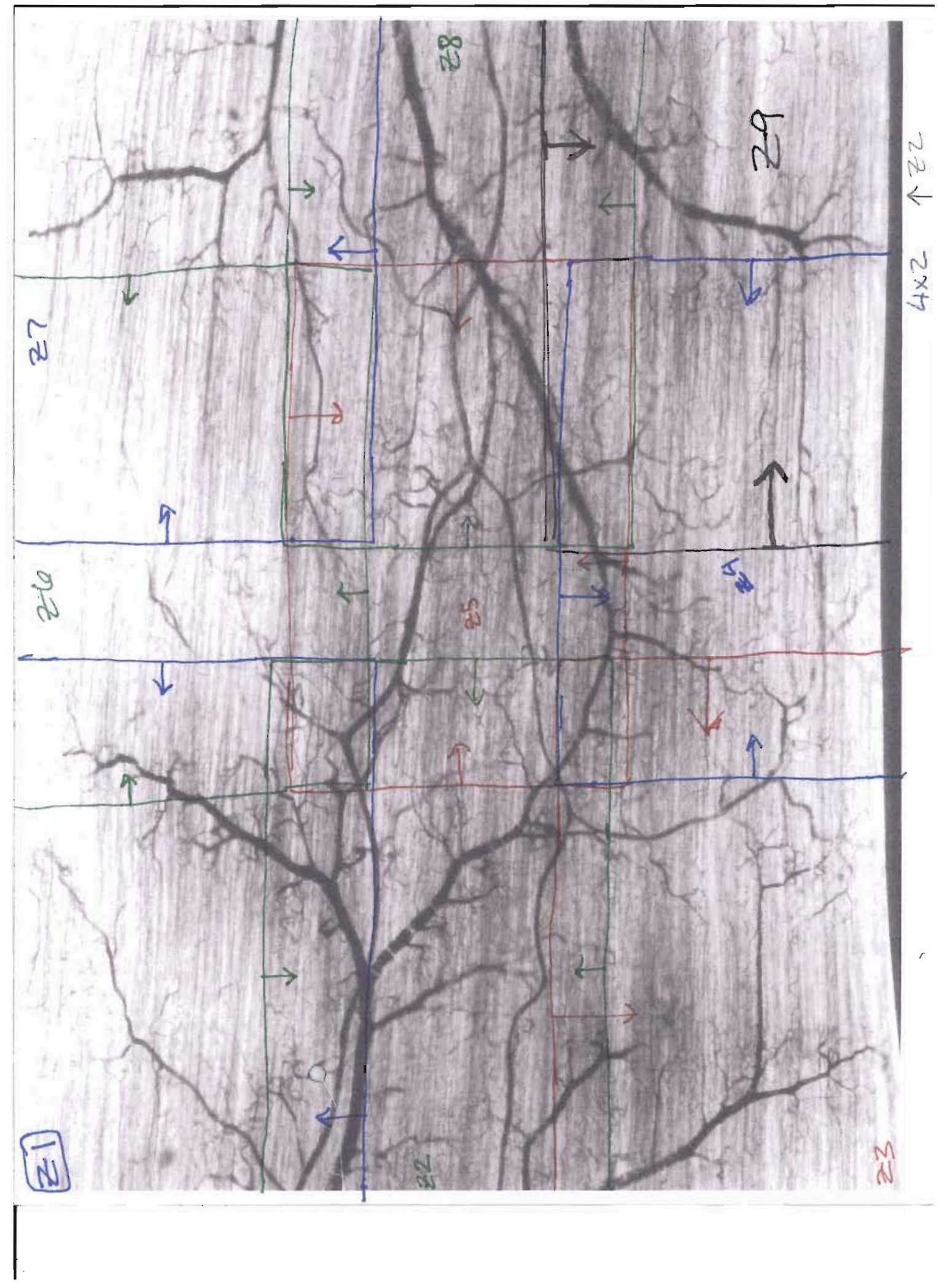



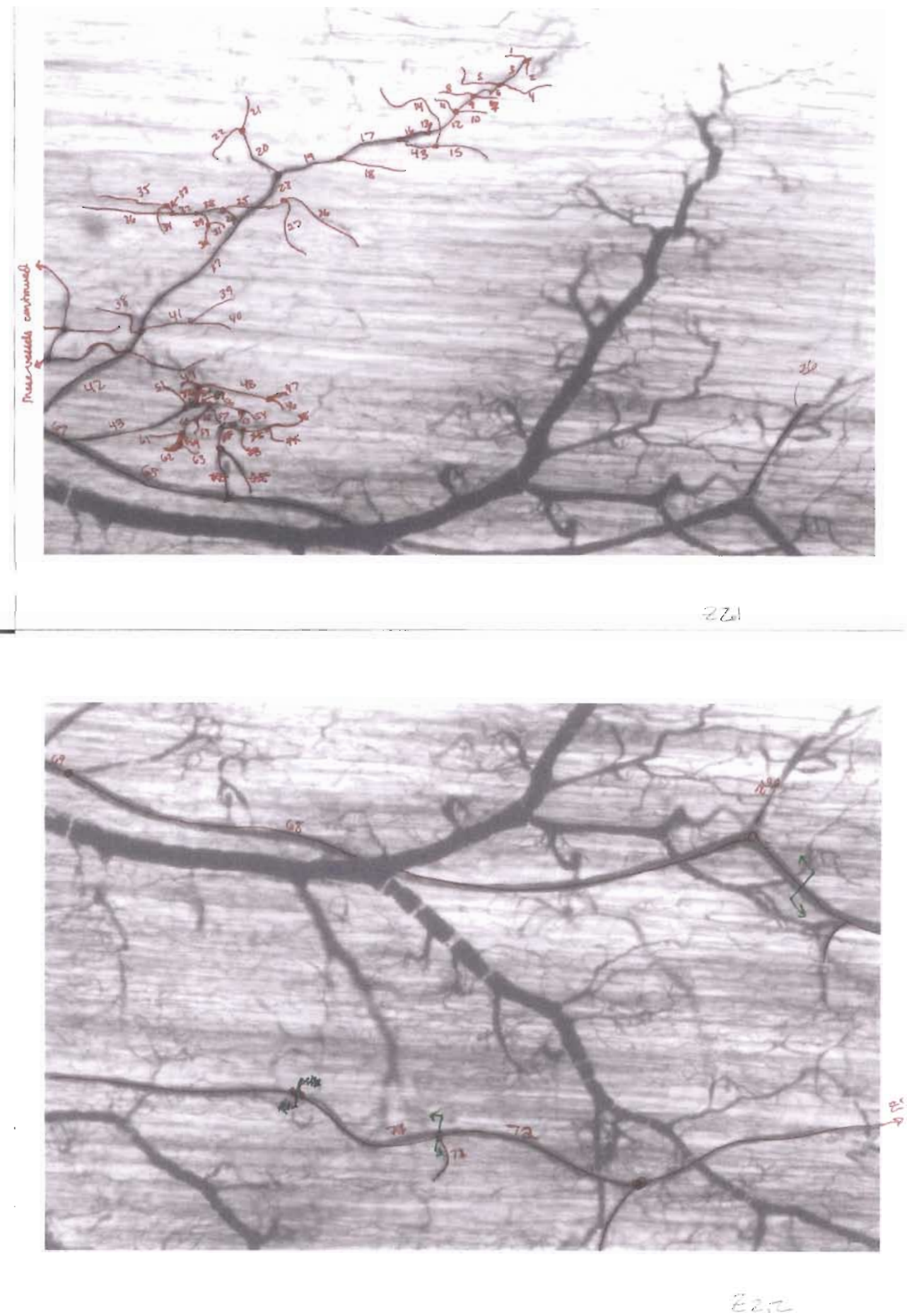


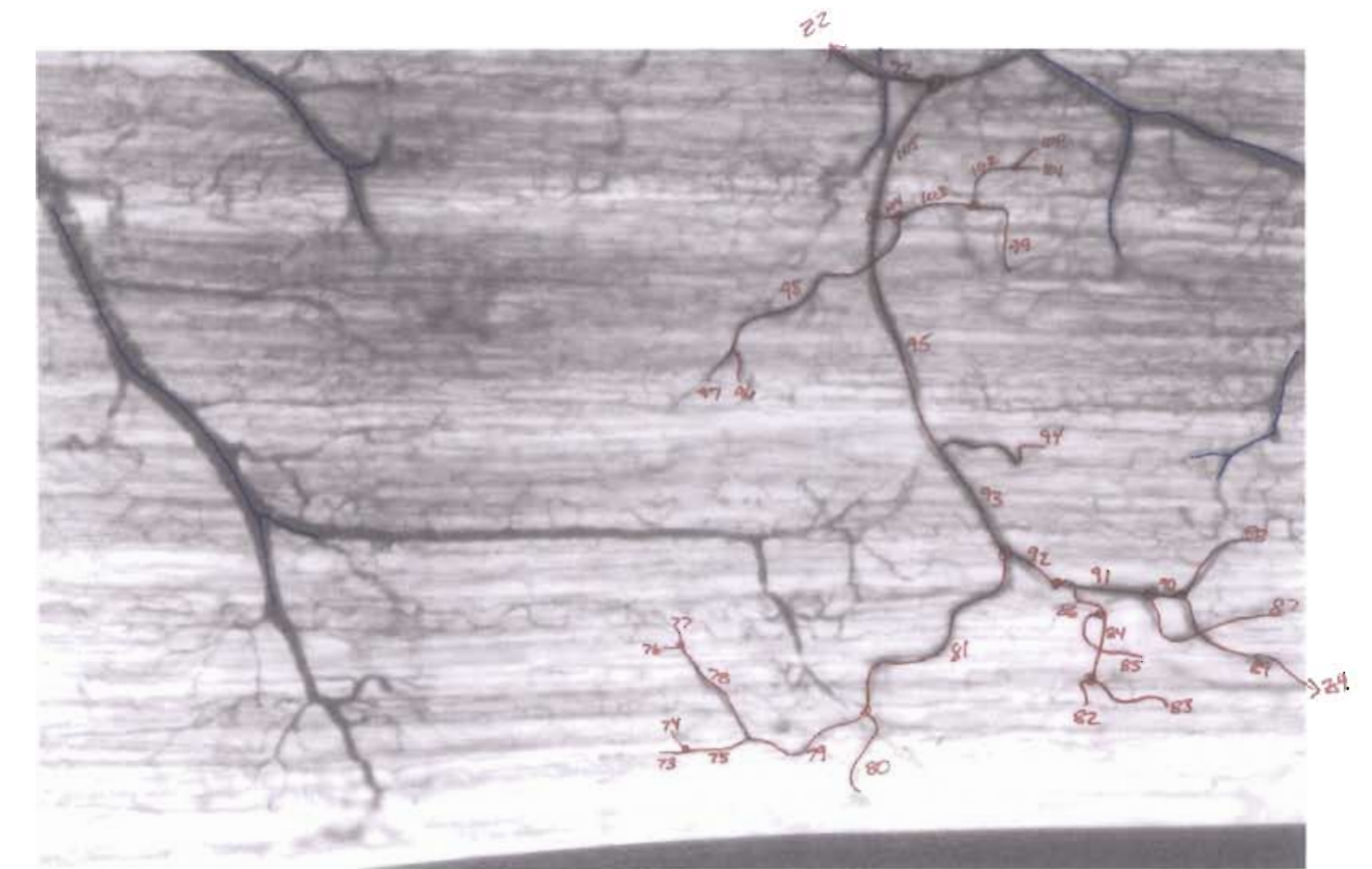

Zo.

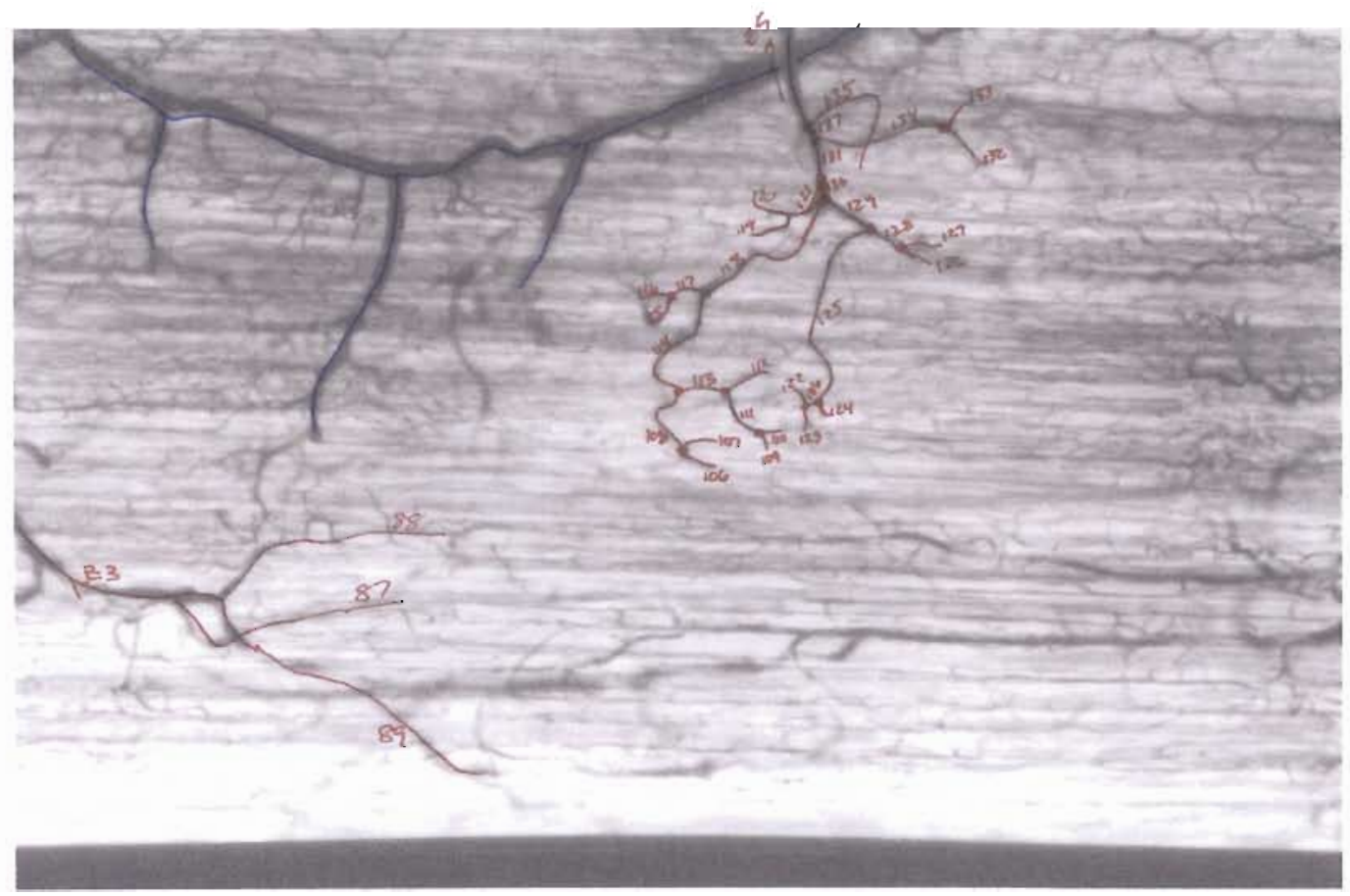

$$
z=2.4
$$




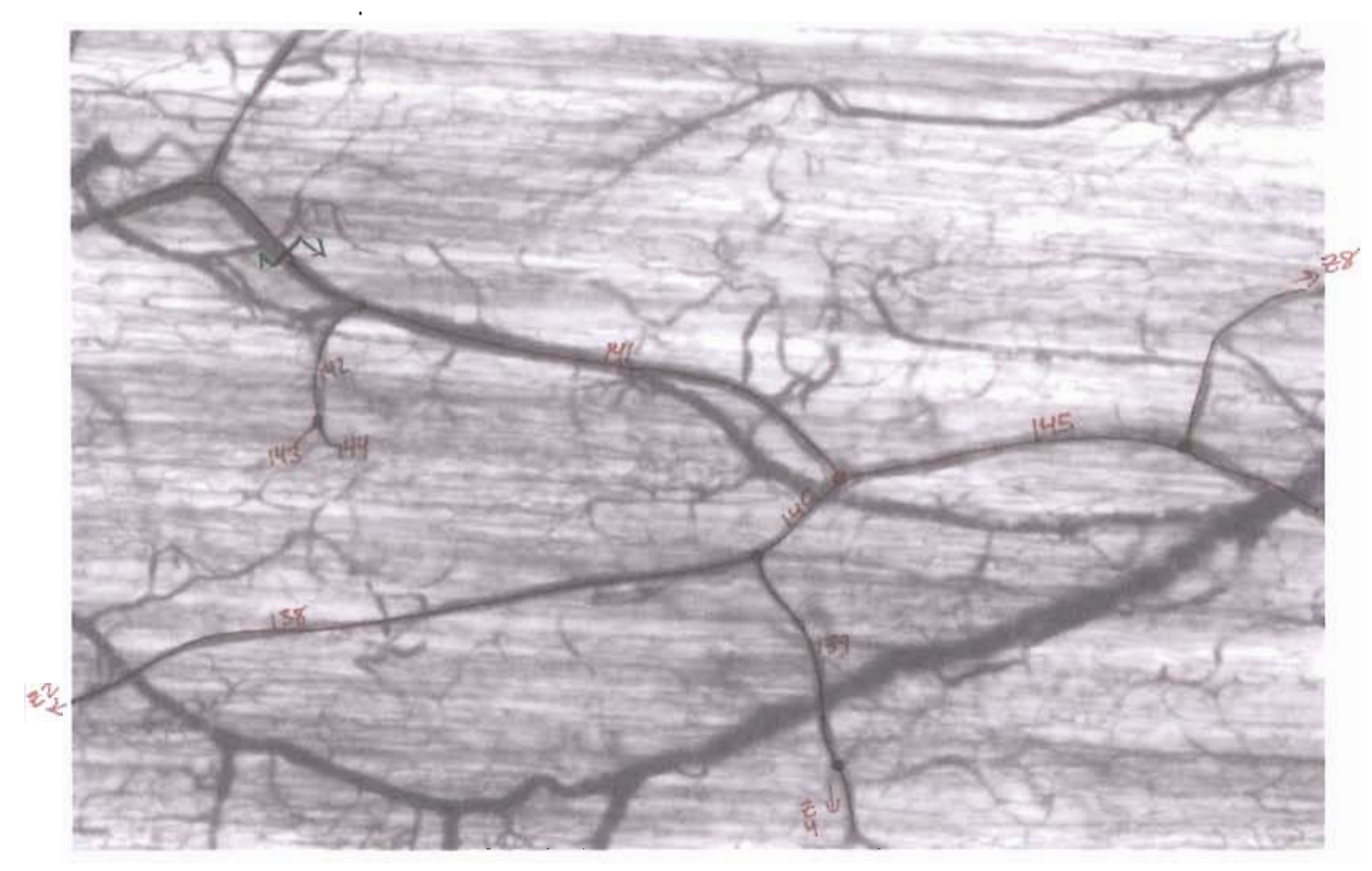

2.5

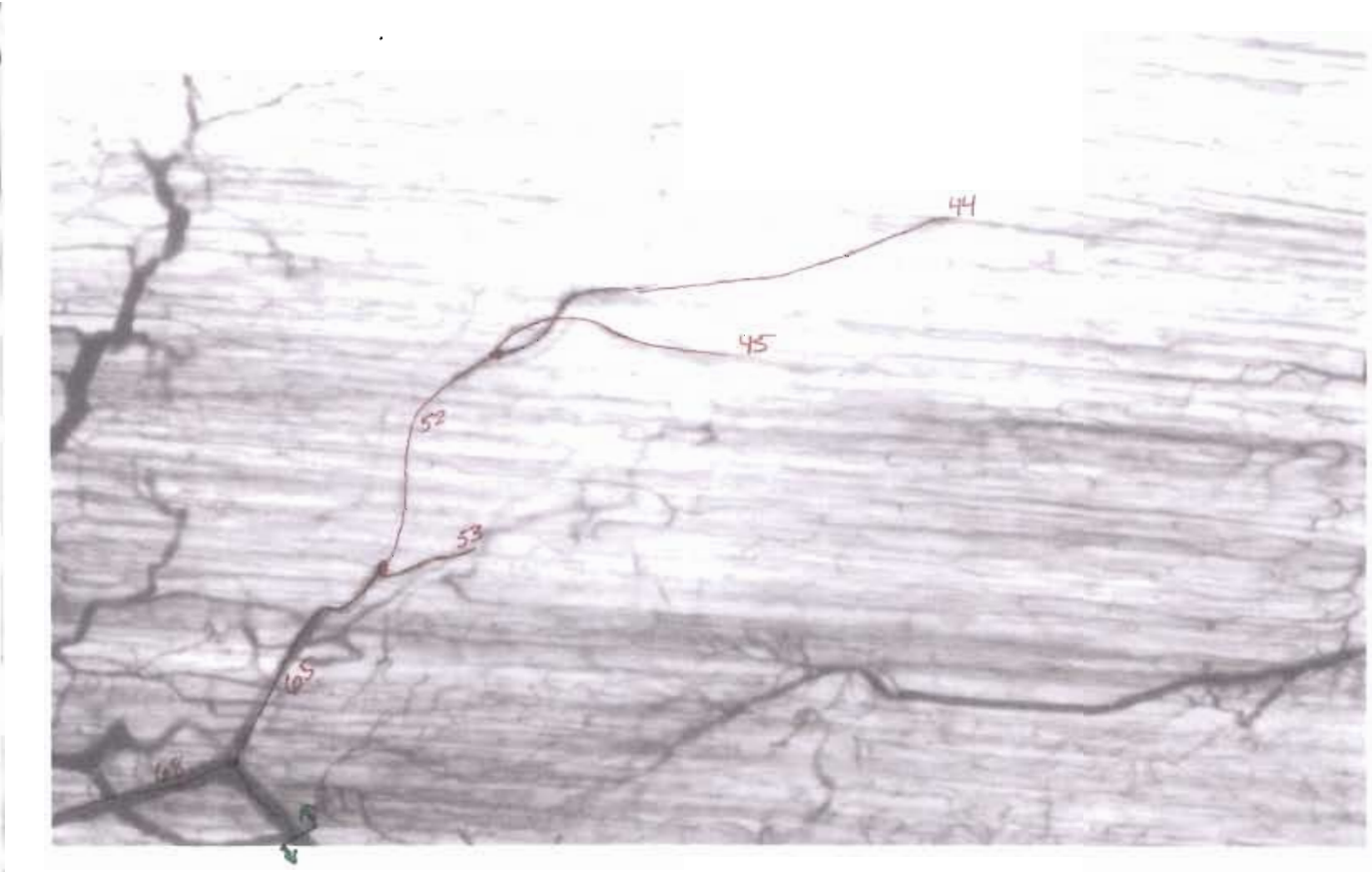

$z=6$ 


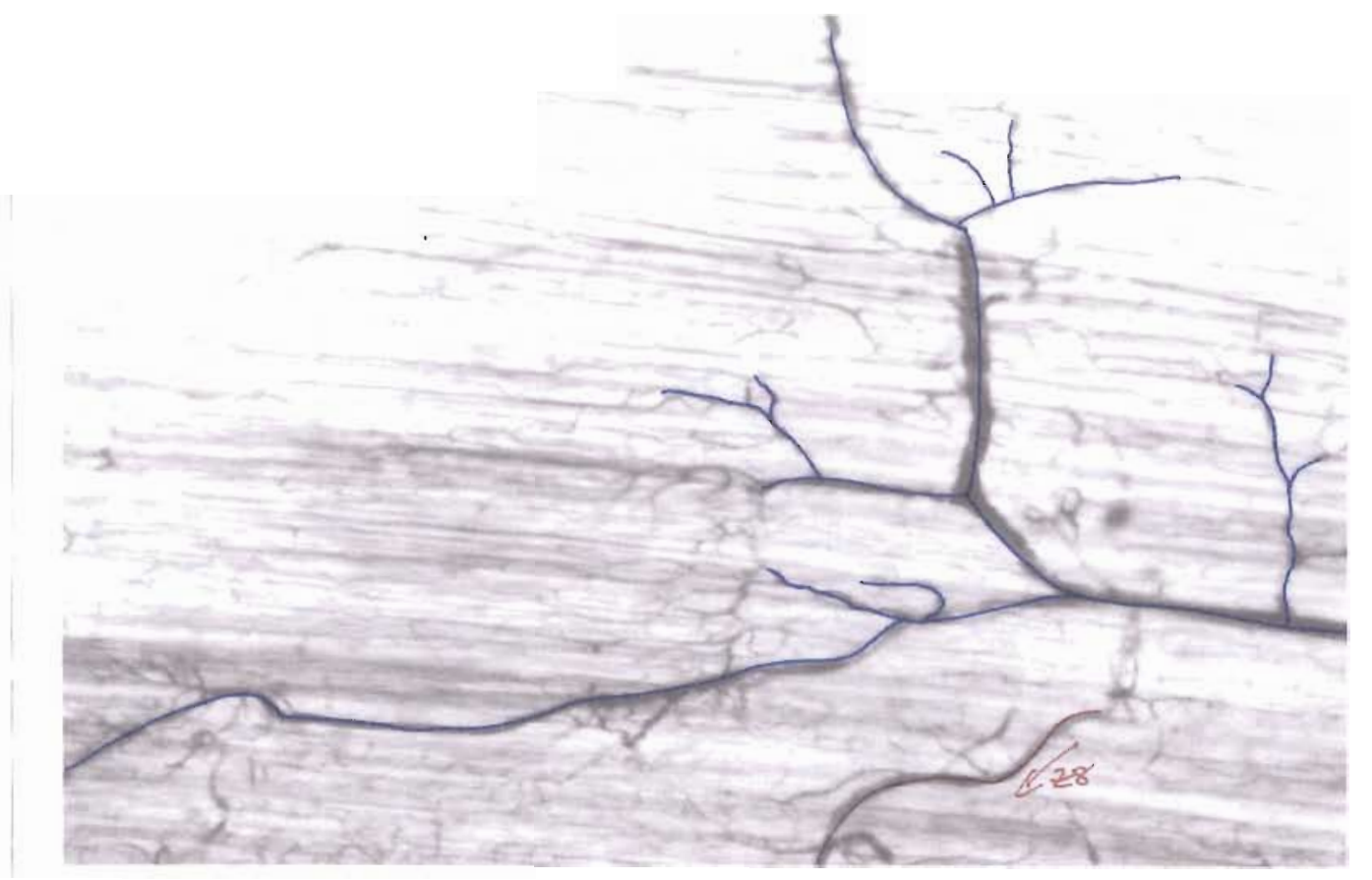

2.7

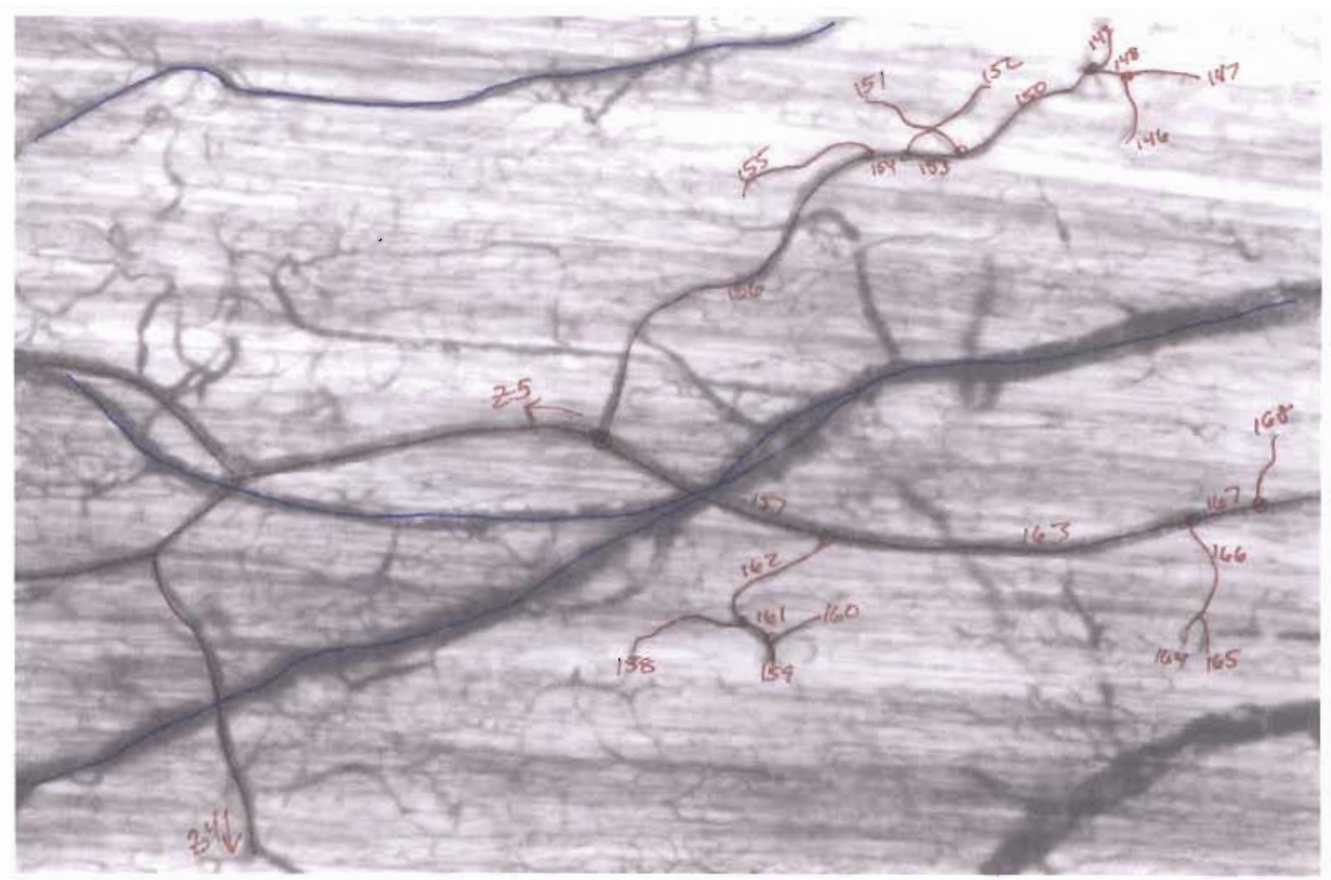

$z 2.8$ 


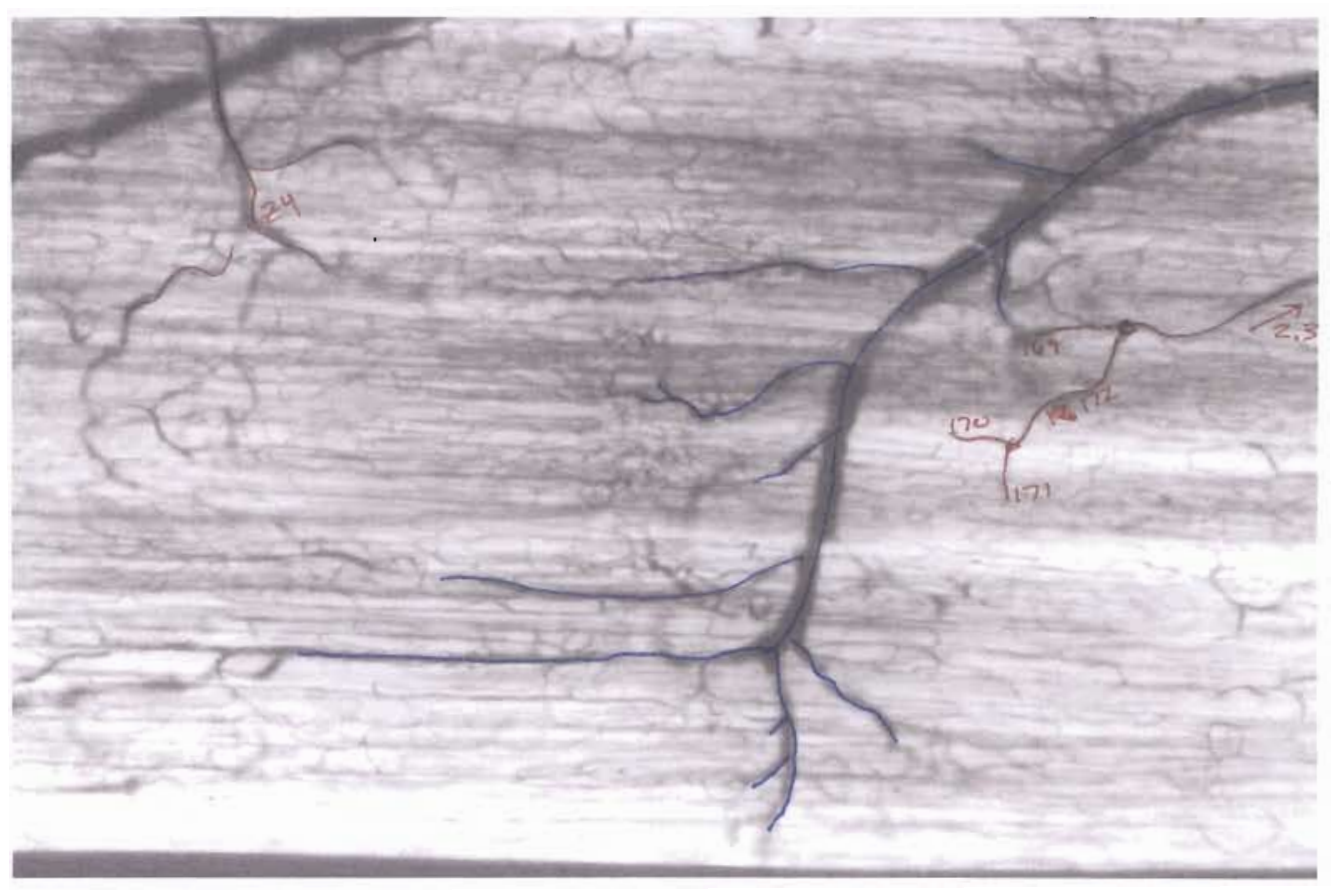

2.2 .9 


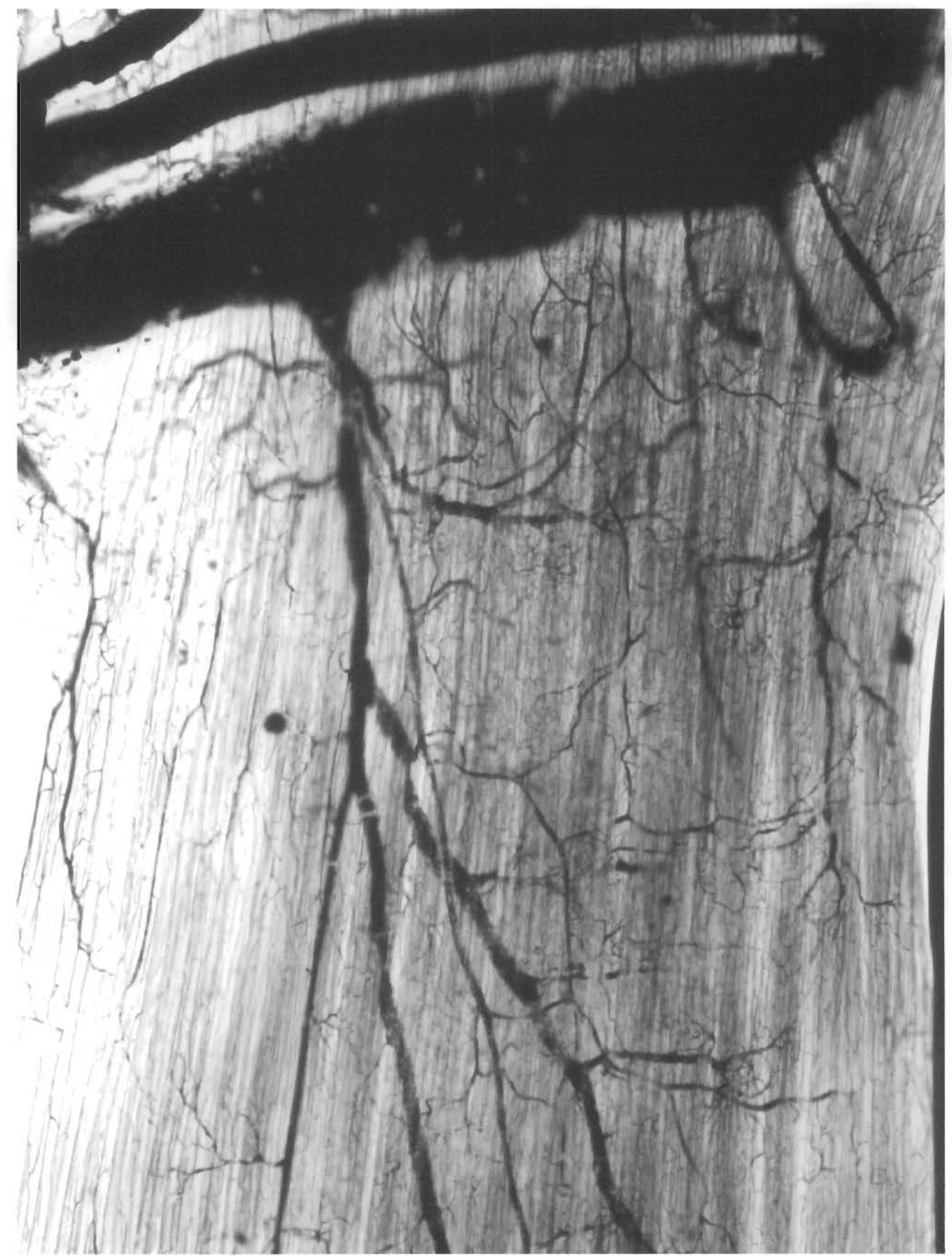




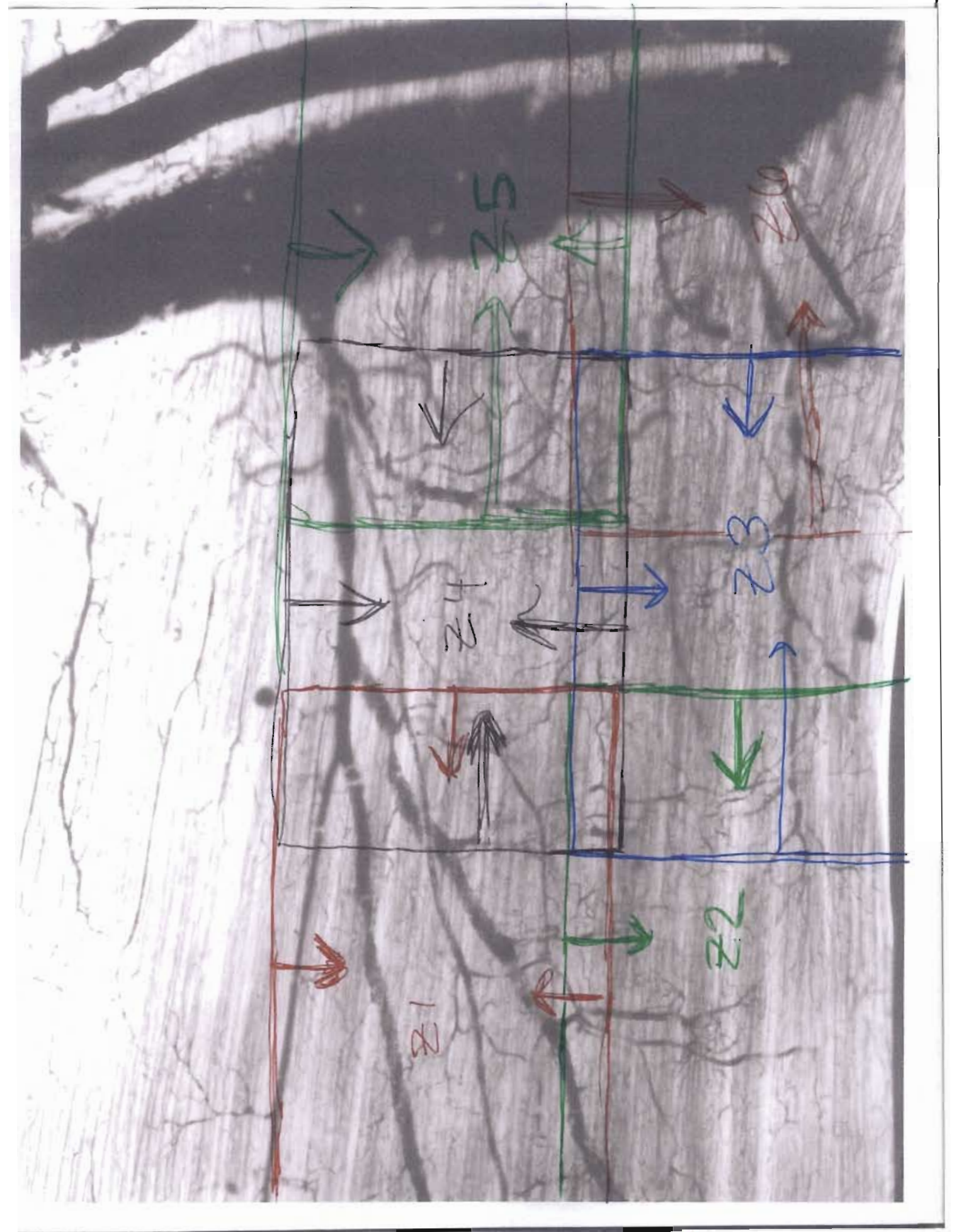



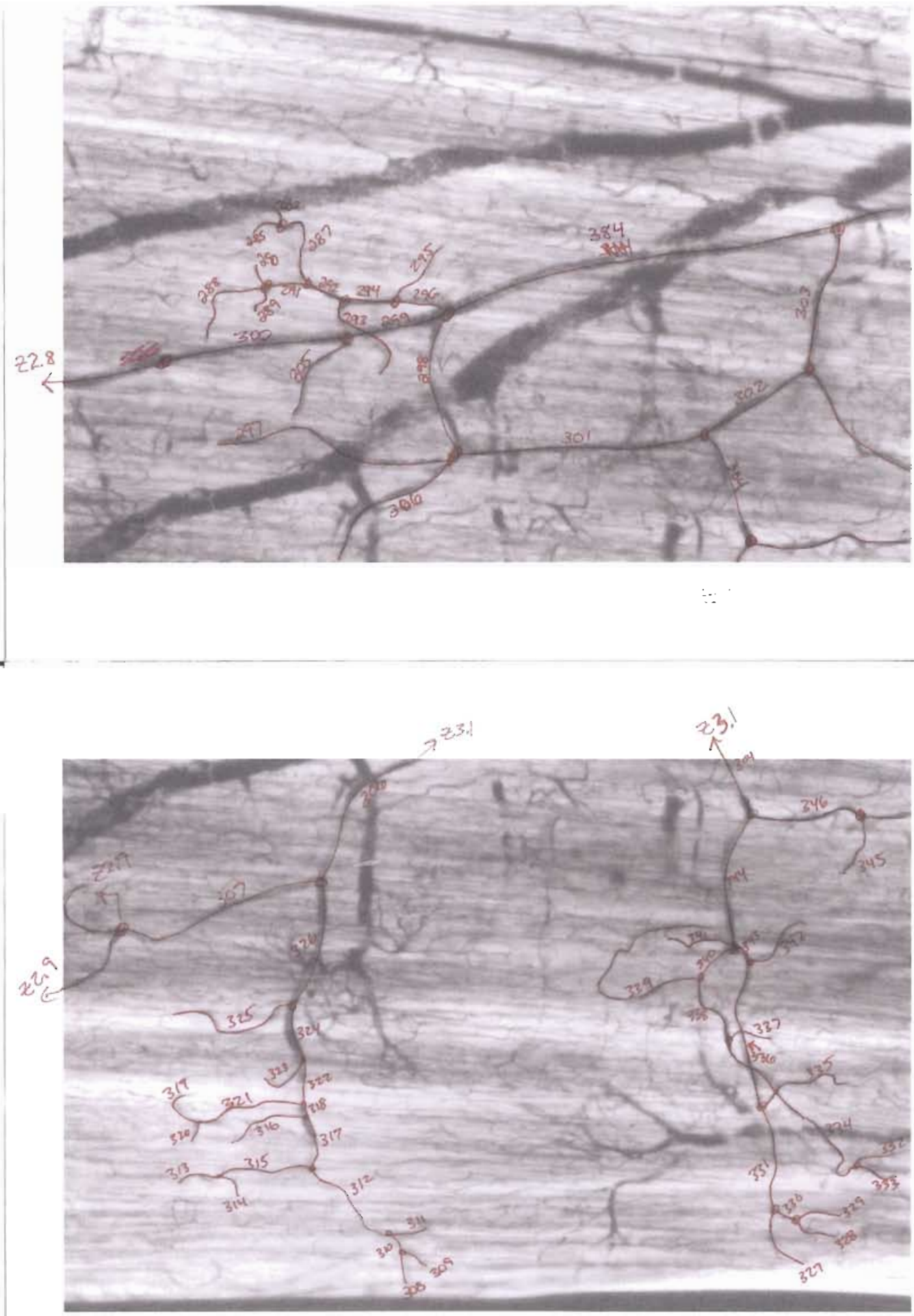

z 3.2 

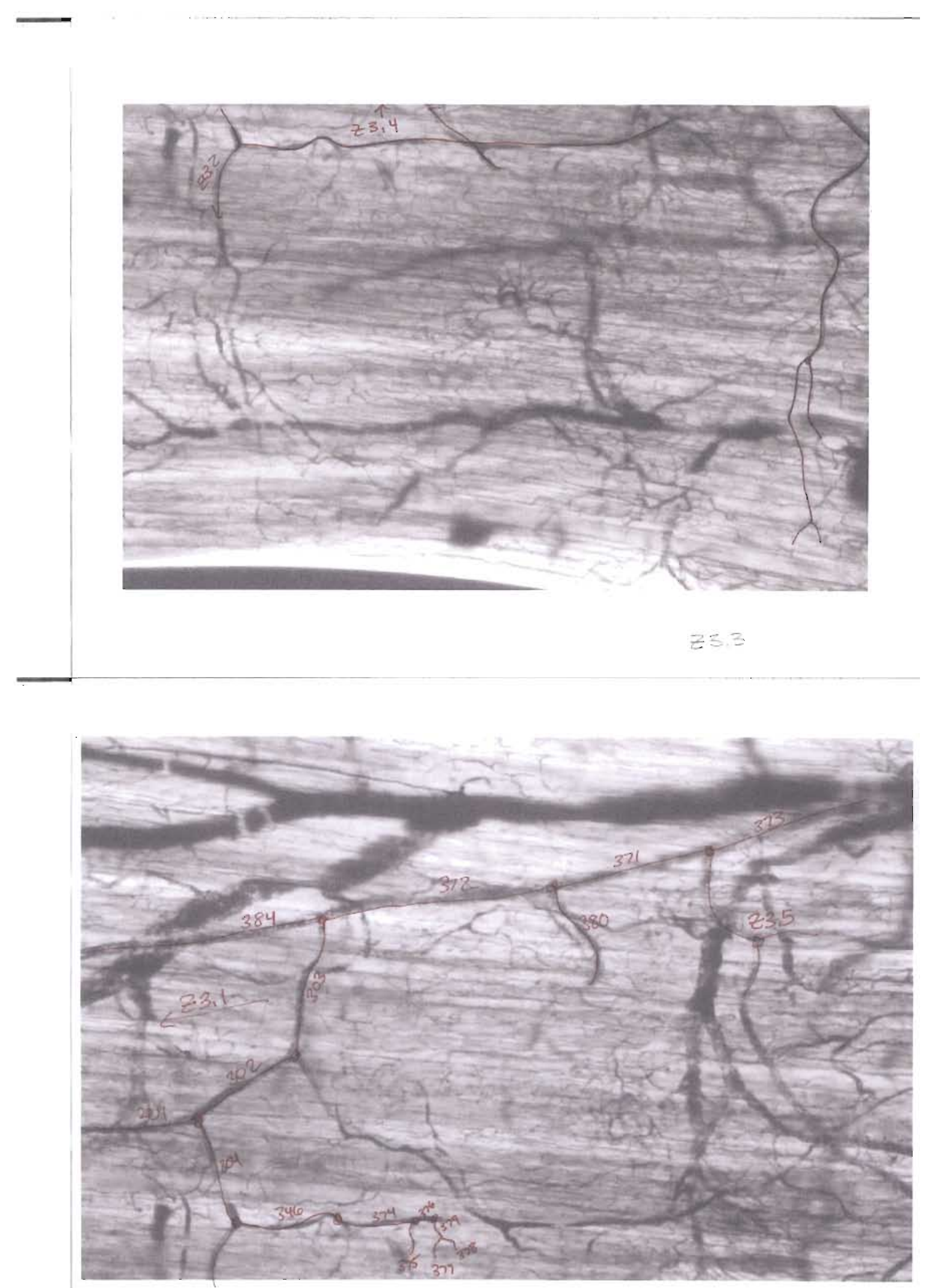

23.4 

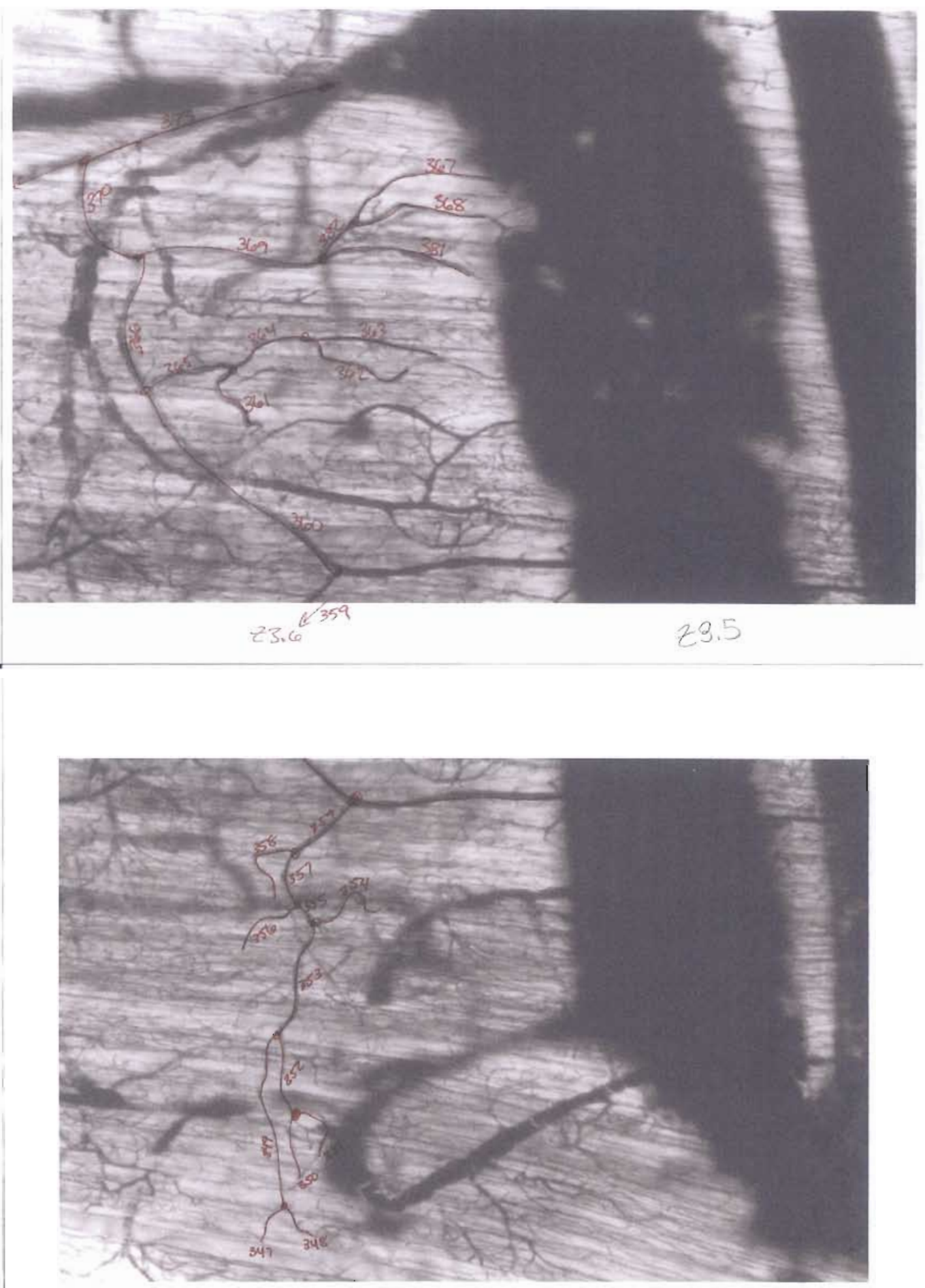
B: Orginal morphological data from images 
Original Data

\begin{tabular}{|c|c|c|c|c|c|}
\hline Zone & Label & P1 & Order & $L$ (micron) & $\mathrm{D}$ (micron) \\
\hline 2.1 & 1 & 3 & 1 & 67.2 & 5.2 \\
\hline 2.1 & 2 & 3 & 1 & 18 & 7.0 \\
\hline 2.1 & 3 & 6 & 2 & 63.9 & 9.6 \\
\hline 2.1 & 4 & 6 & 1 & 84.8 & 6.4 \\
\hline 2.1 & 5 & 6 & 1 & 60.9 & 7.0 \\
\hline 2.1 & 6 & 9 & 2 & 54 & 8.8 \\
\hline 2.1 & 7 & 9 & 1 & 73.4 & 5.5 \\
\hline 2.1 & 8 & 9 & 1 & 77.5 & 5.5 \\
\hline 2.1 & 9 & 12 & 2 & 44.2 & 8.8 \\
\hline 2.1 & 10 & 12 & 1 & 63.1 & 6.4 \\
\hline 2.1 & 11 & 12 & 1 & 50.4 & 6.8 \\
\hline 2.1 & 12 & 16 & 2 & 65.3 & 10.3 \\
\hline 2.1 & 13 & 16 & 1 & 17.3 & 8.6 \\
\hline 2.1 & 14 & 43 & 1 & 186.1 & 7.5 \\
\hline 2.1 & 15 & 43 & 1 & 96.3 & 8.1 \\
\hline 2.1 & 16 & 17 & 2 & 44.7 & 12.6 \\
\hline 2.1 & 17 & 19 & 3 & 115.7 & 12.6 \\
\hline 2.1 & 18 & 19 & 1 & 116.6 & 5.6 \\
\hline 2.1 & 19 & 23 & 3 & 114.5 & 14.8 \\
\hline 2.1 & 20 & 23 & 2 & 101.5 & 12.4 \\
\hline 2.1 & 21 & 20 & 1 & 47.8 & 10.8 \\
\hline 2.1 & 22 & 20 & 1 & 94.2 & 9.5 \\
\hline 2.1 & 23 & 37 & 3 & 112.2 & 15.7 \\
\hline 2.1 & 24 & 37 & 3 & 31 & 13.7 \\
\hline 2.1 & 25 & 24 & 2 & 108.3 & 10.3 \\
\hline 2.1 & 26 & 25 & 1 & 166.5 & 7.9 \\
\hline 2.1 & 27 & 25 & 1 & 98.9 & 7.2 \\
\hline 2.1 & 28 & 24 & 3 & 45.2 & 9.6 \\
\hline 2.1 & 29 & 28 & 2 & 27.3 & 7.2 \\
\hline 2.1 & 30 & 29 & 1 & 30.3 & 7.2 \\
\hline 2.1 & 31 & 29 & 1 & 29.4 & 7.2 \\
\hline 2.1 & 32 & 28 & 2 & 33.1 & 8.7 \\
\hline 2.1 & 33 & 32 & 2 & 27.9 & 7.9 \\
\hline 2.1 & 34 & 33 & 1 & 53.5 & 7.9 \\
\hline 2.1 & 35 & 33 & 1 & 92.8 & 7.9 \\
\hline 2.1 & 36 & 32 & 1 & 167.1 & 7.2 \\
\hline 2.1 & 37 & 42 & 4 & 248.5 & 15.7 \\
\hline 2.1 & 38 & 42 & 1 & 76.8 & 8.7 \\
\hline 2.1 & 39 & 41 & 1 & 71.5 & 5.6 \\
\hline 2.1 & 40 & 41 & 1 & 88.5 & 5.6 \\
\hline 2.1 & 41 & 42 & 2 & 80.5 & 5.7 \\
\hline 2.1 & 42 & 250 & 4 & 241.3 & 20.4 \\
\hline 2.1 & 43 & 69 & 3 & 216.9 & 13.1 \\
\hline 2.6 & 44 & 52 & 1 & 199 & 10.9 \\
\hline 2.6 & 45 & 52 & 1 & 168.9 & 9.8 \\
\hline 2.1 & 46 & 48 & 1 & 50.1 & 6.8 \\
\hline 2.1 & 47 & 48 & 1 & 30.7 & 6.8 \\
\hline 2.1 & 48 & 50 & 2 & 120 & 10.4 \\
\hline 2.1 & 49 & 50 & 1 & 36.4 & 8.8 \\
\hline 2.1 & 50 & 70 & 2 & 29.7 & 11.7 \\
\hline 2.1 & 51 & 43 & 1 & 47.4 & 6.8 \\
\hline 2.6 & 52 & 65 & 2 & 279.2 & 13.8 \\
\hline 2.6 & 53 & 65 & 1 & 100.2 & 10.5 \\
\hline 2.1 & 54 & 56 & 1 & 26.5 & 7.3 \\
\hline 2.1 & 55 & 56 & 1 & 24.2 & 7.3 \\
\hline 2.1 & 56 & 385 & 2 & 45.5 & 7.3 \\
\hline 2.1 & 57 & 385 & 1 & 42.7 & 7.3 \\
\hline 2.1 & 58 & 385 & 2 & 28.4 & 7.3 \\
\hline
\end{tabular}


Original Data

\begin{tabular}{|c|c|c|c|c|c|}
\hline Zone & Label & P1 & Order & $\mathrm{L}$ (micron) & $\mathrm{D}$ (micron) \\
\hline 2.1 & 59 & 58 & 1 & 21 & 7.3 \\
\hline 2.1 & 60 & 58 & 2 & 28.9 & 7.3 \\
\hline 2.1 & 61 & 60 & 1 & 74.1 & 7.0 \\
\hline 2.1 & 62 & 64 & 1 & 12 & 6.2 \\
\hline 2.1 & 63 & 64 & 1 & 23.4 & 6.5 \\
\hline 2.1 & 64 & 60 & 2 & 21 & 6.8 \\
\hline 2.6 & 65 & 68 & 2 & 266.4 & 18.7 \\
\hline 2.2 & 68 & 69 & 3 & 1145 & 22.1 \\
\hline 2.1 & 69 & 250 & 3 & 68.4 & 21.8 \\
\hline 2.1 & 70 & 43 & 3 & 11.4 & 11.7 \\
\hline 2.2 & 71 & 268 & 1 & 81.1 & 10.0 \\
\hline 2.2 & 72 & 268 & 2 & 342.2 & 17.6 \\
\hline 2.3 & 73 & 75 & 1 & 57 & 5.9 \\
\hline 2.3 & 74 & 75 & 1 & 57.5 & 5.9 \\
\hline 2.3 & 75 & 79 & 2 & 75.8 & 6.9 \\
\hline 2.3 & 76 & 78 & 1 & 37.3 & 5.9 \\
\hline 2.3 & 77 & 78 & 1 & 47.2 & 6.9 \\
\hline 2.3 & 78 & 79 & 2 & 114.7 & 7.9 \\
\hline 2.3 & 79 & 81 & 3 & 149.1 & 7.9 \\
\hline 2.3 & 80 & 81 & 1 & 122.2 & 9.5 \\
\hline 2.3 & 81 & 93 & 3 & 281 & 13.5 \\
\hline 2.3 & 82 & 84 & 1 & 53.3 & 6.4 \\
\hline 2.3 & 83 & 84 & 1 & 101.5 & 6.4 \\
\hline 2.3 & 84 & 86 & 2 & 74.4 & 8.3 \\
\hline 2.3 & 85 & 86 & 1 & 103.8 & 5.9 \\
\hline 2.3 & 86 & 92 & 2 & 86 & 8.3 \\
\hline 2.3 & 87 & 91 & 1 & 308.6 & 9.2 \\
\hline 2.3 & 88 & 90 & 1 & 264.8 & 8.6 \\
\hline 2.3 & 89 & 90 & 1 & 392.5 & 9.5 \\
\hline 2.3 & 90 & 91 & 2 & 43.1 & 12.6 \\
\hline 2.3 & 91 & 92 & 2 & 92.2 & 12.6 \\
\hline 2.3 & 92 & 93 & 3 & 62.2 & 12.6 \\
\hline 2.3 & 93 & 95 & 4 & 137.9 & 17.3 \\
\hline 2.3 & 94 & 95 & 1 & 155.4 & 9.8 \\
\hline 2.3 & 95 & 105 & 4 & 264.4 & 17.4 \\
\hline 2.3 & 96 & 98 & 1 & 86 & 9.2 \\
\hline 2.3 & 97 & 98 & 1 & 46.7 & 9.2 \\
\hline 2.3 & 98 & 104 & 2 & 257.9 & 10.1 \\
\hline 2.3 & 99 & 103 & 1 & 153.6 & 5.9 \\
\hline 2.3 & 100 & 102 & 1 & 37.3 & 5.9 \\
\hline 2.3 & 101 & 102 & 1 & 43.7 & 5.9 \\
\hline 2.3 & 102 & 103 & 2 & 72.7 & 5.9 \\
\hline 2.3 & 103 & 104 & 2 & 83.5 & 8.5 \\
\hline 2.3 & 104 & 105 & 3 & 24.2 & 8.7 \\
\hline 2.3 & 105 & 138 & 4 & 159.2 & 17.4 \\
\hline 2.4 & 106 & 108 & 1 & 24.6 & 6.2 \\
\hline 2.4 & 107 & 108 & 1 & 21.8 & 6.2 \\
\hline 2.4 & 108 & 114 & 2 & 50.5 & 6.8 \\
\hline 2.4 & 109 & 111 & 1 & 9.9 & 5.2 \\
\hline 2.4 & 110 & 111 & 1 & 118.5 & 5.2 \\
\hline 2.4 & 111 & 113 & 2 & 32 & 5.9 \\
\hline 2.4 & 112 & 113 & 1 & 25.6 & 5.9 \\
\hline 2.4 & 113 & 114 & 2 & 28.8 & 5.9 \\
\hline 2.4 & 114 & 118 & 3 & 77.5 & 6.6 \\
\hline 2.4 & 115 & 117 & 1 & 20.2 & 5.5 \\
\hline 2.4 & 116 & 117 & 1 & 16.3 & 5.5 \\
\hline 2.4 & 117 & 118 & 2 & 22.8 & 5.5 \\
\hline 2.4 & 118 & 130 & 3 & 93.7 & 8.2 \\
\hline
\end{tabular}


Original Data

\begin{tabular}{|c|c|c|c|c|c|}
\hline Zone & Label & $\mathrm{P} 1$ & Order & $L$ (micron) & $D$ (micron) \\
\hline 2.4 & 119 & 121 & 1 & 29.5 & 5.2 \\
\hline 2.4 & 120 & 121 & 1 & 114.8 & 5.2 \\
\hline 2.4 & 121 & 131 & 2 & 21.3 & 7.2 \\
\hline 2.4 & 122 & 136 & 1 & 10 & 5.6 \\
\hline 2.4 & 123 & 136 & 1 & 10.5 & 5.6 \\
\hline 2.4 & 124 & 125 & 1 & 11 & 5.6 \\
\hline 2.4 & 125 & 129 & 2 & 114.7 & 9.4 \\
\hline 2.4 & 126 & 128 & 1 & 16.4 & 5.2 \\
\hline 2.4 & 127 & 128 & 1 & 18.2 & 5.2 \\
\hline 2.4 & 128 & 129 & 2 & 21.8 & 7.0 \\
\hline 2.4 & 129 & 130 & 3 & 32.7 & 7.9 \\
\hline 2.4 & 130 & 131 & 4 & 5.7 & 10.8 \\
\hline 2.4 & 131 & 137 & 4 & 29.9 & 10.8 \\
\hline 2.4 & 132 & 134 & 1 & 30 & 5.2 \\
\hline 2.4 & 133 & 134 & 1 & 17.5 & 5.2 \\
\hline 2.4 & 134 & 137 & 2 & 70.6 & 7.8 \\
\hline 2.4 & 135 & 139 & 1 & 81.5 & 5.2 \\
\hline 2.4 & 136 & 125 & 2 & 5.4 & 5.6 \\
\hline 2.4 & 137 & 139 & 4 & 11.4 & 10.8 \\
\hline 2.5 & 138 & 140 & 4 & 788.5 & 17.4 \\
\hline 2.5 & 139 & 140 & 4 & 247.4 & 13.9 \\
\hline 2.5 & 140 & 145 & 5 & 126.7 & 17.8 \\
\hline 2.5 & 141 & 145 & 2 & 556.2 & 18.3 \\
\hline 2.5 & 142 & 141 & 2 & 137.9 & 13.5 \\
\hline 2.5 & 143 & 142 & 1 & 36.64 & 8.5 \\
\hline 2.5 & 144 & 142 & 1 & 35.04 & 8.5 \\
\hline 2.5 & 145 & 157 & 5 & 332.16 & 24.2 \\
\hline 2.8 & 146 & 148 & 1 & 69.92 & 8.3 \\
\hline 2.8 & 147 & 148 & 1 & 69.44 & 8.3 \\
\hline 2.8 & 148 & 150 & 2 & 30.88 & 8.3 \\
\hline 2.8 & 149 & 150 & 1 & 41.12 & 8.3 \\
\hline 2.8 & 150 & 153 & 2 & 148.16 & 15.2 \\
\hline 2.8 & 151 & 153 & 1 & 103.52 & 8.3 \\
\hline 2.8 & 152 & 154 & 1 & 95.2 & 8.3 \\
\hline 2.8 & 153 & 154 & 2 & 53.92 & 15.2 \\
\hline 2.8 & 154 & 156 & 2 & 34.72 & 15.2 \\
\hline 2.8 & 155 & 156 & 1 & 121.76 & 9.4 \\
\hline 2.8 & 156 & 157 & 2 & 387.68 & 16.8 \\
\hline 2.8 & 157 & 163 & 5 & 226.08 & 24.2 \\
\hline 2.8 & 158 & 162 & 1 & 152.48 & 10.8 \\
\hline 2.8 & 159 & 161 & 1 & 22.24 & 11.9 \\
\hline 2.8 & 160 & 161 & 1 & 54.08 & 8.3 \\
\hline 2.8 & 161 & 162 & 2 & 38.88 & 11.9 \\
\hline 2.8 & 162 & 163 & 2 & 124.48 & 13.3 \\
\hline 2.8 & 163 & 167 & 5 & 334.24 & 24.2 \\
\hline 2.8 & 164 & 166 & 1 & 36.48 & 8.3 \\
\hline 2.8 & 165 & 166 & 1 & 37.6 & 8.3 \\
\hline 2.8 & 166 & 167 & 2 & 92.8 & 8.3 \\
\hline 2.8 & 167 & 300 & 5 & 61.44 & 24.2 \\
\hline 2.8 & 168 & 167 & 1 & 77.12 & 8.3 \\
\hline 2.9 & 169 & 307 & 1 & 47.4 & 5.2 \\
\hline 2.9 & 170 & 172 & 1 & 40.7 & 5.2 \\
\hline 2.9 & 171 & 172 & 1 & 31.2 & 5.2 \\
\hline 2.9 & 172 & 307 & 2 & 100.1 & 5.9 \\
\hline 1.2 & 173 & 176 & 1 & 64.2 & 7.3 \\
\hline 1.2 & 174 & 176 & 1 & 183.1 & 7.3 \\
\hline 1.2 & 175 & 177 & 1 & 384.7 & 7.3 \\
\hline 1.2 & 176 & 179 & 2 & 407.2 & 7.9 \\
\hline
\end{tabular}


Original Data

\begin{tabular}{|c|c|c|c|c|c|}
\hline Zone & Label & $\mathrm{P} 1$ & Order & $L$ (micron) & $\mathrm{D}$ (micron) \\
\hline 1.2 & 177 & 178 & 2 & 95.5 & 13.0 \\
\hline 1.2 & 178 & 179 & 2 & 58.3 & 19.0 \\
\hline 1.2 & 179 & 187 & 3 & 207.9 & 19.5 \\
\hline 1.2 & 180 & 185 & 1 & 133.7 & 8.3 \\
\hline 1.2 & 181 & 186 & 1 & 367.5 & 7.9 \\
\hline 1.2 & 182 & 184 & 1 & 53.4 & 7.2 \\
\hline 1.2 & 183 & 184 & 1 & 74.1 & 7.9 \\
\hline 1.2 & 184 & 185 & 2 & 185.3 & 7.9 \\
\hline 1.2 & 185 & 186 & 2 & 93.7 & 9.5 \\
\hline 1.2 & 186 & 187 & 2 & 239.6 & 12.5 \\
\hline 1.2 & 187 & 193 & 3 & 232 & 19.8 \\
\hline 1.2 & 188 & 190 & 1 & 112.3 & 6.0 \\
\hline 1.2 & 189 & 190 & 1 & 114.8 & 9.5 \\
\hline 1.2 & 190 & 192 & 2 & 133 & 9.5 \\
\hline 1.2 & 191 & 192 & 1 & 154.5 & 11.4 \\
\hline 1.2 & 192 & 197 & 2 & 655 & 15.9 \\
\hline 1.2 & 193 & 383 & 4 & 299.5 & 22.9 \\
\hline 1.2 & 194 & 196 & 1 & 65.8 & 6.8 \\
\hline 1.2 & 195 & 196 & 1 & 85 & 6.8 \\
\hline 1.2 & 196 & 197 & 2 & 182.9 & 6.8 \\
\hline 1.2 & 197 & 193 & 3 & 30 & 15.9 \\
\hline 1.4 & 198 & 204 & 1 & 398 & 7.5 \\
\hline 1.4 & 199 & 202 & 1 & 138.8 & 7.5 \\
\hline 1.4 & 200 & 202 & 1 & 111.7 & 7.5 \\
\hline 1.4 & 201 & 203 & 1 & 57.5 & 7.5 \\
\hline 1.4 & 202 & 203 & 2 & 52 & 7.5 \\
\hline 1.4 & 203 & 204 & 2 & 28.6 & 7.5 \\
\hline 1.4 & 204 & 208 & 2 & 131.7 & 10.0 \\
\hline 1.4 & 205 & 207 & 1 & 80.8 & 9.0 \\
\hline 1.4 & 206 & 207 & 1 & 164.6 & 9.8 \\
\hline 1.4 & 207 & 208 & 2 & 85.7 & 10.9 \\
\hline 1.4 & 208 & 211 & 3 & 130.5 & 11.2 \\
\hline 1.4 & 209 & 211 & 1 & 208.1 & 8.3 \\
\hline 1.4 & 210 & 212 & 1 & 59.4 & 6.8 \\
\hline 1.4 & 211 & 212 & 3 & 29.1 & 15.9 \\
\hline 1.4 & 212 & 215 & 3 & 51.1 & 15.9 \\
\hline 1.4 & 213 & 215 & 1 & 225.5 & 9.6 \\
\hline 1.4 & 214 & 216 & 1 & 124.2 & 8.6 \\
\hline 1.4 & 215 & 216 & 3 & 39.9 & 15.9 \\
\hline 1.4 & 216 & 218 & 3 & 141 & 17.3 \\
\hline 1.4 & 217 & 218 & 1 & 162.3 & 9.5 \\
\hline 1.4 & 218 & 220 & 3 & 32.9 & 17.7 \\
\hline 1.4 & 219 & 220 & 1 & 127.3 & 10.7 \\
\hline 1.4 & 220 & 178 & 3 & 235.4 & 19.0 \\
\hline 1.3 & 221 & 177 & 1 & 488.9 & 7.9 \\
\hline 1.6 & 222 & 224 & 1 & 43.2 & 5.9 \\
\hline 1.6 & 223 & 224 & 1 & 33.6 & 5.9 \\
\hline 1.6 & 224 & 226 & 2 & 29.1 & 5.9 \\
\hline 1.6 & 225 & 226 & 1 & 44.9 & 6.5 \\
\hline 1.6 & 226 & 228 & 2 & 98.2 & 10.7 \\
\hline 1.6 & 227 & 228 & 1 & 169.6 & 10.7 \\
\hline 1.6 & 228 & 232 & 2 & 141.9 & 13.0 \\
\hline 1.6 & 229 & 231 & 1 & 285.6 & 8.3 \\
\hline 1.6 & 230 & 231 & 1 & 218.3 & 8.3 \\
\hline 1.6 & 231 & 232 & 2 & 16.4 & 8.3 \\
\hline 1.6 & 232 & 242 & 3 & 342.8 & 13.0 \\
\hline 1.6 & 233 & 237 & 1 & 198.3 & 7.9 \\
\hline 1.6 & 234 & 236 & 1 & 151.6 & 5.2 \\
\hline
\end{tabular}


Original Data

\begin{tabular}{|c|c|c|c|c|c|}
\hline Zone & Label & P1 & Order & $L$ (micron) & $\mathrm{D}$ (micron) \\
\hline 1.6 & 235 & 236 & 1 & 166.6 & 7.8 \\
\hline 1.6 & 236 & 237 & 2 & 28 & 7.8 \\
\hline 1.6 & 237 & 241 & 2 & 227.7 & 12.0 \\
\hline 1.6 & 238 & 240 & 1 & 241.2 & 7.9 \\
\hline 1.6 & 239 & 240 & 1 & 137.8 & 7.8 \\
\hline 1.6 & 240 & 241 & 2 & 58.4 & 8.6 \\
\hline 1.6 & 241 & 242 & 3 & 159.4 & 13.4 \\
\hline 1.6 & 242 & 243 & 4 & 117.8 & 13.0 \\
\hline 1.6 & 243 & 244 & 4 & 174.2 & 13.0 \\
\hline 1.6 & 244 & 383 & 5 & 129.4 & 22.9 \\
\hline 1.6 & 245 & 244 & 4 & 627.4 & 22.9 \\
\hline 1.5 & 246 & 248 & 1 & 334.2 & 12.2 \\
\hline 1.5 & 247 & 248 & 1 & 251.8 & 12.2 \\
\hline 1.5 & 248 & 245 & 2 & 194.5 & 18.3 \\
\hline 1.7 & 249 & 245 & 4 & 591.5 & 22.9 \\
\hline 1.7 & 250 & 249 & 4 & 352.3 & 22.9 \\
\hline 1.8 & 251 & 253 & 1 & 123.6 & 6.8 \\
\hline 1.8 & 252 & 253 & 1 & 115 & 6.8 \\
\hline 1.8 & 253 & 257 & 2 & 195.3 & 10.1 \\
\hline 1.8 & 254 & 257 & 1 & 298.2 & 7.8 \\
\hline 1.8 & 255 & 258 & 1 & 117.7 & 6.5 \\
\hline 1.8 & 256 & 258 & 1 & 75.2 & 6.5 \\
\hline 1.8 & 257 & 259 & 2 & 76.5 & 8.8 \\
\hline 1.8 & 258 & 259 & 2 & 59.5 & 8.5 \\
\hline 1.8 & 259 & 261 & 3 & 75.9 & 10.0 \\
\hline 1.8 & 260 & 261 & 1 & 192.3 & 9.2 \\
\hline 1.8 & 261 & 264 & 3 & 115.2 & 10.1 \\
\hline 1.8 & 262 & 264 & 3 & 131.9 & 16.3 \\
\hline 1.8 & 263 & 262 & 1 & 286.5 & 13.0 \\
\hline 1.8 & 264 & 265 & 4 & 140.3 & 16.3 \\
\hline 1.8 & 265 & 267 & 5 & 43.2 & 17.6 \\
\hline 1.8 & 266 & 267 & 1 & 109.6 & 9.8 \\
\hline 1.8 & 267 & 249 & 5 & 463.8 & 19.9 \\
\hline 1.8 & 268 & 265 & 4 & 637.58 & 17.6 \\
\hline 1.9 & 269 & 271 & 1 & 160.9 & 9.6 \\
\hline 1.9 & 270 & 271 & 1 & 91.1 & 7.2 \\
\hline 1.9 & 271 & 274 & 2 & 230.5 & 11.2 \\
\hline 1.9 & 272 & 274 & 1 & 122.8 & 6.5 \\
\hline 1.9 & 273 & 274 & 1 & 66.9 & 11.7 \\
\hline 1.9 & 274 & 278 & 3 & 185 & 14.7 \\
\hline 1.9 & 275 & 277 & 1 & 124.6 & 6.8 \\
\hline 1.9 & 276 & 277 & 1 & 281.9 & 6.8 \\
\hline 1.9 & 277 & 278 & 2 & 44 & 7.4 \\
\hline 1.9 & 278 & 280 & 3 & 45.4 & 15.6 \\
\hline 1.9 & 279 & 280 & 1 & 114 & 9.5 \\
\hline 1.9 & 280 & 284 & 3 & 234.4 & 15.6 \\
\hline 1.9 & 281 & 283 & 1 & 46.1 & 6.8 \\
\hline 1.9 & 282 & 283 & 1 & 74 & 6.8 \\
\hline 1.9 & 283 & 284 & 2 & 80 & 8.7 \\
\hline 1.9 & 284 & 262 & 3 & 112 & 15.6 \\
\hline 3.1 & 285 & 287 & 1 & 69 & 9.4 \\
\hline 3.1 & 286 & 287 & 1 & 130.8 & 9.4 \\
\hline 3.1 & 287 & 292 & 2 & 129.2 & 9.6 \\
\hline 3.1 & 288 & 291 & 1 & 159.8 & 6.5 \\
\hline 3.1 & 289 & 291 & 1 & 54.7 & 6.4 \\
\hline 3.1 & 290 & 291 & 1 & 38 & 6.4 \\
\hline 3.1 & 291 & 292 & 2 & 62.2 & 10.4 \\
\hline 3.1 & 292 & 294 & 3 & 73.2 & 9.9 \\
\hline
\end{tabular}


Original Data

\begin{tabular}{|c|c|c|c|c|c|}
\hline Zone & Label & $\mathrm{P} 1$ & Order & $L$ (micron) & $\mathrm{D}$ (micron) \\
\hline 3.1 & 293 & 294 & 1 & 158.5 & 10.8 \\
\hline 3.1 & 294 & 296 & 3 & 82.2 & 10.7 \\
\hline 3.1 & 295 & 296 & 1 & 155.6 & 5.9 \\
\hline 3.1 & 296 & 384 & 3 & 79.2 & 12.4 \\
\hline 3.1 & 297. & 301 & 1 & 438.8 & 9.5 \\
\hline 3.1 & 298 & 384 & 3 & 226.6 & 12.4 \\
\hline 3.1 & 299 & 384 & 5 & 145.7 & 24.2 \\
\hline 3.1 & 300 & 299 & 5 & 288.8 & 24.2 \\
\hline 3.1 & 301 & 302 & 3 & 367.6 & 14.3 \\
\hline 3.1 & 302 & 303 & 4 & 191 & 14.3 \\
\hline 3.1 & 303 & 372 & 4 & 223.2 & 19.0 \\
\hline 3.1 & 304 & 302 & 4 & 175.4 & 14.3 \\
\hline 3.1 & 305 & 299 & 3 & 161.6 & 14.0 \\
\hline 3.2 & 306 & 301 & 3 & 323.9 & 14.3 \\
\hline 3.2 & 307 & 306 & 2 & 324.4 & 10.9 \\
\hline 3.2 & 308 & 310 & 1 & 48.1 & 5.9 \\
\hline 3.2 & 309 & 310 & 1 & 48.8 & 5.9 \\
\hline 3.2 & 310 & 312 & 2 & 38.7 & 6.6 \\
\hline 3.2 & 311 & 312 & 1 & 78.9 & 5.9 \\
\hline 3.2 & 312 & 317 & 2 & 166.6 & 9.2 \\
\hline 3.2 & 313 & 315 & 1 & 120.2 & 6.9 \\
\hline 3.2 & 314 & 315 & 1 & 74.6 & 6.9 \\
\hline 3.2 & 315 & 317 & 2 & 168.1 & 6.9 \\
\hline 3.2 & 316 & 318 & 1 & 124.3 & 5.5 \\
\hline 3.2 & 317 & 318 & 3 & 82.5 & 10.4 \\
\hline 3.2 & 318 & 322 & 3 & 21.9 & 10.4 \\
\hline 3.2 & 319 & 321 & 1 & 62 & 5.3 \\
\hline 3.2 & 320 & 321 & 1 & 43.6 & 5.3 \\
\hline 3.2 & 321 & 322 & 2 & 173.8 & 5.5 \\
\hline 3.2 & 322 & 324 & 3 & 60.6 & 13.0 \\
\hline 3.2 & 323 & 324 & 1 & 72.5 & 7.4 \\
\hline 3.2 & 324 & 326 & 3 & 87.3 & 13.0 \\
\hline 3.2 & 325 & 326 & 1 & 218 & 5.5 \\
\hline 3.2 & 326 & 306 & 3 & 205.9 & 14.3 \\
\hline 3.2 & 327 & 331 & 1 & 106.6 & 6.5 \\
\hline 3.2 & 328 & 330 & 1 & 71.4 & 6.5 \\
\hline 3.2 & 329 & 330 & 1 & 67.3 & 6.5 \\
\hline 3.2 & 330 & 331 & 2 & 25.3 & 6.5 \\
\hline 3.2 & 331 & 336 & 2 & 167.5 & 7.8 \\
\hline 3.2 & 332 & 334 & 1 & 68.6 & 5.9 \\
\hline 3.2 & 333 & 334 & 1 & 75 & 5.9 \\
\hline 3.2 & 334 & 338 & 2 & 328.7 & 7.8 \\
\hline 3.2 & 335 & 336 & 1 & 198.1 & 7.2 \\
\hline 3.2 & 336 & 343 & 2 & 228.2 & 9.1 \\
\hline 3.2 & 337 & 338 & 1 & 63.3 & 5.9 \\
\hline 3.2 & 338 & 340 & 2 & 112.6 & 9.1 \\
\hline 3.2 & 339 & 340 & 1 & 376.8 & 7.8 \\
\hline 3.2 & 340 & 344 & 2 & 79.5 & 11.3 \\
\hline 3.2 & 341 & 344 & 1 & 102.9 & 6.2 \\
\hline 3.2 & 342 & 343 & 1 & 112 & 7.9 \\
\hline 3.2 & 343 & 344 & 2 & 47.2 & 10.4 \\
\hline 3.2 & 344 & 304 & 3 & 199 & 12.4 \\
\hline 3.2 & 345 & 346 & 1 & 92.9 & 7.2 \\
\hline 3.2 & 346 & 304 & 3 & 175 & 10.4 \\
\hline 3.6 & 347 & 349 & 1 & 70.5 & 6.4 \\
\hline 3.6 & 348 & 349 & 1 & 82.4 & 6.4 \\
\hline 3.6 & 349 & 353 & 2 & 286.1 & 6.4 \\
\hline 3.6 & 350 & 352 & 1 & 116.9 & 6.4 \\
\hline
\end{tabular}


Original Data

\begin{tabular}{|c|c|c|c|c|c|}
\hline Zone & Label & P1 & Order & L (micron) & D (micron) \\
\hline 3.6 & 351 & 352 & 1 & 108.2 & 6.4 \\
\hline 3.6 & 352 & 353 & 2 & 130.6 & 8.1 \\
\hline 3.6 & 353 & 355 & 3 & 186.6 & 10.3 \\
\hline 3.6 & 354 & 355 & 1 & 162.9 & 6.8 \\
\hline 3.6 & 355 & 357 & 3 & 41 & 11.4 \\
\hline 3.6 & 356 & 357 & 1 & 152.3 & 5.6 \\
\hline 3.6 & 357 & 359 & 3 & 99.7 & 12.7 \\
\hline 3.6 & 358 & 359 & 1 & 149.4 & 6.8 \\
\hline 3.6 & 359 & 360 & 3 & 113 & 12.9 \\
\hline 3.5 & 360 & 366 & 4 & 377.6 & 15.7 \\
\hline 3.5 & 361 & 365 & 1 & 137.9 & 8.7 \\
\hline 3.5 & 362 & 364 & 1 & 175.5 & 7.9 \\
\hline 3.5 & 363 & 364 & 1 & 228 & 7.9 \\
\hline 3.5 & 364 & 365 & 2 & 111.6 & 7.9 \\
\hline 3.5 & 365 & 366 & 2 & 130.2 & 11.7 \\
\hline 3.5 & 366 & 370 & 4 & 200.7 & 15.7 \\
\hline 3.5 & 367 & 382 & 1 & 260.4 & 7.2 \\
\hline 3.5 & 368 & 382 & 1 & 227.3 & 7.2 \\
\hline 3.5 & 369 & 370 & 2 & 272.9 & 10.5 \\
\hline 3.5 & 370 & 373 & 4 & 178.8 & 15.7 \\
\hline 3.4 & 371 & 373 & 5 & 241.5 & 24.2 \\
\hline 3.4 & 372 & 371 & 5 & 364.1 & 24.2 \\
\hline 3.4 & 373 & Main & 5 & 373 & 24.2 \\
\hline 3.4 & 374 & 346 & 2 & 108.5 & 8.8 \\
\hline 3.4 & 375 & 374 & 1 & 78.6 & 6.4 \\
\hline 3.4 & 376 & 374 & 2 & 32.8 & 8.8 \\
\hline 3.4 & 377 & 379 & 1 & 38.1 & 5.6 \\
\hline 3.4 & 378 & 379 & 1 & 36 & 5.6 \\
\hline 3.4 & 379 & 376 & 2 & 22.3 & 5.6 \\
\hline 3.4 & 380 & 371 & 1 & 194.9 & 11.7 \\
\hline 3.5 & 381 & 382 & 1 & 227.8 & 7.2 \\
\hline 3.5 & 382 & 369 & 2 & 74.1 & 8.1 \\
\hline 1.1 & 383 & Main & 5 & 726.3 & 22.9 \\
\hline 3.1 & 384 & 372 & 5 & 606.9 & 24.2 \\
\hline 2.1 & 385 & 70 & 3 & 21.3 & 6.8 \\
\hline
\end{tabular}


$C:$ Excel worksheets 
This spreadsheet is designed such that the user should only be making manual entries into the first five columns of the segment worksheet, and into the Manual Entries Entered Constants worksheet. Otherwise, the rest is automated, combined with three macros that process the data initially and upon any changes. Any manual entries made where there is a formula in the cell will possibly disrupt later calculations.

Formula range The formulas encompass a range from row 2 through 16001 . This means that there can be 16,000 segments entered into the Segment worksheet and the

Formula range formulas will capture that data. If data is entered beyond row 16001, the formulas will not capture it.

In general, nodes are named according to their parent element (vessel). So if an element \# 46 feeds three vessels, then the node where the three vessels branch off from the parent vessel is called Node \#46. An assumption is made that there is only one node (i.e. even if the vessels leave from different locations along the length of the element, it is assumed that the all leave from the end.

m

Pastes the mathematica code for the Segments, no capillaries added

Pastes the mathematica code for the Segments, with added capillaries

Pastes the mathematica code for the Elements, with added capillaries

Pastes the mathematica code ror the Elements, with add

**To generate Element equations: ctrl $\mathrm{m}$, $\mathrm{ctrl} h$, ctrl y

***o generate Segment equations with no capillaries added: ctrl g, ctrl h, ctrl

****To generate Element equations with capillaries added: $\mathrm{ctrl}$ m, $\mathrm{ctrl} h$, ctrl $u$

\section{Sheet}

Segments

Elements

Reorder

Elements

Segment

Matrix

列

and Matrix calculates the conductance value for that element that is later used in the flow equations.

Flow Eq 1 Generates equations for each node that describe the inlet and outlet flows. Requires either ctrl $\mathrm{m}$ (elements) or ctrl $\mathrm{g}$ (segments).

Flow Eq 2 Compiles the equations from Flow Eq 2 and puts them in a form that can be used in mathematica. Requires Macro h.

Add caps Generates the equations for adding capillaries according to user input densities (capillary per unit length of vessel)

Scode Compiles all the mathematica equations generated by this workbook and pastes them into this sheet. Macros $u, t, r$, and $y$ involve pasting code into this sheet. The grey values are the constants, the green values are the variables to be solved for, and the orange values are the sets of equations.

Entered User enteres in the boundary conditions and other constants that will be used in the calculations.

Notes This sheet is designed as a guide and reference for the use of this workbook. 
7 If the number of vessel segments of that order is greater than zero, formula sums the diameters of that order and divides by the Segments
total quantity of that order, yieldina averaqe diameter of that order
Calculates the standard deviation in the segment diameters of that order, if the number of segments of that order is greater than

Caiculates the standard deviation in the segment diameters of that order, if the number of segments of that order is greater than Segments

Calculates the lower diameter limit to have that segment classified under that order. Also sets lower bound for diameter of order

91 vessels to be 0 microns. Each time segments are reordered, the average diameter and std. deviation changes and therefore several iterations are required. These calculations are broken out separately, instead of using excels iterative capabilities, in order to limit the chance of error.

Calculates the upper diameter limit to have that segment classified under that order. Also, for the highest order, sets the max according to the upper limit specified in the "entered constants" sheet to make sure all diameters are captured.

Segments

Excel only allows a limited number of embedded "if" statements, therefore, four columns were used to look at whether the

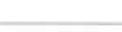

Segments

11 Excel only allows a limited number of embedded "if" statements, therefore, four columns we

12 Recalculated segment order, taken from values in (11)

13 Recalculates the average segment diameter of each order after the segments are reordered 14 Recalculates standard deviation for the diameters after reordering. First the ( $x$-xbar $)^{\wedge} 2$ value is calculated in one column for

15 Recalculates the lower diameter limit to have that vessel classified under that order, sets the diameter lower bound for order 1 vessels to be 0 microns.

16 Recalculates the upper diameter limit to have that vessel classified under that order. Also, for the highest order, sets according to the upper limit specified in the "entered constants" sheet to make sure all diameters are captured.

17 Calculates starting quantity of each segment order

18 Calculates quantity of each seament order after re-ordering for that iteration

Segments

Segments

Segments

Segments

Segments

Segments

Segments

Look-up tables that trace the parental generations and orders of those parent vessels to be used in consolidating segments into

19 elements if vessels of the same order are connected in series. Additionally, this is used to create the connectivity matrix and provides numerical representation of how the vessels are connected together.

Purpose of this column is to start to create the elements: segments of the same order that are grouped together in series. The

formulas look to see if successive parental generations are of the same order or different, and names the element according to the "oldest" parent that is the same order. If elements are not formed, then the vessels would be treated as if in parallel regardless of the arrangement (yielding a lower resistance than what is actually present).

If a segment has a parent of the same order, it gets assigned an "ID" number. The end purpose of this is to see if there are vessels of identical order that have the exact same parental tree, yielding identical ID numbers. If vessels have identical ID

21 numbers and each have the same order as their parent, then one of the vessels needs to remain as a segment (instead of part of an element). This can be likened to vessels connected in series leading to a "Y", where one of the vessels should be considered in series and one should not.

22 Counts the number of seqments containing the ID number in (21) 23 If (22) is greater than 1 (meaning that there is more than one vessel with the same parental tree), then the formula sums the

Segments

Elements

In the case of a " $Y$ " (see 21), the assumption / decision was made that the vessel of the shortest diameter would be left as a

24 segment and not included in the element formation. Additionally, if the vessels are of equal diameter, then they are both treated

at which vessel's diameter makes up the smallest portion of (23) and giving an output of "1". 


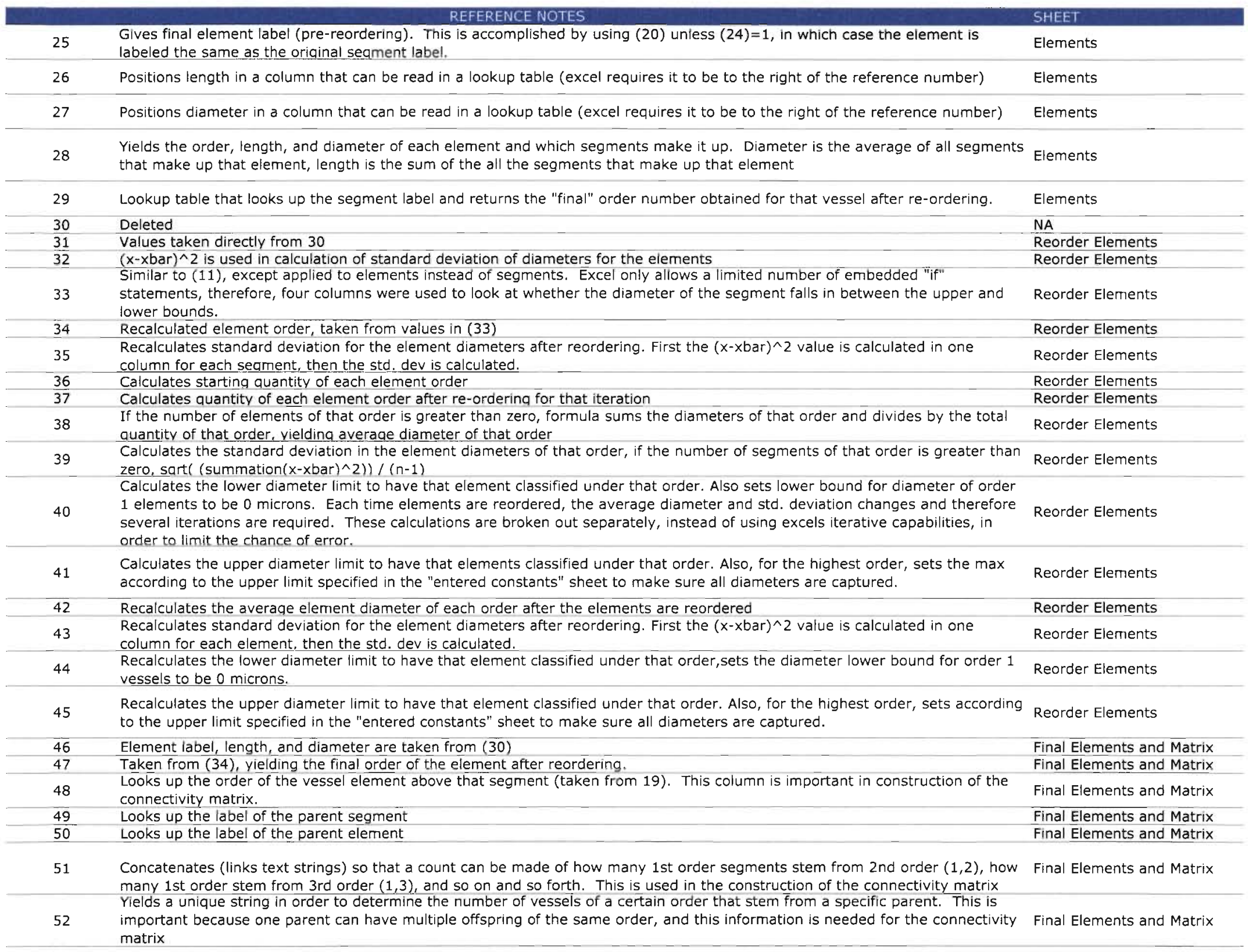


55 Connectivity Matrix, Each cell calculates: (Number of offspring of order $m$ / Number of parents of order $n$ that have offspring of order $\mathrm{m}$ )/(Total number of vessel elements of order $\mathrm{n}$ ). In general each cell represents the average ratio fo the number of

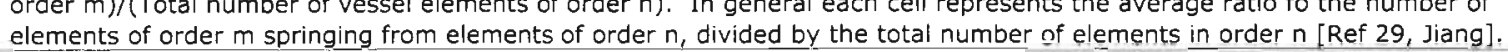

56 Counts the number of vessels that have the same parent ID. Tells how many outlets there are to each node

57 Creates a label for the pressure at the end of the element for future use in equations and generation of code. All capillaries are Flow eq 1 labeled Pcap (its assumed that they are all at the same pressure, set by the boundary conditions).

58 Creates a label for the pressure at the end of the feeding parent vessel for future use in equations and generation of code. Flow eq 1

59 Not currentiy used in calculations (5/14/08). Calls out the connectivity matrix location that describes that particular node in the network.

Describes the pressure drop across that element's length. Its called "inlet" because all nodes are named according to the

Flow eq 1

60 Describes the pressure drop across that element's length. Its called "inlet" because

Cails out "conductance" value for that vessel for use future use in equations and generation of code.

62 Creates flow equation through this element

Each of these columns creates the outlet flow equations for each node assuming it has 1,2,3,4, etc offspring. These columns are Each of these columns are then referenced according to the actual number of offspring.

Creates the flows at how many offspring a parent vessel has and references the appropriate equation from. These are to be referenced by the parent node (63). Note that the column headings must be numbers because the Hlookup function references these cells.

65 Creates table (for reference later) that describes the outlet flow for that node.

66 Is used tô teill tilookup to pull the data in a certain cell from that row

67 Same as parent data pasted into the sheet by $\mathrm{ctrl} \mathrm{g}$ or $\mathrm{ctrl} \mathrm{m}$ (there for easy reference later)

68 Looks to see how many offspring a particular parent vessel has, and then look

Used later to concatenate the letter " $\mathrm{C}$ " with this number so that the correct conductance value can be used in the flow

Final Elements and Matrix Flow eq 1

equations. This column is adjusted with the macros ctri $y$, ctrl $t$, and ctrl $r$, depending on if segments or elements are being

used. For the segments, these numbers correspond to the segment ID. For the elements these numbers correspond to the order

number

$70 \quad$ Looks up the correct outlet flow equation for that segment (from the Flow eq1 sheet)

If " $Y$ " is entered into the Entered Constants worksheet, this column will display the capillary equations generated according to the

71 capillary density entered by the user into the Entered Values sheet. If " $N$ " is entered, no equations will display or propagate to the math code.

72 Retrieves the order of the node listed. If there is no node with that label, it will return a blank cell so that when the linear equations are generated, there won't be \#NA displayed at an order 1 vessel, no equation is generated since this point is the boundary condition and it is defined in the Entered

Constants worksheet as the capillary pressure.
If the node is not at an order 1 vessel and the node exists, it will concatenate the equations from (70) and (71) (the original

Flow eq 2 outlet equation for the node and the added capillaries equations, respectively)

Flow eq 2

75 If the node is at an order 1 vessel, sets the pressure of that node equal to the capillary pressure. If the node exists and is at an Flow eq 2 order greater than 1 , it forms an equation that is the concatenation of Inlet - Outlet $=0$ from (73) and (74)

order greater than 1 , it forms an equation that is the concatenation of Inlet - Outlet $=0$ from (73) and (74)

76 Same as 75, except doesn't ist an equation if node is a capillary. This is because the pressure is set by the boundary condition flow eq 2 77 flow equations that need to be solved.

78 Creates equation that Mathematica can read that sets the nodal pressure of order 1 vessels at the capillary pressure (set by the user). 

Computes the number of vessels to add based on the user defined density. Number of capillaries is based on \#/unit length of each vessel.

Add caps

References the user entered value for the total number of segments. Then, it starts numbering the new vessels up from there.

Add caps

Creates a portion of an equation that can be added on to the original data for that node to simulate additional vessels.

Add caps Creates an equation for the inlet of the simulated vessel.

Creates the first set of equations that defines inlet - outlet for the simulated vessels for Mathematica to solve.

Creates the second set of equations for Mathematica to solve, setting the flow in the vessel equal to the inlet.

Creates a list of the pressure variables that mathematica will need to solve for

Creates a list of the flow variables that mathematica wili need to solve for

Lists the order of the vessel that is added to that node (see $91,92,93,94$ )

Lists the number of capillaries per linear distance along the orginal network vessels. The value varies linearly with order

according to user defined min and max densities defined by the user in the Entered Constants sheet.

Lists the length of the vessel added for that order. The value varies linearly with order according to user defined min and max densities defined by the user in the Entered Constants sheet.

Lists the diameter of the vessel added for that order. The value varies linearly with order according to user defined min and max densities defined by the user in the Entered Constants sheet.

Calculates the conductance of the vessel of that length and diameter according to $\left(P P^{*} D^{\wedge} 4\right) /\left(128^{*} L^{*} v i s c o s i t y\right)$, where viscosity is

defined in the Entered Constants sheet. These values will later be used in flow calculations.

Defines the conductance of each vessel of that order in a form that mathematica can read. " $G$ " is used instead of " $C$ " in order to

avoid confusion with the actual network conductance values and equations.

User enters in a number that is greater than the largest diameter measured in the network, ensures that all vessels are captured in the calculations

User enters the highest ID segment ID number in the orginal data. This tells excel where to start numbering when adding vessels (See 82).

Is altered by the macros used, tells excel whether or not to include the additional capillary / vessel equations into the

Add caps

Add caps

Add caps

Add caps

Add caps

Add caps

Add caps

Add caps

Add caps

Add caps

Add caps

Add caps

Entered Constants mathematica code equations.

Entered Constants

Entered Constants

User enters in the smallest and largest values for Linear Distance, Length, and Diamter of the added vessels. The smallest and largest values can be equal if the user wants to use values that don't change. Otherwise, these values will change linearly with

order number. Linear Distance is defined as the \# of vessels added per unit distance of original vessels.

1 User enters the value for the outlet pressure $(\overline{\mathrm{mmHg}})$ in the capillary bed

Entered Constants (n) enters the upper value for viscosity which will be used in the larger vessels. This will be varied linearly with the lower value Entered Constants according to order. If constant viscosity is desired, enter upper and lower values to be the same

User enters the lower value for viscosity which will be used in the smaller vessels. This will be varied linearly with the upper value according to order. If constant viscosity is desired, enter upper and lower values to be the same

The user defines the diameters to associate with each order for calculating viscosity. Therefore, one can vary between average segment and average element diameters.

Summary table of average lengths, diameters, and conductances for segments

Computes the average initial and final lengths before and after reordering. Mainly used for reference and calculation of standard deviations.

Table that shows the progress of each iteration for reordering of the segments

Entered Constants

Entered Constants

Entered Constants

Segments 


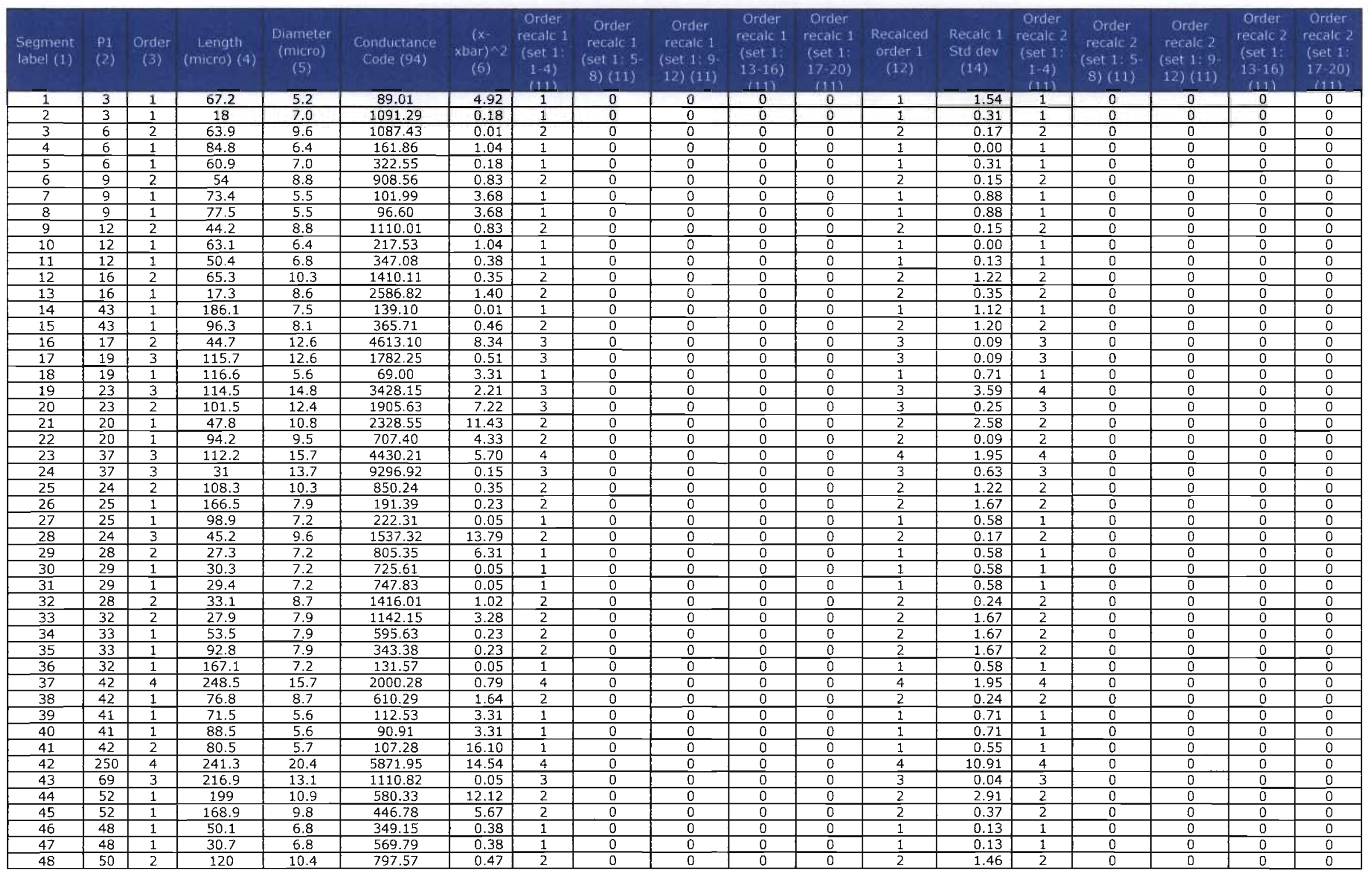




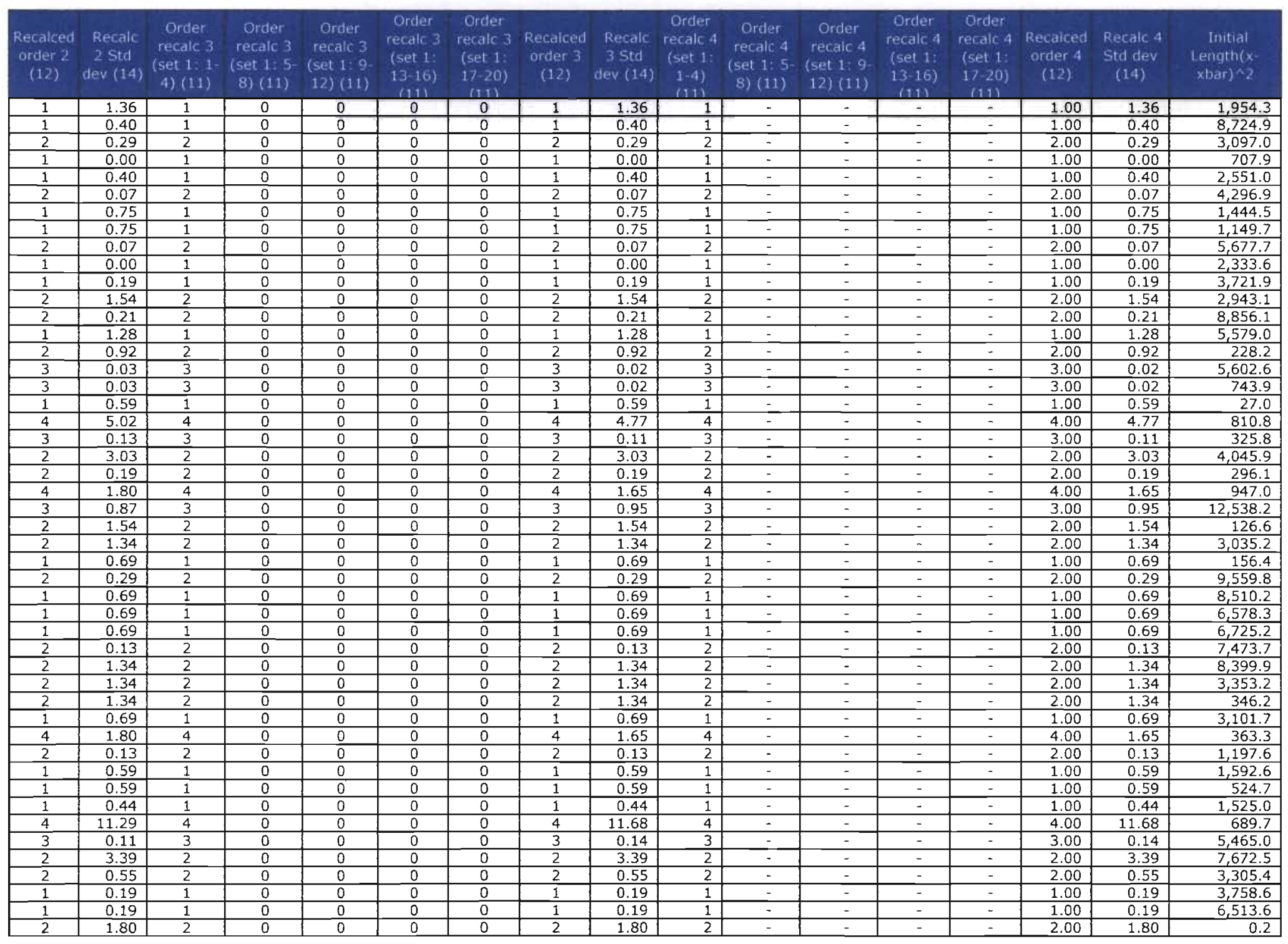

2 of 4

Pages move horizontal to the right 


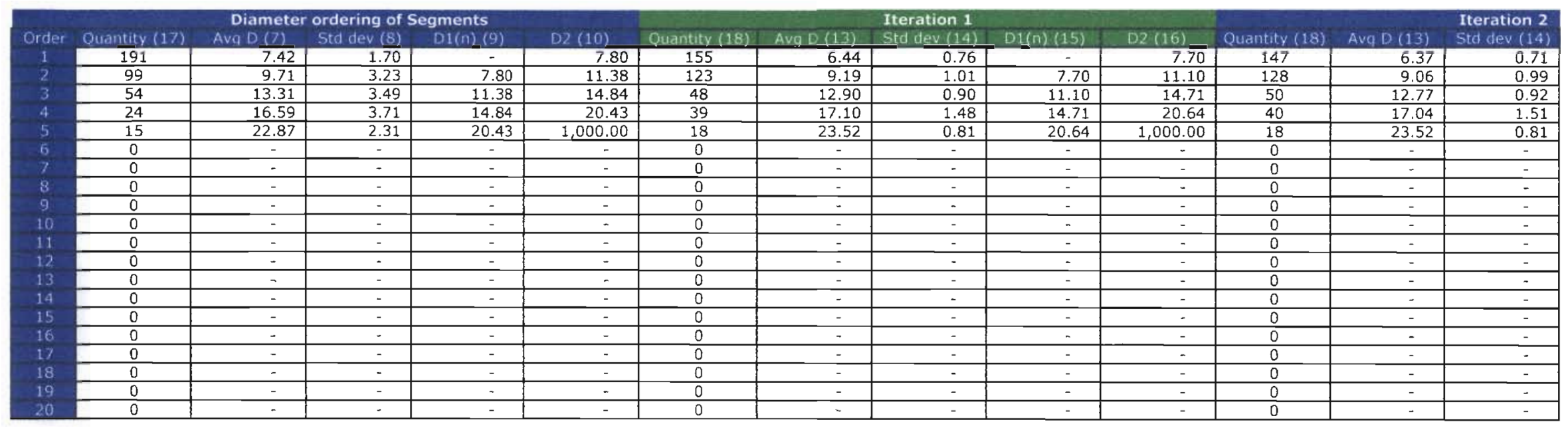

Note: 105
\begin{tabular}{|c|c|c|c|c|c|}
\hline Order & Qty (N) & Avg D & Std Dev & Avg L & C \\
\hline 1 & 147 & 6.367 & 0.715 & 111.41 & 120.658 \\
\hline 2 & 128 & 9.059 & 0.989 & 119.55 & 460.797 \\
\hline 3 & 49 & 12.727 & 0.889 & 142.97 & $1,501.072$ \\
\hline 4 & 41 & 16.983 & 1.534 & 267.56 & $2,543.577$ \\
\hline 5 & 18 & 23.517 & 0.813 & 297.55 & $8,409.205$ \\
\hline 6 & - & - & - & - & - \\
\hline 7 & - & - & - & - & - \\
\hline 8 & - & - & - & - & - \\
\hline 9 & - & - & - & - & - \\
\hline 10 & - & - & - & - & - \\
\hline 11 & - & - & - & - & - \\
\hline 12 & - & - & - & - & - \\
\hline 13 & - & - & - & - & - \\
\hline 14 & - & - & - & - & - \\
\hline 15 & - & - & - & - & - \\
\hline 16 & - & - & - & - & - \\
\hline 17 & - & - & - & - & - \\
\hline 18 & - & - & - & - & - \\
\hline 19 & - & - & - & - & - \\
\hline 20 & - & - & - & - & - \\
\hline
\end{tabular}
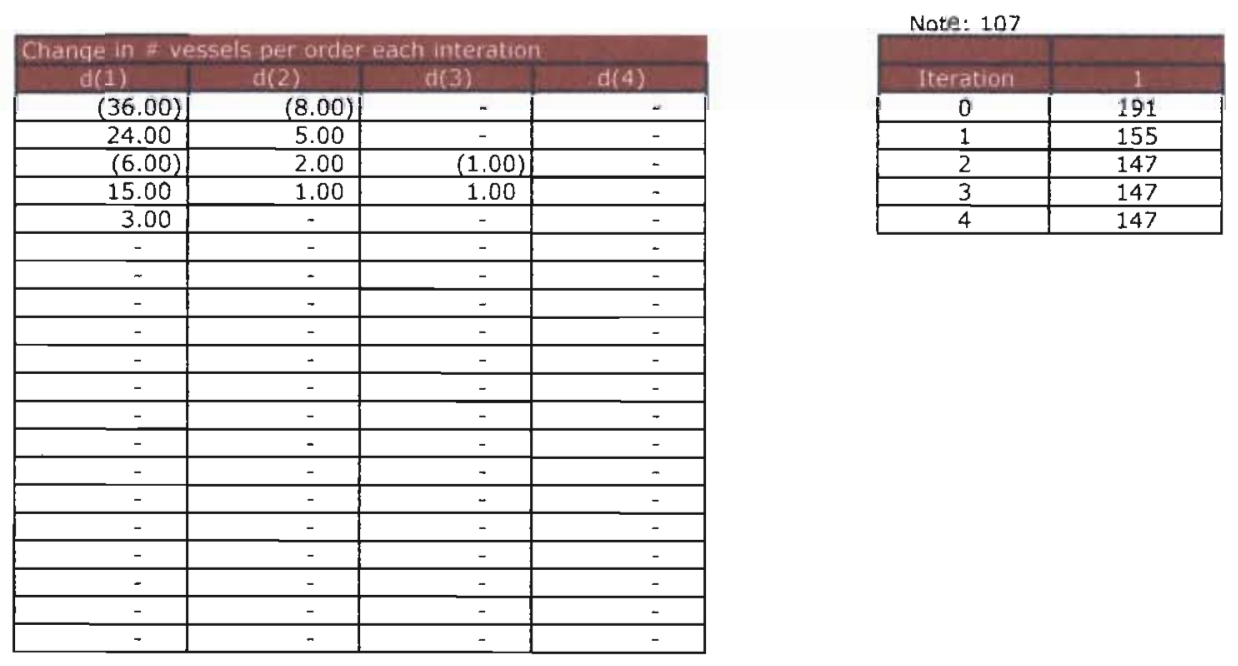


\begin{tabular}{|c|c|c|c|c|c|c|c|c|c|c|c|c|c|c|c|}
\hline & & & & Iteration 3 & & & & & Iteration 4 & & & Initia & (106) & Final & $(106)$ \\
\hline D1(n) (15) & $D 2(16)$ & Luantity (18 & Ava D (13) & Std dev (14) & D1 $(n)(15)$ & $D 2(16)$ & Suantity (18 & Avg D (13) & Std dev (14: & $D 1(n)(15)$ & $D 2(16)$ & Avg L & Std Dev & Ava $L$ & Std Dev \\
\hline & 7.58 & 147 & 6.37 & 0.71 & - & 7.58 & 147 & 6.37 & 0.71 & - & 7.58 & 111.41 & 89.71 & 80.62 & 102.25 \\
\hline 7.58 & 10.95 & 128 & 9.06 & 0.99 & 7.58 & 10.94 & 128 & 9.06 & 0.99 & 7.58 & 10.94 & 119.55 & 113.23 & 129.07 & 99.58 \\
\hline 10.95 & 14.61 & 49 & 12.73 & 0.89 & 10.94 & 14.53 & 49 & 12.73 & 0.89 & 10.94 & 14.53 & 142.97 & 162.67 & 154.48 & 170.77 \\
\hline 14.61 & 20.63 & 41 & 16.98 & 1.53 & 14.53 & 20.61 & 41 & 16.98 & 1.53 & 14.53 & 20.61 & 267.56 & 199.97 & 216.18 & 153.00 \\
\hline 20.63 & $1,000.00$ & 18 & 23.52 & 0.81 & 20.61 & $1,000.00$ & 18 & 23.52 & 0.81 & 20.61 & $1,000.00$ & 297.55 & 187.82 & 384.10 & 171.45 \\
\hline- & - & - & - & - & - & - & 0 & - & - & - & - & - & - & - & - \\
\hline- & - & - & - & $=$ & - & - & 0 & - & - & - & - & - & - & - & - \\
\hline- & - & - & $\sim$ & - & - & - & 0 & - & - & - & - & - & - & $=$ & - \\
\hline- & - & - & - & - & - & - & 0 & - & - & - & - & $\sim$ & $=$ & - & - \\
\hline- & - & - & - & - & - & - & 0 & - & - & - & - & - & - & - & - \\
\hline- & $=$ & - & - & - & - & - & 0 & - & - & - & - & - & - & - & - \\
\hline- & - & - & - & - & - & - & 0 & $=$ & - & - & - & - & - & - & - \\
\hline- & - & - & - & - & - & - & 0 & - & - & - & - & - & - & - & - \\
\hline- & - & - & - & - & - & - & 0 & - & - & - & - & - & - & - & - \\
\hline- & - & - & - & - & - & - & 0 & - & - & - & - & - & - & - & - \\
\hline- & - & - & - & - & - & - & 0 & - & - & - & $=$ & - & - & - & - \\
\hline- & - & - & - & - & - & - & 0 & - & - & - & - & - & - & - & - \\
\hline- & - & - & - & - & - & - & 0 & - & - & - & - & - & - & - & - \\
\hline- & - & - & - & - & - & $=$ & 0 & - & - & - & - & - & - & - & - \\
\hline 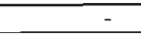 & - & - & - & - & - & - & 0 & - & 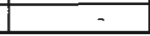 & - & - & - & - & 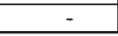 & 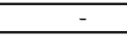 \\
\hline
\end{tabular}

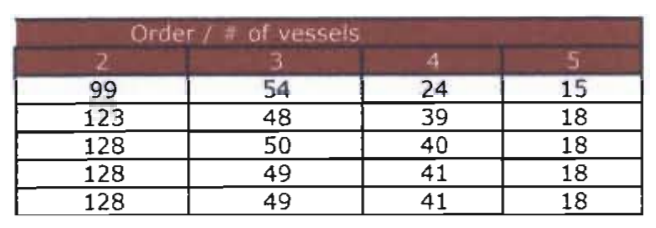




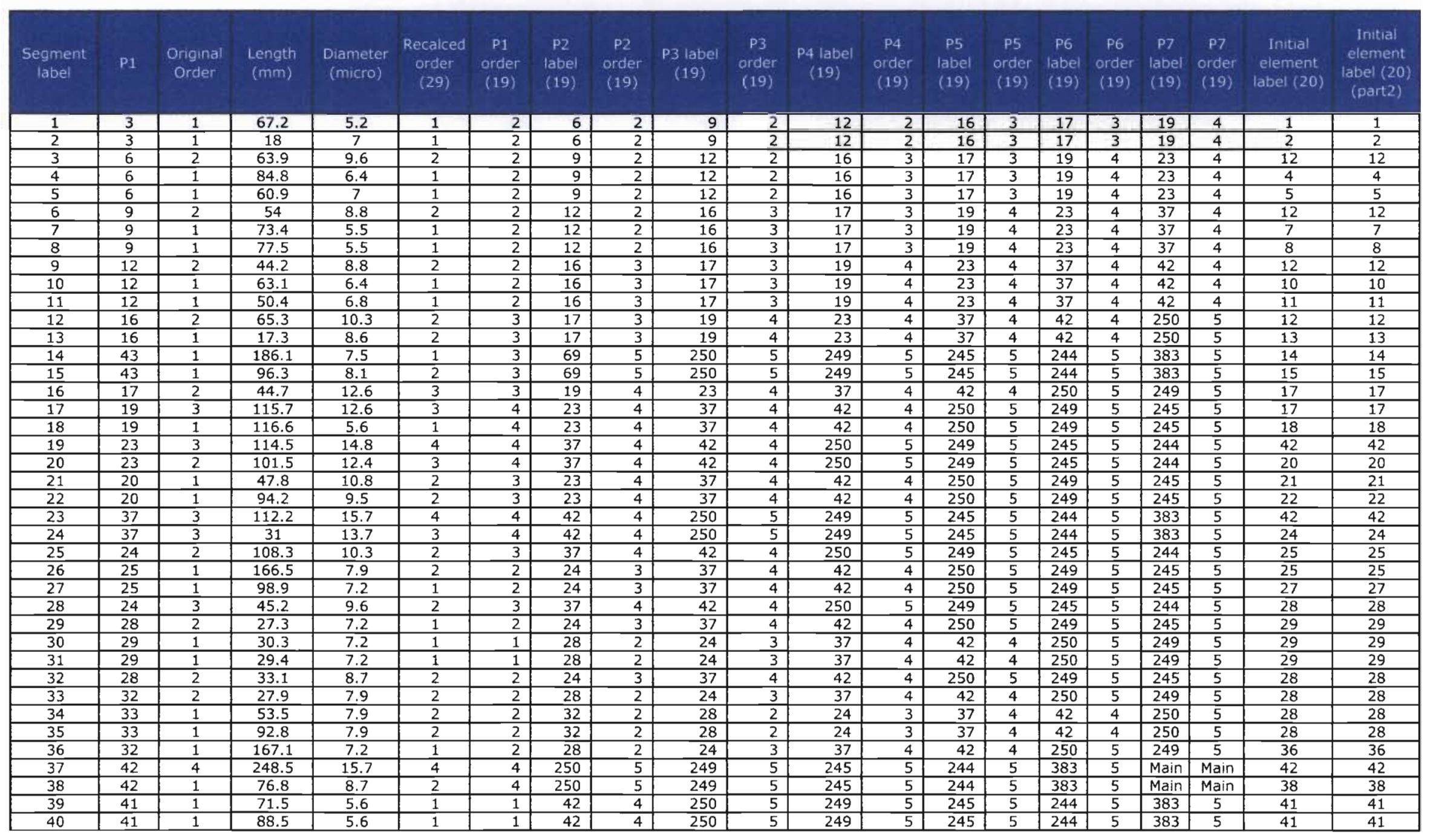




\begin{tabular}{|c|c|c|c|c|c|c|c|c|c|c|c|}
\hline ID (21) & $\begin{array}{c}\text { Count } \\
\text { duplicates } \\
\text { (22) }\end{array}$ & $\begin{array}{l}\text { Sum diameter } \\
\text { for duplicate } \\
\text { IDS (23) }\end{array}$ & $\begin{array}{l}\text { Find diameter } \\
\text { length to break } \\
\text { off from element } \\
\text { (24) }\end{array}$ & $\begin{array}{l}\text { Final } \\
\text { Element } \\
\text { Label, pre- } \\
\text { reordering } \\
\text { (25) }\end{array}$ & Order & Length (26) & $\begin{array}{l}\text { Diameter } \\
\text { (27) }\end{array}$ & $\begin{array}{l}\text { Element } \\
\text { label (28) }\end{array}$ & $\begin{array}{l}\text { Order } \\
(28)\end{array}$ & $\begin{array}{l}\text { Length } \\
(\mathrm{mm})(28)\end{array}$ & $\begin{array}{l}\text { Diameter: } \\
\text { (micron) (28) }\end{array}$ \\
\hline 0 & 0 & 0 & 0 & 1 & 1 & 67.2 & 5.2 & 1 & 1 & 67.20 & 5.20 \\
\hline 0 & 0 & 0 & 0 & 2 & 1 & 18 & 7 & 2 & 1 & 18.00 & 7.00 \\
\hline 6291216171923 & 1 & 0 & 0 & 12 & 2 & 63.9 & 9.6 & 3 & 0 & 0.00 & 0.00 \\
\hline 0 & 0 & 0 & 0 & 4 & 1 & 84.8 & 6.4 & 4 & 1 & 84.80 & 6.40 \\
\hline 0 & 0 & 0 & 0 & 5 & 1 & 60.9 & 7 & 5 & 1 & 60.90 & 7.00 \\
\hline 92121617192337 & 1 & 0 & 0 & 12 & 2 & 54 & 8.8 & 6 & 0 & 0.00 & 0.00 \\
\hline 0 & 0 & 0 & 0 & 7 & 1 & 73.4 & 5.5 & 7 & 1 & 73.40 & 5.50 \\
\hline 0 & 0 & 0 & 0 & 8 & 1 & 77.5 & 5.5 & 8 & 1 & 77.50 & 5.50 \\
\hline 122161719233742 & 1 & 0 & 0 & 12 & 2 & 44.2 & 8.8 & 9 & 0 & 0.00 & 0.00 \\
\hline 0 & 0 & 0 & 0 & 10 & 1 & 63.1 & 6.4 & 10 & 1 & 63.10 & 6.40 \\
\hline 0 & 0 & 0 & 0 & 11 & 1 & 50.4 & 6.8 & 11 & 1 & 50.40 & 6.80 \\
\hline 0 & 0 & 0 & 0 & 12 & 2 & 65.3 & 10.3 & 12 & 2 & 227.40 & 9.38 \\
\hline 0 & 0 & 0 & 0 & 13 & 2 & 17.3 & 8.6 & 13 & 2 & 17.30 & 8.60 \\
\hline 0 & 0 & 0 & 0 & 14 & 1 & 186.1 & 7.5 & 14 & 1 & 186.10 & 7.50 \\
\hline 0 & 0 & 0 & 0 & 15 & 2 & 96.3 & 8.1 & 15 & 2 & 96.30 & 8.10 \\
\hline 17319233742250249 & 1 & 0 & 0 & 17 & 3 & 44.7 & 12.6 & 16 & 0 & 0.00 & 0.00 \\
\hline 0 & 0 & 0 & 0 & 17 & 3 & 115.7 & 12.6 & 17 & 3 & 160.40 & 12.60 \\
\hline 0 & 0 & 0 & 0 & 18 & 1 & 116.6 & 5.6 & 18 & 1 & 116.60 & 5.60 \\
\hline 2343742250249245244 & 1 & 0 & 0 & 42 & 4 & 114.5 & 14.8 & 19 & 0 & 0.00 & 0.00 \\
\hline 0 & 0 & 0 & 0 & 20 & 3 & 101.5 & 12.4 & 20 & 3 & 101.50 & 12.40 \\
\hline 0 & 0 & 0 & 0 & 21 & 2 & 47.8 & 10.8 & 21 & 2 & 47.80 & 10.80 \\
\hline 0 & 0 & 0 & 0 & 22 & 2 & 94.2 & 9.5 & 22 & 2 & 94.20 & 9.50 \\
\hline 37442250249245244383 & 1 & 0 & 0 & 42 & 4 & 112.2 & 15.7 & 23 & 0 & 0.00 & 0.00 \\
\hline 0 & 0 & 0 & 0 & 24 & 3 & 31 & 13.7 & 24 & 3 & 31.00 & 13.70 \\
\hline 0 & 0 & 0 & 0 & 25 & 2 & 108.3 & 10.3 & 25 & 2 & 274.80 & 9.10 \\
\hline 252243742250249245 & 1. & 0 & 0 & 25 & 2 & 166.5 & 7.9 & 26 & 0 & 0.00 & 0.00 \\
\hline 0 & 0 & 0 & 0 & 27 & 1 & 98.9 & 7.2 & 27 & 1 & 98.90 & 7.20 \\
\hline 0 & 0 & 0 & 0 & 28 & 2 & 45.2 & 9.6 & 28 & 2 & 106.20 & 8.73 \\
\hline 0 & 0 & 0 & 0 & 29 & 1 & 27.3 & 7.2 & 29 & 1 & 27.30 & 7.20 \\
\hline 29128243742250249 & 2 & 14.4 & 1 & 30 & 1 & 30.3 & 7.2 & 30 & 1 & 30.30 & 7.20 \\
\hline 29128243742250249 & 2 & 14.4 & 1 & 31 & 1 & 29.4 & 7.2 & 31 & 1 & 29.40 & 7.20 \\
\hline 282243742250249245 & 1 & 0 & 0 & 28 & 2 & 33.1 & 8.7 & 32 & 0 & 0.00 & 0.00 \\
\hline 32228243742250249 & 1 & 0 & 0 & 28 & 2 & 27.9 & 7.9 & 33 & 0 & 0.00 & 0.00 \\
\hline 3323228243742250 & 2 & 15.8 & 1 & 34 & 2 & 53.5 & 7.9 & 34 & 2 & 53.50 & 7.90 \\
\hline 3323228243742250 & 2 & 15.8 & 1 & 35 & 2 & 92.8 & 7.9 & 35 & 2 & 92.80 & 7.90 \\
\hline 0 & 0 & 0 & 0 & 36 & 1 & 167.1 & 7.2 & 36 & 1 & 167.10 & 7.20 \\
\hline 424250249245244383 main & 1 & 0 & 0 & 42 & 4 & 248.5 & 15.7 & 37 & 0 & 0.00 & 0.00 \\
\hline 0 & 0 & 0 & 0 & 38 & 2 & 76.8 & 8.7 & 38 & 2 & 76.80 & 8.70 \\
\hline 41142250249245244383 & 2 & 11.2 & 1 & 39 & 1 & 71.5 & 5.6 & 39 & 1 & 71.50 & 5.60 \\
\hline 41142250249245244383 & 2 & 11.2 & 1 & 40 & 1 & 88.5 & 5.6 & 40 & 1 & 88.50 & 5.60 \\
\hline
\end{tabular}




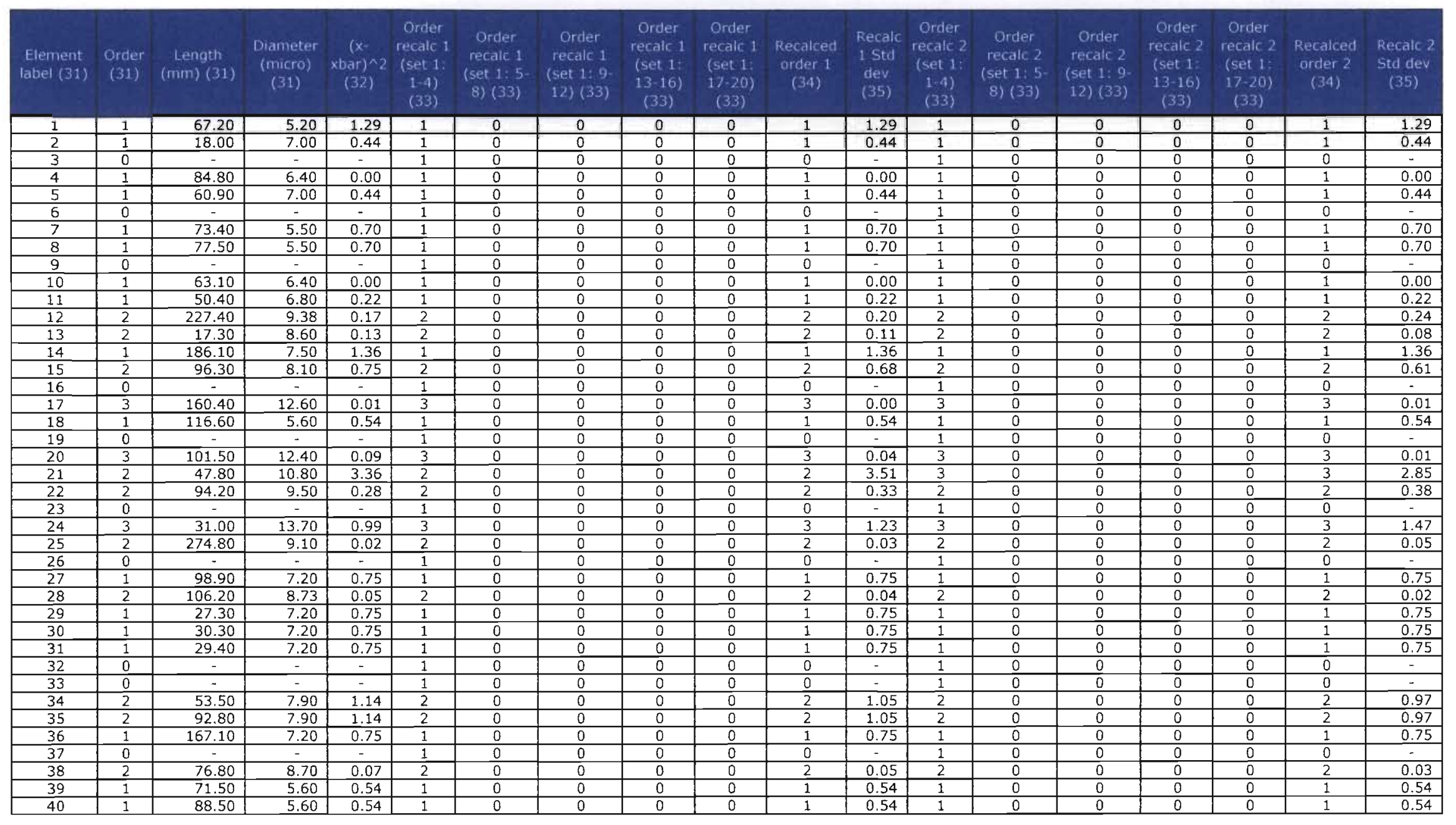

1 of 5

Pages move horizontal to the right 


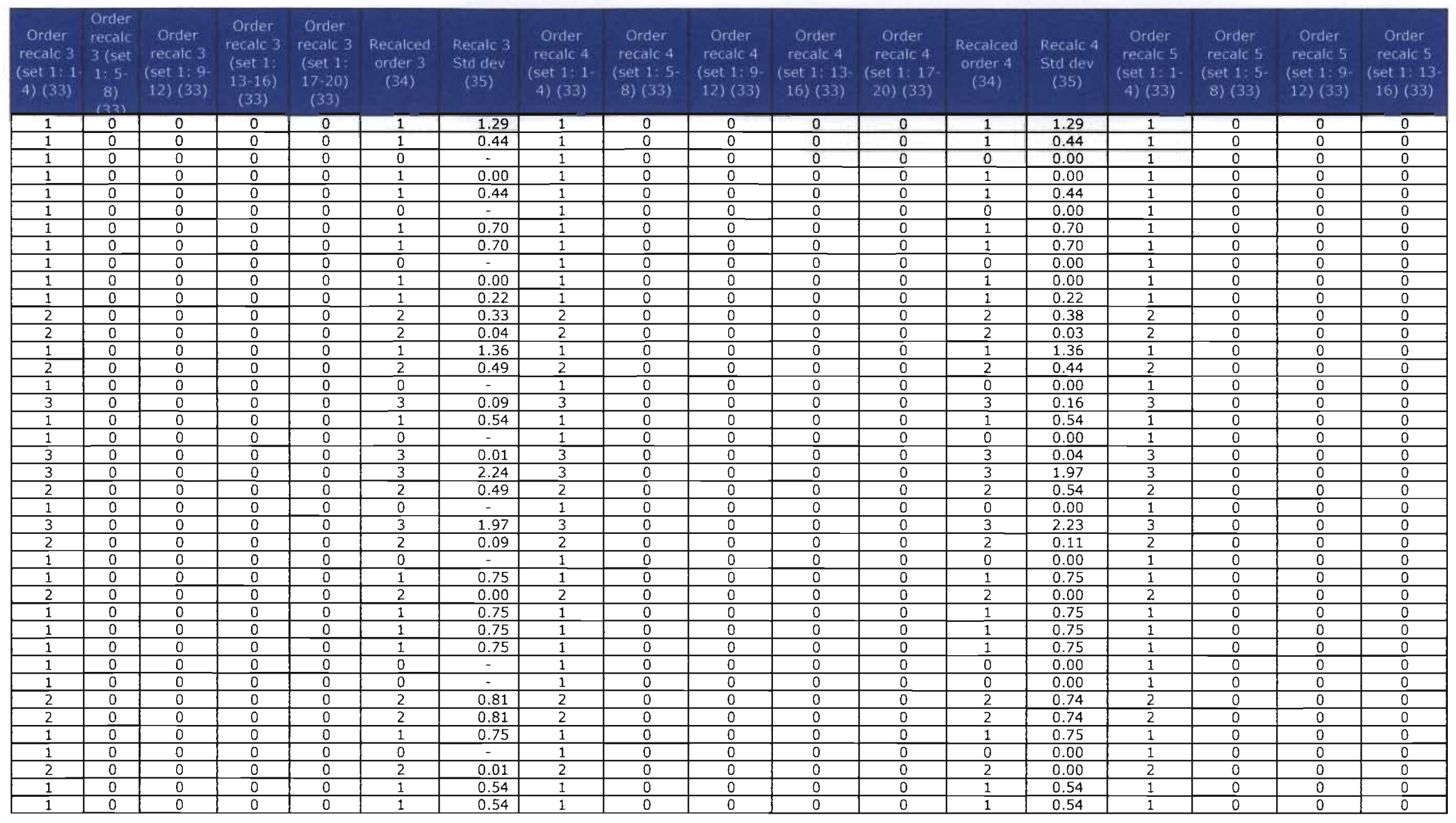

2 of 5

Pages move horizontal to the right 

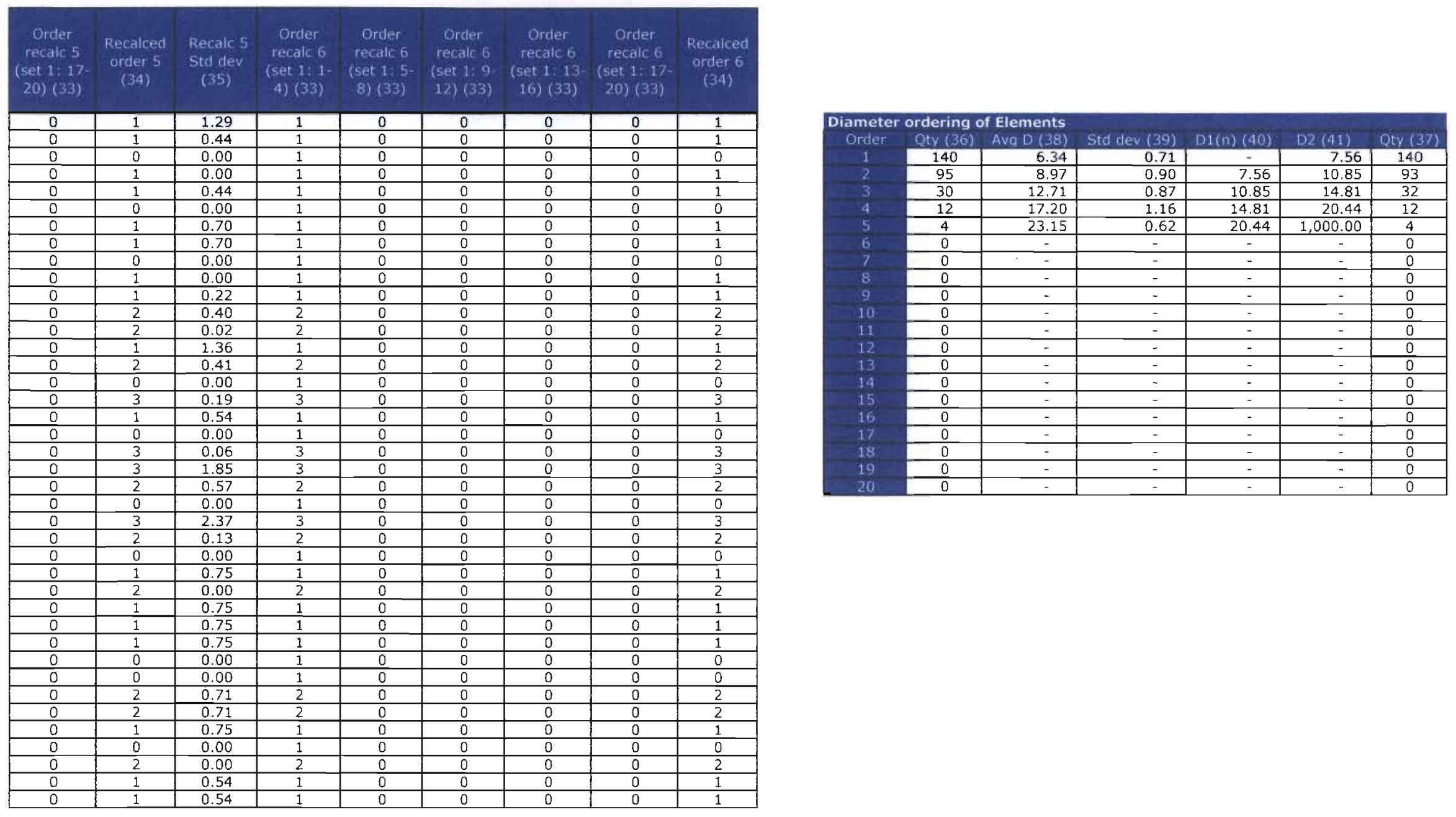


\begin{tabular}{|c|c|c|c|c|c|c|c|c|c|c|c|c|c|c|}
\hline Avg D (42) & $\begin{array}{r}\text { Iteration 1 } \\
\text { Std dev }(43)\end{array}$ & $D 1(n)(44)$ & D2 (45) & Oty (37) & Avg D (42) & $\begin{array}{r}\text { Iteration } 2 \\
\text { Std dev (43) }\end{array}$ & $D 1(n)(44)$ & D2 (45) & Qty (37) & Avq D (42) & $\begin{array}{r}\text { Iteration } 3 \\
\text { Std dev }(43)\end{array}$ & $\mathrm{D} 1(\mathrm{n})(44)$ & $D 2(45)$ & Oty (37) \\
\hline 6.34 & 0.71 & - & 7.56 & 140 & 6.34 & 0.71 & - & 7.55 & 140 & 6.34 & 0.71 & - & 7.55 & 140 \\
\hline 8.93 & 0.86 & 7.56 & 10.71 & 91 & 8.88 & 0.83 & 7.55 & 10.59 & 87 & 8.80 & 0.75 & 7.55 & 10.37 & 85 \\
\hline 12.59 & 0.95 & 10.71 & 14.79 & 34 & 12.49 & 1.02 & 10.59 & 14.77 & 38 & 12.30 & 1.11 & 10.37 & 14.72 & 40 \\
\hline 17.20 & 1.16 & 14.79 & 20.44 & 12 & 17.20 & 1.16 & 14.77 & 20.44 & 12 & 17.20 & 1.16 & 14.72 & 20.44 & 12 \\
\hline 23.15 & 0.62 & 20.44 & $1,000.00$ & 4 & 23.15 & 0.62 & 20.44 & $1,000.00$ & 4 & 23.15 & 0.62 & 20.44 & $1,000.00$ & 4 \\
\hline- & - & - & - & 0 & - & - & - & - & 0 & - & - & - & - & 0 \\
\hline- & - & - & - & 0 & - & - & - & - & 0 & - & - & - & - & 0 \\
\hline- & - & - & - & 0 & - & - & - & - & 0 & - & - & - & - & 0 \\
\hline- & - & - & - & 0 & - & $=$ & - & - & 0 & - & - & - & - & 0 \\
\hline- & - & - & - & 0 & - & - & - & - & 0 & - & - & - & - & 0 \\
\hline- & - & - & - & 0 & - & - & - & - & 0 & - & - & - & - & 0 \\
\hline - & - & - & - & 0 & - & - & - & - & 0 & - & - & - & - & 0 \\
\hline- & - & - & - & 0 & - & - & - & - & 0 & - & - & - & - & 0 \\
\hline - & - & - & - & 0 & - & - & - & - & 0 & - & - & - & - & 0 \\
\hline- & - & - & - & 0 & - & - & - & - & 0 & - & - & - & - & 0 \\
\hline- & - & - & - & 0 & - & - & $=$ & - & 0 & - & - & - & - & 0 \\
\hline- & - & - & - & 0 & - & - & - & - & 0 & - & - & - & - & 0 \\
\hline- & - & - & - & 0 & - & - & - & - & 0 & - & - & - & - & 0 \\
\hline- & - & - & - & 0 & - & - & - & - & 0 & - & - & - & - & 0 \\
\hline- & - & 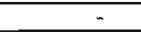 & - & 0 & - & - & - & - & 0 & - & - & - & - & 0 \\
\hline
\end{tabular}

Order / \# of vessels

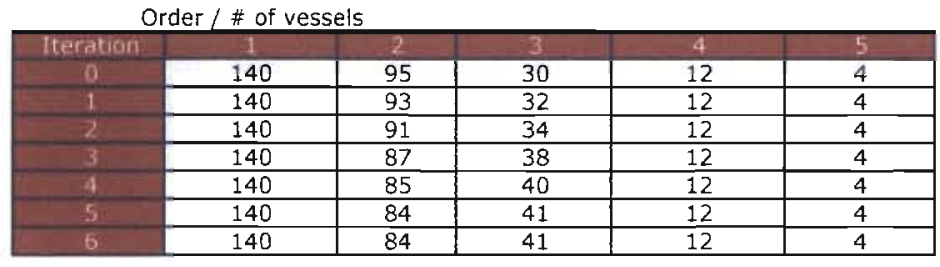




\begin{tabular}{|c|c|c|c|c|c|c|c|c|c|c|c|c|c|}
\hline Avg D (42) & $\begin{array}{r}\text { Iteration } 4 \\
\text { Std dev (43) }\end{array}$ & $D 1(n)(44)$ & $D 2(45)$ & Qty (37) & Avg D (42) & $\begin{array}{r}\text { Iteration } 5 \\
\text { Std dev (43) }\end{array}$ & $D 1(n)(44)$ & D2 (45) & Qty (37) & Avg D (42) & $\begin{array}{l}\text { Iteration } 6 \\
\text { Std dev (43) }\end{array}$ & $D 1(\mathrm{n})(44)$ & D2 (45) \\
\hline 6.34 & 0.71 & - & 7.55 & 140 & 6.34 & 0.71 & - & 7.55 & 140 & & & & \\
\hline 8.76 & 0.71 & 7.55 & 10.26 & 84 & 8.74 & 0.69 & 7.55 & 10.21 & 84 & No change f & from previous & interation & \\
\hline 12.21 & 1.15 & 10.26 & 14.70 & 41 & 12.16 & 1.17 & 10.21 & 14.69 & 41 & & & & \\
\hline 17.20 & 1.16 & 14.70 & 20.44 & 12 & 17.20 & 1.16 & 14.69 & 20.44 & 12 & & & & \\
\hline 23.15 & 0.62 & 20.44 & $1,000.00$ & 4 & 23.15 & 0.62 & 20.44 & $1,000.00$ & 4 & & & & \\
\hline- & - & - & - & 0 & - & - & - & - & 0 & & & & \\
\hline- & - & - & - & 0 & - & - & - & - & 0 & & & & \\
\hline- & - & - & - & 0 & - & - & - & - & 0 & & & & \\
\hline- & - & - & - & 0 & - & - & - & - & 0 & & & & \\
\hline- & - & - & - & 0 & - & - & - & - & 0 & & & & \\
\hline- & - & - & - & 0 & - & - & - & - & 0 & & & & \\
\hline- & - & - & - & 0 & - & $=$ & - & - & 0 & & & & \\
\hline- & - & - & - & 0 & - & - & - & - & 0 & & & & \\
\hline- & - & - & - & 0 & - & - & - & - & 0 & & & & \\
\hline- & - & - & - & 0 & - & - & - & - & 0 & & & & \\
\hline- & - & - & - & 0 & - & - & - & - & 0 & & & & \\
\hline- & - & - & - & 0 & - & - & - & - & 0 & & & & \\
\hline- & - & $\therefore$ & - & 0 & - & - & - & - & 0 & & & & \\
\hline- & - & - & - & 0 & - & - & - & - & 0 & & & & \\
\hline$=$ & - & - & - & 0 & $=$ & - & - & - & 0 & & & & \\
\hline
\end{tabular}




\begin{tabular}{|c|c|c|c|c|c|c|c|c|c|c|c|c|c|c|c|c|c|}
\hline $\begin{array}{l}\text { Segment: } \\
\text { label (1) }\end{array}$ & $\begin{array}{l}\text { Recalce } \\
\text { d order } 4 \\
\text { (12) }\end{array}$ & $\begin{array}{l}\text { Length (micro) } \\
\text { (4) }\end{array}$ & $\begin{array}{l}\text { Diameter } \\
\text { (imicro) (5) }\end{array}$ & $\begin{array}{l}\text { Pl order } \\
\text { (19) }\end{array}$ & P1 (2) & $\mathrm{P}_{1}(2)$ & $\begin{array}{l}\text { Offpsning + } \\
\text { Parent order } \\
\text { Concatenate } \\
\text { (51) }\end{array}$ & $\begin{array}{l}\text { Plus parent } \\
\text { olement } \\
\text { label } \\
\text { concatenate } \\
\text { (52) }\end{array}$ & $\begin{array}{l}\text { Identical } \\
\text { counts (53) }\end{array}$ & $\begin{array}{c}\text { 1/Hof } \\
\text { parents of } \\
\text { that number } \\
\text { (54) }\end{array}$ & $\begin{array}{c}\text { Diameter }(x= \\
\text { xbari } 12\end{array}$ & $\begin{array}{l}\text { Length }(x) \\
x \text { barik2 }\end{array}$ & Order & $\operatorname{ary}(\mathbb{N})$ & $\begin{array}{l}\text { Averaga D: } \\
\text { (micram) }\end{array}$ & $\begin{array}{l}\text { Average } \\
\text { Length } \\
\text { imicromi }\end{array}$ & $\begin{array}{c}\text { G (mi) - } \\
\text { Conductance (94) }\end{array}$ \\
\hline 1 & 1 & 67.20 & 5.20 & 2 & 3 & 3 & 1,2 & $1,2, \overline{3}$ & 2 & 0.50 & 9.28 & $1 \overline{8}$ & 1 & 147 & 8.2 & 80.6 & 469.398 \\
\hline 2 & 1 & 18.00 & 7.00 & 2 & 3 & 3 & 1,2 & $1,2,3$ & 2 & 0.50 & 1.55 & 3,921 & 2 & 128 & 9.1 & 129.1 & 426.798 \\
\hline 3 & 2 & 63.90 & 9.60 & 2 & 6 & 6 & 2,2 & $2,2,6$ & 1. & 1.00 & 0.29 & 4,248 & 3 & 49 & 12.7 & 154.5 & $1,389.236$ \\
\hline 4 & 1 & 84.80 & 6.40 & 2 & 6 & 6 & 1,2 & $1,2,6$ & 2 & 0.50 & 3.41 & 17 & 4 & 41 & 17.0 & 216.2 & 3.148 .106 \\
\hline 5 & 1 & 60.90 & 7.00 & 2 & 6 & 6 & 1,2 & $1,2,6$ & 2 & 0.50 & 1.55 & 389 & 5 & 18 & 23.5 & 384.1 & $6,514.520$ \\
\hline 6 & 2 & 54.00 & 8.80 & 2 & 9 & 9 & 2,2 & $2,2,9$ & 1 & 1.00 & 0.07 & 5,636 & 6 & - & - & - & - \\
\hline 7 & 1 & 73.40 & 5.50 & 2 & 9 & 9 & 1,2 & $1,2,9$ & 2 & 0.50 & 7.55 & 52 & 7 & - & - & - & - \\
\hline 8 & 1 & 77.50 & 5.50 & 2 & 9 & 9 & 1,2 & $1,2,9$ & 2 & 0.50 & 7.55 & 10 & 8 & - & - & - & - \\
\hline 9 & 2 & 44.20 & 8.80 & 2 & 12 & 12 & 2,2 & $2,2,12$ & 1 & 1.00 & 0.07 & 7,204 & 9 & - & - & - & - \\
\hline 10 & 1 & 63.10 & 6.40 & 2 & 12 & 12 & 1.2 & $1,2,12$ & 2 & 0.50 & 3.41 & 307 & 10 & & - & - & - \\
\hline 11 & 4 & 50.40 & 6.80 & 2 & 12 & 12 & 1,2 & $1,2,12$ & \begin{tabular}{l|l}
2 \\
\end{tabular} & 0.50 & 2.09 & 913 & 11 & - & - & - & - \\
\hline 12 & 2 & \begin{tabular}{ll|}
65.30 \\
\end{tabular} & 10.30 & 3 & 16 & 16 & 2,3 & $2,3,16$ & 2 & 0.50 & 1.54 & 4,067 & 12 & - & - & - & - \\
\hline 13 & 2 & 17.30 & 8.60 & 3 & 16 & 16 & 2,3 & $2,3,16$ & \begin{tabular}{l|l}
2 \\
\end{tabular} & 0.50 & 0.21 & 12,493 & 13 & - & - & - & - \\
\hline 94 & 1 & 186.10 & 7.50 & 3 & 43 & 43 & 1.3 & $1,3,43$ & 2 & 0.50 & 0.56 & \begin{tabular}{ll|}
11,126 \\
\end{tabular} & 14 & - & - & - & - \\
\hline 15 & 2 & 96.30 & 8.10 & 3 & 43 & 43 & 2,3 & $2,3,43$ & 1 & 1.00 & 0.92 & 1,074 & 15 & - & - & - & - \\
\hline 16 & 3 & \begin{tabular}{ll|}
44.70 \\
\end{tabular} & 12.50 & 3 & 17 & 17 & 3,3 & $3,3,17$ & 1 & 1.00 & 0.02 & 12,052 & 16 & - & - & - & - \\
\hline 17 & 3 & $\$ 15.70$ & 12.60 & 4 & 19 & 19 & 3,4 & $3,4,19$ & 1 & 1.00 & 0.02 & 1,504 & 17 & - & - & - & - \\
\hline 18 & 1 & 116.60 & 5.60 & 4 & 19 & 19 & 1,4 & $1,4,19$ & 1 & 1.00 & 7.01 & 1,294 & 18 & - & - & - & - \\
\hline 19 & 4 & 114.50 & 14.80 & 4 & 23 & 23 & 4,4 & $4,4,23$ & 1 & 1.00 & 4.77 & 10,339 & 19 & - & - & - & - \\
\hline 20 & 3 & 101.50 & 12.40 & 4 & 23 & 23 & 3,4 & $3,4,23$ & 1 & 1.00 & 0.11 & 2,807 & 20 & - & - & - & - \\
\hline 21 & 2 & 47.80 & 10.80 & 3 & 20 & 20 & 2,3 & $2,3,20$ & 2 & 0.50 & 3.03 & 6,605 & & & & & \\
\hline 22 & 2 & \begin{tabular}{|l|l}
94.20 \\
\end{tabular} & 9.50 & 3 & 20 & 20 & 2,3 & $2,3,20$ & \begin{tabular}{l|l}
2 \\
\end{tabular} & 0.50 & 0.19 & 1.216 & & & & & \\
\hline 23 & 4 & \begin{tabular}{|l|}
112.20 \\
\end{tabular} & 15.70 & 4 & 37 & 37 & 4,4 & $4,4,37$ & 1 & 1.00 & 1.65 & 10,812 & & & & & \\
\hline 24 & 3 & 31.00 & 13.70 & 4 & 37 & 37 & 3,4 & $3,4,37$ & 1 & 1.00 & 0.95 & 15,248 & & & & & \\
\hline 25 & 2 & 108.30 & 10.30 & 3 & 24 & 24 & 2,3 & $2,3,24$ & 2 & 0.50 & 9.54 & 432 & & & & & \\
\hline 26 & 2 & 166.50 & 7.90 & 2 & 25 & 25 & 2,2 & $2,2,25$ & 1 & 1.00 & 7.34 & 1,401 & & & & & \\
\hline 27 & 1 & 98.90 & 7.20 & 2 & 25 & 25 & 1,2 & $1,2,25$ & 1 & 1.00 & 1.10 & 334 & & & & & \\
\hline 28 & 2 & 45.20 & 9.60 & 3 & 24 & 24 & 2,3 & $2,3,24$ & 21 & 0.50 & 0.29 & 7,035 & & & & & \\
\hline
\end{tabular}




\begin{tabular}{|c|c|c|}
\hline $\begin{array}{l}\text { Mathematic } \\
\text { Code }\end{array}$ & $\begin{array}{l}\text { Diamerer } \\
\text { Sta Dey }\end{array}$ & $\begin{array}{c}\text { Langth Sto } \\
\text { Desy }\end{array}$ \\
\hline $\mathrm{C} 1=469.39782$ & 2.01 & 68.06 \\
\hline $\mathrm{C} 2=426.79841 \mathrm{I}$ & 0.99 & 94.73 \\
\hline$C 3=1389.2364$ & 0.89 & 93.18 \\
\hline$C 4=3148.1061 \mathrm{~A}$ & 1.53 & 180.38 \\
\hline $\mathrm{C} 5=6514.5199$ & 0.81 & 262.64 \\
\hline$C 6=0$ & & \\
\hline$C 7=0$ & & \\
\hline $\mathrm{C} 8=0$ & & \\
\hline$C 9=0$ & & \\
\hline $\mathrm{C}_{10}=0$ & & \\
\hline $\mathrm{C} 11=0$ & & \\
\hline $\mathrm{C} 12=0$ & & \\
\hline $\mathrm{C} 13=0$ & & \\
\hline $\mathrm{C} 14=0$ & & \\
\hline $\mathrm{C} 15=0$ & & \\
\hline$C 16=0$ & & \\
\hline $\mathrm{C} 17=0$ & & \\
\hline $\mathrm{C} 18=0$ & & \\
\hline$C 19=0$ & & \\
\hline $\mathrm{C} 2 \mathrm{O}=0$ & & \\
\hline
\end{tabular}

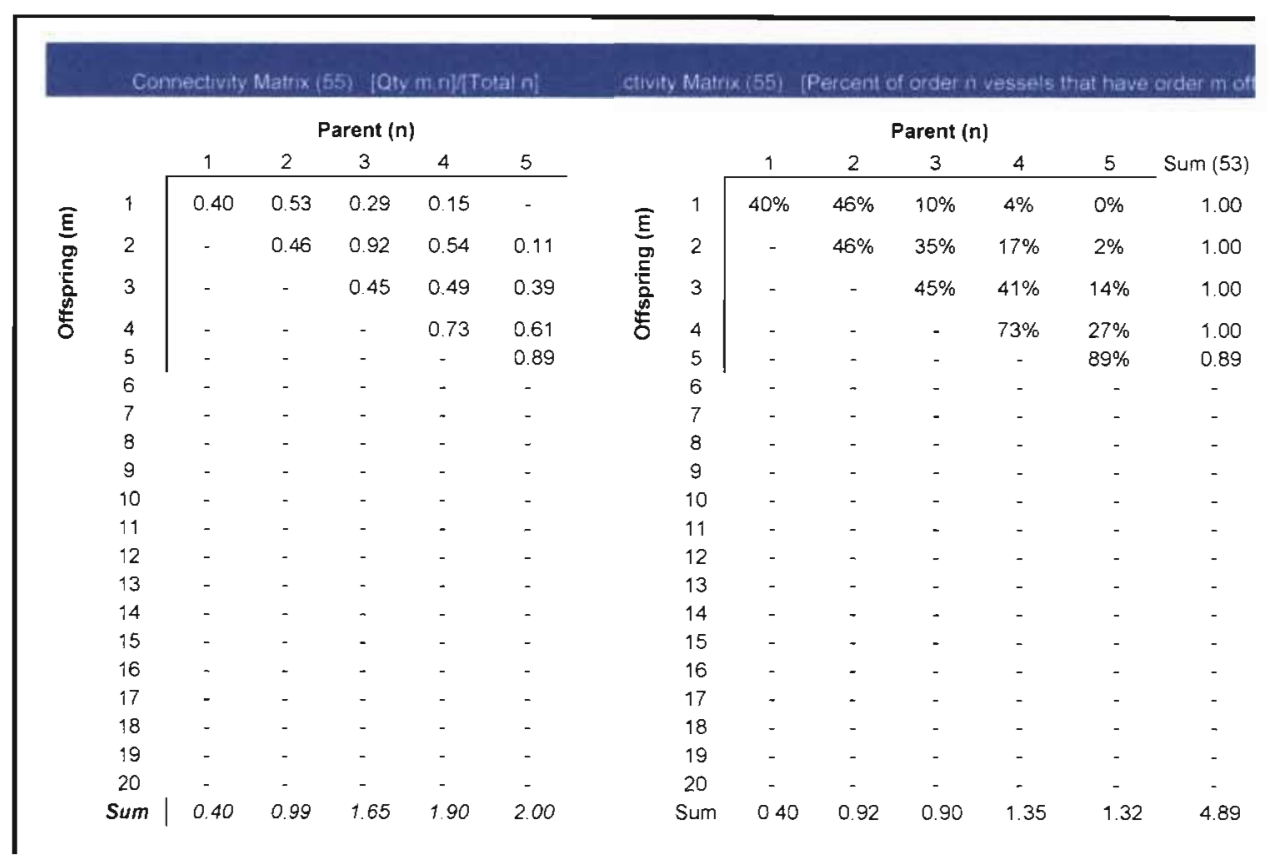




\begin{tabular}{|c|c|c|c|c|c|c|c|c|c|c|c|c|c|c|c|c|c|}
\hline $\begin{array}{l}\text { Element } \\
\text { abel ( } 46 \text { ) }\end{array}$ & $\begin{array}{l}\text { Order } \\
\text { (47) }\end{array}$ & Length (mM) (46) & $\begin{array}{c}\text { Dianeter } \\
\text { (micro) (46) }\end{array}$ & $\begin{array}{l}\text { Parent } \\
\text { order (48) }\end{array}$ & $\begin{array}{c}\text { Parent } \\
\text { Segment } \\
\text { Label (49) } \\
\end{array}$ & $\begin{array}{l}\text { Finat } \\
\text { Parent } \\
\text { Element } \\
\text { label }(50) \\
\end{array}$ & $\begin{array}{l}\text { Olipsring + } \\
\text { Parent ordar } \\
\text { Concatenate } \\
\text { (51) }\end{array}$ & $\begin{array}{l}\text { Plus parent } \\
\text { element } \\
\text { label } \\
\text { concatenate } \\
\text { (52) }\end{array}$ & $\begin{array}{l}\text { Identical } \\
\text { counts (53) }\end{array}$ & $\begin{array}{l}\text { tiłt of } \\
\text { parents of } \\
\text { that number } \\
(64)\end{array}$ & $\begin{array}{l}\text { Diameter i } x- \\
\text { xtari) } 12\end{array}$ & $\begin{array}{l}\text { Length }(x- \\
\text { xbar } 12 \\
\end{array}$ & Order & $\begin{array}{l}\text { Oty } \\
\text { IN }\end{array}$ & $\begin{array}{l}\text { Average D } \\
\text { (microm) }\end{array}$ & $\begin{array}{l}\text { Average } \\
\text { Length } \\
\text { (microm) }\end{array}$ & $\begin{array}{l}\mathrm{C}(\mathrm{m}) \text { - } \\
\text { Conductance } \\
(94)\end{array}$ \\
\hline 1 & 1 & 67.20 & 5.20 & 2 & 3 & 12 & 1,2 & $1,2,12$ & 8 & 0.13 & 1.21 & 234 & 1 & 140 & 6.3 & 82.5 & 156.1 \\
\hline 2 & 1 & 18.00 & 7.00 & 2 & 3 & 12 & 1,2 & $1,2,12$ & 8 & 0.13 & 0.49 & 4,159 & 2 & 84 & 8.7 & 174.2 & 274.6 \\
\hline 3 & 0 & - & - & - & - & - & 0,0 & $0,0,0$ & - & - & & & 3 & 41 & 12.2 & 230.8 & 775.1 \\
\hline 4 & 1 & 84.80 & 6.40 & 2 & 6 & 12 & 1,2 & $1,2,12$ & 8 & 0.13 & 0.01 & 5 & 4 & 12 & 17.2 & 738.6 & 969.6 \\
\hline 5 & 1 & 60.90 & 7.00 & 2 & 6 & 12 & 1,2 & $1,2,12$ & 8 & 0.13 & 0.49 & 466 & 5 & 4 & 23.1 & $1,728.4$ & $1,358.5$ \\
\hline 6 & 0 & - & - & - & - & - & 0,0 & $0,0,0$ & - & - & & & 6 & - & - & - & - \\
\hline 7 & 1 & 73.40 & 5.50 & 2 & 9 & 12 & 1,2 & $1,2,12$ & 8 & 0.13 & 0.64 & 83 & 7 & - & - & - & - \\
\hline 8 & 1 & 77.50 & 5.50 & 2 & 9 & 12 & 1,2 & $1,2,12$ & 8 & 0.13 & 0.64 & 25 & 8 & - & - & - & - \\
\hline 9 & 0 & - & - & - & - & - & 0,0 & $0,0,0$ & - & - & & & 9 & - & . & - & - \\
\hline 10 & 1 & 63.10 & 6.40 & 2 & 12 & 12 & 1,2 & $1,2,12$ & 8 & 0.13 & 0.01 & 376 & 10 & - & - & - & - \\
\hline 11 & 1 & 50.40 & 6.80 & 2 & 12 & 12 & 1,2 & $1,2,12$ & 8 & 0.13 & 0.25 & 1,030 & 11 & - & - & - & - \\
\hline 12 & 2 & 227.40 & 9.38 & 3 & 16 & 17 & 2,3 & $2,3,17$ & 2 & 0.50 & 0.40 & 2,835 & 12 & - & - & - & - \\
\hline 13 & 2 & 17.30 & 8.60 & 3 & 16 & 17 & 2,3 & $2,3,17$ & 2 & 0.50 & 0.02 & 24,605 & 13 & - & - & - & - \\
\hline 14 & 1 & 186.10 & 7.50 & 3 & 43 & 43 & 1,3 & $1,3,43$ & 2 & 0.50 & 1.44 & 10,735 & 14 & - & . & - & - \\
\hline 15 & 2 & 96.30 & 8.10 & 3 & 43 & 43 & 2,3 & $2,3,43$ & 2 & 0.50 & 0.41 & 6,062 & 15 & - & - & - & - \\
\hline 16 & 0 & - & - & - & - & 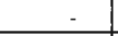 & 0,0 & $0,0,0$ & - & - & & & 16 & - & - & - & - \\
\hline 17 & 3 & 160.40 & 12.60 & 4 & 19 & 42 & 3,4 & $3,4,42$ & 3 & 0.33 & 0.19 & 4,953 & 17 & - & - & - & - \\
\hline 18 & 1 & 116.60 & 5.60 & 4 & 19 & 42 & 1,4 & $1,4,42$ & 2 & 0.50 & 0.49 & 1,163 & 18 & - & - & - & - \\
\hline 19 & 0 & - & - & - & - & - & 0,0 & $0,0,0$ &. & - & & & 19 & - & - & - & - \\
\hline 20 & 3 & 101.50 & 12.40 & 4 & 23 & 42 & 3,4 & $3,4,42$ & 3 & 0.33 & 0.06 & 16,713 & 20 & - & & - & - \\
\hline 21 & 3 & 47.80 & 10.80 & 3 & 20 & 20 & 3,3 & $3,3,20$ & 1 & 1.00 & 1.85 & 33,481 & & & & & \\
\hline 22 & 2 & 94.20 & 9.50 & 3 & 20 & 20 & 2,3 & $2,3,20$ & 1 & 1.00 & 0.57 & 6,393 & & & & & \\
\hline 23 & 0 & - & - & - & - & - & 0,0 & $0,0,0$ & - & - & & & & & & & \\
\hline 24 & 3 & 31.00 & 13.70 & 4 & 37 & 42 & 3,4 & $3,4,42$ & 3 & 0.33 & 2.37 & 39,911 & & & & & \\
\hline 25 & 2 & 274.80 & 8.10 & 3 & 24 & 24 & 2.3 & $2,3,24$ & 2 & 0.50 & 0.13 & 10,129 & & & & & \\
\hline 26 & 0 & - & - & - & - & - & 0,0 & $0,0,0$ & - & - & & & & & & & \\
\hline 27 & 1 & 98.90 & 7.20 & 2 & 25 & 25 & 1,2 & $1,2,25$ & 1 & 1.00 & 0.81 & 269 & & & & & \\
\hline 28 & 2 & 105.20 & 8.73 & 3 & 24 & 24 & 2,3 & $2,3,24$ & 2 & 0.50 & 0.00 & 4,618 & & & & & \\
\hline 29 & 1 & 27.30 & 7.20 & 2 & 28 & 28 & 1,2 & $1,2,28$ & 2 & 0.50 & 0.81 & 3,046 & & & & & \\
\hline
\end{tabular}




\begin{tabular}{|c|c|c|}
\hline Mathematic Code & $\begin{array}{l}\text { Disminter } \\
\text { Stad Dey }\end{array}$ & $\begin{array}{l}\text { Lengih Sid } \\
\text { Der }\end{array}$ \\
\hline$C 1=155.09242201$ & 0.72 & 69.14 \\
\hline$C 2=274,55281148$ & 0.69 & 121.86 \\
\hline $\mathrm{C} 3=775.09402897$ & 1.17 & 193.37 \\
\hline$C 4=969.60435273$ & 1.16 & 573.25 \\
\hline$C 5=1358.4952959$ & 0.62 & $1,527.02$ \\
\hline$c 6=0$ & & \\
\hline$C 7=0$ & & \\
\hline$C 8=0$ & & \\
\hline$C 9=0$ & & \\
\hline$C_{10}=0$ & & \\
\hline$C 11=0$ & & \\
\hline$c_{12}=0$ & & \\
\hline$C_{13}=0$ & & \\
\hline$C_{14}=0$ & & \\
\hline$C+5=0$ & & \\
\hline $\mathrm{C} 16=0$ & & \\
\hline$C_{17}=0$ & & \\
\hline $\mathrm{C} 18=0$ & & \\
\hline$C_{19}=0$ & & \\
\hline $\mathrm{C} 20=0$ & & \\
\hline
\end{tabular}

\begin{tabular}{|c|c|c|c|c|c|c|c|c|c|c|c|c|c|c|}
\hline & \multicolumn{6}{|c|}{ Connectivity Matrix (55) [Qty $\left.m_{n} n\right] /$ Total $\left.n\right]$} & \multicolumn{8}{|c|}{$\begin{array}{c}\text { Connectivity Matrix (55) [Percent of order } n \text { vessels that have } \\
\text { order } m \text { offspring] }\end{array}$} \\
\hline & \multicolumn{6}{|c|}{ Parent (n) } & \multicolumn{8}{|c|}{ Parent (n) } \\
\hline \multirow{22}{*}{ 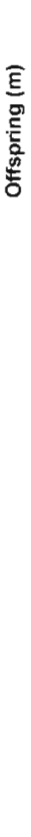 } & & 1 & 2 & 3 & 4 & 5 & \multirow{6}{*}{ 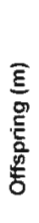 } & & 1 & 2 & 3 & 4 & 5 & Sum (53) \\
\hline & 1 & 0.38 & 0.81 & 0.32 & 0.50 & - & & 1 & $38 \%$ & $49 \%$ & $9 \%$ & $4 \%$ & $0 \%$ & 1.00 \\
\hline & 2 & - & 0.31 & 0.88 & 1.67 & 0.50 & & 2 & - & $31 \%$ & $43 \%$ & $24 \%$ & $2 \%$ & 1.00 \\
\hline & 3 & - & - & 0.29 & 1.83 & 1.75 & & 3 & - & - & $29 \%$ & $54 \%$ & $17 \%$ & 1.00 \\
\hline & 4 & - & - & - & 0.08 & 275 & & 4 & - & - & - & $8 \%$ & $92 \%$ & 1.00 \\
\hline & 5 & - & - & - & . & 0.50 & & 5 & - & - & - & - & $50 \%$ & 0.50 \\
\hline & 6 & - & - & - & - & - & & 6 & - & - & - & - & - & - \\
\hline & 7 & - & - & & & - & & 7 & - & - & - & - & - & - \\
\hline & 8 & - & - & - & - & - & & 8 & - & - & - & - & - & - \\
\hline & 9 & - & - & - & - & - & & 9 & - & - & - & - & - & - \\
\hline & 10 & - & - & - & - & - & & 10 & - & - & - & - & - & - \\
\hline & 11 & - & . & - & - & - & & 11 & - & - & - & - & - & - \\
\hline & 12 & - & - & - & - & - & & 12 & - & - & - & . & - & - \\
\hline & 13 & - & - & - & - & - & & 13 & - & - & - & - & - & - \\
\hline & 14 & - & - & - & & - & & 14 & & & & - & - & - \\
\hline & 15 & - & - & - & - & - & & 15 & - & - & - & - & - & - \\
\hline & 16 & - & - & - & - & - & & 16 & - & - & - & - & - & - \\
\hline & 17 & - & - & - & - & - & & 17 & - & - & - & - & - & - \\
\hline & 18 & - & - & - & - & - & & 18 & - & - & - & - & - & - \\
\hline & 19 & - & - & - & & - & & 19 & - & - & - & - & - & - \\
\hline & 20 & - & - & - & - & - & & 20 & - & - & - & - & - & - \\
\hline & Sum & 0.38 & 1.12 & 1.49 & 4.08 & 5.50 & & Sum & 0.38 & 0.80 & 0.81 & 0.90 & 1.61 & 4.50 \\
\hline
\end{tabular}




\begin{tabular}{|c|c|c|c|c|c|c|c|c|c|c|c|c|c|}
\hline $\begin{array}{l}\text { Segment } \\
\text { label (1) }\end{array}$ & $\begin{array}{c}\text { Recalced } \\
\text { order } 4 \\
(12)\end{array}$ & P1 (2) & $\begin{array}{l}\text { P1 order } \\
\text { (19) }\end{array}$ & $\begin{array}{l}\text { \# of } \\
\text { outiets } \\
\text { from a } \\
\text { vessel } \\
(56)\end{array}$ & $\begin{array}{l}\mathrm{Pm} \\
(57)\end{array}$ & $\begin{array}{l}P(p 1) \\
(58)\end{array}$ & $\begin{array}{l}\text { Matrix location } \\
\text { (59) }\end{array}$ & $\begin{array}{l}\text { Conductan } \\
\text { ce }(69)\end{array}$ & $\begin{array}{l}\text { Inlet }(P(p 1) \\
P(m))(60)\end{array}$ & $\begin{array}{l}\text { Inlet } \\
\text { Flow } \\
\text { Conducta } \\
\text { nce }(61)\end{array}$ & $\begin{array}{l}\text { Inlet flow expression } \\
\qquad(62)\end{array}$ & 1 & 2. \\
\hline 1 & 1.00 & 3 & 2 & 2 & Pc & P3 & $P(3,1)$ & 1 & $P 3-P C$ & $\mathrm{C} 1$ & $(P 3-P C)^{*} C 1$ & $(\mathrm{P} 3-\mathrm{P} 1) * \mathrm{Cl}$ & $(P 3-P 1)^{*} \mathrm{C} 1+(P 3-P 2)^{*} \mathrm{C} 2$ \\
\hline 2 & 1.00 & 3 & 2 & 2 & $P_{C}$ & P3 & $P(3,2)$ & 2 & P3-PC & $\mathrm{C} 2$ & $(\mathrm{P} 3-\mathrm{PC}) * \mathrm{C} 2$ & $(\mathrm{P} 3-\mathrm{P} 2) * \mathrm{C} 2$ & $(\mathrm{P} 3-\mathrm{P} 2)^{*} \mathrm{C} 2+(\mathrm{P} 3-\mathrm{P} 3)^{*} \mathrm{C} 3$ \\
\hline 3 & 2.00 & 6 & 2 & 3 & $\mathrm{P} 3$ & P6 & $P(6,3)$ & 3 & $\mathrm{P6}-\mathrm{P3}$ & $\mathrm{C} 3$ & $(P 6-P 3) * C 3$ & $(P 6-P 3) * C_{3}$ & $(P 6-P 3) * C 3+(P 6-P 4) * C 4$ \\
\hline 4 & 1.00 & 6 & 2 & 3 & Pc & $\mathrm{P} 6$ & $P(6,4)$ & 4 & $\mathrm{P6}-\mathrm{PC}$ & $\mathrm{C} 4$ & $(P 6-P C) * C 4$ & $(\mathrm{P} 6-\mathrm{P} 4)^{*} \mathrm{C} 4$ & $(P 6-P 4)^{*} \mathrm{C} 4+(\mathrm{P} 6-\mathrm{P} 5)^{*} \mathrm{C} 5$ \\
\hline 5 & 1.00 & 6 & 2 & 3 & PC & $\mathrm{P} 6$ & $P(6,5)$ & 5 & P6-PC & $\mathrm{C} 5$ & $(P E-P C) * C 5$ & $(P 6-P 5) * C 5$ & $(\mathrm{P} 6-\mathrm{P} 5) * \mathrm{C} 5+(\mathrm{P} 6-\mathrm{P} 6) * \mathrm{C} 6$ \\
\hline 6 & 2.00 & 9 & 2 & 3 & $\mathrm{P} 6$ & P9 & $P(9,6)$ & 6 & $P 9-P 6$ & $\mathrm{C} 6$ & $(P 9-P 6) * C 6$ & $(\mathrm{Pg}-\mathrm{P6})^{*} \mathrm{C} 6$ & $(\mathrm{P9}-\mathrm{P} 6)^{*} \mathrm{C} 6+(\mathrm{Pg}-\mathrm{P} 7)^{*} \mathrm{C} 7$ \\
\hline 7 & 1.00 & 9 & 2 & 3 & Pc & $\mathrm{Pg}$ & $P(9,7)$ & 7 & $\mathrm{P9} 9-\mathrm{PC}$ & $\mathrm{C} 7$ & $(P 9-P C) * C 7$ & $(\mathrm{PS}-\mathrm{P} 7)^{*} \mathrm{C} 7$ & $(\mathrm{Pg}-\mathrm{P} 7)^{*} \mathrm{C} 7+(\mathrm{Pg}-\mathrm{P} 8)^{*} \mathrm{C} 8$ \\
\hline 8 & 1.00 & 9 & 2 & 3 & PC & $\mathrm{P9}$ & $P(9,8)$ & 8 & $P 9-P C$ & $\mathrm{C} 8$ & $(P 9-P C) * C 8$ & $(\mathrm{Pg}-\mathrm{P8})^{*} \mathrm{C} 8$ & $(\mathrm{Pg}-\mathrm{P} 8)^{*} \mathrm{C} 8+(\mathrm{Pg}-\mathrm{P9})^{*} \mathrm{C} \mathrm{C}$ \\
\hline 9 & 2.00 & 12 & 2 & 3 & P9 & P12 & $P(12,9)$ & 9 & P12-P9 & $\mathrm{C} 9$ & $(P 12-P 9)^{*} \mathrm{C} 9$ & $(\mathrm{P} 12-\mathrm{Pg})^{*} \mathrm{C} 9$ & $(\mathrm{P} 12-\mathrm{P} 9)^{*} \mathrm{C} 9+(\mathrm{P} 12-\mathrm{P} 10) * \mathrm{C} 10$ \\
\hline 10 & 1.00 & 12 & 2 & 3 & PC & P12 & $P(12,10)$ & 10 & $P 12-P C$ & $\mathrm{C} 10$ & $(P 12-P C)^{*} C 10$ & $(\mathrm{P} 12-\mathrm{P} 10) * \mathrm{C} 10$ & $(P 12-P 10) * C 10+(P 12-P 11) * C 11$ \\
\hline 11 & 1.00 & 12 & 2 & 3 & Pc & P12 & $P(12,11)$ & 11 & P12-Pc & C11 & $(\mathrm{P} 12-\mathrm{PC})^{*} \mathrm{C} 11$ & $(\mathrm{P} 12-\mathrm{P} 11)^{*} \mathrm{C} 11$ & $(\mathrm{P} 12-\mathrm{P} 11)^{*} \mathrm{C} 11+(\mathrm{P} 12-\mathrm{P} 12)^{*} \mathrm{C} 12$ \\
\hline 12 & 2.00 & 16 & 3 & 2 & $\mathrm{P} 12$ & P16 & $P(16,12)$ & 12 & $\begin{array}{l}\mathrm{P} 16-\mathrm{P} 12 \\
\end{array}$ & $\mathrm{C} 12$ & $(P 16-P 12) * C 12$ & $(\mathrm{P} 16-\mathrm{P} 12) * \mathrm{C} 12$ & $(\mathrm{P} 16-\mathrm{P} 12)^{*} \mathrm{C} 12+(\mathrm{P} 16-\mathrm{P} 13)^{*} \mathrm{C} 13$ \\
\hline 13 & 2.00 & 16 & 3 & 2 & $\mathrm{P} 13$ & P16 & $P(16,13)$ & 13 & P16-P13 & $\mathrm{C} 13$ & $(\mathrm{P} 16-\mathrm{P} 13) * \mathrm{C} 13$ & $(\mathrm{P} 16-\mathrm{P} 13)^{*} \mathrm{C} 13$ & $(\mathrm{P} 16-\mathrm{P} 13)^{*} \mathrm{C} 13+(\mathrm{P} 16-\mathrm{P} 16)^{*} \mathrm{C} 16$ \\
\hline 16 & 3.00 & 17 & 3 & 1 & P16 & P17 & $P(17,16)$ & 16 & $\begin{array}{l}\mathrm{P} 17-\mathrm{P} 16 \\
\end{array}$ & C16 & $(\mathrm{P} 17-\mathrm{P} 16) * \mathrm{C} 16$ & $(\mathrm{P} 17-\mathrm{P} 16) * \mathrm{C} 16$ & $(\mathrm{P} 17-\mathrm{P} 16)^{*} \mathrm{C} 16+(\mathrm{P} 17-\mathrm{P} 17)^{*} \mathrm{C} 17$ \\
\hline 17 & 3.00 & 19 & 4 & 2 & P17 & P19 & $P(19,17)$ & 17 & P19-P17 & C17 & $(P 19-P 17) * C_{17}$ & $(\mathrm{P} 19-\mathrm{P} 17) * \mathrm{C} 17$ & $(\mathrm{P} 19-\mathrm{P} 17) * \mathrm{C} 17+(\mathrm{P} 19-\mathrm{P} 18) * \mathrm{C} 18$ \\
\hline 18 & 1.00 & 19 & 4 & 2 & $\mathrm{PC}_{\mathrm{C}}$ & P19 & $P(19,18)$ & 18 & P19-PC & C18 & $(P 19-P C) * C 18$ & $(\mathrm{P} 19-\mathrm{P} 18)^{*} \mathrm{C} 18$ & $(\mathrm{P} 19-\mathrm{P} 18)^{*} \mathrm{C} 18+(\mathrm{P} 19-\mathrm{P} 21)^{*} \mathrm{C} 21$ \\
\hline 21 & 2.00 & 20 & 3 & 2 & $\mathrm{P} 21$ & $\mathrm{P} 20$ & $P(20,21)$ & 21 & $\mathrm{P} 20-\mathrm{P} 21$ & $\mathrm{C} 21$ & $(P 20-P 21) * C 21$ & $(\mathrm{P} 20-\mathrm{P} 21) * \mathrm{C} 21$ & $(\mathrm{P} 20-\mathrm{P} 21)^{*} \mathrm{C} 21+(\mathrm{P} 20-\mathrm{P} 22)^{*} \mathrm{C} 22$ \\
\hline 22 & 2.00 & 20 & 3 & 2 & P22 & $\mathrm{P20}$ & $P(20,22)$ & 22 & $\mathrm{P} 20-\mathrm{P} 22$ & $\mathrm{C} 22$ & $(\mathrm{P} 20-\mathrm{P} 22)^{*} \mathrm{C} 22$ & $(\mathrm{P} 20-\mathrm{P} 22)^{*} \mathrm{C} 22$ & $(\mathrm{P} 20-\mathrm{P} 22)^{*} \mathrm{C} 22+(\mathrm{P} 20-\mathrm{P} 19)^{*} \mathrm{C} 19$ \\
\hline 19 & 4.00 & 23 & 4 & 2 & P19 & P23 & $P(23,19)$ & 19 & P23-P19 & $\mathrm{C} 19$ & $(P 23-P 19) * C 19$ & $(P 23-P 19) * C 19$ & $(\mathrm{P} 23-\mathrm{P} 19) * \mathrm{C} 19+(\mathrm{P} 23-\mathrm{P} 20) * \mathrm{C} 20$ \\
\hline 20 & 3.00 & 23 & 4 & 2 & $\mathrm{P} 20$ & P23 & $P(23,20)$ & 20 & $\mathrm{P} 23-\mathrm{P} 2 \mathrm{O}$ & $\mathrm{C} 20$ & $(\mathrm{P} 23-\mathrm{P} 20) * \mathrm{C} 20$ & $(\mathrm{P} 23-\mathrm{P} 20)^{*} \mathrm{C} 20$ & $(\mathrm{P} 23-\mathrm{P} 20)^{*} \mathrm{C} 20+(\mathrm{P} 23-\mathrm{P} 25)^{*} \mathrm{C} 25$ \\
\hline 25 & 2.00 & 24 & 3 & 2 & P25 & P24 & $P(24,25)$ & 25 & $P 24-P 25$ & $\mathrm{C} 25$ & $(P 24-P 25) * C 25$ & $(\mathrm{P} 24-\mathrm{P} 25) * \mathrm{C} 25$ & $(\mathrm{P} 24-\mathrm{P} 25) * \mathrm{C} 25+(\mathrm{P} 24-\mathrm{P} 28) * \mathrm{C} 28$ \\
\hline 28 & 2.00 & 24 & 3 & 2 & $\mathrm{P2} 28$ & $\mathrm{P} 24$ & $P(24,28)$ & 28 & P24-P28 & $\mathrm{C} 28$ & $(\mathrm{P} 24-\mathrm{P} 28) * \mathrm{C} 28$ & $(\mathrm{P} 24-\mathrm{P} 28) * \mathrm{C} 28$ & $(\mathrm{P} 24-\mathrm{P} 28)^{*} \mathrm{C} 28+(\mathrm{P} 24-\mathrm{P} 26) * \mathrm{C} 26$ \\
\hline 26 & 2.00 & 25 & 2 & 2 & $\mathrm{P26}$ & P25 & $P(25,26)$ & 26 & P25-P26 & $\mathrm{C} 26$ & $(\mathrm{P} 25-\mathrm{P} 26) * \mathrm{C} 26$ & $(P 25-P 26) * C 26$ & $(\mathrm{P} 25-\mathrm{P} 26)^{*} \mathrm{C} 26+(\mathrm{P} 25-\mathrm{P} 27)^{*} \mathrm{C} 27$ \\
\hline 27 & 1.00 & 25 & 2 & 2 & $\mathrm{Pc}$ & $\mathrm{P25}$ & $P(25,27)$ & 27 & $P 25-P C$ & $\mathrm{C} 27$ & $(P 25-P C)^{*} C 27$ & $(\mathrm{P} 25-\mathrm{P} 27) * \mathrm{C} 27$ & $(P 25-P 27) * C 27+(P 25-P 29) * C 29$ \\
\hline 29 & 1.00 & 28 & 2 & 2 & Pc & P28 & $P(28,29)$ & 29 & $\mathrm{P} 28-\mathrm{PC}$ & $\mathrm{C} 29$ & $(\mathrm{P} 28-\mathrm{PC})^{*} \mathrm{C} 29$ & $(P 28-P 29) * C 29$ & $(P 28-P 29) * C 29+(P 28-P 32) * C 32$ \\
\hline 32 & 2.00 & 28 & 2 & 2 & P32 & P28 & $\mathrm{P}(28,32)$ & 32 & $P 28-P 32$ & $\mathrm{C} 32$ & $(P 28-P 32) * C 32$ & $(\mathrm{P} 28-\mathrm{P} 32) * \mathrm{C} 32$ & $(P 28-P 32) * C 32+(P 28-P 30) * C 30$ \\
\hline 30 & 1.00 & 29 & 1 & 2 & PC & P29 & $P(29,30)$ & 30 & $P 29-P C$ & $\mathrm{C} 30$ & $(P 29-P C)^{*} C 3 D$ & $(\mathrm{P} 29-\mathrm{P} 30)^{*} \mathrm{C} 30$ & $(P 29-P 30)^{*} C 30+(P 29-P 31)^{*} C 31$ \\
\hline 31 & 1.00 & 29 & 1 & 2 & $\mathrm{PC}$ & P29 & $P(29,31)$ & 31 & $P 29-P C$ & $\mathrm{C} 31$ & $(P 29-P C)^{*} \mathrm{C} 31$ & $(P 29-P 31) * C 31$ & $(P 29-P 31) * C 31+(P 29-P 33) * C 33$ \\
\hline 33 & 2.00 & 32 & 2 & 2 & P33 & P32 & $P(32,33)$ & 33 & $P 32-P 33$ & $\mathrm{C} 33$ & $(P 32-P 33) * C 33$ & $(P 32-P 33) * C 33$ & $(\mathrm{P} 32-\mathrm{P} 33)^{*} \mathrm{C} 33+(\mathrm{P} 32-\mathrm{P} 36)^{*} \mathrm{C} 36$ \\
\hline 36 & 1.00 & 32 & 2 & 2 & PC & P32 & $P(32,36)$ & 36 & P32-PC & $\mathrm{C} 36$ & $(P 32-P C)^{*} \mathrm{C} 36$ & $(P 32-P 36)^{*} \mathrm{C} 36$ & $(P 32-P 36)^{*} \mathrm{C} 36+(\mathrm{P} 32-\mathrm{P} 34)^{*} \mathrm{C} 34$ \\
\hline 34 & 2.00 & 33 & 2 & 2 & P34 & P33 & $P(33,34)$ & 34 & P33-P34 & $\mathrm{C} 34$ & $(P 33-P 34) * C 34$ & $(P 33-P 34) * C 34$ & $(\mathrm{P} 33-\mathrm{P} 34) * \mathrm{C} 34+(\mathrm{P} 33-\mathrm{P} 35) * \mathrm{C} 35$ \\
\hline 35 & 2.00 & 33 & 2 & 2 & P35 & P33 & $P(33,35)$ & 35 & P33-P35 & $\mathrm{C} 35$ & $(\mathrm{P} 33-\mathrm{P} 35) * \mathrm{C} 35$ & $(P 33-P 35) * C 35$ & $(P 33-P 35)^{*} \mathrm{C} 35+(P 33-P 23)^{*} \mathrm{C} 23$ \\
\hline 23 & 4.00 & 37 & 4 & 2 & $\mathrm{P} 23$ & P37 & $P(37,23)$ & 23 & P37-P23 & $\mathrm{C} 23$ & $(P 37-P 23) * C 23$ & $(P 37-P 23) * C 23$ & $(P 37-P 23)^{*} C 23+(P 37-P 24) * C 24$ \\
\hline 24 & 3.00 & 37 & 4 & 2 & P24 & P37 & $P(37,24)$ & 24 & P37-P24 & C24 & $(\mathrm{P} 37-\mathrm{P} 24) * \mathrm{C} 24$ & $(P 37-P 24) * C 24$ & $(\mathrm{P37}-\mathrm{P} 24) * \mathrm{C} 24+(\mathrm{P3} 7-\mathrm{P} 39) * \mathrm{C} 39$ \\
\hline 39 & 1.00 & 41 & 1 & 2 & $\mathrm{Pc}$ & P41 & $P(41,39)$ & 39 & $\mathrm{P} 41-\mathrm{PC}$ & C39 & $(P 41-P C)^{*} C 39$ & $(P 41-P 39) * C 39$ & $(P 41-P 39)^{*} \mathrm{C} 39+(\mathrm{P} 41-\mathrm{P} 40) * \mathrm{C} 40$ \\
\hline 40 & 1.00 & 41 & 1 & 2 & $\mathrm{PC}$ & P41 & $P(41,40)$ & 40 & $\mathrm{P} 41-\mathrm{Pc}$ & $C 40$ & $(P 41-P C) * C 40$ & $(\mathrm{P} 41-\mathrm{P} 40) * \mathrm{C} 40$ & $(P 41-P 40) * C 40+(P 41-P 37) * C 37$ \\
\hline 37 & 4.00 & 42 & 4 & 3 & P37 & $\mathrm{P} 42$ & $P(42,37)$ & 37 & P42-P37 & $\mathrm{C} 37$ & $(\mathrm{P} 42-\mathrm{P} 37) * \mathrm{C} 37$ & $(P 42-P 37) * C 37$ & $(\mathrm{P} 42-\mathrm{P} 37)^{*} \mathrm{C} 37+(\mathrm{P} 42-\mathrm{P} 38) * \mathrm{C} 38$ \\
\hline 38 & 2.00 & 42 & 4 & 3 & P38 & P42 & $P(42,38)$ & 38 & P42-P38 & C38 & $(P 42-P 38) * C 38$ & $(P 42-P 38) * C 38$ & $(P 42-P 38) * C 38+(P 42-P 41) * C 41$ \\
\hline 41 & 1.00 & 42 & 4 & 3 & $P c$ & P42 & $P(42,41)$ & 41 & $\mathrm{P} 42-\mathrm{PC}$ & C41 & $\left(P 42-P_{C}\right)^{*} C 41$ & $(\mathrm{P} 42-\mathrm{P} 41) * \mathrm{C} 41$ & $(\mathrm{P} 42-\mathrm{P} 41)^{*} \mathrm{C} 41+(\mathrm{P} 42-\mathrm{P} 14)^{*} \mathrm{C} 14$ \\
\hline
\end{tabular}




\begin{tabular}{|c|c|c|c|c|c|}
\hline & $\begin{array}{l}\text { Row } \\
(66)\end{array}$ & $\begin{array}{l}\text { Parent } \\
\text { (67) }\end{array}$ & Hlookup (68) & Node & \\
\hline$(P 3-P 1)^{*} C 1+(P 3-P 2) * C 2+(P 3-P 3) * C 3$ & 2 & 3 & $(P 3-P 1) * C 1+(P 3-P 2) * C 2$ & 1 & \\
\hline$(\mathrm{P} 3-\mathrm{P} 2)^{*} \mathrm{C} 2+(\mathrm{P} 3-\mathrm{P} 3)^{*} \mathrm{C} 3+(\mathrm{P} 3-\mathrm{P} 4)^{*} \mathrm{C} 4$ & 3 & 3 & $(\mathrm{P} 3-\mathrm{P} 2) * \mathrm{C} 2+(\mathrm{P} 3-\mathrm{P} 3)^{*} \mathrm{C} 3$ & 2 & \\
\hline$(P 6-P 3) * C 3+(P 6-P 4) * C 4+(P 6-P 5) * C 5$ & 4 & 6 & $(P 6-P 3)^{*} \mathrm{C} 3+(\mathrm{P} 6-\mathrm{P} 4)^{*} \mathrm{C} 4+(\mathrm{P} 6-\mathrm{P} 5)^{*} \mathrm{C} 5$ & 3 & $(\mathrm{P} 3-\mathrm{P} 1)^{*} \mathrm{C} 1+(\mathrm{P} 3-\mathrm{P} 2) * \mathrm{C} 2$ \\
\hline$(\mathrm{P} 6-\mathrm{P} 4)^{*} \mathrm{C} 4+(\mathrm{P} 6-\mathrm{P} 5) * \mathrm{C} 5+(\mathrm{P} 6-\mathrm{P} 6) * \mathrm{C} 6$ & 5 & 6 & $(\mathrm{P} 6-\mathrm{P} 4)^{*} \mathrm{C} 4+(\mathrm{P} 6-\mathrm{P} 5) * \mathrm{C} 5+(\mathrm{P} 6-\mathrm{P} 6) * \mathrm{C} 6$ & 4 & \\
\hline$(P 6-P 5) * C 5+(P 6-P 6) * C 6+(P 6-P 7) * C 7$ & 6 & 6 & $(\mathrm{P} 6-\mathrm{P} 5)^{*} \mathrm{C} 5+(\mathrm{P} 6-\mathrm{P} 6)^{*} \mathrm{C} 6+(\mathrm{P} 6-\mathrm{P} 7)^{*} \mathrm{C} 7$ & 5 & \\
\hline$(\mathrm{P} 9-\mathrm{P} 6))^{*} \mathrm{C} 6+(\mathrm{Pg}-\mathrm{P} 7)^{*} \mathrm{C} 7+(\mathrm{Pg}-\mathrm{P} 8)^{*} \mathrm{C} 8$ & 7 & 9 & $(\mathrm{P9}-\mathrm{P} 6)^{*} \mathrm{C} 6+(\mathrm{Pg}-\mathrm{P} 7) * \mathrm{C} 7+(\mathrm{P} 9-\mathrm{P8}) * \mathrm{C} 8$ & 6 & $(\mathrm{P} 6-\mathrm{P} 3)^{*} \mathrm{C} 3+(\mathrm{P} 6-\mathrm{P} 4)^{*} \mathrm{C} 4+(\mathrm{P} 6-\mathrm{P} 5)^{*} \mathrm{C} 5$ \\
\hline$(P 9-P 7)^{*} \mathrm{C} 7+(\mathrm{Pg}-\mathrm{PB})^{*} \mathrm{C} 8+(\mathrm{Pg}-\mathrm{Pg})^{*} \mathrm{C} 9$ & 8 & 9 & $(\mathrm{PS}-\mathrm{P} 7)^{*} \mathrm{C} 7+(\mathrm{Pg}-\mathrm{P8})^{*} \mathrm{C} 8+(\mathrm{Pg}-\mathrm{P9})^{*} \mathrm{C} 9$ & 7 & \\
\hline$(\mathrm{P} 9-\mathrm{P} 8) * \mathrm{C} 8+(\mathrm{Pg}-\mathrm{Pg}) * \mathrm{C} 9+(\mathrm{Pg}-\mathrm{P} 10) * \mathrm{C} 10$ & 9 & 9 & $(\mathrm{P9}-\mathrm{PB}) * \mathrm{C} 8+(\mathrm{Pg}-\mathrm{P9}) * \mathrm{C} 9+(\mathrm{Pg}-\mathrm{P} 10) * \mathrm{C} 10$ & 8 & \\
\hline$(\mathrm{P} 12-\mathrm{PS}) * \mathrm{C} 9+(\mathrm{P} 12-\mathrm{P} 10) * \mathrm{C} 10+(\mathrm{P} 12-\mathrm{P} 11) * \mathrm{C} 11$ & 10 & 12 & $(\mathrm{P} 12-\mathrm{P} 9)^{*} \mathrm{C} 9+(\mathrm{P} 12-\mathrm{P} 10) * \mathrm{C} 10+(\mathrm{P} 12-\mathrm{P} 11)^{*} \mathrm{C} 11$ & 9 & $(\mathrm{P9}-\mathrm{P} 6)^{*} \mathrm{C} 6+(\mathrm{P9}-\mathrm{P} 7)^{*} \mathrm{C} 7+(\mathrm{P} 9-\mathrm{P} 8)^{*} \mathrm{C} 8$ \\
\hline$(\mathrm{P} 12-\mathrm{P} 10) * \mathrm{C} 10+(\mathrm{P} 12-\mathrm{P} 11) * \mathrm{C} 11+(\mathrm{P} 12-\mathrm{P} 12) * \mathrm{C} 12$ & 11 & 12 & $(\mathrm{P} 12-\mathrm{P} 10) * \mathrm{C} 10+(\mathrm{P} 12-\mathrm{P} 11) * \mathrm{C} 11+(\mathrm{P} 12-\mathrm{P} 12) * \mathrm{C} 12$ & 10 & \\
\hline$(\mathrm{P} 12-\mathrm{P} 11)^{*} \mathrm{C} 11+(\mathrm{P} 12-\mathrm{P} 12) * \mathrm{C} 12+(\mathrm{P} 12-\mathrm{P} 13){ }^{*} \mathrm{C} 13$ & 12 & 12 & $(\mathrm{P} 12-\mathrm{P} 11)^{*} \mathrm{C} 11+(\mathrm{P} 12-\mathrm{P} 12)^{*} \mathrm{C} 12+(\mathrm{P} 12-\mathrm{P} 13)^{*} \mathrm{C} 13$ & 11 & \\
\hline$(\mathrm{P} 16-\mathrm{P} 12)^{*} \mathrm{C} 12+(\mathrm{P} 16-\mathrm{P} 13)^{*} \mathrm{C} 13+(\mathrm{P} 16-\mathrm{P} 16){ }^{*} \mathrm{C} 16$ & 13 & 16 & $(P 16-P 12)^{*} \mathrm{C} 12+(P 16-P 13)^{*} \mathrm{C} 13$ & 12 & $(\mathrm{P} 12-\mathrm{P} 9)^{*} \mathrm{C} 9+(\mathrm{P} 12-\mathrm{P} 10)^{*} \mathrm{C} 10+(\mathrm{P} 12-\mathrm{P} 11){ }^{*} \mathrm{C} 11$ \\
\hline$(\mathrm{P} 16-\mathrm{P} 13) * \mathrm{C} 13+(\mathrm{P} 16-\mathrm{P} 16) * \mathrm{C} 16+(\mathrm{P} 16-\mathrm{P} 17) * \mathrm{C} 17$ & 14 & 16 & $(\mathrm{P} 16-\mathrm{P} 13) * \mathrm{C} 13+(\mathrm{P} 16-\mathrm{P} 16) * \mathrm{C} 16$ & 13 & \\
\hline$(\mathrm{P} 17-\mathrm{P} 16)^{*} \mathrm{C} 16+(\mathrm{P} 17-\mathrm{P} 17)^{*} \mathrm{C} 17+(\mathrm{P} 17-\mathrm{P} 18)^{*} \mathrm{C} 18$ & 15 & 17 & $(\mathrm{P} 17-\mathrm{P} 16)^{*} \mathrm{C} 16$ & 14 & \\
\hline$(\mathrm{P} 19-\mathrm{P} 17) * \mathrm{C} 17+(\mathrm{P} 19-\mathrm{P} 18) * \mathrm{C} 18+(\mathrm{P} 19-\mathrm{P} 21) * \mathrm{C} 21$ & 16 & 19 & $(\mathrm{P} 19-\mathrm{P} 17)^{*} \mathrm{C} 17+(\mathrm{P} 19-\mathrm{P} 18)^{*} \mathrm{C} 18$ & 15 & \\
\hline$(\mathrm{P} 19-\mathrm{P} 18)^{*} \mathrm{C} 18+(\mathrm{P} 19-\mathrm{P} 21) * \mathrm{C} 21+(\mathrm{P} 19-\mathrm{P} 22) * \mathrm{C} 22$ & 17 & 19 & $(\mathrm{P} 19-\mathrm{P} 18) * \mathrm{C} 18+(\mathrm{P} 19-\mathrm{P} 21) * \mathrm{C} 21$ & 16 & $(\mathrm{P} 16-\mathrm{P} 12)^{*} \mathrm{C} 12+(\mathrm{P} 16-\mathrm{P} 13)^{*} \mathrm{C} 13$ \\
\hline$(\mathrm{P} 20-\mathrm{P} 21)^{*} \mathrm{C} 21+(\mathrm{P} 20-\mathrm{P} 22) * \mathrm{C} 22+(\mathrm{P} 20-\mathrm{P} 19) * \mathrm{C} 19$ & 18 & 20 & $(\mathrm{P} 20-\mathrm{P} 21)^{*} \mathrm{C} 21+(\mathrm{P} 20-\mathrm{P} 22) * \mathrm{C} 22$ & 17 & $(\mathrm{P} 17-\mathrm{P} 16) * \mathrm{C} 16$ \\
\hline$(\mathrm{P} 20-\mathrm{P} 22) * \mathrm{C} 22+(\mathrm{P} 20-\mathrm{P} 19) * \mathrm{C} 19+(\mathrm{P} 20-\mathrm{P} 20) * \mathrm{C} 20$ & 19 & 20 & $(\mathrm{P} 20-\mathrm{P} 22) * \mathrm{C} 22+(\mathrm{P} 20-\mathrm{P} 19) * \mathrm{C} 19$ & 18 & \\
\hline$(\mathrm{P} 23-\mathrm{P} 19)^{*} \mathrm{C} 19+(\mathrm{P} 23-\mathrm{P} 20)^{*} \mathrm{C} 20+(\mathrm{P} 23-\mathrm{P} 25)^{*} \mathrm{C} 25$ & 20 & 23 & $(P 23-P 19) * C 19+(P 23-P 20) * C 20$ & 19 & $(\mathrm{P} 19-\mathrm{P} 17) * \mathrm{C} 17+(\mathrm{P} 19-\mathrm{P} 18) * \mathrm{C} 18$ \\
\hline$(\mathrm{P} 23-\mathrm{P} 20) * \mathrm{C} 20+(\mathrm{P} 23-\mathrm{P} 25) * \mathrm{C} 25+(\mathrm{P} 23-\mathrm{P} 28) * \mathrm{C} 28$ & 21 & 23 & $(\mathrm{P} 23-\mathrm{P} 20) * \mathrm{C} 20+(\mathrm{P} 23-\mathrm{P} 25) * \mathrm{C} 25$ & 20 & $(\mathrm{P} 20-\mathrm{P} 21) * \mathrm{C} 21+(\mathrm{P} 20-\mathrm{P} 22) * \mathrm{C} 22$ \\
\hline$(\mathrm{P} 24-\mathrm{P} 25)^{*} \mathrm{C} 25+(\mathrm{P} 24-\mathrm{P} 28)^{*} \mathrm{C} 28+(\mathrm{P} 24-\mathrm{P} 26) * \mathrm{C} 26$ & 22 & 24 & $(\mathrm{P} 24-\mathrm{P} 25)^{*} \mathrm{C} 25+(\mathrm{P} 24-\mathrm{P} 28)^{*} \mathrm{C} 28$ & 21 & \\
\hline$(\mathrm{P} 24-\mathrm{P} 28) * \mathrm{C} 28+(\mathrm{P} 24-\mathrm{P} 26) * \mathrm{C} 26+(\mathrm{P} 24-\mathrm{P} 27) * \mathrm{C} 27$ & 23 & 24 & $(\mathrm{P} 24-\mathrm{P} 28)^{*} \mathrm{C} 28+(\mathrm{P} 24-\mathrm{P} 26) * \mathrm{C} 26$ & 22 & \\
\hline$(\mathrm{P} 25-\mathrm{P} 26) * \mathrm{C} 26+(\mathrm{P} 25-\mathrm{P} 27)^{*} \mathrm{C} 27+(\mathrm{P} 25-\mathrm{P} 29)^{*} \mathrm{C} 29$ & 24 & 25 & $(\mathrm{P} 25-\mathrm{P} 26)^{*} \mathrm{C} 26+(\mathrm{P} 25-\mathrm{P} 27)^{*} \mathrm{C} 27$ & 23 & $(\mathrm{P} 23-\mathrm{P} 19) * \mathrm{C} 19+(\mathrm{P} 23-\mathrm{P} 20)^{*} \mathrm{C} 20$ \\
\hline$(\mathrm{P} 25-\mathrm{P} 27) * \mathrm{C} 27+(\mathrm{P} 25-\mathrm{P} 29)^{*} \mathrm{C} 29+(\mathrm{P} 25-\mathrm{P} 32) * \mathrm{C} 32$ & 25 & 25 & $(\mathrm{P} 25-\mathrm{P} 27) * \mathrm{C} 27+(\mathrm{P} 25-\mathrm{P} 29) * \mathrm{C} 29$ & 24 & $(\mathrm{P} 24-\mathrm{P} 25) * \mathrm{C} 25+(\mathrm{P} 24-\mathrm{P} 28) * \mathrm{C} 28$ \\
\hline$(\mathrm{P} 28-\mathrm{P} 29)^{*} \mathrm{C} 29+(\mathrm{P} 28-\mathrm{P} 32)^{*} \mathrm{C} 32+(\mathrm{P} 28-\mathrm{P} 30) * \mathrm{C} 30$ & 26 & 28 & $(\mathrm{P} 28-\mathrm{P} 29)^{*} \mathrm{C} 29+(\mathrm{P} 28-\mathrm{P} 32)^{*} \mathrm{C} 32$ & 25 & $(\mathrm{P} 25-\mathrm{P} 26)^{*} \mathrm{C} 26+(\mathrm{P} 25-\mathrm{P} 27)^{*} \mathrm{C} 27$ \\
\hline$(\mathrm{P} 28-\mathrm{P} 32)^{*} \mathrm{C} 32+(\mathrm{P} 28-\mathrm{P} 30)^{*} \mathrm{C} 30+(\mathrm{P} 28-\mathrm{P} 31)^{*} \mathrm{C} 31$ & 27 & 28 & $(\mathrm{P} 28-\mathrm{P} 32)^{*} \mathrm{C} 32+(\mathrm{P} 28-\mathrm{P} 30)^{*} \mathrm{C} 30$ & 26 & \\
\hline$(\mathrm{P} 29-\mathrm{P} 30) * \mathrm{C} 30+(\mathrm{P} 29-\mathrm{P} 31) * \mathrm{C} 31+(\mathrm{P} 29-\mathrm{P} 33) * \mathrm{C} 33$ & 28 & 29 & $(P 29-P 30) * C 30+(P 29-P 31) * C 31$ & 27 & \\
\hline$(\mathrm{P} 29-\mathrm{P} 31)^{*} \mathrm{C} 31+(\mathrm{P} 29-\mathrm{P} 33)^{*} \mathrm{C} 33+(\mathrm{P} 29-\mathrm{P} 36) * \mathrm{C} 36$ & 29 & 29 & $(\mathrm{P} 29-\mathrm{P} 31)^{*} \mathrm{C} 31+(\mathrm{P} 29-\mathrm{P} 33)^{*} \mathrm{C} 33$ & 28 & $(\mathrm{P} 28-\mathrm{P} 29)^{*} \mathrm{C} 29+(\mathrm{P} 28-\mathrm{P} 32)^{*} \mathrm{C} 32$ \\
\hline$(\mathrm{P} 32-\mathrm{P} 33) * \mathrm{C} 33+(\mathrm{P} 32-\mathrm{P} 36) * \mathrm{C} 36+(\mathrm{P} 32-\mathrm{P} 34) * \mathrm{C} 34$ & 30 & 32 & $(P 32-P 33) * C 33+(P 32-P 36) * C 36$ & 29 & $(\mathrm{P} 29-\mathrm{P} 30) * \mathrm{C} 30+(\mathrm{P} 29-\mathrm{P} 31) * \mathrm{C} 31$ \\
\hline$(\mathrm{P} 32-\mathrm{P} 36)^{*} \mathrm{C} 36+(\mathrm{P} 32-\mathrm{P} 34)^{*} \mathrm{C} 34+(\mathrm{P} 32-\mathrm{P} 35) * \mathrm{C} 35$ & 31 & 32 & $(P 32-P 36)^{*} \mathrm{C} 36+(\mathrm{P} 32-\mathrm{P} 34)^{*} \mathrm{C} 34$ & 30 & \\
\hline$(\mathrm{P} 33-\mathrm{P} 34)^{*} \mathrm{C} 34+(\mathrm{P} 33-\mathrm{P} 35) * \mathrm{C} 35+(\mathrm{P} 33-\mathrm{P} 23) * \mathrm{C} 23$ & 32 & 33 & $(\mathrm{P} 33-\mathrm{P} 34) * \mathrm{C} 34+(\mathrm{P} 33-\mathrm{P} 35) * \mathrm{C} 35$ & 31 & \\
\hline$(\mathrm{P} 33-\mathrm{P} 35) * \mathrm{C} 35+(\mathrm{P} 33-\mathrm{P} 23) * \mathrm{C} 23+(\mathrm{P} 33-\mathrm{P} 24) * \mathrm{C} 24$ & 33 & 33 & $(\mathrm{P} 33-\mathrm{P} 35) * \mathrm{C} 35+(\mathrm{P} 33-\mathrm{P} 23) * \mathrm{C} 23$ & 32 & $(\mathrm{P} 32-\mathrm{P} 33) * \mathrm{C} 33+(\mathrm{P} 32-\mathrm{P} 36) * \mathrm{C} 36$ \\
\hline$(\mathrm{P} 37-\mathrm{P} 23)^{*} \mathrm{C} 23+(\mathrm{P} 37-\mathrm{P} 24)^{*} \mathrm{C} 24+(\mathrm{P} 37-\mathrm{P} 39)^{*} \mathrm{C} 39$ & 34 & 37 & $(\mathrm{P} 37-\mathrm{P} 23)^{*} \mathrm{C} 23+(\mathrm{P} 37-\mathrm{P} 24)^{*} \mathrm{C} 24$ & 33 & $(\mathrm{P} 33-\mathrm{P} 34)^{*} \mathrm{C} 34+(\mathrm{P} 33-\mathrm{P} 35) * \mathrm{C} 35$ \\
\hline$(\mathrm{P} 37-\mathrm{P} 24) * \mathrm{C} 24+(\mathrm{P} 37-\mathrm{P} 39) * \mathrm{C} 39+(\mathrm{P} 37-\mathrm{P} 40) * \mathrm{C} 40$ & 35 & 37 & $(\mathrm{P} 37-\mathrm{P} 24) * \mathrm{C} 24+(\mathrm{P} 37-\mathrm{P} 39) * \mathrm{C} 39$ & 34 & \\
\hline$(\mathrm{P} 41-\mathrm{P} 39) * \mathrm{C} 39+(\mathrm{P} 41-\mathrm{P} 40) * \mathrm{C} 40+(\mathrm{P} 41-\mathrm{P} 37) * \mathrm{C} 37$ & 36 & 41 & $(\mathrm{P} 41-\mathrm{P} 39)^{*} \mathrm{C} 39+(\mathrm{P} 41-\mathrm{P} 40)^{*} \mathrm{C} 40$ & 35 & \\
\hline$(\mathrm{P} 41-\mathrm{P} 40) * \mathrm{C} 40+(\mathrm{P} 41-\mathrm{P} 37) * \mathrm{C} 37+(\mathrm{P} 41-\mathrm{P} 38) * \mathrm{C} 38$ & 37 & 41 & $(\mathrm{P} 41-\mathrm{P} 40) * \mathrm{C} 40+(\mathrm{P} 41-\mathrm{P} 37) * \mathrm{C} 37$ & 36 & \\
\hline$(\mathrm{P} 42-\mathrm{P} 37) * \mathrm{C} 37+(\mathrm{P} 42-\mathrm{P} 38)^{*} \mathrm{C} 38+(\mathrm{P} 42-\mathrm{P} 41)^{*} \mathrm{C} 41$ & 38 & 42 & $(\mathrm{P} 42-\mathrm{P} 37)^{*} \mathrm{C} 37+(\mathrm{P} 42-\mathrm{P} 38)^{*} \mathrm{C} 38+(\mathrm{P} 42-\mathrm{P} 41)^{*} \mathrm{C} 41$ & 37 & $(\mathrm{P} 37-\mathrm{P} 23) * \mathrm{C} 23+(\mathrm{P} 37-\mathrm{P} 24)^{*} \mathrm{C} 24$ \\
\hline$(\mathrm{P} 42-\mathrm{P} 38) * \mathrm{C} 38+(\mathrm{P} 42-\mathrm{P} 41) * \mathrm{C} 41+(\mathrm{P} 42-\mathrm{P} 14)^{*} \mathrm{C} 14$ & 39 & 42 & $(P 42-P 38)^{*} \mathrm{C} 38+(\mathrm{P} 42-\mathrm{P} 41)^{*} \mathrm{C} 41+(\mathrm{P} 42-\mathrm{P} 14) * \mathrm{C} 14$ & 38 & \\
\hline$(\mathrm{P} 42-\mathrm{P} 41) * \mathrm{C} 41+(\mathrm{P} 42-\mathrm{P} 14) * \mathrm{C} 14+(\mathrm{P} 42-\mathrm{P} 15) * \mathrm{C} 15$ & 40 & 42 & $(\mathrm{P} 42-\mathrm{P} 41)^{*} \mathrm{C} 41+(\mathrm{P} 42-\mathrm{P} 14) * \mathrm{C} 14+(\mathrm{P} 42-\mathrm{P} 15) * \mathrm{C} 15$ & 39 & \\
\hline
\end{tabular}




\begin{tabular}{|c|c|c|c|c|c|c|}
\hline $\begin{array}{l}\text { Segment } \\
\text { label (1) }\end{array}$ & $\begin{array}{c}\text { Recalc } \\
\text { ed } \\
\text { order } \\
4(12)\end{array}$ & P1 (2) & $\begin{array}{c}\text { P1 } \\
\text { order } \\
\text { (19) }\end{array}$ & $\begin{array}{l}\text { Inlet flow } \\
\text { expression (62) }\end{array}$ & Outlet flow expression (70) & Capillary equations? (71) \\
\hline 1 & 1 & 3 & 2 & $(P 3-P C) * C 1$ & & $+4 *(P 1-P 386) * G 1$ \\
\hline 2 & 1 & 3 & 2 & $(P 3-P C)^{*} \mathrm{C} 2$ & & $+1^{*}(\mathrm{P} 2-\mathrm{P} 387) * \mathrm{G} 1$ \\
\hline 3 & 2 & 6 & 2 & $(P 6-P 3)^{*} \mathrm{C} 3$ & $(\mathrm{P} 3-\mathrm{P} 1)^{*} \mathrm{C} 1+(\mathrm{P} 3-\mathrm{P} 2)^{*} \mathrm{C} 2$ & \\
\hline 4 & 1 & 6 & 2 & $(\mathrm{P} 6-\mathrm{PC})^{*} \mathrm{C} 4$ & & $+6 *(\mathrm{P} 4-\mathrm{P} 389) * \mathrm{G} 1$ \\
\hline 5 & 1 & 6 & 2 & $(P 6-P C) * C 5$ & & $+4^{*}(\mathrm{P} 5-\mathrm{P} 390) * \mathrm{G} 1$ \\
\hline 6 & 2 & 9 & 2 & $(\mathrm{P9}-\mathrm{P} 6) * \mathrm{C} 6$ & $(\mathrm{P} 6-\mathrm{P} 3)^{*} \mathrm{C} 3+(\mathrm{P} 6-\mathrm{P} 4)^{*} \mathrm{C} 4+(\mathrm{P} 6-\mathrm{P} 5)^{*} \mathrm{C} 5$ & \\
\hline 7 & 1 & 9 & 2 & $(\mathrm{Pg}-\mathrm{PC}) * \mathrm{C} 7$ & & $+5 *(P 7-P 392) * G 1$ \\
\hline 8 & 1 & 9 & 2 & $(\mathrm{PS}-\mathrm{PC})^{*} \mathrm{C} 8$ & & $+5^{*}(\mathrm{P} 8-\mathrm{P} 393)^{*} \mathrm{GI}$ \\
\hline 9 & 2 & 12 & 2 & $(P 12-P 9)^{*} \mathrm{C} 9$ & $(P 9-P 6)^{*} \mathrm{C} 6+(P 9-P 7) * C 7+(P 9-P 8) * C 8$ & \\
\hline 10 & 1 & 12 & 2 & $\left(P_{12}-P_{C}\right) * C_{10}$ & & $+4^{*}(\mathrm{P} 10-\mathrm{P} 395)^{*} \mathrm{G} 1$ \\
\hline 11 & 1 & 12 & 2 & $(\mathrm{P} 12-\mathrm{PC})^{*} \mathrm{C} 11$ & & $+3^{*}(P 11-P 396) * G 1$ \\
\hline 12 & 2 & 16 & 3 & $(\mathrm{P} 16-\mathrm{P} 12) * \mathrm{C} 12$ & $(\mathrm{P} 12-\mathrm{P} 9) * \mathrm{C} 9+(\mathrm{P} 12-\mathrm{P} 10) * \mathrm{C} 10+(\mathrm{P} 12-\mathrm{P} 11) * \mathrm{C} 11$ & $+11 *(\mathrm{P} 12-\mathrm{P} 397) * \mathrm{G} 2$ \\
\hline 13 & 2 & 16 & 3 & $(\mathrm{P} 16-\mathrm{P} 13)^{*} \mathrm{C} 13$ & & $+1 *(P 13-P 398)^{*} \mathrm{G} 2$ \\
\hline 14 & 1 & 43 & 3 & $(\mathrm{P} 43-\mathrm{PC})^{*} \mathrm{C} 14$ & & $+12^{*}\left(P_{14}-\mathrm{P} 399\right) * \mathrm{G} 1$ \\
\hline 15 & 2 & 43 & 3 & $(\mathrm{P} 43-\mathrm{P} 15)^{*} \mathrm{C} 15$ & & $+5^{*}(\mathrm{P} 15-\mathrm{P} 400) * \mathrm{G} 2$ \\
\hline 16 & 3 & 17 & 3 & $(P 17-P 16)^{*} C 16$ & $(\mathrm{P} 16-\mathrm{P} 12) * \mathrm{C} 12+(\mathrm{P} 16-\mathrm{P} 13) * \mathrm{C} 13$ & \\
\hline 17 & 3 & 19 & 4 & $(\mathrm{P} 19-\mathrm{P} 17) * \mathrm{C} 17$ & $(\mathrm{P} 17-\mathrm{P} 16) * \mathrm{C} 16$ & $+6^{*}(\mathrm{P} 17-\mathrm{P} 402)^{*} \mathrm{G} 3$ \\
\hline 18 & 1 & 19 & 4 & $(\mathrm{P} 19-\mathrm{PC})^{*} \mathrm{C} 18$ & & $+8^{*}(\mathrm{P} 18-\mathrm{P} 403) * \mathrm{G} 1$ \\
\hline 19 & 4 & 23 & 4 & $(\mathrm{P} 23-\mathrm{P} 19) * \mathrm{C} 19$ & $(\mathrm{P} 19-\mathrm{P} 17) * \mathrm{C} 17+(\mathrm{P} 19-\mathrm{P} 18) * \mathrm{C} 18$ & \\
\hline 20 & 3 & 23 & 4 & $(\mathrm{P} 23-\mathrm{P} 2 \mathrm{O}) * \mathrm{C} 20$ & $(\mathrm{P} 20-\mathrm{P} 21)^{*} \mathrm{C} 21+(\mathrm{P} 20-\mathrm{P} 22) * \mathrm{C} 22$ & $+4 *(P 20-P 405) * G 3$ \\
\hline 21 & 2 & 20 & 3 & $(\mathrm{P} 20-\mathrm{P} 21)^{*} \mathrm{C} 21$ & & $+2 *(P 21-P 406) * G 3$ \\
\hline 22 & 2 & 20 & 3 & $(\mathrm{P} 20-\mathrm{P} 22)^{*} \mathrm{C} 22$ & & $+4^{*}(\mathrm{P} 22-\mathrm{P} 407) * \mathrm{G} 2$ \\
\hline 23 & 4 & 37 & 4 & $(\mathrm{P} 37-\mathrm{P} 23)^{*} \mathrm{C} 23$ & $(\mathrm{P} 23-\mathrm{P} 19)^{*} \mathrm{C} 19+(\mathrm{P} 23-\mathrm{P} 20)^{*} \mathrm{C} 20$ & \\
\hline 24 & 3 & 37 & 4 & $(\mathrm{P} 37-\mathrm{P} 24) * \mathrm{C} 24$ & $(\mathrm{P} 24-\mathrm{P} 25) * \mathrm{C} 25+(\mathrm{P} 24-\mathrm{P} 28) * \mathrm{C} 28$ & $+1^{*}(\mathrm{P} 24-\mathrm{P} 409) * \mathrm{G} 3$ \\
\hline 25 & 2 & 24 & 3 & $(\mathrm{P} 24-\mathrm{P} 25)^{*} \mathrm{C} 25$ & $(\mathrm{P} 25-\mathrm{P} 26)^{*} \mathrm{C} 26+(\mathrm{P} 25-\mathrm{P} 27)^{*} \mathrm{C} 27$ & $+13^{*}(\mathrm{P} 25-\mathrm{P} 410) * G 2$ \\
\hline 26 & 2 & 25 & 2 & $(\mathrm{P} 25-\mathrm{P} 26) * \mathrm{C} 26$ & & \\
\hline 27 & 1 & 25 & 2 & $(P 25-P C)^{*} \mathrm{C} 27$ & & $+7 *(P 27-P 412) * G 1$ \\
\hline 28 & 2 & 24 & 3 & $(\mathrm{P} 24-\mathrm{P} 28) * \mathrm{C} 28$ & $(\mathrm{P} 28-\mathrm{P} 29)^{*} \mathrm{C} 29+(\mathrm{P} 28-\mathrm{P} 32) * \mathrm{C} 32$ & $+5^{*}(\mathrm{P} 28-\mathrm{P} 413)^{*} \mathrm{G} 2$ \\
\hline 29 & 1 & 28 & 2 & $(\mathrm{P} 28-\mathrm{PC})^{* \mathrm{C} 29}$ & $(\mathrm{P} 29-\mathrm{P} 30)^{*} \mathrm{C} 30+(\mathrm{P} 29-\mathrm{P} 31)^{*} \mathrm{C} 31$ & $+2^{*}(\mathrm{P} 29-\mathrm{P} 414)^{*} \mathrm{G} 1$ \\
\hline 30 & 1 & 29 & $\frac{2}{1}$ & $(\mathrm{P} 29-\mathrm{PC})^{*} \mathrm{C} 30$ & & $+2 *(\mathrm{P} 30-\mathrm{P} 415)^{*} \mathrm{G} 1$ \\
\hline 31 & 1 & 29 & 1 & $(P 29-P C) * C 31$ & & $+2^{*}(\mathrm{P} 31-\mathrm{P} 416)^{*} \mathrm{G} 1$ \\
\hline 32 & 2 & 28 & 2 & $(P 28-P 32) * C 32$ & $(\mathrm{P} 32-\mathrm{P} 33) * \mathrm{C} 33+(\mathrm{P} 32-\mathrm{P} 36) * \mathrm{C} 36$ & \\
\hline 33 & 2 & 32 & 2 & $(\mathrm{P} 32-\mathrm{P} 33) * \mathrm{C} 33$ & $($ P33-P34 $) * C 34+($ P33-P35 $) * C 35$ & \\
\hline 34 & 2 & 33 & $\frac{2}{2}$ & $(\mathrm{P} 33-\mathrm{P} 34) * \mathrm{C} 34$ & & $+3^{* *}(\mathrm{P} 34-\mathrm{P} 419)^{*} \mathrm{G} 2$ \\
\hline 35 & 2 & 33 & 2 & $(\mathrm{P} 33-\mathrm{P} 35) * \mathrm{C} 35$ & & $+4 *(P 35-P 420) * G 2$ \\
\hline 36 & 1 & 32 & 2 & $(P 32-P C)^{*} \mathrm{C} 36$ & & $+11^{*}(\mathrm{P} 36-\mathrm{P} 421)^{*} \mathrm{G} 1$ \\
\hline 37 & 4 & 42 & 4 & $(\mathrm{P} 42-\mathrm{P} 37)^{*} \mathrm{C} 37$ & $(P 37-P 23)^{*} \mathrm{C} 23+(\mathrm{P} 37-\mathrm{P} 24)^{*} \mathrm{C} 24$ & \\
\hline 38 & $\frac{1}{2}$ & 42 & 4 & $(\mathrm{P} 42-\mathrm{P} 38) * \mathrm{C} 38$ & & $+4^{*}(\mathrm{P} 38-\mathrm{P} 423)^{*} \mathrm{G} 2$ \\
\hline 39 & 1 & 41 & 1 & $(\mathrm{P} 41-\mathrm{PC})^{*} \mathrm{C} 39$ & & $+5^{*}(\mathrm{P} 39-\mathrm{P} 424) * \mathrm{G} 1$ \\
\hline 40 & 1 & 41 & 1 & $(\mathrm{P} 41-\mathrm{PC})^{*} \mathrm{C} 40$ & & $+6^{*}(\mathrm{P} 40-\mathrm{P} 425)^{*} \mathrm{G} 1$ \\
\hline
\end{tabular}

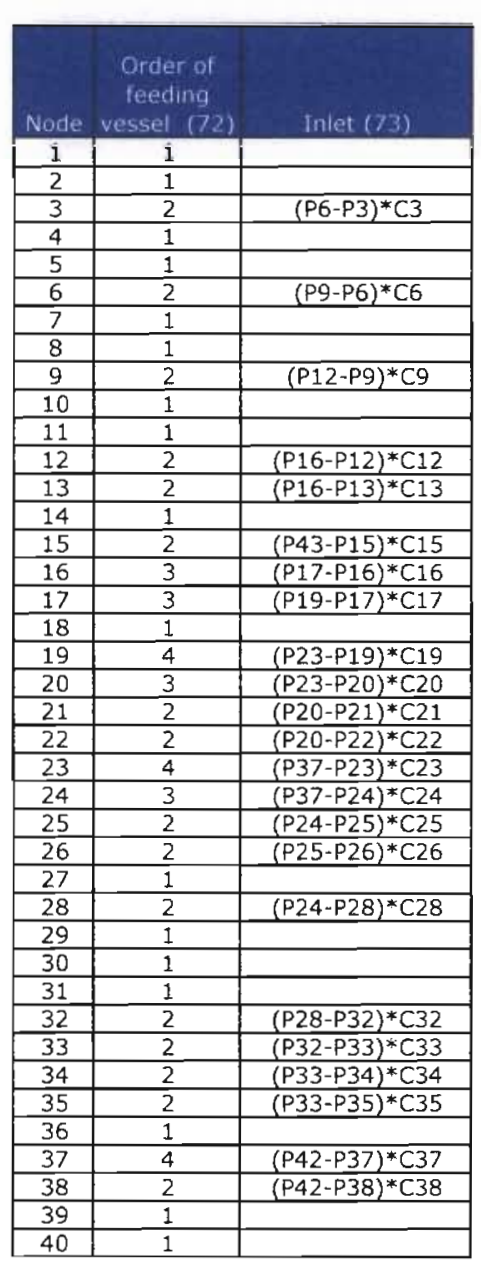




\begin{tabular}{|c|c|}
\hline Outiet (74) & Mathematica Code (75) \\
\hline & $\mathrm{P} 1=\mathrm{PC}$ \\
\hline & $\mathrm{P} 2=\mathrm{PC}$ \\
\hline \multirow{3}{*}{$(\mathrm{P} 3-\mathrm{P} 1)^{*} \mathrm{C} 1+(\mathrm{P} 3-\mathrm{P} 2)^{*} \mathrm{C} 2$} & $(P 6-P 3) * C 3-((P 3-P 1) * C 1+(P 3-P 2) * C 2)==0$ \\
\hline & $\mathrm{P} 4=\mathrm{PC}$ \\
\hline & $P 5=P C$ \\
\hline \multirow[t]{3}{*}{$(\mathrm{P} 6-\mathrm{P} 3)^{*} \mathrm{C} 3+(\mathrm{P} 6-\mathrm{P} 4)^{*} \mathrm{C} 4+(\mathrm{P} 6-\mathrm{P} 5)^{*} \mathrm{C} 5$} & $(\mathrm{P} 9-\mathrm{P} 6)^{*} \mathrm{C} 6-\left((\mathrm{P} 6-\mathrm{P} 3)^{*} \mathrm{C} 3+(\mathrm{P} 6-\mathrm{P} 4)^{*} \mathrm{C} 4+(\mathrm{P} 6-\mathrm{P} 5)^{*} \mathrm{C} 5\right)==0$, \\
\hline & P7 $=P C$ \\
\hline & $P 8=P C$ \\
\hline \multirow[t]{3}{*}{$(P 9-P 6)^{*} \mathrm{C} 6+(P 9-P 7)^{*} \mathrm{C} 7+(\mathrm{Pg}-\mathrm{P} 8)^{*} \mathrm{C} 8$} & $(\mathrm{P} 12-\mathrm{P} 9)^{*} \mathrm{C} 9-\left((\mathrm{P9}-\mathrm{P6} 6)^{*} \mathrm{C} 6+(\mathrm{P9}-\mathrm{P} 7)^{*} \mathrm{C} 7+(\mathrm{P} 9-\mathrm{P} 8)^{*} \mathrm{C} 8\right)==0$, \\
\hline & 年 \\
\hline & $\mathrm{P} 11=\mathrm{PC}$ \\
\hline$(\mathrm{P} 12-\mathrm{P} 9)^{*} \mathrm{C} 9+(\mathrm{P} 12-\mathrm{P} 10) * \mathrm{C} 10+(\mathrm{P} 12-\mathrm{P} 11)^{*} \mathrm{C} 11+11^{*}(\mathrm{P} 12-\mathrm{P} 397) * \mathrm{G} 2$ & $(\mathrm{P} 16-\mathrm{P} 12) * \mathrm{C} 12-\left((\mathrm{P} 12-\mathrm{P} 9)^{*} \mathrm{C} 9+(\mathrm{P} 12-\mathrm{P} 10)^{*} \mathrm{C} 10+(\mathrm{P} 12-\mathrm{P} 11)^{*} \mathrm{C} 11+11 *(\mathrm{P} 12-\mathrm{P} 397) * \mathrm{G} 2\right)==0$ \\
\hline \multirow[t]{2}{*}{$(\mathrm{P} 13-\mathrm{PC})^{*} \mathrm{CC}$} & $(\mathrm{P} 16-\mathrm{P} 13)^{*} \mathrm{C} 13-\left((\mathrm{P} 13-\mathrm{PC})^{*} \mathrm{CC}\right)=0$, \\
\hline & $\mathrm{P} 14=\mathrm{PC}$ \\
\hline$\left(\mathrm{P} 15-\mathrm{PC}_{\mathrm{C}}\right)^{*} \mathrm{C} C$ & $(\mathrm{P} 43-\mathrm{P} 15) * \mathrm{C} 15-\left((\mathrm{P} 15-\mathrm{PC})^{*} \mathrm{C} C\right)==0$, \\
\hline$(\mathrm{P} 16-\mathrm{P} 12) * \mathrm{C} 12+(\mathrm{P} 16-\mathrm{P} 13) * \mathrm{C} 13$ & $(\mathrm{P} 17-\mathrm{P} 16) * \mathrm{C} 16-((\mathrm{P} 16-\mathrm{P} 12) * \mathrm{C} 12+(\mathrm{P} 16-\mathrm{P} 13) * \mathrm{C} 13)==0$ \\
\hline \multirow[t]{2}{*}{$(P 17-P 16) * C 16+6 *(P 17-P 402) * G 3$} & $(P 19-P 17) * C 17-\left((P 17-P 16) * C 16+6^{*}(P 17-P 402) * G 3\right)==0$, \\
\hline & P18=PC \\
\hline$(\mathrm{P} 19-\mathrm{P} 17)^{*} \mathrm{C} 17+(\mathrm{P} 19-\mathrm{P} 18)^{*} \mathrm{C} 18$ & $(P 23-P 19)^{*} \mathrm{C} 19-\left((\mathrm{P} 19-\mathrm{P} 17)^{*} \mathrm{C} 17+(\mathrm{P} 19-\mathrm{P} 18)^{*} \mathrm{C} 18\right)==0$, \\
\hline$(\mathrm{P} 20-\mathrm{P} 21) * \mathrm{C} 21+(\mathrm{P} 20-\mathrm{P} 22) * \mathrm{C} 22+4 *(\mathrm{P} 20-\mathrm{P} 405) * \mathrm{G} 3$ & $(\mathrm{P} 23-\mathrm{P} 20) * \mathrm{C} 20-((\mathrm{P} 20-\mathrm{P} 21) * \mathrm{C} 21+(\mathrm{P} 20-\mathrm{P} 22) * \mathrm{C} 22+4 *(\mathrm{P} 20-\mathrm{P} 405) * \mathrm{G} 3)=0$ \\
\hline$(\mathrm{P} 21-\mathrm{PC})^{*} \mathrm{CC}$ & $(P 20-P 21)^{*} C 21-\left((P 21-P C)^{*} C C\right)==0$ \\
\hline$(P 22-P c)^{*} C c$ & $(\mathrm{P} 20-\mathrm{P} 22) * \mathrm{C} 22-\left((\mathrm{P} 22-\mathrm{PC})^{*} \mathrm{Cc}\right)=0$, \\
\hline$(\mathrm{P} 23-\mathrm{P} 19) * \mathrm{C} 19+(\mathrm{P} 23-\mathrm{P} 20) * \mathrm{C} 20$ & $($ P37-P23)*C23-((P23-P19)*C19+(P23-P20)*C20 $)=0$ \\
\hline$(\mathrm{P} 24-\mathrm{P} 25) * \mathrm{C} 25+(\mathrm{P} 24-\mathrm{P} 28) * \mathrm{C} 28+1 *(\mathrm{P} 24-\mathrm{P} 409) * \mathrm{G} 3$ & $(\mathrm{P} 37-\mathrm{P} 24)^{*} \mathrm{C} 24-\left((\mathrm{P} 24-\mathrm{P} 25)^{*} \mathrm{C} 25+(\mathrm{P} 24-\mathrm{P} 28)^{*} \mathrm{C} 28+11^{*}(\mathrm{P} 24-\mathrm{P} 409) * \mathrm{G} 3\right)==0$ \\
\hline$(\mathrm{P} 25-\mathrm{P} 26)^{*} \mathrm{C} 26+(\mathrm{P} 25-\mathrm{P} 27)^{*} \mathrm{C} 27+13^{*}(\mathrm{P} 25-\mathrm{P} 410)^{*} \mathrm{G} 2$ & $(\mathrm{P} 24-\mathrm{P} 25) * \mathrm{C} 25-\left((\mathrm{P} 25-\mathrm{P} 26)^{*} \mathrm{C} 26+(\mathrm{P} 25-\mathrm{P} 27)^{*} \mathrm{C} 27+13^{*}(\mathrm{P} 25-\mathrm{P} 410)^{*} \mathrm{G} 2\right)=0$ \\
\hline \multirow[t]{2}{*}{$(\mathrm{P} 26-\mathrm{PC})^{*} \mathrm{CC}$} & $(P 25-P 26) * C 26-((P 26-P C) * C C)==0$ \\
\hline & P27 $=P C$ \\
\hline \multirow[t]{4}{*}{$(\mathrm{P} 28-\mathrm{P} 29)^{*} \mathrm{C} 29+(\mathrm{P} 28-\mathrm{P} 32)^{*} \mathrm{C} 32+5^{*}(\mathrm{P} 28-\mathrm{P} 413)^{*} \mathrm{G} 2$} & $(\mathrm{P} 24-\mathrm{P} 28)^{*} \mathrm{C} 28-\left((\mathrm{P} 28-\mathrm{P} 29)^{*} \mathrm{C} 29+(\mathrm{P} 28-\mathrm{P} 32)^{*} \mathrm{C} 32+5^{*}(\mathrm{P} 28-\mathrm{P} 413) * \mathrm{G} 2\right)==0$ \\
\hline & $\mathrm{P} 29=\mathrm{PC}$ \\
\hline & $\mathrm{P} 30=\mathrm{PC}$ \\
\hline & $\mathrm{P} 31=\mathrm{PC}$ \\
\hline$(\mathrm{P} 32-\mathrm{P} 33) * \mathrm{C} 33+(\mathrm{P} 32-\mathrm{P} 36) * \mathrm{C} 36$ & $(\mathrm{P} 28-\mathrm{P} 32) * \mathrm{C} 32-((\mathrm{P} 32-\mathrm{P} 33) * \mathrm{C} 33+(\mathrm{P} 32-\mathrm{P} 36) * \mathrm{C} 36)==0$ \\
\hline$(\mathrm{P} 33-\mathrm{P} 34)^{*} \mathrm{C} 34+(\mathrm{P} 33-\mathrm{P} 35) * \mathrm{C} 35$ & $(\mathrm{P} 32-\mathrm{P} 33)^{*} \mathrm{C} 33-\left((\mathrm{P} 33-\mathrm{P} 34)^{*} \mathrm{C} 34+(\mathrm{P} 33-\mathrm{P} 35)^{*} \mathrm{C} 35\right)=0$, \\
\hline$(\mathrm{P} 34-\mathrm{PC}) * \mathrm{CC}$ & $(\mathrm{P33}-\mathrm{P} 34) * \mathrm{C} 34-((\mathrm{P} 34-\mathrm{PC}) * \mathrm{CC})==0$ \\
\hline \multirow[t]{2}{*}{$(\mathrm{P} 35-\mathrm{PC})^{*} \mathrm{CC}$} & $(\mathrm{P} 33-\mathrm{P} 35) * \mathrm{C} 35-((\mathrm{P} 35-\mathrm{PC}) * \mathrm{Cc})==0$, \\
\hline & $\mathrm{P} 36=\mathrm{PC}$ \\
\hline$(\mathrm{P} 37-\mathrm{P} 23) * \mathrm{C} 23+(\mathrm{P} 37-\mathrm{P} 24) * \mathrm{C} 24$ & $(\mathrm{P} 42-\mathrm{P} 37) * \mathrm{C} 37-((\mathrm{P} 37-\mathrm{P} 23) * \mathrm{C} 23+(\mathrm{P} 37-\mathrm{P} 24) * \mathrm{C} 24)==0$ \\
\hline \multirow[t]{3}{*}{$(\mathrm{P} 38-\mathrm{PC})^{*} \mathrm{CC}$} & $(\mathrm{P} 42-\mathrm{P} 38)^{*} \mathrm{C} 38-\left((\mathrm{P} 38-\mathrm{PC})^{*} \mathrm{CC}\right)==0$ \\
\hline & $P 39=P c$ \\
\hline & $\mathrm{P} 40=\mathrm{PC}$ \\
\hline
\end{tabular}

2 of 3

Pages move horizontally to the right 


\begin{tabular}{|c|c|c|c|}
\hline Equation conly lists the equation if its not a & $\begin{array}{r}\text { Node } \\
(77) \\
\end{array}$ & $\begin{array}{c}\text { Defined values } \\
\text { (78) }\end{array}$ & $\begin{array}{l}\text { Flow rates (equations that } \\
\text { solve for flow rate) }(79)\end{array}$ \\
\hline & & $\mathrm{P} 1=\mathrm{PC}$ & \\
\hline & & $P 2=P C$ & \\
\hline \multirow[t]{3}{*}{$(P 6-P 3)^{*} \mathrm{C} 3-((P 3-P 1) * C 1+(P 3-P 2) * C 2)=\equiv 0}$, & 3 & & $93-(P 6-P 3) * C 3==0$, \\
\hline & & $P_{4}=P_{C}$ & \\
\hline & & $P 5=P C$ & \\
\hline \multirow[t]{3}{*}{$(P 9-P 6)^{*} \mathrm{C} 6-\left((P 6-P 3)^{*} \mathrm{C} 3+(\mathrm{P} 6-\mathrm{P} 4)^{*} \mathrm{C} 4+(\mathrm{P} 6-\mathrm{P} 5)^{*} \mathrm{C} 5\right)==0}$, & 6 & & $\mathrm{q} 6-(\overline{\mathrm{P} 9}-\mathrm{P} 6)^{*} \mathrm{C} 6==0$, \\
\hline & & $P 7=P C$ & \\
\hline & & $P 8=P C$ & \\
\hline \multirow[t]{3}{*}{$(P 12-P 9)^{*} \mathrm{C} 9-\left((P 9-P 6)^{*} \mathrm{C} 6+(P 9-P 7)^{*} \mathrm{C} 7+(\mathrm{P9}-\mathrm{PB})^{*} \mathrm{C} 8\right)==0}$, & 9 & & $\mathrm{q} 9-(\mathrm{P} 12-\mathrm{P} 9)^{*} \mathrm{C} 9==0$ \\
\hline & & $\mathrm{P} 10=\mathrm{PC}$ & \\
\hline & & $\mathrm{P} 11=\mathrm{Pc}$ & \\
\hline$\left.(\mathrm{P} 16-\mathrm{P} 12){ }^{*} \mathrm{C} 12-(\mathrm{P} 12-\mathrm{P} 9) * \mathrm{C} 9+(\mathrm{P} 12-\mathrm{P} 10) * \mathrm{C} 10+(\mathrm{P} 12-\mathrm{P} 11) * \mathrm{C} 11+11^{*}(\mathrm{P} 12-\mathrm{P} 397) * \mathrm{G} 2\right)==0$ & 12 & & $\mathrm{Q} 12-(\mathrm{P} 16-\overline{\mathrm{P}} 12) * \mathrm{C} 12=0$, \\
\hline \multirow[t]{2}{*}{$(\mathrm{P} 16-\mathrm{P} 13)^{*} \mathrm{C} 13-\left((\mathrm{P} 13-\mathrm{PC})^{*} \mathrm{CC}\right)==0}$, & 13 & & $q 13-(P 16-P 13) * C 13==0$, \\
\hline & & $\mathrm{P} 14=\mathrm{PC}$ & \\
\hline$(\mathrm{P} 43-\mathrm{P} 15) * \mathrm{C} 15-((\mathrm{P} 15-\mathrm{PC}) * \mathrm{CC})=\simeq 0$, & 15 & & $\mathrm{q} 15-(\mathrm{P} 43-\mathrm{P} 15) * \mathrm{C} 15==0$ \\
\hline$(\mathrm{P} 17-\mathrm{P} 16) * \mathrm{C} 16-((\mathrm{P} 16-\mathrm{P} 12) * \mathrm{C} 12+(\mathrm{P} 16-\mathrm{P} 13) * \mathrm{C} 13)==0$ & 16 & & $\mathrm{q16}-(\mathrm{P} 17-\mathrm{P} 16) * \mathrm{C} 16==0$ \\
\hline \multirow{2}{*}{$(\mathrm{P} 19-\mathrm{P} 17))^{*} \mathrm{C} 17-\left((\mathrm{P} 17-\mathrm{P} 16)^{*} \mathrm{C} 16+6^{*}(\mathrm{P} 17-\mathrm{P} 402)^{*} \mathrm{G} 3\right)==0}$, & 17 & & Q17-(P19-P17)*C17= =0 \\
\hline & & $\mathrm{P} 18=\mathrm{PC}_{\mathrm{C}}$ & \\
\hline$(P 23-P 19)^{*} \mathrm{C} 19-((\mathrm{P} 19-\mathrm{P} 17) * \mathrm{C} 17+(\mathrm{P} 19-\mathrm{P} 18) * \mathrm{C} 18)==0$, & 19 & & $\mathrm{Q} 19-(\mathrm{P} 23-\mathrm{P} 19) * \mathrm{C} 19==0$ \\
\hline$(\mathrm{P} 23-\mathrm{P} 20)^{*} \mathrm{C} 20-\left((\mathrm{P} 20-\mathrm{P} 21)^{*} \mathrm{C} 21+(\mathrm{P} 20-\mathrm{P} 22)^{*} \mathrm{C} 22+4^{*}(\mathrm{P} 20-\mathrm{P} 405)^{*} \mathrm{G} 3\right)==0$ & 20 & & $\mathrm{Q} 20-(\mathrm{P} 23-\mathrm{P} 20) * \mathrm{C} 20=0$ \\
\hline$(P 20-P 21)^{*} C 21-\left((P 21-P C)^{*} C C\right)==0$ & 21 & & $\mathrm{q} 21-(\mathrm{P} 20-\mathrm{P} 21)^{*} \mathrm{C} 21=0$, \\
\hline$(\mathrm{P} 20-\mathrm{P} 22)^{*} \mathrm{C} 22-\left((\mathrm{P} 22-\mathrm{PC})^{*} \mathrm{CC}\right)==0$ & 22 & & $\mathrm{Q} 22-(\mathrm{P} 20-\mathrm{P} 22) * \mathrm{C} 22=0$ \\
\hline$(\mathrm{P37}-\mathrm{P} 23)^{*} \mathrm{C} 23-\left((\mathrm{P} 23-\mathrm{P} 19){ }^{*} \mathrm{C} 19+(\mathrm{P} 23-\mathrm{P} 20)^{*} \mathrm{C} 2 \mathrm{O}\right)==0$ & 23 & & $\mathrm{q} 23-(\mathrm{P} 37-\mathrm{P} 23)^{*} \mathrm{C} 23==0$ \\
\hline$(\mathrm{P} 37-\mathrm{P} 24) * \mathrm{C} 24-((\mathrm{P} 24-\mathrm{P} 25) * \mathrm{C} 25+(\mathrm{P} 24-\mathrm{P} 28) * \mathrm{C} 28+1 *(\mathrm{P} 24-\mathrm{P} 409) * \mathrm{G} 3)==0$, & 24 & & $\mathrm{q} 24-(\mathrm{P} 37-\mathrm{P} 24) * \mathrm{C} 24==0$ \\
\hline$(\mathrm{P} 24-\mathrm{P} 25)^{*} \mathrm{C} 25-\left((\mathrm{P} 25-\mathrm{P} 26) * \mathrm{C} 26+(\mathrm{P} 25-\mathrm{P} 27)^{*} \mathrm{C} 27+13^{*}(\mathrm{P} 25-\mathrm{P} 410)^{*} \mathrm{G} 2\right)=0$ & 25 & & $\mathrm{q} 25-(\mathrm{P} 24-\mathrm{P} 25) * \mathrm{C} 25==0$ \\
\hline \multirow{2}{*}{$(\mathrm{P} 25-\mathrm{P} 26)^{*} \mathrm{C} 26-((\mathrm{P} 26-\mathrm{PC}) * \mathrm{C} C)==0}$, & 26 & & $\mathrm{q} 26-(\mathrm{P} 25-\mathrm{P} 26) * \mathrm{C} 26=0$ \\
\hline & & $P 27=P_{C}$ & \\
\hline \multirow[t]{4}{*}{$(\mathrm{P} 24-\mathrm{P} 28)^{*} \mathrm{C} 28-\left((\mathrm{P} 28-\mathrm{P} 29)^{*} \mathrm{C} 29+(\mathrm{P} 28-\mathrm{P} 32)^{*} \mathrm{C} 32+5^{*}(\mathrm{P} 28-\mathrm{P} 413)^{*} \mathrm{G} 2\right)= \pm 0}$, & 28 & & $\mathrm{q} 28-(\mathrm{P} 24-\mathrm{P} 28)^{*} \mathrm{C} 28=0=0$ \\
\hline & & $P 29=P C$ & \\
\hline & & $\mathrm{P} 30=\mathrm{PC}_{\mathrm{C}}$ & \\
\hline & & $P 31=P C$ & \\
\hline$(\mathrm{P} 28-\mathrm{P} 32)^{*} \mathrm{C} 32-\left((\mathrm{P} 32-\mathrm{P} 33)^{*} \mathrm{C} 33+(\mathrm{P} 32-\mathrm{P} 36)^{*} \mathrm{C} 36\right)==0$, & 32 & & $\mathrm{q} 32-(\mathrm{P} 28-\mathrm{P} 32) * \mathrm{C} 32==0$ \\
\hline$(\mathrm{P32}-\mathrm{P} 33){ }^{*} \mathrm{C} 33-((\mathrm{P} 33-\mathrm{P} 34) * \mathrm{C} 34+(\mathrm{P} 33-\mathrm{P} 35) * \mathrm{C} 35)==0_{1}$ & 33 & & $\mathrm{q} 33-(\mathrm{P} 32-\mathrm{P} 33) * \mathrm{C} 33==0$ \\
\hline$(\mathrm{P} 33-\mathrm{P} 34) * \mathrm{C} 34-((\mathrm{P} 34-\mathrm{PC}) * \mathrm{C} \mathrm{C})=0$ & 34 & & $934-(P 33-P 34) * C 34==0$ \\
\hline \multirow[t]{2}{*}{$(\mathrm{P} 33-\mathrm{P} 35)^{*} \mathrm{C} 35-\left((\mathrm{P} 35-\mathrm{PC})^{*} \mathrm{C} \mathrm{C}\right)=0, \mathrm{U}$} & 35 & & $q 35-(P 33-P 35) * C 35==0$ \\
\hline & & $P 36=P C$ & \\
\hline$(\mathrm{P} 42-\mathrm{P} 37)^{*} \mathrm{C} 37-\left((\mathrm{P} 37-\mathrm{P} 23)^{*} \mathrm{C} 23+(\mathrm{P} 37-\mathrm{P} 24)^{*} \mathrm{C} 24\right)==0$ & 37 & & $\mathrm{q} 37-(\mathrm{P} 42-\mathrm{P} 37)^{*} \mathrm{C} 37==0$ \\
\hline \multirow{3}{*}{ 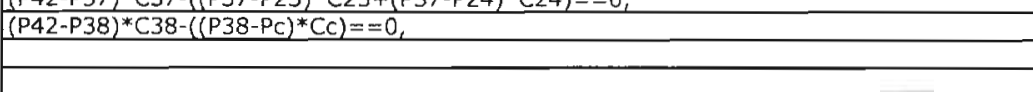 } & 38 & & $q 38-(P 42-P 38)^{*} \mathrm{C} 38=0$ \\
\hline & & $P 39=P C$ & \\
\hline & & $\mathrm{P} 40=\mathrm{PC}$ & \\
\hline
\end{tabular}




\begin{tabular}{|c|c|c|c|c|c|c|c|c|c|c|c|c|}
\hline $\begin{array}{l}\text { Element } \\
\text { label (46) }\end{array}$ & $\begin{array}{c}\text { Final Parent } \\
\text { Element } \\
\text { label }(50)\end{array}$ & Order (47) & $\begin{array}{l}\text { Length } \\
\text { (mm) (46) }\end{array}$ & $\begin{array}{c}\text { Diameler } \\
\text { (micio) (46) }\end{array}$ & Node & $\begin{array}{l}\text { \# vesseis to } \\
\text { add (81) }\end{array}$ & $\begin{array}{c}\text { New } \\
\text { vessel ID } \\
\text { (82) }\end{array}$ & Parent Outlet eqn (83) & $\begin{array}{l}\text { New vessel Inler } \\
\text { (84) }\end{array}$ & $\begin{array}{c}\text { New vessei Outlef } \\
\text { (B5) }\end{array}$ & New vessel equation (86) & Flow eqs $(87)$ \\
\hline 1 & 12 & 1 & 67.20 & 5.20 & 386 & 4 & 386 & $+4^{*}(\mathrm{P} 1-\mathrm{P} 386)^{*} \mathrm{G} 1$ & $(\mathrm{P} 1-\mathrm{P} 386)^{*} \mathrm{G} 1$ & $(\mathrm{P} 3 \mathrm{~B} 6-\mathrm{PC})^{*} \mathrm{Cc}$ & $(\mathrm{P} 1-\mathrm{P} 386)^{*} \mathrm{G} 1-(\mathrm{P} 386-\mathrm{PC})^{*} \mathrm{C} \mathrm{C}==0$, & $q^{3} 86-(\mathrm{P} 1-\mathrm{P} 386)^{*} \mathrm{G} 1==0$, \\
\hline 2 & 12 & 1 & 18.00 & 7.00 & 387 & 1 & 387 & $+1^{*}(\mathrm{P} 2-\mathrm{P} 387)^{*} \mathrm{G} 1$ & $(\mathrm{P} 2-\mathrm{P} 387)^{*} \mathrm{G} 1$ & $(\mathrm{P} 387-\mathrm{PC})^{*} \mathrm{CC}$ & $(P 2-P 387)^{*} \mathrm{G} 1-(\mathrm{P} 387-\mathrm{PC})^{*} \mathrm{CC}==0$ & $\mathrm{q} 387-(\mathrm{P} 2-\mathrm{P} 387)^{*} \mathrm{G} 1==0$ \\
\hline 3 & - & 0 & - & - & & & 388 & & & & & \\
\hline 4 & 12 & 1 & 84.80 & 6.40 & 389 & 6 & 389 & $+6^{*}(P 4-P 389)^{*} \mathrm{G} 1$ & $(\mathrm{P} 4-\mathrm{P} 389)^{*} \mathrm{G} 1$ & $(\mathrm{P} 389-\mathrm{Pc})^{*} \mathrm{Cc}$ & $(\mathrm{P} 4-\mathrm{P} 389)^{*} \mathrm{G} 1-(\mathrm{P} 389-\mathrm{Pc})^{*} \mathrm{Cc}==0$ & $\mathrm{q} 389-(\mathrm{P} 4-\mathrm{P} 389)^{*} \mathrm{G} 1==0$ \\
\hline 5 & 12 & 1 & 60.90 & 7.00 & 390 & 4 & 390 & $+4^{*}(\mathrm{P} 5-\mathrm{P} 390)^{*} \mathrm{G} 1$ & $(\mathrm{P} 5-\mathrm{P} 390)^{*} \mathrm{G} 1$ & $(\mathrm{P} 390-\mathrm{PC})^{*} \mathrm{Cc}$ & $(P 5-P 390)^{*} \mathrm{G} 1-(\mathrm{P} 390-\mathrm{Pc})^{*} \mathrm{Cc}==0$ & $q 390-(P 5-P 390)^{*} G 1==0$ \\
\hline 6 & - & 0 & - & - & & & 391 & & & & & \\
\hline 7 & 12 & 1 & 73.40 & 5.50 & 392 & 5 & 392 & $+5^{*}(\mathrm{P} 7-\mathrm{P} 392)^{*} \mathrm{G} 1$ & $(\mathrm{P} 7-\mathrm{P} 392){ }^{*} \mathrm{G} 1$ & $(\mathrm{P} 392-\mathrm{PC})^{*} \mathrm{CC}$ & $(\mathrm{P} 7-\mathrm{P} 392)^{*} \mathrm{G} 1-(\mathrm{P} 392-\mathrm{Pc})^{*} \mathrm{C} c==0$, & $\mathrm{q} 392-(\mathrm{P} 7-\mathrm{P} 392)^{*} \mathrm{G} 1==0$ \\
\hline 8 & 12 & 1 & 77.50 & 5.50 & 393 & 5 & 393 & $+5^{*}(\mathrm{P} 8-\mathrm{P} 393)^{*} \mathrm{G} 1$ & $(\mathrm{P} 8-\mathrm{P} 393)^{*} \mathrm{G} 1$ & $(\mathrm{P} 393-\mathrm{PC})^{*} \mathrm{Cc}$ & $(\mathrm{P} 8-\mathrm{P} 393)^{*} \mathrm{G} 1-(\mathrm{P} 393-\mathrm{Pc})^{*} \mathrm{C} \mathrm{C}==0$ & q393-(P8-P393)*G1==0, \\
\hline 9 & - & 0 & & - & & & 394 & & & & & \\
\hline 10 & 12 & 1 & 63.10 & 6.40 & 395 & 4 & 395 & $+4^{*}(\mathrm{P} 10-\mathrm{P} 395)^{*} \mathrm{G} 1$ & $(P 10-P 395) * G 1$ & $(\mathrm{P} 395-\mathrm{PC})^{*} \mathrm{CC}$ & $(\mathrm{P} 10-\mathrm{P} 395)^{*} \mathrm{G} 1-(\mathrm{P} 395-\mathrm{PC})^{*} \mathrm{C} \mathrm{c}==0$, & $\mathrm{q} 395-(\mathrm{P} 10-\mathrm{P} 395)^{*} \mathrm{G} 1==0$, \\
\hline 11 & 12 & 1 & 50.40 & 6.80 & 396 & 3 & 396 & $+3^{*}(P 11-P 396)^{*} G 1$ & $(\mathrm{P} 11-\mathrm{P} 396)^{*} \mathrm{G} 1$ & $(\mathrm{P} 396-\mathrm{PC})^{*} \mathrm{CC}$ & $(\mathrm{P} 11-\mathrm{P} 396)^{*} \mathrm{G} 1-(\mathrm{P} 396-\mathrm{PC})^{*} \mathrm{C} \mathrm{C}==0$ & $q 396-(P 11-P 396)^{*} G 1==0$ \\
\hline 12 & 17 & 2 & 227.40 & 9.38 & 397 & 11 & 397 & $+11^{*}(\mathrm{P} 12-\mathrm{P} 397)^{*} \mathrm{G} 2$ & $(\mathrm{P} 12-\mathrm{P} 397)^{*} \mathrm{G} 2$ & $(\mathrm{P} 397-\mathrm{PC})^{*} \mathrm{CC}$ & $(\mathrm{P} 12-\mathrm{P} 397)^{*} \mathrm{G} 2-(\mathrm{P} 397-\mathrm{Pc})^{*} \mathrm{Cc}==0$, & $\mathrm{q} 397-(\mathrm{P} 12-\mathrm{P} 397)^{*} \mathrm{G} 2==0$, \\
\hline 13 & 17 & 2 & 17.30 & 8.60 & 398 & 1 & 398 & $+1^{*}(\mathrm{P} 13-\mathrm{P} 398)^{*} \mathrm{G} 2$ & $(\mathrm{P} 13-\mathrm{P} 398)^{*} \mathrm{G} 2$ & $(\mathrm{P} 398-\mathrm{PC})^{*} \mathrm{Cc}$ & $(\mathrm{P} 13-\mathrm{P} 398)^{*} \mathrm{G} 2-(\mathrm{P} 398-\mathrm{PC})^{*} \mathrm{C} \mathrm{c}==0$, & $\mathrm{q} 398-(\mathrm{P} 13-\mathrm{P} 398)^{*} \mathrm{G} 2==0$, \\
\hline 14 & 43 & 1 & 186.10 & 7.50 & 399 & 12 & 399 & $+12^{*}(\mathrm{P} 14-\mathrm{P} 399)^{*} \mathrm{G} 1$ & $(\mathrm{P} 14-\mathrm{P} 399)^{*} \mathrm{G} 1$ & $(\mathrm{P} 399-\mathrm{PC})^{*} \mathrm{Cc}$ & $(\mathrm{P} 14-\mathrm{P} 399)^{*} \mathrm{G} 1-(\mathrm{P} 399-\mathrm{PC})^{*} \mathrm{Cc}==0$, & $\mathrm{q} 399-(\mathrm{P} 14-\mathrm{P} 399)^{*} \mathrm{G} 1==0$ \\
\hline 15 & 43 & 2 & 96.30 & 8.10 & 400 & 5 & 400 & $+5^{*}(\mathrm{P} 15-\mathrm{P} 400)^{*} \mathrm{G} 2$ & $(\mathrm{P} 15-\mathrm{P} 400)^{*} \mathrm{G} 2$ & $(\mathrm{P} 400-\mathrm{Pc}){ }^{*} \mathrm{Cc}$ & $(\mathrm{P} 15-\mathrm{P} 400)^{*} \mathrm{G} 2-(\mathrm{P} 400-\mathrm{Pc})^{*} \mathrm{C} \mathrm{c}==0$, & $\mathrm{q} 400-(\mathrm{P} 15-\mathrm{P} 400)^{*} \mathrm{G} 2==0$ \\
\hline 16 & - & 0 & - & - & & & 401 & & & & & \\
\hline 17 & 42 & 3 & 160.40 & 12.60 & 402 & 6 & 402 & $+6^{*}(\mathrm{P} 17-\mathrm{P} 402)^{*} \mathrm{G} 3$ & $(\mathrm{P} 17-\mathrm{P} 402)^{*} \mathrm{G} 3$ & $(\mathrm{P} 402-\mathrm{PC})^{*} \mathrm{Cc}$ & $(\mathrm{P} 17-\mathrm{P} 402)^{*} \mathrm{G} 3-(\mathrm{P} 402-\mathrm{Pc})^{*} \mathrm{C} c=0$ & $\mathrm{q} 402-(\mathrm{P} 17-\mathrm{P} 402)^{*} \mathrm{G} 3==0$ \\
\hline 18 & 42 & 1 & 116.60 & 5.60 & 403 & 8 & 403 & $+8^{*}(\mathrm{P} 18-\mathrm{P} 403)^{*} \mathrm{G} 1$ & $(\mathrm{P} 18-\mathrm{P} 403)^{*} \mathrm{G} 1$ & $(\mathrm{P} 403-\mathrm{Pc})^{*} \mathrm{Cc}$ & $(\mathrm{P} 18-\mathrm{P} 403)^{*} \mathrm{G} 1-(\mathrm{P} 403-\mathrm{PC})^{*} \mathrm{C} \mathrm{C}==0$, & $\mathrm{Q} 403-(\mathrm{P} 18-\mathrm{P} 403)^{*} \mathrm{G} 1==0$ \\
\hline 19 & & 0 & & - & & & 404 & & & & & \\
\hline 20 & 42 & 3 & 101.50 & 12.40 & 405 & 4 & 405 & $+4^{*}(P 20-P 405)^{*} G 3$ & $(\mathrm{P} 20-\mathrm{P} 405)^{*} \mathrm{G} 3$ & $(\mathrm{P} 405-\mathrm{PC})^{*} \mathrm{CC}$ & $(\mathrm{P} 20-\mathrm{P} 405)^{*} \mathrm{G} 3-(\mathrm{P} 405-\mathrm{PC})^{*} \mathrm{C} \mathrm{C}==0$, & $\mathrm{Q} 405-(\mathrm{P} 20-\mathrm{P} 405)^{*} \mathrm{G} 3==0$, \\
\hline 21 & 20 & 3 & 47.80 & 10.80 & 406 & 2 & 406 & $+2^{*}(\mathrm{P} 21-\mathrm{P} 406)^{*} \mathrm{G} 3$ & $(P 21-P 406)^{*} \mathrm{G} 3$ & $(\mathrm{P} 406-\mathrm{Pc})^{*} \mathrm{Cc}$ & $(P 21-P 406)^{*} G 3-(P 406-P C)^{*} C c==0$, & $\mathrm{q} 406-(\mathrm{P} 21-\mathrm{P} 406)^{*} \mathrm{G} 3==0$ \\
\hline 22 & 20 & 2 & 94.20 & 9.50 & 407 & 4 & 407 & $+4^{*}(\mathrm{P} 22-\mathrm{P} 407)^{*} \mathrm{G} 2$ & $(\mathrm{P} 22-\mathrm{P} 407)^{*} \mathrm{G} 2$ & $(\mathrm{P} 407-\mathrm{PC})^{*} \mathrm{Cc}$ & $(\mathrm{P} 22-\mathrm{P} 407)^{\star} \mathrm{G} 2-(\mathrm{P} 407-\mathrm{PC})^{*} \mathrm{CC}==0$, & $\mathrm{q} 407-(\mathrm{P} 22-\mathrm{P} 407)^{*} \mathrm{G} 2==0$ \\
\hline 23 & - & 0 & - & - & & & 408 & & & & & \\
\hline 24 & 42 & 3 & 31.00 & 13.70 & 409 & 1 & 409 & $+1^{*}(\mathrm{P} 24-\mathrm{P} 409)^{*} \mathrm{G} 3$ & $(P 24-P 409)^{*} G 3$ & $(\mathrm{P} 409-\mathrm{PC})^{*} \mathrm{CC}$ & $(\mathrm{P} 24-\mathrm{P} 409)^{*} \mathrm{G} 3-(\mathrm{P} 409-\mathrm{PC})^{*} \mathrm{Cc}==0$, & $\mathrm{q} 409-(\mathrm{P} 24-\mathrm{P} 409)^{*} \mathrm{G} 3==0$ \\
\hline 25 & 24 & 2 & 274.80 & 9.10 & 410 & 13 & 410 & $+13^{*}(\mathrm{P} 25-\mathrm{P} 410)^{*} \mathrm{G} 2$ & $(\mathrm{P} 25-\mathrm{P} 410)^{*} \mathrm{G} 2$ & $(\mathrm{P} 410-\mathrm{PC})^{*} \mathrm{Cc}$ & $(\mathrm{P} 25-\mathrm{P} 410)^{*} \mathrm{G} 2-(\mathrm{P} 410-\mathrm{Pc})^{*} \mathrm{Cc}==0$, & $\mathrm{q} 410-(\mathrm{P} 25-\mathrm{P} 410)^{*} \mathrm{G} 2==0$ \\
\hline 26 & - & 0 & - & - & & & 411 & & & & & \\
\hline 27 & 25 & 1 & 98.90 & 7.20 & 412 & 7 & 412 & $+7^{*}(\mathrm{P} 27-\mathrm{P} 412)^{*} \mathrm{G} 1$ & $(\mathrm{P} 27-\mathrm{P} 412)^{*} \mathrm{G} 1$ & $(\mathrm{P} 412-\mathrm{PC})^{*} \mathrm{Cc}$ & $(\mathrm{P} 27-\mathrm{P} 412)^{*} \mathrm{G} 1-(\mathrm{P} 412-\mathrm{Pc})^{*} \mathrm{C} \mathrm{c}==0$, & $\mathrm{q} 412-(\mathrm{P} 27-\mathrm{P} 412)^{*} \mathrm{G} 1==0$, \\
\hline 28 & 24 & 2 & 106.20 & 8.73 & 413 & 5 & 413 & $+5^{*}(\mathrm{P} 28-\mathrm{P} 413)^{*} \mathrm{G} 2$ & $(\mathrm{P} 28-\mathrm{P} 413)^{*} \mathrm{G} 2$ & $(\mathrm{P} 413-\mathrm{Pc})^{*} \mathrm{Cc}$ & $(\mathrm{P} 28-\mathrm{P} 413)^{*} \mathrm{G} 2-(\mathrm{P} 413-\mathrm{PC})^{*} \mathrm{Cc}==0$ & $\mathrm{q} 413-(\mathrm{P} 28-\mathrm{P} 413)^{*} \mathrm{G} 2==0$, \\
\hline 29 & 28 & 1 & 27.30 & 7.20 & 414 & 2 & 414 & $+2^{*}(\mathrm{P} 29-\mathrm{P} 414)^{*} \mathrm{G} 1$ & $(\mathrm{P} 29-\mathrm{P} 414)^{*} \mathrm{G} 1$ & $(\mathrm{P} 414-\mathrm{PC})^{*} \mathrm{C} C$ & $(\mathrm{P} 29-\mathrm{P} 414)^{*} \mathrm{G} 1-(\mathrm{P} 414-\mathrm{PC})^{*} \mathrm{C} c==0$, & $\mathrm{q414}-(\mathrm{P} 29-\mathrm{P} 414)^{*} \mathrm{G} 1==0$ \\
\hline 30 & 29 & 1 & 30.30 & 7.20 & 415 & 2 & 415 & $+2^{*}(\mathrm{P} 30-\mathrm{P} 415)^{*} \mathrm{G} 1$ & $(\mathrm{P} 30-\mathrm{P} 415)^{*} \mathrm{G} 1$ & $(\mathrm{P} 415-\mathrm{Pc})^{*} \mathrm{Cc}$ & $(P 30-P 415)^{*} G 1-(P 415-P C)^{*} C c=0$, & $q 415-(P 30-P 415)^{*} G 1==0$, \\
\hline 31 & 29 & 1 & 29.40 & 7.20 & 416 & 2 & 416 & $+2^{*}(\mathrm{P} 31-\mathrm{P} 416)^{*} \mathrm{G} 1$ & $(\mathrm{P} 31-\mathrm{P} 416)^{*} \mathrm{G} 1$ & $(\mathrm{P} 416-\mathrm{PC})^{*} \mathrm{CC}$ & $(\mathrm{P} 31-\mathrm{P} 416)^{*} \mathrm{G} 1-(\mathrm{P} 416-\mathrm{PC})^{*} \mathrm{C} \mathrm{C}=\mathrm{0}=0$ & $\mathrm{q416}-(\mathrm{P} 31-\mathrm{P} 416)^{*} \mathrm{G} 1==0$ \\
\hline 32 & - & 0 & - & - & & & 417 & & & & & \\
\hline 33 & - & 0 & - & - & & & 418 & & & & & \\
\hline 34 & 28 & 2 & 53.50 & 7.90 & 419 & 3 & 419 & $+3^{*}(\mathrm{P} 34-\mathrm{P} 419)^{*} \mathrm{G} 2$ & $(\mathrm{P} 34-\mathrm{P} 419)^{*} \mathrm{G} 2$ & $(\mathrm{P} 419-\mathrm{PC})^{*} \mathrm{CC}$ & $(\mathrm{P} 34-\mathrm{P} 419)^{*} \mathrm{G} 2-(\mathrm{P} 419-\mathrm{PC})^{*} \mathrm{C} \mathrm{C}==0$, & $\mathrm{q} 419-(\mathrm{P} 34-\mathrm{P} 419)^{*} \mathrm{G} 2==0$, \\
\hline 35 & 28 & 2 & 92.80 & 7.90 & 420 & 4 & 420 & $+4^{*}(P 35-P 420)^{*} G 2$ & $(\mathrm{P} 35-\mathrm{P} 420)^{*} \mathrm{G} 2$ & $(\mathrm{P} 420-\mathrm{Pc})^{*} \mathrm{Cc}$ & $(P 35-P 420)^{*} G 2-(P 420-P c)^{*} \mathrm{Cc}=0$, & $\mathrm{q} 420-(\mathrm{P} 35-\mathrm{P} 420)^{*} \mathrm{G} 2==0$ \\
\hline 36 & 28 & 1 & 167.10 & 7.20 & 421 & 11 & 421 & $+11^{*}(\mathrm{P} 36-\mathrm{P} 421)^{*} \mathrm{G} 1$ & $(\mathrm{P} 36-\mathrm{P} 421)^{*} \mathrm{G} 1$ & $(\mathrm{P} 421-\mathrm{PC})^{*} \mathrm{Cc}$ & $(\mathrm{P} 36-\mathrm{P} 421)^{*} \mathrm{G} 1-(\mathrm{P} 421-\mathrm{Pc})^{*} \mathrm{C} \mathrm{c}==0$, & $\mathrm{q} 421-(\mathrm{P} 36-\mathrm{P} 421)^{*} \mathrm{G} 1==0$, \\
\hline 37 & - & 0 & - & - & & & 422 & & & & & \\
\hline 38 & 42 & 2 & 76.80 & 8.70 & 423 & 4 & 423 & $+4^{*}(\mathrm{P} 38-\mathrm{P} 423)^{*} \mathrm{G} 2$ & $(\mathrm{P} 38-\mathrm{P} 423)^{*} \mathrm{G} 2$ & $(\mathrm{P} 423-\mathrm{PC})^{*} \mathrm{C} c$ & $(\mathrm{P} 38-\mathrm{P} 423)^{*} \mathrm{G} 2-(\mathrm{P} 423-\mathrm{PC})^{*} \mathrm{C} c=0$, & $\mathrm{q} 423-(\mathrm{P} 38-\mathrm{P} 423)^{*} \mathrm{G} 2==0$, \\
\hline 39 & 41 & 1 & 71.50 & 5.60 & 424 & 5 & 424 & $+5^{*}(\mathrm{P} 39-\mathrm{P} 424)^{*} \mathrm{G} 1$ & $(\mathrm{P} 39-\mathrm{P} 424)^{*} \mathrm{G} 1$ & $(\mathrm{P} 424-\mathrm{PC})^{*} \mathrm{Cc}$ & $(\mathrm{P} 39-\mathrm{P} 424)^{\star} \mathrm{G} 1-(\mathrm{P} 424-\mathrm{Pc})^{*} \mathrm{Cc}=0$, & $Q 424-(P 39-P 424)^{*} G 1==0$, \\
\hline 40 & 41 & 1 & 88.50 & 5.60 & 425 & 6 & 425 & $+6^{*}(\mathrm{P} 40-\mathrm{P} 425)^{*} \mathrm{G} 1$ & $(\mathrm{P} 40-\mathrm{P} 425)^{*} \mathrm{G} 1$ & $(\mathrm{P} 425-\mathrm{Pc})^{*} \mathrm{CC}$ & $(P 40-P 425)^{*} G 1-(P 425-P c)^{*} C c==0$ & $\mathrm{q} 425-(\mathrm{P} 40-\mathrm{P} 425)^{*} \mathrm{G} 1==0$ \\
\hline
\end{tabular}




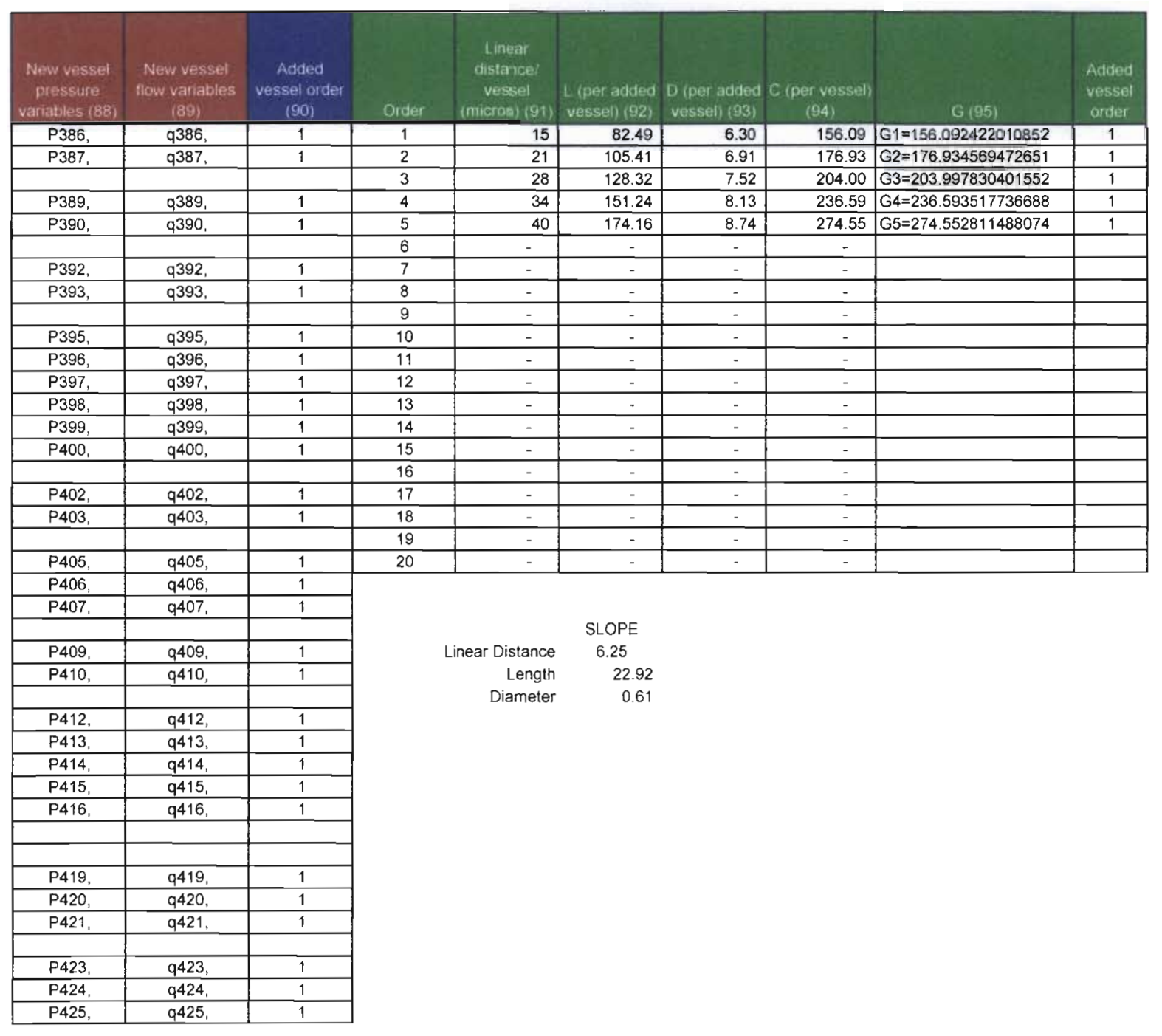




\begin{tabular}{|l|c|c|}
\hline Upper diameter limit (round to nearest hundred microns) (96) & Value & Mathematica Code \\
\hline Average Blood viscosity (Pas) & 1000 & \\
\hline Main artery pressure (Pa) & 0.003 & \\
\hline Terminal capillary pressure (Pa) & 10265.794 & PMain=10265.794 \\
\hline Highest ID number (used for reference for adding caps) (97) & 3999.66 & $\mathrm{PC}=3999.66$ \\
\hline Conductance of capillaries & 385 & \\
\hline Add capillaries???? (Y or N) (98) & & $\mathrm{Cc}=120.657565303582$ \\
\hline Linear distance per capillary (smallest vessels) (99) & 15 & \\
\hline Linear distance per capillary (largest vessels) (99) & 40 & \\
\hline Length of capillary being added to small vessels (microns) (99) & 82.5 & \\
\hline Diameter of capillary being added to small vessels (microns) (99) & 6.3 & \\
\hline Length of capillary being added to large vessels (microns) (99) & 174.2 & \\
\hline Diameter of capillary being added to large vessels (microns) (99) & 8.7 & \\
\hline
\end{tabular}

Diameter of capillary being added to large vessels (microns)

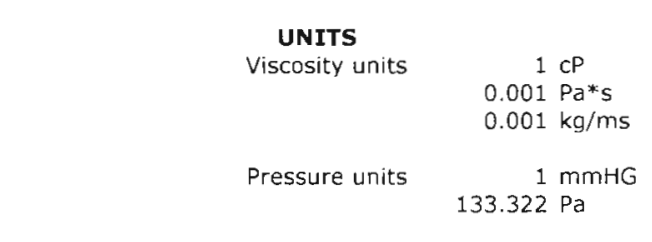

ENTERED VALUES

Max Blood viscosity Terminal Capillery pressure (100) 77. $\mathrm{mmHg}$

\section{CALCULATED VALUES}

Blood viscosity $0.003 \mathrm{~Pa}^{*} \mathrm{~s}$ $\begin{array}{rrr}\text { Main artery pressure } & 10265.794 \mathrm{~Pa} \\ \text { Terminal Capillary pressure } & 3999.66 \mathrm{~Pa}\end{array}$

High (102) 3 cP

\begin{tabular}{|c|c|c|c|}
\hline & $\begin{array}{l}\text { High (102) } \\
\text { Low (103) }\end{array}$ & 3 & \\
\hline$D(104)$ & Order & viscosity & $\mathbf{P a}^{*} \mathbf{s}$ \\
\hline 0.0 & & 3 & 0.003 \\
\hline 6.4 & 1 & 3 & 0.003 \\
\hline 9.1 & 2 & 3 & 0.003 \\
\hline 12.7 & 3 & 3 & 0.003 \\
\hline 17.0 & 4 & 3 & 0.003 \\
\hline & & & \\
\hline 23.5 & 5 & 3 & 0.003 \\
\hline 40.0 & & 3 & 0.003 \\
\hline
\end{tabular}


D: Mathematica inputs 
Mathematica Input Procedure

First, the known values for pressure and conductance are defined similar to the following examples:

PMain $=10265$ (describes the inlet pressure in Pascal)

$\mathrm{Pc}=4000$ (Describes capillary pressure in Pascal)

$\mathrm{C} 1=89$ (Defines conductance for vessel 1 in $\mu \mathrm{m}^{3} / \mathrm{Pa}^{*} \mathrm{~s}$ )

$\mathrm{C} 2=1091$ (Defines conductance for vessel 2 in $\left.\mu \mathrm{m}^{3} / \mathrm{Pa}^{*} \mathrm{~s}\right)$

$\mathrm{P} 25=\mathrm{Pc}$ (Defines the pressure of node 25 as capillary pressure Pascal)

Next, the set of equations are defined. The name is arbitrary, however here "eqns" is used:

eqns $=\{$ comma separated equations $\}$

For example:

eqns $=\{($ PMain-P373 $) * C 373-((\mathrm{P} 373-\mathrm{P} 370) * \mathrm{C} 370+(\mathrm{P} 373-\mathrm{P} 371) * \mathrm{C} 371)=0,(\mathrm{P} 9-$

P6)*C6-((P6-P3)*C3+(P6-P4)*C4+(P6-P5)*C5) $=0$, (P98-P97)*C97-((P97-

$\left.\mathrm{Pc})^{*} \mathrm{C} 1\right)=0,(\mathrm{P} 98-\mathrm{P} 96)^{*} \mathrm{C} 96-\left((\mathrm{P} 96-\mathrm{Pc})^{*} \mathrm{C} 1\right)=0,(\mathrm{P} 95-\mathrm{P} 94) * \mathrm{C} 94-((\mathrm{P} 94-$

$\left.\mathrm{Pc})^{* \mathrm{C} 1}\right)=0, \ldots \ldots . \mathrm{q} 98-(\mathrm{P} 104-\mathrm{P} 98) * \mathrm{C} 98=0$, q97-(P98-P97)*C97 $=0, \mathrm{q} 96-(\mathrm{P} 98-$

$\mathrm{P} 96)^{*} \mathrm{C} 96==0, \ldots \ldots \ldots \ldots$,

Next, the array was generated for those equations using the CoefficientArray operation. The variables to be solved for are included in the last set of brackets. The first set of brackets $\{b, m\}$ are arbitrary letters that are used to define the matrix system. "b" represents the values to the right of the equal sign in the linear equations, and the " $\mathrm{m}$ " 
represents the matrix containing the coefficients of the values to the left of the equal sign. The output to this step is a sparse array.

$$
\{\mathrm{b}, \mathrm{m}\}=\text { CoefficientArrays[eqns, }\{\text { comma separated variables }\}]
$$

For example:

$$
\{b, m\}=\text { CoefficientArrays[eqns, }\{\mathrm{P} 3, \mathrm{P} 6, \mathrm{P} 9, \mathrm{P} 12, \mathrm{P} 13, \mathrm{P} 15, \ldots \ldots \mathrm{q} 3, \mathrm{q} 6, \mathrm{q} 9, \mathrm{q} 12 \text {, }
$$

$$
\mathrm{q} 13, \mathrm{q} 15, \ldots .\}
$$

The last step involves exporting the solution to an Excel file. The name of the file can be anything followed by a ".xls". Other file types can be exported by simply changing the extension, such as ".csv" for comma separated values, or ".txt" for simple text files. The code following the file name defines what is to be exported. In this case the solutions are exported using the LinearSolve operation. The output to this step is a 1x470 matrix that when exported to excel is a single column of values organized in the same order as the variables listed above when defining $\{b, m\}$.

\section{Export["file.xls",LinearSolve[m,-b]]}

Pressures were output in Pascal and flow rates in $\mu \mathrm{m} 3 / \mathrm{s}$. The same calculation approach was used for both segments and elements. The difference was in the data used (segment nodes vs. element nodes) and how the conductances were defined (each individual segment vs. average for each order). 
E: Output sheet example 


\begin{tabular}{|c|c|c|c|c|c|c|c|c|c|c|}
\hline Node & Order & Diameter & $\mathbf{P}, \mathbf{P a}$ & $P(\mathrm{mmHg})$ & $(x-x b a r)^{\wedge} 2$ & $\mathrm{micom}^{\wedge} 3 / \mathrm{s}$ & $\mathrm{mm}^{\wedge} 3 / \mathrm{s}$ & $\mathrm{nl} / \mathrm{s}$ & $\mathrm{nl} / \mathrm{min}$ & $\mathrm{ml} / \mathrm{min} / \mathrm{g}$ \\
\hline 3 & 2 & 9.6 & 4023.78 & 30.18 & 26.22 & 28463.86 & 0.000028 & 0.03 & 1.71 & 0.00031 \\
\hline 6 & 2 & 8.8 & 4049.95 & 30.37 & 24.24 & 52825.28 & 0.000053 & 0.05 & 3.17 & 0.00058 \\
\hline 9 & 2 & 8.8 & 4108.09 & 30.81 & 20.14 & 74359.07 & 0.000074 & 0.07 & 4.46 & 0.00081 \\
\hline 12 & 2 & 10.3 & 4175.08 & 31.31 & 15.88 & 173402.43 & 0.000173 & 0.17 & 10.40 & 0.00189 \\
\hline 13 & 2 & 8.6 & 4284.75 & 32.14 & 10.00 & 34398.84 & 0.000034 & 0.03 & 2.06 & 0.00038 \\
\hline 15 & 2 & 8.1 & 4330.48 & 32.48 & 7.95 & 39915.70 & 0.000040 & 0.04 & 2.39 & 0.00044 \\
\hline 16 & 3 & 12.6 & 4298.05 & 32.24 & 61.14 & 207801.27 & 0.000208 & 0.21 & 12.47 & 0.00227 \\
\hline 17 & 3 & 12.6 & 4343.10 & 32.57 & 55.97 & 207801.27 & 0.000208 & 0.21 & 12.47 & 0.00227 \\
\hline 19 & 4) & 14.8 & 4459.69 & 33.45 & 54.98 & 239545.28 & 0.000240 & 0.24 & 14.37 & 0.00261 \\
\hline 20 & 3) & 12.4 & 4475.22 & 33.56 & 42.12 & 103571.91 & 0.000104 & 0.10 & 6.21 & 0.00113 \\
\hline 21 & 2 & 10.8 & 4451.79 & 33.39 & 3.65 & 54553.05 & 0.000055 & 0.05 & 3.27 & 0.00060 \\
\hline 22 & 2 & 9.5 & 4405.92 & 33.04 & 5.08 & 49018.86 & 0.000049 & 0.05 & 2.94 & 0.00053 \\
\hline 23 & 4 & 15.7 & 4529.57 & 33.97 & 47.48 & 343117.19 & 0.000343 & 0.34 & 20.59 & 0.00374 \\
\hline 24 & 3 & 13.7 & 4556.51 & 34.17 & 34.58 & 469560.55 & 0.000470 & 0.47 & 28.17 & 0.00512 \\
\hline 25 & 2 & 10.3 & 4412.60 & 33.09 & 4.86 & 122358.36 & 0.000122 & 0.12 & 7.34 & 0.00133 \\
\hline 26 & 2 & 7.9 & 4252.93 & 31.90 & 11.57 & 30558.93 & 0.000031 & 0.03 & 1.83 & 0.00033 \\
\hline 28 & 2 & 9.6 & 4330.66 & 32.48 & 7.94 & 347202.19 & 0.000347 & 0.35 & 20.83 & 0.00379 \\
\hline 32 & 2 & 8.7 & 4273.72 & 32.05 & 10.53 & 80627.88 & 0.000081 & 0.08 & 4.84 & 0.00088 \\
\hline 33 & 2 & 7.9 & 4234.70 & 31.76 & 12.52 & 44568.11 & 0.000045 & 0.04 & 2.67 & 0.00049 \\
\hline 34 & 2 & 7.9 & 4195.11 & 31.46 & 14.71 & 23582.43 & 0.000024 & 0.02 & 1.41 & 0.00026 \\
\hline 35 & 2 & 7.9 & 4173.59 & 31.30 & 15.97 & 20985.67 & 0.000021 & 0.02 & 1.26 & 0.00023 \\
\hline 37 & $4 !$ & 15.7 & 4607.02 & 34.55 & 39.82 & 812677.74 & 0.000813 & 0.81 & 48.76 & 0.00887 \\
\hline 38 & 2 & 8.7 & 4845.98 & 36.35 & 1.09 & 102114.73 & 0.000102 & 0.10 & 6.13 & 0.00111 \\
\hline 42 & 4 & 20.4 & 5013.30 & 37.60 & 10.65 & 1023536.72 & 0.001024 & 1.02 & 61.41 & 0.01117 \\
\hline 43 & 3 & 13.1 & 4439.62 & 33.30 & 45.66 & 788031.53 & 0.000788 & 0.79 & 47.28 & 0.00860 \\
\hline 44 & 2 & 10.9 & 4652.20 & 34.89 & 0.17 & 78733.36 & 0.000079 & 0.08 & 4.72 & 0.00086 \\
\hline 45 & 2 & 9.8 & 4620.27 & 34.65 & 0.42 & 74880.75 & 0.000075 & 0.07 & 4.49 & 0.00082 \\
\hline 48 & 2 & 10.4 & 4168.39 & 31.26 & 16.29 & 155050.93 & 0.000155 & 0.16 & 9.30 & 0.00169 \\
\hline 49 & 2 & 8.8 & 4332.95 & 32.50 & 7.85 & 40214.53 & 0.000040 & 0.04 & 2.41 & 0.00044 \\
\hline 50 & 3 & 11.7 & 4362.79 & 32.72 & 53.78 & 195265.46 & 0.000195 & 0.20 & 11.72 & 0.00213 \\
\hline 52 & 3] & 13.8 & 4787.87 & 35.91 & 17.18 & 153614.11 & 0.000154 & 0.15 & 9.22 & 0.00168 \\
\hline 53 & 2 & 10.5 & 4831.31 & 36.24 & 0.88 & 100344.45 & 0.000100 & 0.10 & 6.02 & 0.00109 \\
\hline 65 & 4 & 18.7 & 4932.41 & 36.99 & 14.97 & 253958.55 & 0.000254 & 0.25 & 15.24 & 0.00277 \\
\hline 68 & 5 & 22.1 & 5000.04 & 37.50 & 125.37 & 253958.55 & 0.000254 & 0.25 & 15.24 & 0.00277 \\
\hline 69 & 5] & 21.8 & 5149.04 & 38.62 & 101.59 & 1041990.08 & 0.001042 & 1.04 & 62.52 & 0.01137 \\
\hline 70 & 3 & 11.7 & 4400.62 & 33.00 & 49.70 & 524552.47 & 0.000525 & 0.52 & 31.47 & 0.00572 \\
\hline 71 & 2 & 10 & 4789.14 & 35.92 & 0.38 & 95256.73 & 0.000095 & 0.10 & 5.72 & 0.00104 \\
\hline 72 & 4 & 17.6 & 4839.40 & 36.30 & 20.86 & 101320.88 & 0.000101 & 0.10 & 6.08 & 0.00111 \\
\hline 78 & 2 & 7.9 & 4037.38 & 30.28 & 25.18 & 24844.89 & 0.000025 & 0.02 & 1.49 & 0.00027 \\
\hline 79 & 2 & 7.9 & 4126.81 & 30.95 & 18.90 & 55951.66 & 0.000056 & 0.06 & 3.36 & 0.00061 \\
\hline 80 & 2 & 9.5 & 4318.14 & 32.39 & 8.48 & 38426.60 & 0.000038 & 0.04 & 2.31 & 0.00042 \\
\hline 81 & 3 & 13.5 & 4388.60 & 32.91 & 50.98 & 94378.26 & 0.000094 & 0.09 & 5.66 & $0 . \overline{00103}$ \\
\hline 84 & 2 & 8.3 & 4145.50 & 31.09 & 17.70 & 57279.42 & 0.000057 & 0.06 & 3.44 & 0.00062 \\
\hline 86 & 2 & 8.3 & .4255 .26 & 31.91 & 11.45 & 81690.78 & 0.000082 & 0.08 & 4.90 & 0.00089 \\
\hline 87 & 2] & 9.2 & 4243.63 & 31.83 & 12.05 & 29436.56 & 0.000029 & 0.03 & 1.77 & 0.00032 \\
\hline
\end{tabular}

